\title{
Experimental testing of convective spray cooling with the aid of an electrical field using the Coulomb force
}

Paul Joseph Kreitzer

West Virginia University

Follow this and additional works at: https://researchrepository.wvu.edu/etd

\section{Recommended Citation}

Kreitzer, Paul Joseph, "Experimental testing of convective spray cooling with the aid of an electrical field using the Coulomb force" (2006). Graduate Theses, Dissertations, and Problem Reports. 1734.

https://researchrepository.wvu.edu/etd/1734

This Thesis is protected by copyright and/or related rights. It has been brought to you by the The Research Repository @ WVU with permission from the rights-holder(s). You are free to use this Thesis in any way that is permitted by the copyright and related rights legislation that applies to your use. For other uses you must obtain permission from the rights-holder(s) directly, unless additional rights are indicated by a Creative Commons license in the record and/ or on the work itself. This Thesis has been accepted for inclusion in WVU Graduate Theses, Dissertations, and Problem Reports collection by an authorized administrator of The Research Repository @ WVU. For more information, please contact researchrepository@mail.wvu.edu. 


\title{
EXPERIMENTAL TESTING OF CONVECTIVE SPRAY COOLING WITH THE AID OF AN ELECTRICAL FIELD USING THE COULOMB FORCE
}

\author{
By \\ PAUl JosePh KReitzer \\ THESIS \\ Submitted to the College of Engineering and Mineral Resources \\ at \\ West Virginia University
}

In partial fulfillment of the requirements

for the degree of

Master of Science in

Aerospace Engineering

Committee:

John M. Kuhlman, Ph.D., Chair

Donald D. Gray, Ph.D.

Wade W. Huebsch, Ph.D.

Gary J. Morris, Ph.D.

Kirk L. Yerkes, Ph.D.

Department of Mechanical and Aerospace Engineering

Morgantown, West Virginia

2006

Keywords: Spray Cooling, Critical Heat Flux (CHF), Inductive Charging

Copyright (C) 2006 by Kreitzer, Paul Joseph. All rights reserved. 


\section{Abstract}

\section{Experimental Testing of Convective Spray Cooling with the Aid of an Electrical Field Using the Coulomb Force}

\section{PAUl JOSEPH KREITZER}

Continual advances in the electronics industry and other high heat-flux fields have led to a need for increased heat transfer efficiency. Spray cooling is one of many methods for removing heat from surfaces. Experimental testing conducted at West Virginia University was sponsored by the Air Force Office of Scientific Research in collaboration with the Air Force Research Laboratory to test the effectiveness of using inductive spray charging to enhance the heat transfer rate. Modifications made to the experimental test rig built by Hunnell (2005) enabled the study of electro-hydrodynamics.

Experimental testing using working fluids, FC-72 and HFE-7000, was conducted. Electrodes were designed to inductively charge spray droplets (Law, 1978). Research was performed by studying the thermophysics for different spray flow rates ranging from 6 to $10 \mathrm{GPH}$ with a stepwise applied heat load ranging from 0 to $120 \mathrm{~W}$, for an applied electrode voltage between 0 to $6 \mathrm{kV}$. 


\section{TABLE OF CONTENTS}

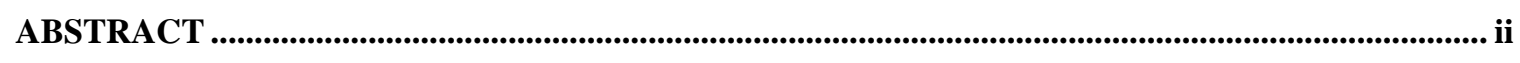

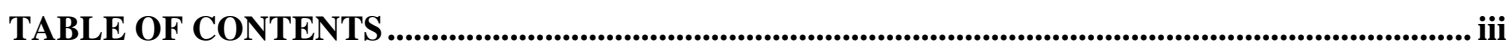

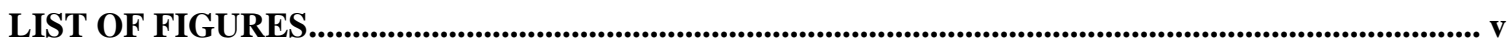

LIST OF TABLES ..................................................................................................................................... xi

ACKNOWLEDGMENTS........................................................................................................................ xii

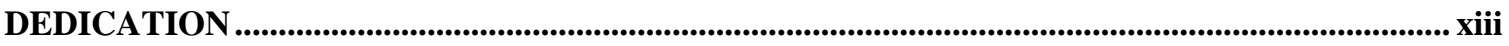

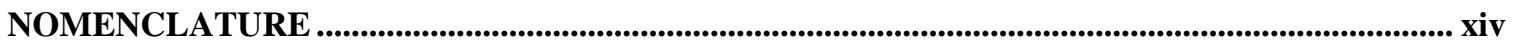

CHAPTER 1 ： INTRODUCTION AND OBJECTIVES ............................................................ 1

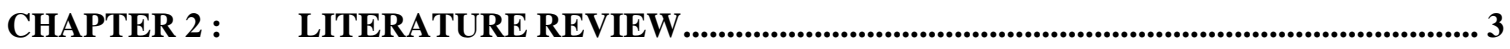

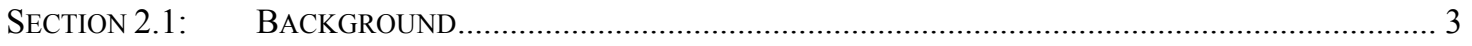

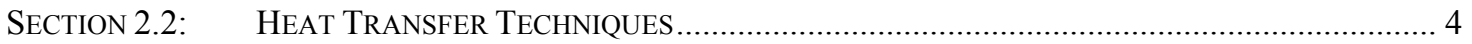

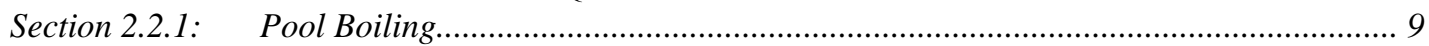

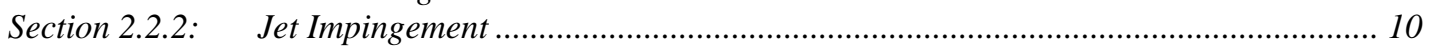

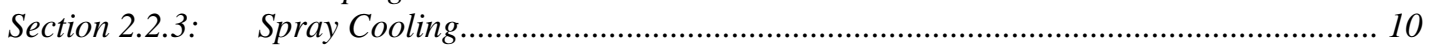

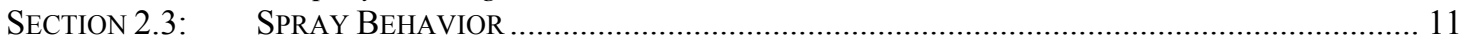

Section 2.3.1: $\quad$ Effects of Electric Fields on Fluid Behavior ........................................................... 13

Section 2.3.2: $\quad$ Effects of Electric Field on Heat Transfer .................................................................. 16

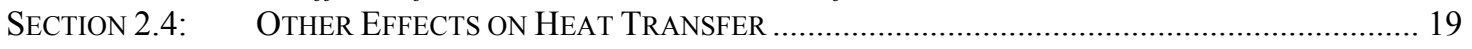

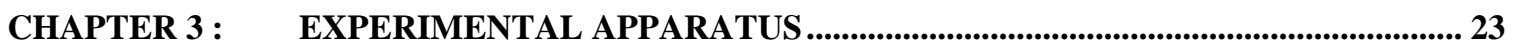

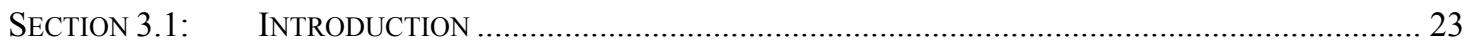

SECTION 3.2: WVU LABORATORY SpRAY COOLING Rig Flow MANAGEMENT SYSTEM................... 25

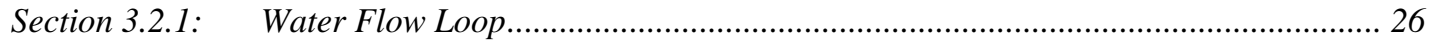

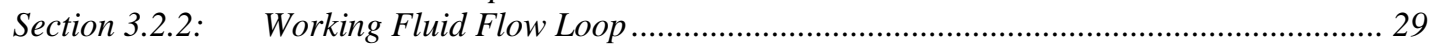

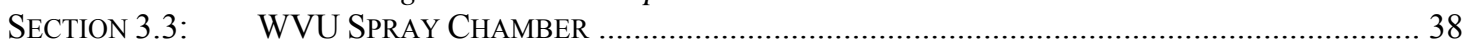

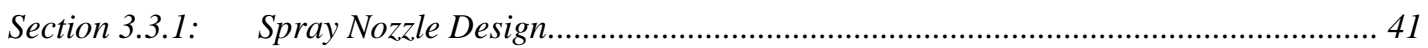

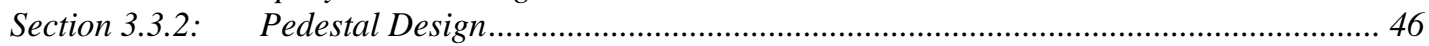

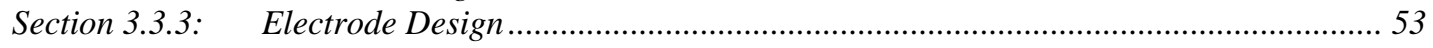

CHAPTER 4 : PROCEDURE AND DATA REDUCTION ............................................................... 59

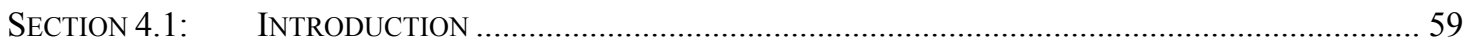

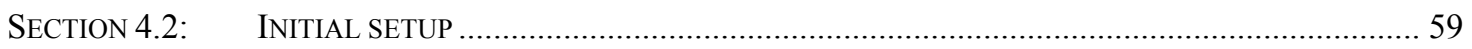

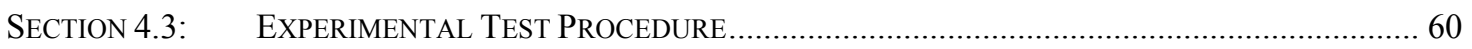

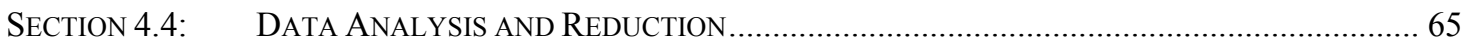

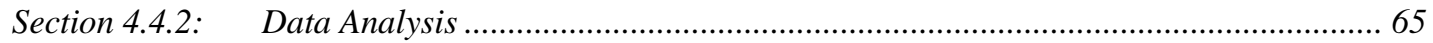

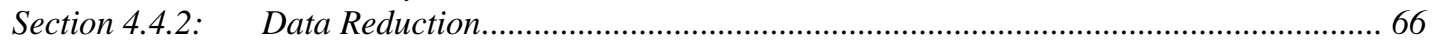

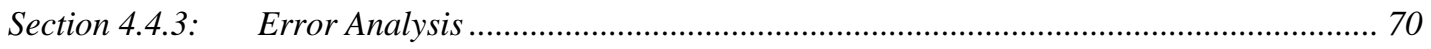

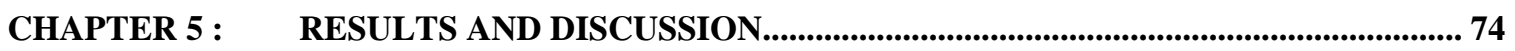

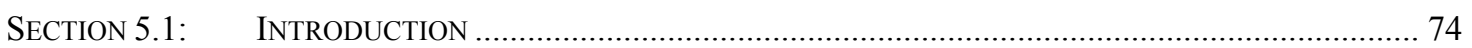

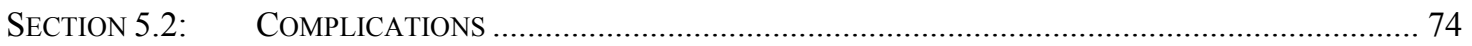

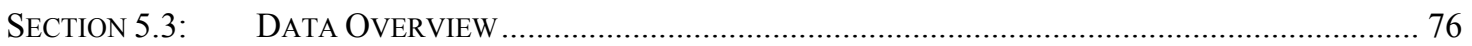

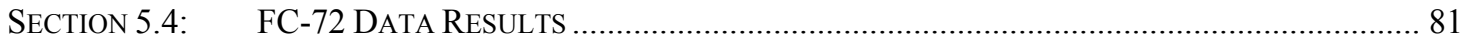

Section 5.4.1: $\quad$ New TFR Pedestal with Electrode 1 using FC-72 Showing Effects due to Electrode 1... 82

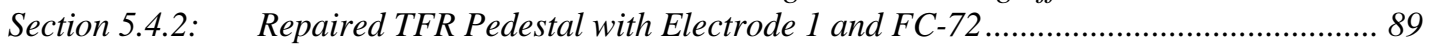

Section 5.4.3: $\quad$ Repaired TFR Pedestal with Electrode 2 and FC-72 ............................................ 93

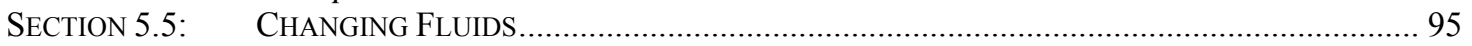




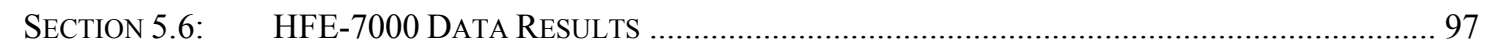

Section 5.6.1: $\quad$ Repaired TFR Pedestal with Electrode 1 and HFE-7000 ……............................... 97

Section 5.6.2: $\quad$ Repaired TFR Pedestal with Electrode 2 and HFE-7000 …................................ 100

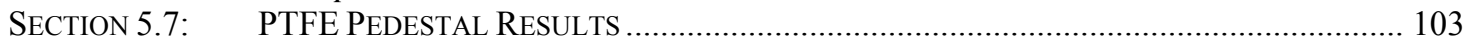

Section 5.7.1: $\quad$ PTFE Pedestal with Electrode 1 and HFE-7000 .............................................. 104

Section 5.7.2: $\quad$ PTFE Pedestal with Electrode 1 using HFE-7000 Comparing Two Flow Rates .......... 107

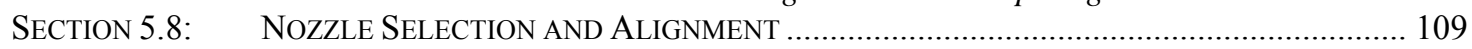

Section 5.8.1: $\quad$ PVC and Brass Nozzle Comparison .................................................................. 110

Section 5.8.2: $\quad$ PTFE Pedestal Going Through CHF Using HFE-7000 at 8 GPH ......................... 112

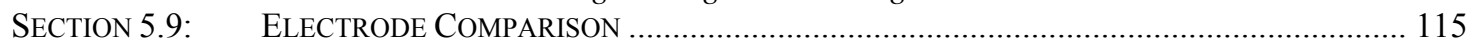

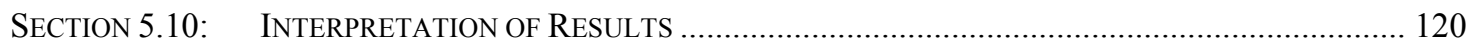

CHAPTER 6 : CONCLUSIONS AND RECOMMENDATIONS ................................................. 127

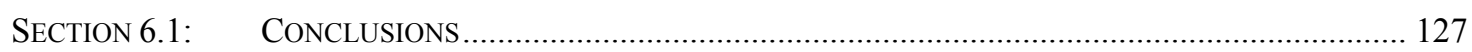

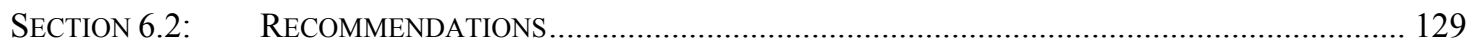

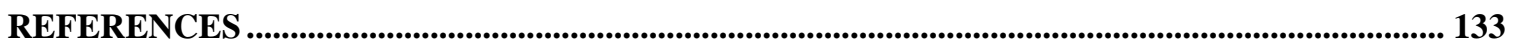

APPENDIX A : THERMOCOUPLE CALIBRATION ............................................................... 135

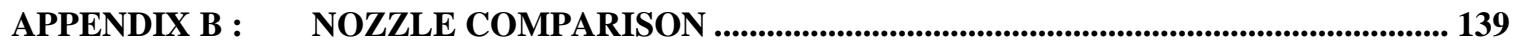

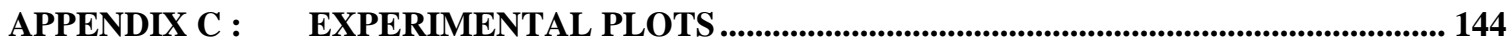

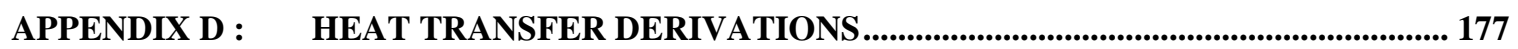

SECTION D.1: DERIVATION OF SURFACE TEMPERATURE................................................................. 177

SECTION D.2: $\quad$ EXPLANATION OF HEAT TRANSFER COEFFICIENT USED ............................................ 181

SECTION D.3: $\quad$ EXPLANATION OF HEAT TRANSFER COEFFICIENT NON-DIMENSIONALIZATION .......... 182 


\section{LIST OF FIGURES}

Figure 2.1: TRENDS IN AIRCRAFT PoWER REQUIREMENTS (MAHEFKEY ET AL., 2004).............................. 4

Figure 2.2: How Heat TRANSFER COEFFICIENTS VARY With Fluid AND COOLING TeChNiQue

(MUDAWAR, 2000), REDRAWN ………….......................................................................... 5

Figure 2.3: HEAT TRANSFER CoEFFICIENTS For DifFERENT CONVECTIVE HEAT TRANSFER TECHNiQUeS

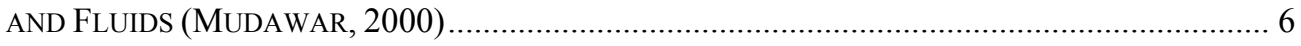

FIGURE 2.4: BOILING CURVE (BERNARDIN ET AL., 1996), REDRAWN ........................................................... 7

Figure 2.5: COMPARISON OF HEAT TRANSFER TECHNIQUES AND THE IMPORTANCE OF CHF (MUDAWAR,

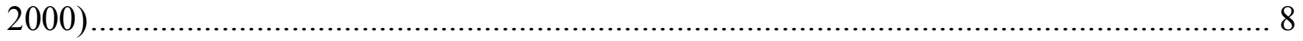

Figure 2.6: Liquid INTERACTIONS RESUlting In SPLASHING DUE TO, A) VAPOR BUbBLE EXPANSION, B)

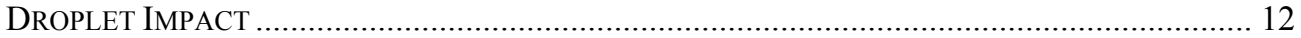

Figure 2.7: SPLASHING AS A FunCTION OF TEMPERATURE (BERNARDIN ET AL., 1996)........................... 13

Figure 2.8: Bubble Trajectory and Flow Patter as AfFected by the Magnetic Kelvin Force (.

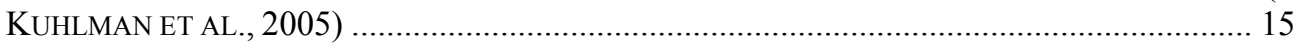

Figure 2.9: Critical Heat Flux Values Vs. High Voltage For FC-72 In 1-G AND Micro-G

CONDITIONS (DI MARCO AND GRASSI, 2002) …………................................................ 18

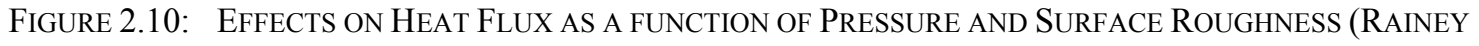

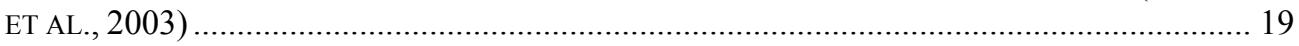

Figure 2.11: NuCleate Boiling CuRve as a Function of DisSolved Gas (You ET AL., 1995) ..... 20

FIGURE 3.1: SCHEMATIC OF WVU LABORATORY RIG ............................................................................. 23

Figure 3.2: PhOtOgRAPH OF A) WVU EXPERIMENTAL Rig B) EXPERIMENTAL SPRAY CHAMBER ........... 24

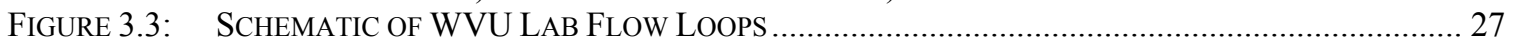

Figure 3.4: PhOTOGRAPH OF COPPER TUBING COVERING SPRAY CHAMBER ....................................... 28

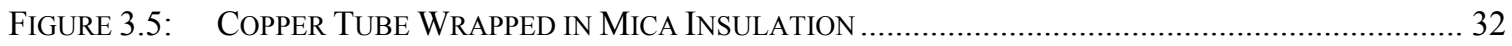

Figure 3.6: Nichol ChromiUm WIRE WraPPED AROUND COPPER TUBE................................................ 32

Figure 3.7: COPPER TUBe COVERED with High TEMPERATURE PERMATEX RTV …..................................... 33

Figure 3.8: COMPLETED RE-HEATER WITH ENDS EXPOSED TO SHOW INSULATION ................................... 34

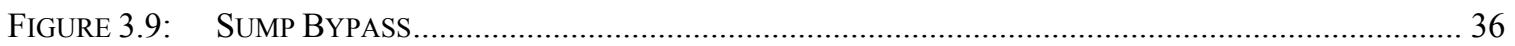

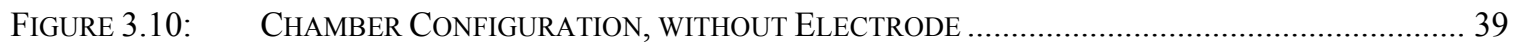

Figure 3.11: PhOtOGRAPH OF CHAMBER CONFIGURATION WiTH ElECTRODE …….............................. 40

Figure 3.12: VElocity Distribution for SPRAying Systems Full Jet 1 NozZle at 9.0 GPH, 40

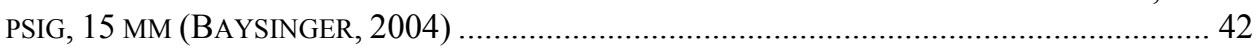

Figure 3.13: Volumetric FluX vs. Position ACross the CENTER of THE SPRAY For a SPRAYing SYSTEMS FULLJET 1 NOZZLE (BAYSINGER, 2004).......................................................... 42

Figure 3.14: Schematic of Full Cone SPRay with a Spraying Systems 1/8-G Nozzle ............... 43

Figure 3.15: Photograph of Full Cone Spray with a Spraying Systems 1/8-G NozZle with

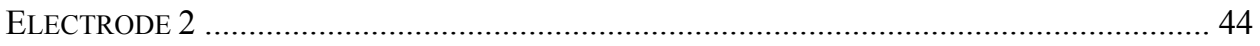

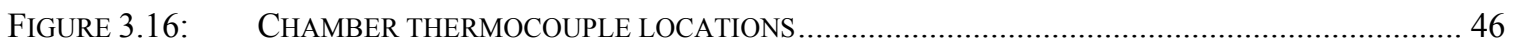

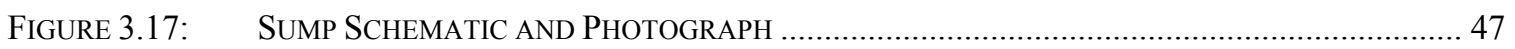

Figure 3.18: GLASS Pedestal Schematic AND PhotograPh........................................................... 47

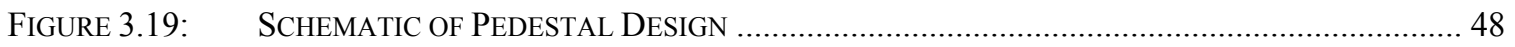

Figure 3.20: Glass Pedestal Close up Photographs a) Assembly b) Side View C) Top View

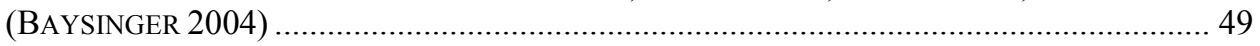

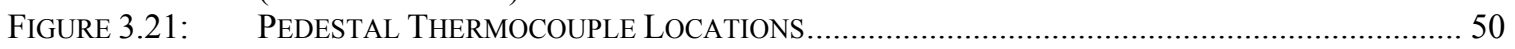

FigURE 3.22: MANUFACTURER DRAWING FROM DATA SHEETS OF TFR HEATER .................................. 51

FigURE 3.23: PTFE THERMOCOUPLE LOCATIONS (GLASPELL 2006) …………................................... 53

Figure 3.24: Schematic of a Liquid-Particulate Charging Electrode Designed and tested BY LAW (1978), MODIFIED AND REDRAWN ……………............................................... 54

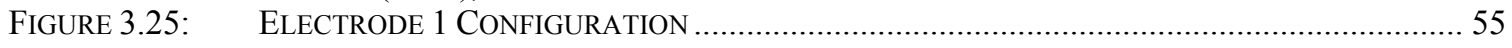

Figure 3.26: SChEMATIC OF EleCtrode 1 CONFiguration............................................................. 56

Figure 3.27: PRO-E Drawing OF EleCtrode 1 Configuration …………...................................... 57

Figure 3.28: SCHEMATIC OF EleCtrode 2 CONFIGURATION............................................................ 58 
Figure 3.29: Photographs of Electrode Configurations a) Electrode 1 Bottom View b) ELECTRODE 1 WITH NOZZLE C) ELECTRODE 2 EXPLODED VIEW .......................................... 58

FIGURE 4.1: SAMPLE STEADY STATE DATA PLOT OVER TIME

FIGURE 5.1:

FIGURE 5.2: DAMAGED TFR HEATERS, A) TFR WITH GLASS LAYER, B) TFR WITHOUT GLASS LAYER....... 76 DAMAGE TO TOP GLASS PEDESTAL LAYER UNDER THE TFR ……………………….......... 76

FIGURE 5.3: TyPical Data Run Using PTFE Pedestal, HFE-7000, 8 GPH, and Electrode 1 .......... 78

FIGURE 5.4: Heat Flux Plot with all Data Collected for PTFE Pedestal, HFE-7000, 8 GPH, AND ELECTRODE 1

Figure 5.5: HeAt FluX Plot With VARIABLE AdJustMents ReMOVED FOR PTFE PEDESTAL, HFE-

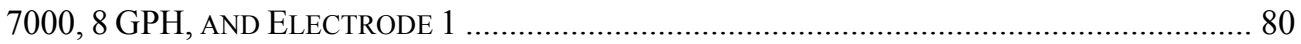

Figure 5.6: Heat Flux Plot Averaged at Each Heater Power LeVel for PTFE Pedestal, HFE-

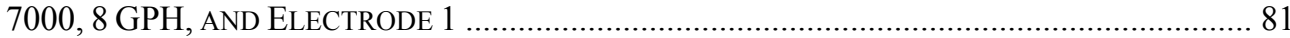

Figure 5.7: Heat Flux Plot For FC-72, 9.3 GPH, and EleCtrode 1 Data Run With EFFECTS ......... 82

Figure 5.8: Time History OF FC-72, 9.3 GPH, AND EleCtrode 1 DATA RUN With EFFECTS ............... 83

Figure 5.9: ZOOM IN ON REGION OF EleCtrode VOlTAGE FOR FC-72, 9.3 GPH, AND ElECTRODE 1

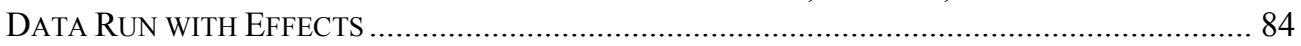

Figure 5.10: ZOOM IN ON REGION OF EleCtROdE VOLTAGE FOR FC-72, 9.3 GPH, AND..................... 85

Figure 5.11: NON-DIMENSIONAL HEAT FluX VERSUS TEMPERATURE DiFFERENCE FOR FC-72, $9.3 \mathrm{GPH}$, AND ELECTRODE 1 DATA RUN WITH EFFECTS ………................................................... 86

Figure 5.12: HeAt Transfer CoEFFicient Versus HeAt FluX For FC-72, 9.3 GPH, AND EleCtrode

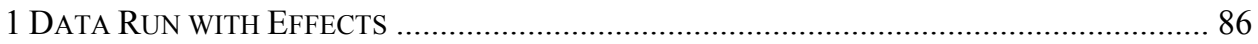

Figure 5.13: NUSSELT NUMBER VERSUS NON-DIMENSIONAL HEAT FLUX FOR FC-72, 9.3 GPH, AND ELECTRODE 1 DATA RUN WITH EFFECTS......................................................................... 87

Figure 5.14: Resistance Versus Time For FC-72, 9.3 GPH, AND EleCtrode 1 Data Run With EFFECTS.............................................................................................................. 88

Figure 5.15: Time History For FC-72 Data Run USing RePaired TFR HEATER PEDESTAL With

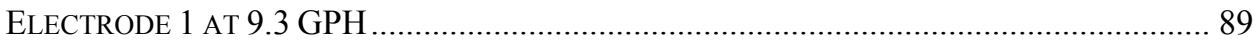

Figure 5.16: HeAt FluX Plot FOR FC-72 DAta Run using RePaired TFR HEATER PEDESTAL With

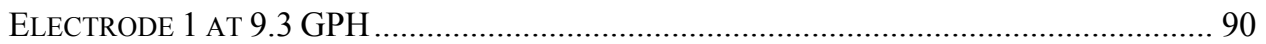

Figure 5.17: NON-Dimensional HEAT FluX VERSUS TEMPERATURE DifFERENCE FOR FC-72 DATA Run using Repaired TFR Heater Pedestal with Electrode 1 at 9.3 GPH ............ 91

Figure 5.18: HEAT TRANSFER COEFFICIENT Plot FOR FC-72 DATA RUN USING REPAIRED TFR HEATER PEDESTAL WITH ELECTRODE 1 AT 9.3 GPH...................................................................... 91

Figure 5.19: NUSSELT NUMBER VERSUS NON-DIMENSIONAL HEAT FlUX FOR FC-72 DATA RUN USING RePaired TFR HEATER Pedestal with EleCtrode 1 AT 9.3 GPH ................................ 92

Figure 5.20: Resistance VERSUS TIME FOR FC-72 DATA RUN USING REPAIRED TFR HEATER PedeStAL WITH ELECTRODE 1 AT 9.3 GPH..................................................................... 92

Figure 5.21: HEAT FluX Plot FOR FC-72 DATA Run USING REPAired TFR HEATER PEDESTAL With

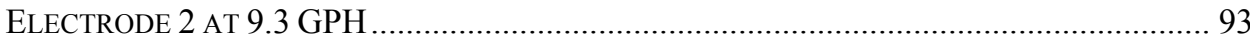

Figure 5.22: NON-DIMENSIONAL HEAT FluX VERSUS TEMPERATURE DifFERENCE FOR FC-72 DATA RUN USING RePaIRED TFR HEATER PEDESTAL WITH ELECTROde 2 AT 9.3 GPH ............ 94

Figure 5.23: HEAT TRANSFER COEFFiCIENT Plot FOR FC-72 DATA Run USING REPAiRED TFR HEATER PedeSTAL with ELECTRODE 2 AT 9.3 GPH.................................................................. 94

Figure 5.24: NuSSElt NUMBER VERSUS NON-DiMENSIONAL HEAT FluX FOR FC-72 DATA RUN USING RePaired TFR HEater Pedestal with Electrode 2 AT 9.3 GPH ................................ 95

Figure 5.25: HeAt FluX Plot FOR HFE-7000 Data Run USING REPAIRED TFR HEATER PEDESTAL WITH ELECTRODE 1 AT 8.0 GPH ......................................................................................... 98

Figure 5.26: NON-Dimensional HEAT FluX VERSus TeMPERATURE DifFERENCE HEAT FLuX Plot for HFE-7000 Data Run using Repaired TFR Heater Pedestal with Electrode 1

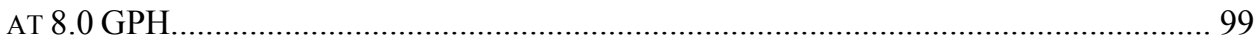

Figure 5.27: HEAT TRANSFER COEFFICIENT Plot HEAT FluX Plot FOR HFE-7000 DATA RUN USING REPAIRED TFR HEATER PEDESTAL WITH EleCtRode 1 AT 8.0 GPH ................................. 99

Figure 5.28: NuSSELT NUMBER VERSUS NON-DimeNSIONAL HEAT FluX HEAT FluX PLOT FOR HFE7000 Data Run using RePaired TFR Heater Pedestal With Electrode 1 at 8.0 $\mathrm{GPH}$ 
Figure 5.29: HeAt FluX Plot Heat Flux Plot for HFE-7000 Data Run using RePaired TFR HEATER Pedestal with EleCtRode 2 AT 8.0 GPH ........................................................ 101

Figure 5.30: NON-DiMENSIONAL HEAT FluX VERSUS TEMPERATURE DiFFERENCE FOR HFE-7000 DATA

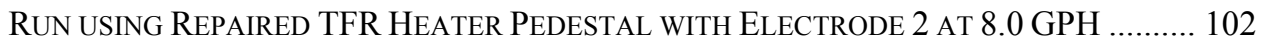

Figure 5.31: HEAT TRANSFER COEFFICIENT PLOT FOR HFE-7000 DATA RUN USING REPAIRED TFR HeAter PedeSTAL WITH EleCtRode 2 AT 8.0 GPH ................................................... 102

Figure 5.32: NUSSELT NUMBER VERSUS NON-DIMENSIONAL HEAT FLUX FOR HFE-7000 DATA RUN USING RePAIRED TFR HEATER PEDESTAL WITH ELECTRODE 2 AT 8.0 GPH .................... 103

Figure 5.33: HEAT FluX Plot FOR HFE-7000 DATA RUN USING PTFE PEDESTAL With TFR HEATER

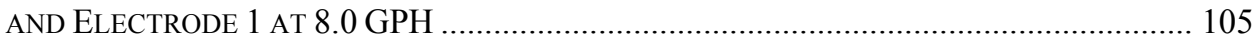

Figure 5.34: NON-DIMENSIONAL HEAT FluX VERSUS TEMPERATURE DIFFERENCE FOR HFE-7000 DATA Run USING PTFE PEDESTAL WITH TFR HEATER AND EleCtrode 1 AT 8.0 GPH........... 105

Figure 5.35: HEAT TRANSFER COEFFicient Plot For HFE-7000 Data Run USING PTFE PEDESTAL WITH TFR HEATER AND ELECTRODE 1 AT 8.0 GPH ........................................................ 106

FiguRE 5.36: NUSSELT NUMBER VERSUS NON-DIMENSIONAL HEAT FLUX FOR HFE-7000 DATA RUN USING PTFE PEDESTAL WITH TFR HEATER AND ELECTROdE 1 AT 8.0 GPH................... 106

Figure 5.37: NON-DIMENSIONAL HEAT FluX VERSUS TEMPERATURE DIFFERENCE FOR HFE-7000 DATA RUN USING PTFE PEDESTAL WITH TFR HEATER AND ELECTROdE 1 COMPARING FLOW

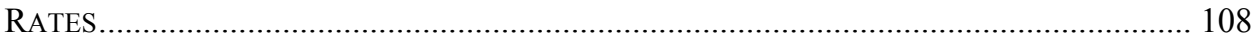

FigURE 5.38: NUSSELT NUMBER VERSUS NON-DIMENSIONAL HEAT FLUX FOR HFE-7000 DATA RUN USING PTFE PEDESTAL WITH TFR HEATER AND ELECTRODE 1 COMPARING FLOW RATES

Figure 5.39: NON-DIMENSIONAL HEAT FluX VERSUS TEMPERATURE DifFERENCE FOR NOZZLE COMPARISON DATA RUN USING FC-72 AND NO ELECTRODE .......................................... 111

Figure 5.40: NUSSELT NUMBER VERSUS NON-DIMENSIONAL HEAT FLUX FOR NOZZLE COMPARISON DATA RUN USING FC-72 AND NO ELECTRODE.................................................................. 111

Figure 5.41: TEMPERATURE VS. TIME FOR THE FIVE THERMOCOUPLES LOCATED BELOW THE TFR HEATER OF THE PTFE PEDESTAL WITH ELECTRODE 1 …................................................... 112

Figure 5.42: TEMPERATURE VS. TIME FOR THE FIVE THERMOCOUPLES LOCATED BELOW THE TFR HEATER OF THE PTFE PEDESTAL AS CHF OCCURS ........................................................ 113

Figure 5.43: TEMPERATURE VS. TIME FOR THE FIVE THERMOCOUPLES LOCATED BELOW THE TFR HEATER OF THE PTFE PEDESTAL FocuSED ON THE CHF EVENT .................................... 114

Figure 5.44: RESISTANCE VS. TIME FOR THE PTFE PEDESTAL SHOWING CHF EVENTS ....................... 115

Figure 5.45: NON-DIMENSIONAL HEAT FlUX VERSUS TEMPERATURE DIFFERENCE FOR COMPARING FC-

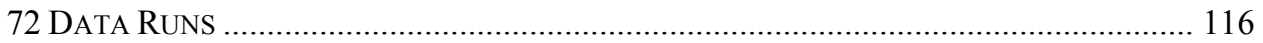

Figure 5.46: NON-DIMENSIONAL HEAT FLUX VERSUS TEMPERATURE DIFFERENCE FOR COMPARING HFE-7000 DATA RUNS ...................................................................................... 117

Figure 5.47: NON-DIMENSIONAL HEAT FluX VERSUS TEMPERATURE DIFFERENCE FOR COMPARING

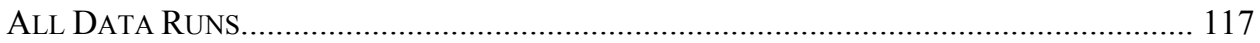

FigURE 5.48: NUSSELT NUMBER VERSUS NON-DIMENSIONAL HEAT FluX FOR NOZZLE COMPARING FC-

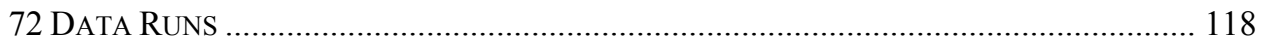

Figure 5.49: NUSSELT NUMBER VERSUS NON-DIMENSIONAL HEAT FluX FOR NOZZLE COMPARING

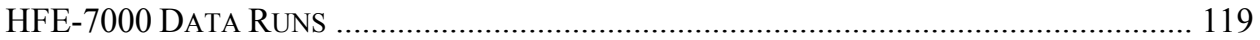

Figure 5.50: NUSSELT NUMBER VERSUS NON-DIMENSIONAL HEAT FLUX FOR NOZZLE COMPARING ALL

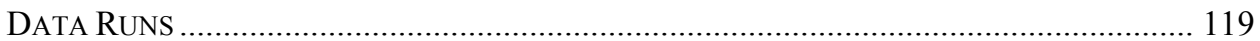

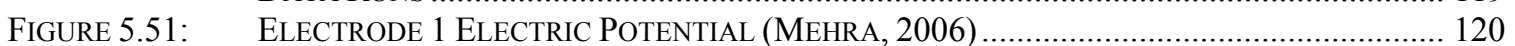

Figure 5.52: Electrode 2 Electric Potential (Mehra, 2006) …................................................ 121

Figure 5.53: Calculated AXial Kelvin Force/Mass For EleCtrode 1 Presented IN N/KG

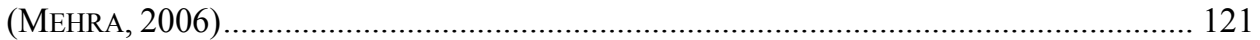

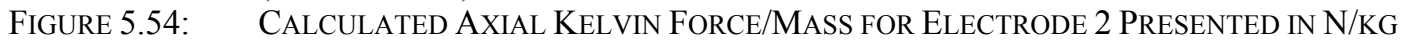

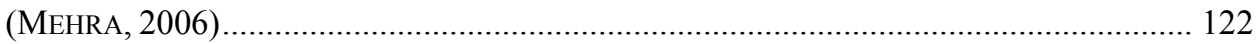

Figure 5.55: CAlculated E field Magnitude for Electrode 1 Presented in N/C (Mehra, 2006) 123

Figure 5.56: Calculated E field Magnitude for Electrode 2 Presented in N/C (Mehra, 2006) 123 
Figure 5.57: CALCUlATEd E FIELD MAGNITUdE ALONG THE CENTERLINE FOR ELECTRODE 1 PRESENTED

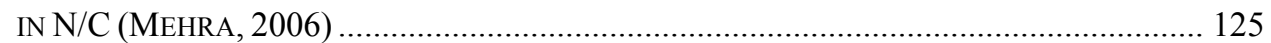

Figure 5.58: CALCULATED E FIELD MAGNITUDE ALONG THE CENTERLINE FOR ELECTRODE 2 PRESENTED

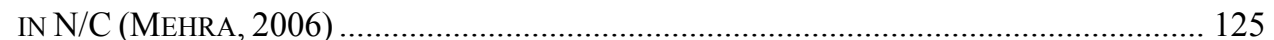

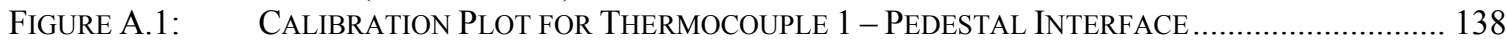

FIGURE B.1: NON-CONDUCTING NOZZLE AND ASSEMBLY ……….................................................. 140

Figure B.2: HEAT FluX AS A FunCTION OF TEMPERATURE DifFERENCE FOR NOZZLE COMPARISON AT DIFFERENT FLOW RATES ........................................................................................... 141

Figure B.3: NON-Dimensional HeAt FluX AS A FunCtion OF NON-Dimensional TEMPERATURE DIFFERENCE FOR NOZZLE COMPARISON AT DIFFERENT FLOW RATES.............................. 142

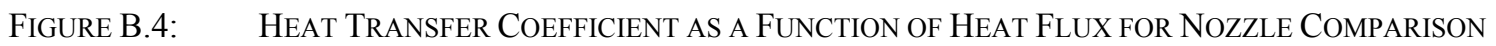
AT DIFFERENT FLOW RATES .................................................................................. 142

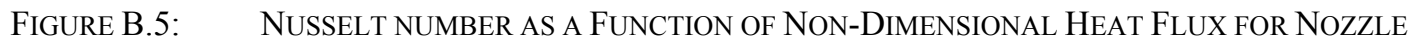
COMPARISON AT DIFFERENT FLOW RATES ........................................................................ 143

Figure C.1: Heat FluX Vs. Temperature DifFERENCE FOR RePaired TFR PEDESTAL With NeW TFR HEATER AND ELECTRODE 1 USING FC-72 AT 6.2 GPH ......................................... 145

Figure C.2: NON-DIMENSIONAL HEAT FluX VS. NON- DIMENSIONAL TEMPERATURE DifFERENCE FOR REPAiRED TFR PEDESTAL With NEW TFR HEATER AND ELECTROdE 1 USING FC-72 AT

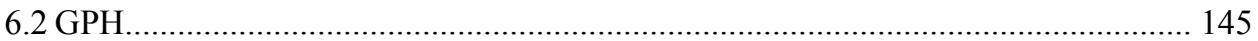

Figure C.3: Heat Transfer Coefficient vs. Heat FluX For Repaired TFR Pedestal with New TFR HEATER AND ELECTRODE 1 USING FC-72 AT 6.2 GPH ............................................. 146

Figure C.4: NON-DimENSIONAL HEAT TRANSFER COEFFICIENT VS. NON-DIMENSIONAL HEAT FluX FOR REPAIRED TFR PEDESTAL WITH NEW TFR HEATER AND ELECTRODE 1 USING FC-72

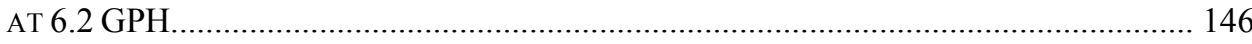

Figure C.5: Heat FluX Vs. TeMPERATURE DifFERENCE FOR RePaired TFR PEDESTAL With NeW TFR HEATER AND ELECTRODE 1 USING FC-72 AT 7.7 GPH ........................................ 147

Figure C.6: NON-DIMENSIONAL HEAT FLUX VS. NON- DIMENSIONAL TEMPERATURE DifFERENCE FOR REPAIRED TFR PEDESTAL WITH NEW TFR HEATER AND ELECTRODE 1 USING FC-72 AT

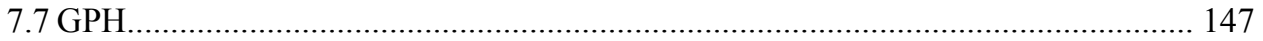

Figure C.7: Heat Transfer CoefFicient vs. HeAt FluX For RePaired TFR Pedestal With NeW TFR HEATER AND ELECTRODE 1 USING FC-72 AT 7.7 GPH ......................................... 148

Figure C.8: Non-Dimensional HEAT TRANSFER COEFFICIENT VS. NON-DIMENSIONAL HEAT FluX FOR REPAIRED TFR PEDESTAL WITH NEW TFR HEATER AND ELECTRODE 1 USING FC-72

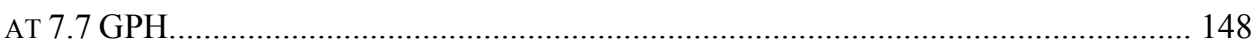

Figure C.9: Heat FluX vs. TeMPERATURe DifFERENCE FOR RePaired TFR PEDESTAL With NEW TFR HEATER AND ELECTRODE 1 USING FC-72 AT 9.3 GPH ......................................... 149

Figure C.10: Non-Dimensional Heat FluX Vs. Non- DimENSIONAL TEMPERATURE DifFERENCE FoR REPAIRED TFR PEDESTAL WITH NEW TFR HEATER AND ELECTRODE 1 USING FC-72 AT $9.3 \mathrm{GPH}$

Figure C.11: Heat Transfer Coefficient vs. Heat FluX For RePaired TFR Pedestal with New TFR HEATER AND ELECTRODE 1 USING FC-72 AT 9.3 GPH ......................................... 150

Figure C.12: NON-Dimensional HEAT TRANSFER COEFFICIENT VS. NON-DiMENSIONAL HEAT FluX FOR REPAIRED TFR PEDESTAL WITH NEW TFR HEATER AND ELECTRODE 1 USING FC-72

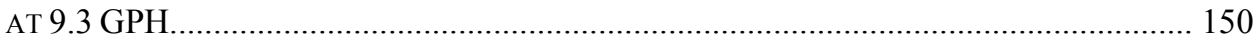

Figure C.13: HEAT FluX VS. TEMPERATURE DifFERENCE FOR REPAIRED TFR PEDESTAL WITH NEW TFR HEATER AND ELECTRODE 2 USING FC-72 AT 6.2 GPH ......................................... 152

Figure C.14: NON-DIMENSIONAL HEAT FluX VS. NON- DIMENSIONAL TEMPERATURE DifFERENCE FOR REPAIRED TFR PEDESTAL WITH NEW TFR HEATER AND ELECTRODE 2 USING FC-72 AT

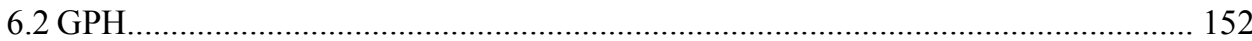

Figure C.15: Heat Transfer CoefFicient vs. Heat Flux for Repaired TFR Pedestal with New TFR HEATER AND ELECTRODE 2 USING FC-72 AT 6.2 GPH ......................................... 153

Figure C.16: NON-Dimensional HeAt TRANSFER COEFFICIENT Vs. NON-DIMENSIONAL HEAT FluX FOR REPAIRED TFR PEDESTAL WITH NEW TFR HEATER AND ELECTRODE 2 USING FC-72

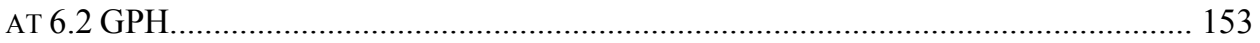

Figure C.17: HEAT FluX VS. TEMPERATURE DifFERENCE FOR REPAIRED TFR PEDESTAL WITH NEW TFR HEATER AND ELECTRODE 2 USING FC-72 AT 7.7 GPH 154 
Figure C.18: NON-DIMENSIONAL HEAT FluX VS. NON- DIMENSIONAL TEMPERATURE DiFFERENCE FOR REPAIRED TFR PEDESTAL WITH NEW TFR HEATER AND ELECTRODE 2 USING FC-72 AT

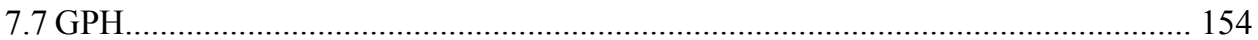

Figure C.19: Heat Transfer CoefFicient vs. Heat Flux For RePaired TFR Pedestal with New TFR HEATER AND ELECTRODE 2 USING FC-72 AT 7.7 GPH .......................................... 155

Figure C.20: NON-DimENSIONAL HEAT TRANSFER COEFFICIENT VS. NON-DIMENSIONAL HEAT FluX FOR REPAIRED TFR PEDESTAL WITH NEW TFR HEATER AND ELECTROde 2 USING FC-72 AT 7.7 GPH......

Figure C.21: Heat FluX Vs. TeMPERATURE DifFERENCE FOR RePaired TFR PEDESTAL With NEW TFR HEATER AND ELECTRODE 2 USING FC-72 AT 9.3 GPH ......................................... 156

Figure C.22: NON-Dimensional HEAT FluX Vs. NON- DimENSIONAL TEMPERATURE DifFERENCE FOR REPAIRED TFR PEDESTAL WITH NEW TFR HEATER AND ELECTRODE 2 USING FC-72 AT

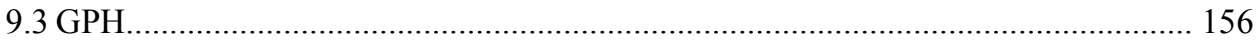

Figure C.23: Heat Transfer CoefFicient vs. Heat FluX For RePaired TFR Pedestal with New TFR HEATER AND ELECTRODE 2 USING FC-72 AT 9.3 GPH .............................................. 157

Figure C.24: Non-Dimensional Heat Transfer CoEfFicient vs. NON-Dimensional Heat FluX FOR REPAIRED TFR PEDESTAL WITH NEW TFR HEATER AND ELECTROde 2 USING FC-72

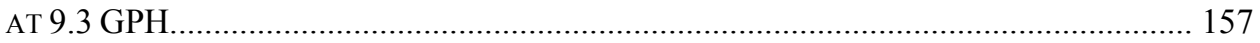

Figure C.25: HEAT FluX Vs. TeMPERATURE DifFERENCE FOR REPAIRED TFR PEDESTAL With NEW TFR HEATER AND ELECTRODE 1 USING HFE-7000 AT 5.9 GPH .................................... 159

Figure C.26: NON-DIMENSIONAL HEAT FluX VS. NON- DIMENSIONAL TEMPERATURE DifFERENCE FOR REPAIRED TFR PEDESTAL WITH NEW TFR HEATER AND ELECTRODE 1 USING HFE-7000 AT $5.9 \mathrm{GPH}$

Figure C.27: Heat Transfer CoefFicient vs. Heat FluX For RePaired TFR Pedestal with NeW TFR HEATER AND ELECTRODE 1 USING HFE-7000 AT 5.9 GPH .................................... 160

Figure C.28: NON-DimENSIONAL HEAT TRANSFER COEFFICIENT VS. NON-DimENSIONAL HEAT FluX FOR REPAIRED TFR PEDESTAL WITH NEW TFR HEATER AND ELECTRODE 1 USING HFE-

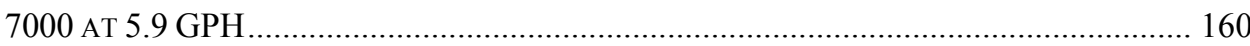

Figure C.29: HEAT FluX Vs. TEMPERATURE DifFERENCE FOR REPAIRED TFR PEDESTAL WITH NEW TFR HEATER AND ELECTRODE 1 USING HFE-7000 AT 8.0 GPH .................................... 161

Figure C.30: NON-DIMENSIONAL HEAT FluX VS. NON- DIMENSIONAL TEMPERATURE DifFERENCE FOR REPAIRED TFR PEDESTAL WITH NEW TFR HEATER AND ELECTROdE 1 USING HFE-7000

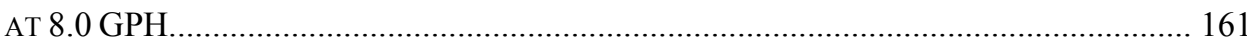

Figure C.31: Heat Transfer CoefFicient vs. Heat FluX For RePaired TFR Pedestal with New TFR HEATER AND ELECTRODE 1 USING HFE-7000 AT 8.0 GPH ................................... 162

Figure C.32: Non-Dimensional HeAt TRANSFER COEFFICIENT Vs. NON-Dimensional HeAt FluX FOR REPAIRED TFR PEDESTAL WITH NEW TFR HEATER AND ELECTRODE 1 USING HFE7000 AT 8.0 GPH............................................................................................... 162

Figure C.33: HEAT FluX vs. TEMPERATURE DifFERENCE FOR REPAIRED TFR PEDESTAL WITH NEW TFR HEATER AND ELECTRODE 1 USING HFE-7000 AT 8.5 GPH ................................... 163

Figure C.34: NON-DimENSIONAL HEAT FluX Vs. NON- DIMENSIONAL TEMPERATURE DifFERENCE FOR Repaired TFR Pedestal with NeW TFR Heater and Electrode 1 USING HFE-7000

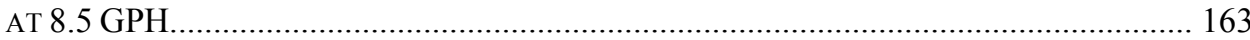

Figure C.35: Heat Transfer Coefficient vs. Heat Flux for Repaired TFR Pedestal with New TFR HEATER AND ELECTRODE 1 USING HFE-7000 AT 8.5 GPH ................................... 164

Figure C.36: NON-DimENSIONAL HEAT TRANSFER COEFFICIENT Vs. NON-DimENSIONAL HEAT FluX FOR REPAIRED TFR PEDESTAL WITH NEW TFR HEATER AND ELECTRODE 1 USING HFE-

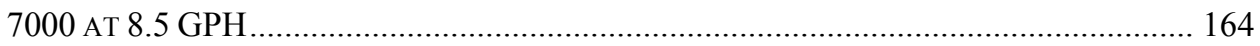

Figure C.37: Heat FluX Vs. TeMPERATURE DifFERENCE FOR REPAired TFR PEDESTAL With NEW TFR HEATER AND ELECTRODE 2 USING HFE-7000 AT 5.9 GPH ................................... 166

Figure C.38: NON-DimENSIONAL HEAT FluX VS. NON- DIMENSIONAL TEMPERATURE DifFERENCE FOR REPAIRED TFR PEDESTAL WITH NEW TFR HEATER AND ELECTRODE 2 USING HFE-7000

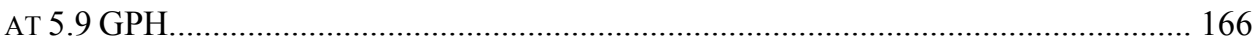

Figure C.39: Heat Transfer CoefFicient vs. Heat FluX For RePaired TFR Pedestal with New TFR HEATER AND ELECTRODE 2 USING HFE-7000 AT 5.9 GPH ..... 167 
Figure C.40: NON-Dimensional Heat Transfer COEFFicient vs. NON-Dimensional HEAT FluX FOR REPAIRED TFR PEDESTAL WITH NEW TFR HEATER AND ELECTRODE 2 USING HFE-

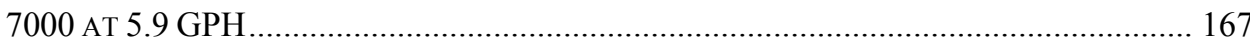

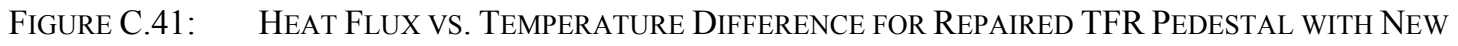
TFR HEATER AND ELECTRODE 2 USING HFE-7000 AT 8.0 GPH …................................ 168

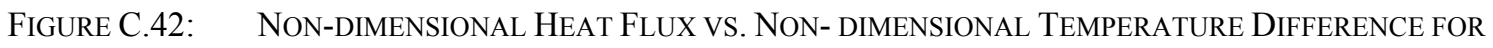
REPAIRED TFR PEDESTAL WITH NEW TFR HEATER AND ELECTRODE 2 USING HFE-7000 AT $8.0 \mathrm{GPH}$

Figure C.43: Heat Transfer Coefficient vs. Heat Flux for Repaired TFR Pedestal with New TFR HEATER AND ELECTRODE 2 USING HFE-7000 AT 8.0 GPH ................................... 169

Figure C.44: Non-Dimensional Heat Transfer CoEfFicient vs. NON-Dimensional Heat FluX FOR REPAIRED TFR PEDESTAL WITH NEW TFR HEATER AND ElECTRODE 2 USING HFE-

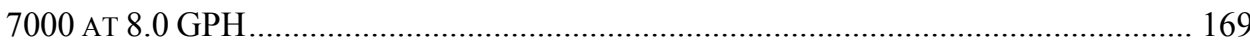

Figure C.45: HEAT FluX VS. TEMPERATURE DifFERENCE FOR REPAIRED TFR PEDESTAL WITH NEW TFR HEATER AND ELECTRODE 2 USING HFE-7000 AT 8.5 GPH ...................................... 170

Figure C.46: NON-DimENSIONAL HEAT FluX Vs. NON- DIMENSIONAL TEMPERATURE DifFERENCE FOR REPAIRED TFR PEDESTAL WITH NEW TFR HEATER AND ELECTRODE 2 USING HFE-7000 AT $8.5 \mathrm{GPH}$. 170

Figure C.47: Heat Transfer CoefFicient vs. Heat Flux for Repaired TFR Pedestal with New TFR HEATER AND ELECTRODE 2 USING HFE-7000 AT 8.5 GPH ................................... 171

Figure C.48: NON-Dimensional Heat Transfer COEFFICIENT VS. NON-DIMENSIONAL Heat FluX FOR REPAIRED TFR PEDESTAL WITH NEW TFR HEATER AND ELECTRODE 2 USING HFE-

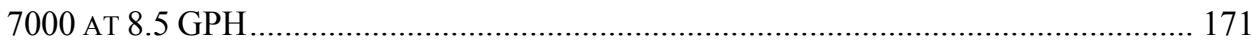

Figure C.49: Heat Flux vs. Temperature DifferenCe for PTFE Pedestal with NeW TFR HEATER AND ELECTRODE 1 USING HFE-7000 AT 5.9 GPH .......................................... 173

Figure C.50: NON-DimeNSIONAL HEAT FluX VS. NON- DimENSIONAL TEMPERATURE DifFERENCE FOR PTFE Pedestal WITH NEW TFR HeATER AND ELECTROde 1 USING HFE-7000 AT 5.9

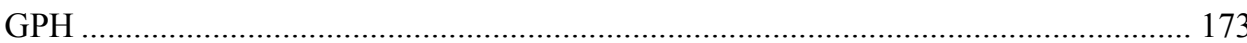

Figure C.51: Heat Transfer CoefFicient vs. Heat FluX for PTFE Pedestal With New TFR HEATER AND ELECTRODE 1 USING HFE-7000 AT 5.9 GPH ........................................... 174

Figure C.52: NON-Dimensional Heat Transfer CoEfFicient Vs. NON-Dimensional Heat FluX FOR PTFE Pedestal With NeW TFR HEATER AND Electrode 1 USING HFE-7000 AT 5.9

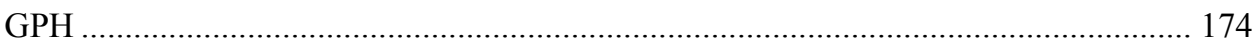

Figure C.53: Heat FluX vs. Temperature DifFERENCE For PTFE Pedestal With NeW TFR HEATER AND ELECTRODE 1 USING HFE-7000 AT 8.5 GPH .......................................... 175

Figure C.54: Non-Dimensional HeAt FluX Vs. NON- DiMENSIONAL TEMPERATURE DifFERENCE For PTFE PEDESTAL With NEW TFR HEATER AND ELECTROdE 1 USING HFE-7000 AT 8.5

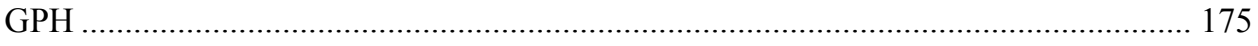

Figure C.55: Heat Transfer Coefficient vs. Heat FluX For PTFE Pedestal with NeW TFR HEATER AND ELECTRODE 1 USING HFE-7000 AT 8.5 GPH ........................................... 176

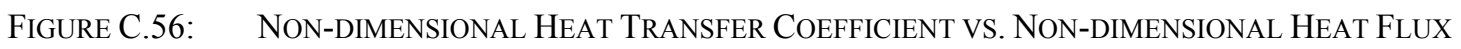
fOr PTFE Pedestal with NeW TFR Heater AND Electrode 1 Using HFE-7000 AT 8.5

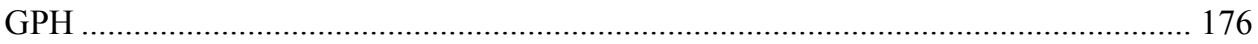

Figure D.1: $\quad$ SCHEMATIC OF PEDESTAL AND TFR HEATER WITH GLASS LAYER.................................. 178

Figure D.2: $\quad$ SCHEMATIC OF TFR HEATER Showing Heat LoSSES ................................................. 179 


\section{LIST OF TABLES}

TABLE 2.1: $\quad$ EXPERIMENTAL EFFECT OF VARYING N ON CHF AND H (CHEN ET AL., 2002) ...................... 21

TABLE 2.2: $\quad$ EXPERIMENTAL EFFECT OF VARYING D 32 ON CHF AND H (CHEN ET AL., 2002) ................... 21

TABLE 2.3: $\quad$ EXPERIMENTAL EFFECT OF VARYING V ON CHF AND H (CHEN ET AL., 2002) ....................... 22

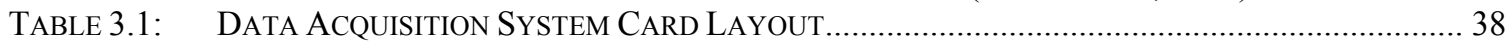

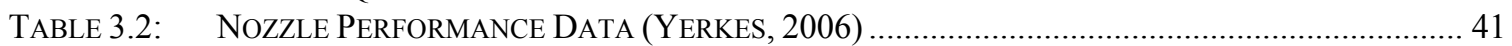

TABLE 3.3: ThICKNESS AND THERMAL CONDUCTIVITY OF TFR LAYERS (GLASPELL, 2006) ................. 52

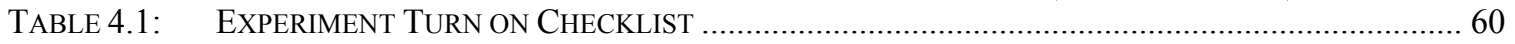

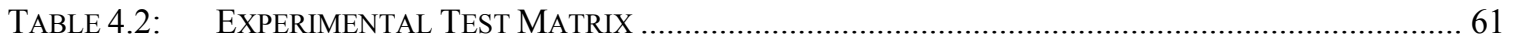

TABle 4.3: $\quad$ EXPERIMENTAl Operation Procedure CHECKLIST .......................................................63

TABLE 4.4: $\quad$ ERROR LEVELS OF DIFFERENT EXPERIMENTAL EQUIPMENT ........................................... 71

TABLE 5.1: FC-72 AND HFE-7000 FLUID PROPERTIES AT $25^{\circ} \mathrm{C}$ UNLESS OTHERWISE STATED ..................96

TABle 5.2: Droplet Charge ANd Resulting COUlomb Force EXERTEd on the Droplet AT THE TOP

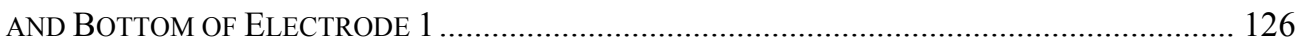

Table 5.3: Droplet Charge and Resulting Coulomb Force Exerted on the Droplet AT The Top

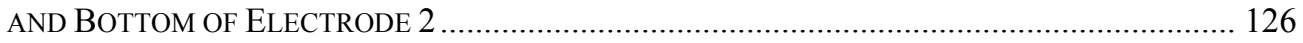

TABLE A.1: RAW CALIBRATION DATA ....................................................................................... 137 


\section{ACKNOWLEDGMENTS}

First and foremost I would like to thank my advisor Dr. John Kuhlman for his advice and guidance throughout the research and writing process. I would also like to thank the other members of my committee, Dr. Donald Gray, Dr. Wade Huebsch, Dr. Gary Morris, and Dr. Kirk Yerkes, for helping guide me in the writing process. Without the help of these individuals this thesis would not be possible.

Next, I would like to thank Mr. Andy Hunnell for paving the way for me to perform this research. I would also like to thank Mr. Chuck Coleman, Mr. David Estep, Ms. Shannon Glaspell, Mr. Cliff Judy, Mr. Deepak Mehra, and Dr. Mike Palmer at West Virginia University for their technical expertise. Without the help of any of the individuals listed above, this thesis would not have been possible.

I would also like to thank Mr. Levi Elston, Mr. Richard Harris, Mr. Travis Michalak, Ms. Rebekah Puterbaugh, and Mr. John Tennant of the Air Force Research Laboratory for their technical assistance throughout the modifications as well as data taking process.

Finally, I would like to thank my family and friends for their support throughout this process. I would like to give special thanks to my parents for making me the man that I am today and paying for my undergraduate studies. 


\section{DEDICATION}

I would like to thank my wonderful wife Natalie for all the support that she has given me through the past few years. Without your love I would not be where I am now. I love you very much. 


\section{NOMENCLATURE}

\begin{tabular}{|c|c|}
\hline A & Pedestal surface area, $\mathrm{m}^{2}$ \\
\hline $\mathrm{b}$ & Pedestal assembly radius, $\mathrm{m}$ \\
\hline $\mathrm{Cp}$ & Specific heat, $\mathrm{J} /(\mathrm{kg}-\mathrm{K})$ \\
\hline$d_{32}$ & Sauter-mean diameter, $\mathrm{m}$ \\
\hline$D_{p}$ & Average droplet diameter, $\mu \mathrm{m}$ \\
\hline $\mathrm{E}$ & Electric potential gradient, $\mathrm{N} / \mathrm{C}$ \\
\hline $\mathrm{f}$ & Fractional heat loss due to conduction down the pedestal \\
\hline $\mathrm{F}_{\mathrm{e}}$ & Force of electric field \\
\hline $\begin{array}{l}g \\
G\end{array}$ & $\begin{array}{l}\text { Volumetric heat generation, } \mathrm{W} / \mathrm{m}^{3}, \mathrm{Q} / \pi \mathrm{b}^{2} \delta \\
\mathrm{gb}^{2} /\left(T_{\infty_{\text {wall }}} \mathrm{k}_{\mathrm{htr}}\right)\end{array}$ \\
\hline $\mathrm{h}$ & Heat transfer coefficient, $\mathrm{W} /\left(\mathrm{m}^{2}-\mathrm{K}\right)$ \\
\hline I & Current, A \\
\hline $\mathrm{k}$ & Thermal conductivity, $\mathrm{W} /\left(\mathrm{m}^{2}-\mathrm{K}\right)$, dielectric constant \\
\hline $\mathrm{K}$ & $\mathrm{k}$ ratio, $\mathrm{k}_{\mathrm{f}} / \mathrm{k}_{\mathrm{htr}}$ \\
\hline $\mathrm{L}_{1}$ & Law electrode ground \\
\hline $\mathrm{L}_{2}$ & Law electrode voltage source \\
\hline $\mathrm{m}_{\mathrm{p}}$ & Particle mass, $\mathrm{kg}$ \\
\hline $\mathrm{N}$ & Droplet number flux \\
\hline $\mathrm{Nu}$ & Nusselt number, $\mathrm{hd} / \mathrm{k}$ \\
\hline$q^{\prime \prime}$ & Heat flux, $\mathrm{W} / \mathrm{m}^{2}$ \\
\hline $\mathrm{q}_{\mathrm{p}}$ & Particle charge, $\mathrm{C}$ \\
\hline $\mathrm{Q}$ & Heat rate, $\mathrm{W}$ \\
\hline $\mathrm{R}$ & Electrical resistance, $\Omega$ \\
\hline$r_{c}$ & Radius of electrode, $\mathrm{m}$ \\
\hline$r_{j}$ & Radius of liquid jet, $\mathrm{m}$ \\
\hline$r_{p}$ & Radius of particle, $\mathrm{m}$ \\
\hline $\mathrm{t}$ & Time, $\mathrm{s}$ \\
\hline $\mathrm{T}$ & Temperature, ${ }^{\circ} \mathrm{C}$ \\
\hline $\mathrm{T}_{\text {int }}$ & Interface temperature, ${ }^{\circ} \mathrm{C}$ \\
\hline $\mathrm{T}_{\mathrm{s}}$ & Heater surface temperature, ${ }^{\circ} \mathrm{C}$ \\
\hline $\mathrm{T}_{\text {sat }}$ & Working fluid saturation temperature, ${ }^{\circ} \mathrm{C}$ \\
\hline $\mathrm{T}_{\text {sub }}$ & Subcooling of impinging fluid with respect to saturation temperature, ${ }^{\circ} \mathrm{C}$ \\
\hline$T_{\infty_{\text {top }}}$ & Free stream fluid temperature flowing over heater surface, ${ }^{\circ} \mathrm{C}$ \\
\hline$T_{\infty_{\text {wall }}}$ & Free stream fluid temperature flowing along pedestal wall, ${ }^{\circ} \mathrm{C}$ \\
\hline $\mathrm{v}$ & Average droplet velocity, $\mathrm{m} / \mathrm{s}$ \\
\hline$V$ & Volumetric flow rate, $\mathrm{m}^{3} / \mathrm{s}, \mathrm{GPH}$ \\
\hline $\mathrm{V}$ & Applied charging voltage, $\mathrm{V}$ \\
\hline W & Watts \\
\hline
\end{tabular}




$\begin{array}{ll}\text { GREEK SYMBOLS } \\ \delta & \text { Thickness, } \mathrm{m} \\ \Delta & \delta / \mathrm{b} \\ \varepsilon & \text { Dielectric permittivity, F/m } \\ \varepsilon_{0} & \text { Vacuum dielectric permittivity, } \mathrm{F} / \mathrm{m} \\ \rho & \text { Density, } \mathrm{kg} / \mathrm{m}^{3}, \text { liquid resistivity, }, \Omega-\mathrm{cm} \\ \rho_{E} & \text { Free electric charge density, } \mathrm{C} / \mathrm{m}^{3} \\ \theta & \text { Non dimensional temperature }\left(\mathrm{T}-\mathrm{T}_{\infty \text { otop }}\right) /\left(\mathrm{T}_{\text {sat }}-\mathrm{T}_{\infty}\right. \\ \mu & \text { Absoll }) \\ \sigma & \text { Surface tension, } \mathrm{kg} / \mathrm{s}^{2}, \mathrm{~m} \text { - electrical conductivity } \\ \tau & \text { Charge relaxation time }, \mathrm{s} \\ \Omega & \text { Ohms }\end{array}$

\section{SUBSCRIPTS}

$\begin{array}{ll}1 & \text { top glass layer } \\ 2 & \text { bottom glass layer } \\ \mathrm{e} & \text { Electrical } \\ \mathrm{f} & \text { Working fluid } \\ \mathrm{g} & \text { Glass } \\ \text { int } & \text { Interface } \\ \mathrm{htr} & \text { Heater } \\ \mathrm{r} & \text { Resistor } \\ \mathrm{s} & \text { Surface } \\ \text { sub } & \text { Substrate } \\ \text { sat } & \text { Saturation }\end{array}$

ACRONYMS

$\begin{array}{ll}\text { AFRL } & \text { Air Force Research Laboratory } \\ \text { CHF } & \text { Critical heat flux, W/m }{ }^{2} \\ \text { GPH } & \text { Gallons per hour } \\ \text { HX } & \text { Heat exchanger } \\ \mathrm{H}_{2} \mathrm{O} & \text { Water } \\ \text { ITO } & \text { Indium tin oxide } \\ \text { PTFE } & \text { Polytetrafluoroethylene, manufactured by DuPont } \\ \text { PVC } & \text { Polyvinyl chloride } \\ \text { RTD } & \text { Resistance temperature detectors } \\ \text { SEM } & \text { Scanning electron microscope } \\ \text { TFR } & \text { Thick film resistor } \\ \text { WPAFB } & \text { Wright Patterson Air Force Base } \\ \text { WVU } & \text { West Virginia University }\end{array}$




\section{CHAPTER 1 : INTRODUCTION AND OBJECTIVES}

Dramatic advances are taking place in the electronics industry resulting in smaller and smaller components. Therefore, advances in thermal management are becoming more and more important in enabling the cooling of their high heat flux components. Heat transfer has been studied for many years including, but not limited to, natural convection, single-phase forced convection and pool boiling (Mudawar, 2000). Utilizing boiling leads to higher heat transfer coefficients, and thus more heat transferred away from the heated surface. Spray cooling has one of the highest levels of critical heat flux (CHF) and heat transfer coefficient compared to those obtained with jet impingement or pool boiling (Chow et al., 1997).

Heat transfer coefficients for spray cooling are reported to be an order of magnitude greater than those for pool boiling (Sehmbey et al., 1995). Directly before the surface reaches critical heat flux (CHF) the largest heat fluxes are present. CHF occurs as a result of the two-phase heat transfer transitioning from nucleate boiling to film boiling when a vapor layer builds between the heated surface and the liquid layer. As a result CHF balances the maximum amount of heat supplied to the heater, with the heat removed by liquid cooling and thus the largest temperature the surface can stably support is obtained. Enhancing the efficiency of heat transferred from a hot surface is an important aspect of the heat transfer field, and one method that accomplishes this is the use of electro-hydro-dynamics (EHD). Di Marco and Grassi (2002) have used EHD to control bubble motion generated from a heated wire in both terrestrial and reduced gravity. Their research has shown a significant increase in the CHFs achieved. The ability to control the motion of a fluid in a reduced gravity/lack of buoyancy environment 
is the first step in creating a controllable level of heat transfer in variable-gravity situations. The present research will investigate the possibility of controlling spray impingement heat transfer using the Coulomb force, by inductively charging the spray droplets.

In order to use the Coulomb force to aid in heat transfer applications an electrode had to be designed to provide the maximum charge on each droplet. Altering an electrode initially designed by Law (1978), two different electrode configurations were developed. The working fluid used for creating the spray was varied between two fluids, FC-72 and HFE-7000. Changing experimental parameters will lead to a better understanding of what influences heat transfer in a convective spray cooling environment.

One such parameter that can be controlled is the presence of an electric field. To accomplish experimental testing of varying this parameter, modifications had to be made to the experimental test rig used by Hunnell (2005). Once the modifications were made, the effects of the Coulomb force by inductively charging individual spray droplets were studied. The charge imparted onto the spray droplets enables them to either be attracted to or repelled from the heated surface. Deciding the ideal electric field conditions will enhance the heat transfer rate from the heated surface. 


\section{CHAPTER 2 : LITERATURE REVIEW}

This chapter gives an overview of previous work that has influenced the present research. Different topics will be addressed giving an explanation of why increasing the efficiency of cooling techniques is paramount, as well as an understanding of why sprays are being used. The use of electric fields is emerging as a possible enhancement technique for different cooling techniques.

\section{Section 2.1: $\quad$ Background}

An increasing trend to have the fastest, most powerful, and yet smallest electronics is occurring throughout the world. Types of electronics that are seeing this trend include, but are not limited to: radar systems, laser systems and microprocessors. These electronics have been targeted for use in a wide variety of applications in automobiles, aircraft and spacecraft. The trends in aircraft power requirements as a result of increased use of electronics can be seen in Figure 2.1 (Mahefkey et al., 2004). With the use of more and more electronic systems, their size and weight is becoming more important. Miniaturization of electronic devices is leading an increase in the amount of heat generated per unit volume. Therefore, it is necessary to develop new and better methods to cool these electronics and keep them operating at their maximum efficiency. 


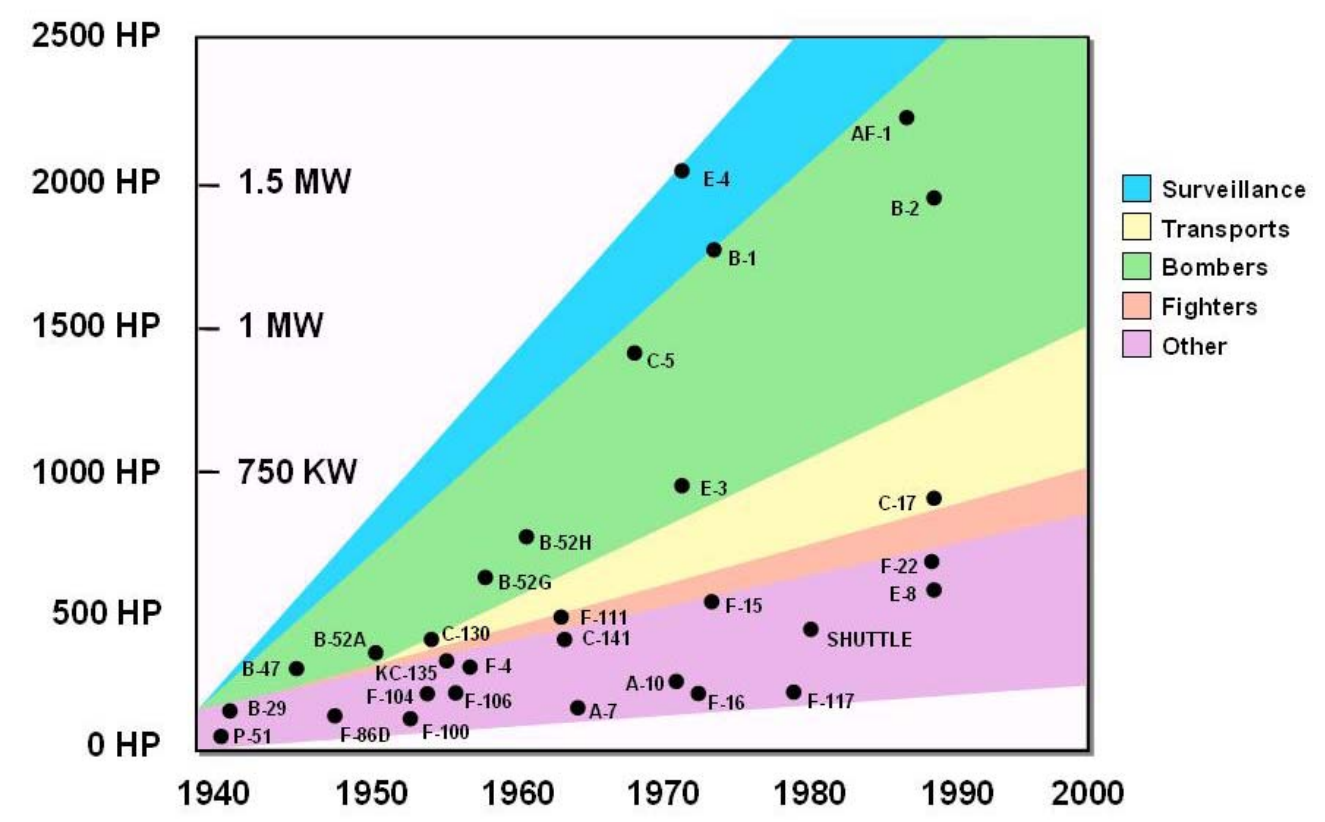

Figure 2.1: $\quad$ Trends in Aircraft Power Requirements (Mahefkey et al., 2004)

A microprocessor in a personal computer is one of the smaller heat generators from the list above, but it can produce a heat flux on the order of $50 \mathrm{~W} / \mathrm{cm}^{2}$ and may be as high as $70 \mathrm{~W} / \mathrm{cm}^{2}$ for a super computer (Pautsch and Shedd, 2005). Either case is a much higher heat flux than produced by an electric stove, which is on the order of only 6 $\mathrm{W} / \mathrm{cm}^{2}$. However, the heat generated in personal computers is small when compared to other electronic devices that generate high heat fluxes, which can be on the order of 1000 $\mathrm{W} / \mathrm{cm}^{2}$ (Mahefkey et al., 2004). Therefore, a much more efficient method of cooling must be developed for these applications.

\section{Section 2.2: $\quad$ Heat Transfer Techniques}

With the continued growth of the electronics field, the choices of methods used for cooling these electronics are becoming more and more important; see the case of convective cooling. Figure 2.2 shows a comparison of different heat transfer coefficients possible with different convective cooling techniques and coolant fluids (Mudawar, 
2000). It is obvious that convective methods that take advantage of phase change through the boiling process have a much higher heat transfer coefficient than either natural convection or single-phase forced convection. According to Mudawar (2000) the three most promising high-heat flux methods of cooling are: 1) natural convection, 2) single-phase forced convection, and 3) boiling.

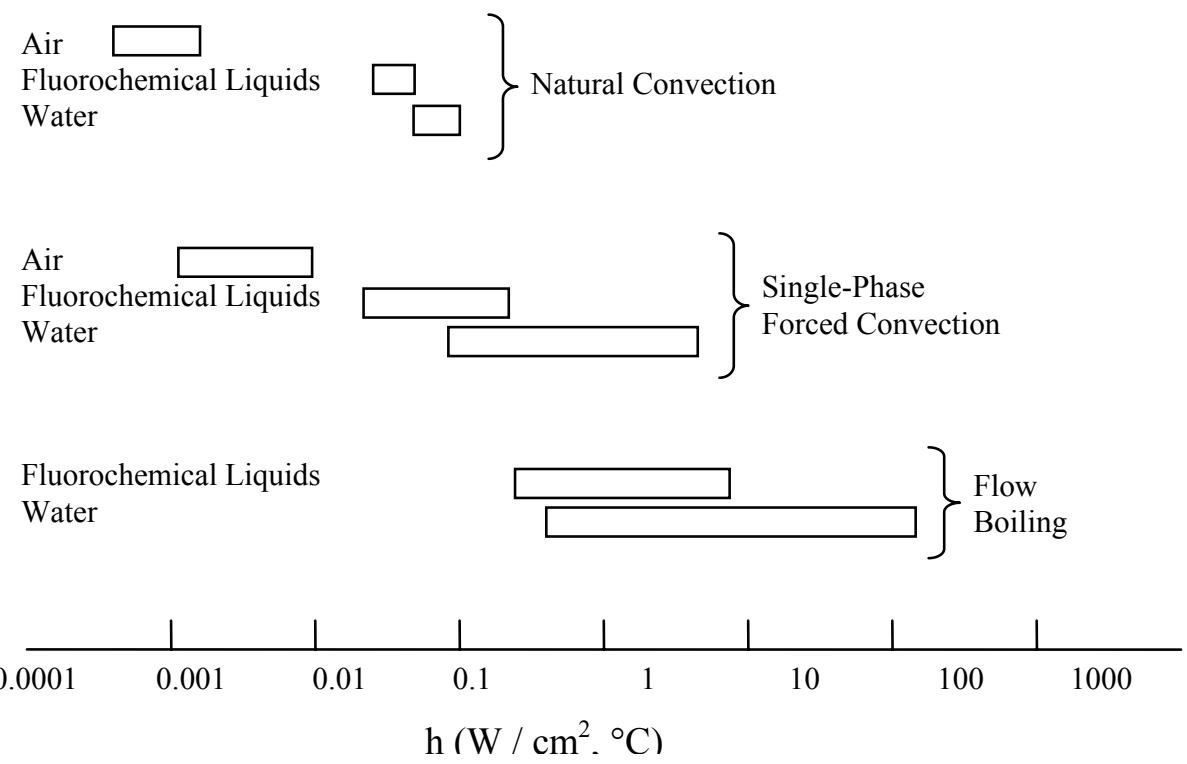

Figure 2.2: $\quad$ How Heat Transfer Coefficients vary with Fluid and Cooling Technique (Mudawar, 2000), redrawn

In the field of heat transfer there are many different methods used to accomplish convective heat transfer from a heated surface. Figure 2.3 represents the range of heat transfer coefficients achievable for different methods of convective heat transfer (Mudawar, 2000). This research will focus on the five with the highest range of heat transfer coefficients. Immediately two of these can be eliminated as possibilities; water is not a desirable working fluid due to its high temperature and pressure requirements to achieve high heat fluxes. Therefore the three remaining with the highest heat transfer coefficients are 1) fluorochemical liquid - boiling heat transfer 2) jet impingement - 
fluorinerts and 3) spray cooling - fluorinerts. All three of these heat transfer techniques can utilize boiling to accomplish maximum heat transfer (Mudawar 2000).

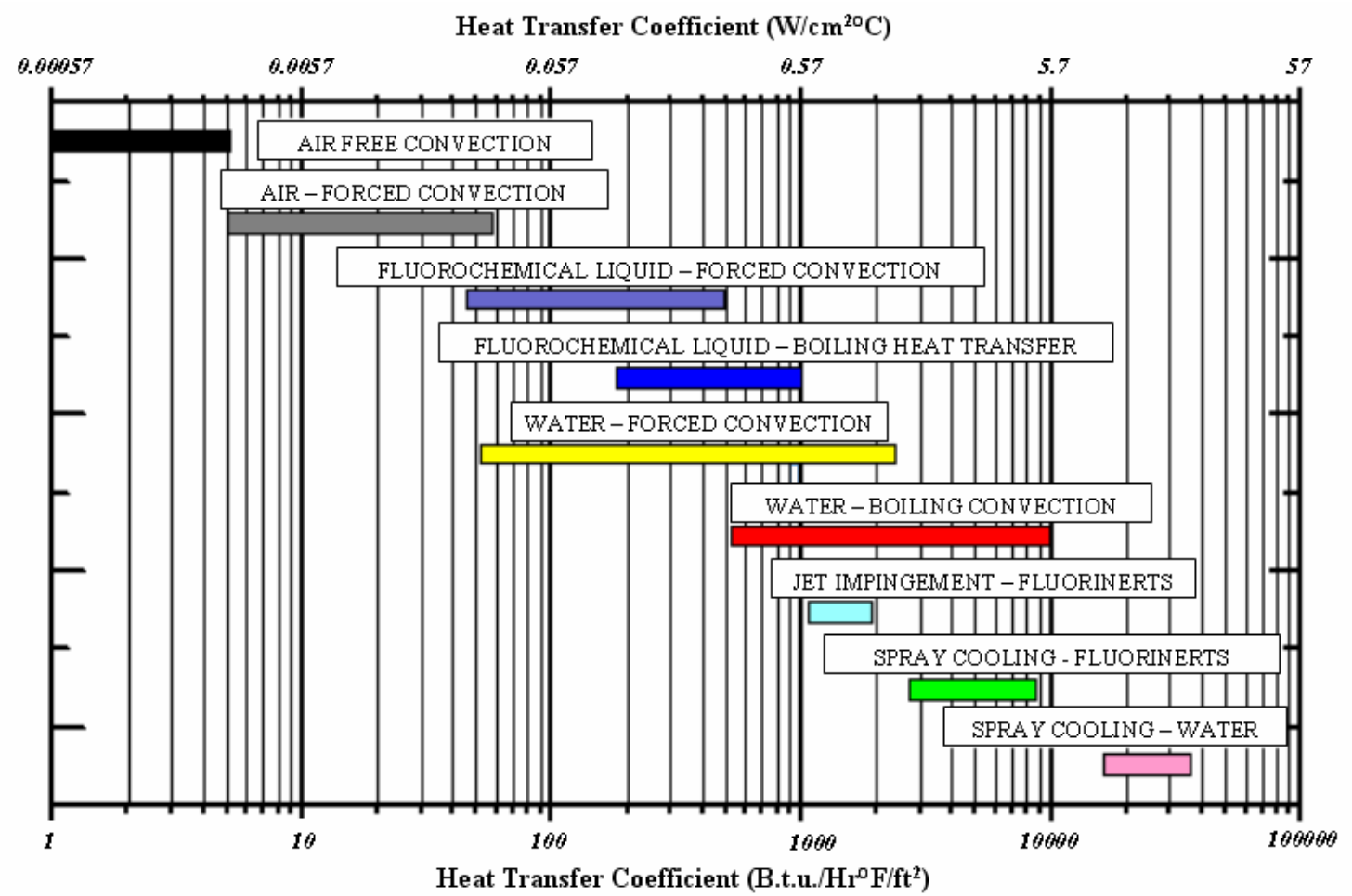

Figure 2.3: Heat Transfer Coefficients for Different Convective Heat Transfer Techniques and Fluids (Mudawar, 2000)

Heat transfer due to boiling is limited by the onset of critical heat flux (CHF). $\mathrm{CHF}$ is the point at which the maximum amount of heat supplied to the surface is balanced by the heat removed from the surface by the working fluid. At this point the highest heat flux occurs, and thus the largest heat transfer will take place. However, once $\mathrm{CHF}$ is reached a stable surface temperature is no longer possible, and thus the surface temperature increases rapidly as a vapor layer forms on the surface and the heat transfer transitions from nucleate boiling to film boiling (Bernardin et al., 1996). According to Tilton (1989), as the fluid is heated toward the Leidenfrost point hydrodynamic instabilities cause vapor columns that have built up adjacent to the heater surface to 
collapse in pool boiling. The Leidenfrost point or minimum heat flux is the lowest temperature at which film boiling occurs.

Figure 2.4 represents a curve of fluid temperatures experienced during boiling (Bernardin et al., 1996). The initial region is mostly single-phase heat transfer that is made up of forced convection and some evaporation. The second region is dominated by nucleate boiling because of the larger amount of latent heat of vaporization compared to sensible heat (Yang, 1993). CHF is reached, and at this point a vapor layer begins to form and the flow transitions from nucleate boiling to film boiling.

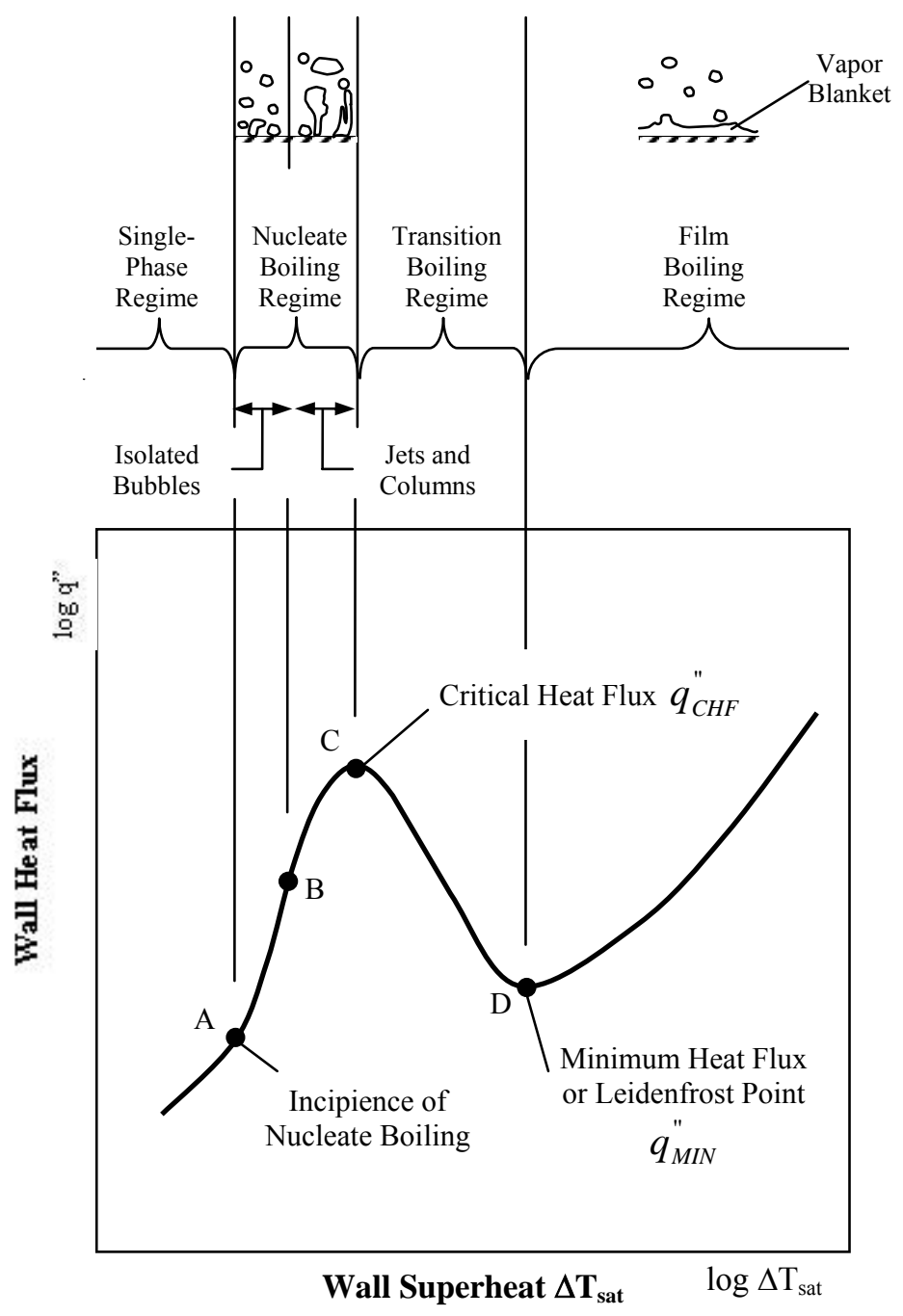

Figure 2.4: Boiling curve (Bernardin et al., 1996), redrawn 
Operating near the CHF is desirable because just before CHF the largest stable heat transfer rate is taking place as can be seen in Figure 2.5 (Mudawar, 2000). Operating in this delicate region will often times result in the surface temperature running away once the CHF is reached. The presence of the vapor layer may cause burnout of the electronics and thus should be the design limitation for spray cooling applications.

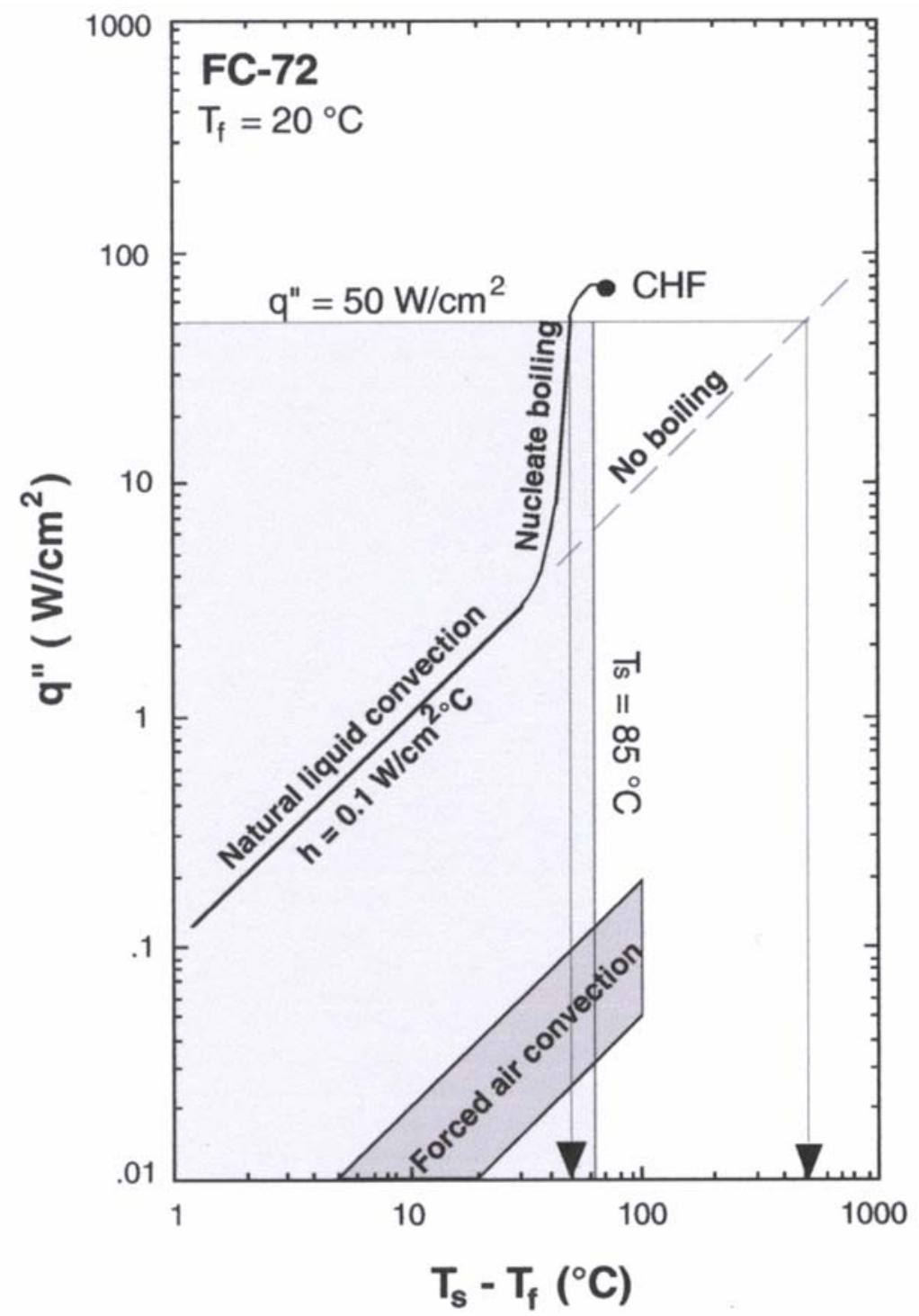

Figure 2.5: Comparison of Heat Transfer Techniques and the Importance of CHF (Mudawar, 2000) 
Looking closer at Figure 2.5 the initial region of the curve labeled natural liquid convection corresponds to single-phase heat transfer. In this region, the only mechanism for heat transfer is through the convective process into the liquid from the heated surface. As the liquid absorbs additional heat, transition into two-phase region occurs due to the latent heat of vaporization. In this region the temperature of the surface remains relatively constant due to the latent heat of vaporization. As the heat transfer rate continues to increase $\mathrm{CHF}$ is reached. At this point instabilities form and the efficiency of the heat transfer begins to decrease rapidly due to the formation of a vapor layer that restricts the liquid vapor heat exchange process (Mudawar, 2000). Therefore, it is desirable to operate in the region directly before $\mathrm{CHF}$.

\section{Section 2.2.1: $\quad$ Pool Boiling}

Pool boiling is a very commonly used method for cooling a heated surface using two-phase heat transfer. For pool boiling to work a heated surface is fully immersed in a liquid that is allowed to boil as the heat is transferred away from the surface. The heat from the surface causes a phase change in the liquid, and then due to buoyancy forces the vapor bubbles are forced away, thus carrying the heat away from the heated surface. The simplicity of this method is one of its advantages. The heat transfer coefficient for pool boiling using a fluorinert working fluid ranges from $0.1 \times 10^{4}-0.57 \times 10^{4} \mathrm{~W} / \mathrm{m}^{2}-{ }^{\circ} \mathrm{C}$ (Mudawar, 2000). Due to the smaller heat transfer coefficients of pool boiling this method is not desirable for this application. 


\section{Section 2.2.2: Jet Impingement}

Jet impingement using fluorinert fluids is another successful method of heat transfer with relatively high heat transfer coefficients. Jet impingement can utilize both single-phase and two-phase heat transfer, depending on the temperature of the heated surface and the working fluid being used. A jet of liquid is directed at the heated surface to cool the surface, and large heat transfer rates will occur at or near the stagnation point and drop off further away. The non-uniform temperatures and heat transfer rates that occur across the heated surface is one of the major downfalls of a liquid jet. Heat transfer coefficients for jet impingement using a fluorinert fluid range from $0.57 \times 10^{4}-1.0 \times 10^{4}$ $\mathrm{W} / \mathrm{m}^{2}-{ }^{\circ} \mathrm{C}$ (Mudawar, 2000).

\section{Section 2.2.3: $\quad$ Spray Cooling}

Spray cooling is emerging as a promising technique to accomplish heat transfer. Spray cooling has the ability to cool high heat fluxes quickly and completely and the versatility to work with a wide variety of applications. Spray cooling has seen heat fluxes on the order of $1000 \mathrm{~W} / \mathrm{cm}^{2}$ achieved using water as the working fluid (Lin and Ponnappan, 2003).

Another aspect of spray cooling that makes it desirable is the high heat transfer coefficients achieved by spray cooling. Heat transfer coefficients for spray cooling, using a fluorinert fluid, range from $1.5 \times 10^{4}-5.0 \times 10^{4} \mathrm{~W} / \mathrm{m}^{2}-{ }^{\circ} \mathrm{C}$ (Mudawar, 2000). Sehmbey et al. (1995) report that pool boiling has heat transfer coefficients on the order of $5 \times 10^{4}$ $\mathrm{W} / \mathrm{m}^{2}-\mathrm{K}$ while spray cooling has demonstrated values on the order of $5 \times 10^{5} \mathrm{~W} / \mathrm{m}^{2}-\mathrm{K}$. Nucleate boiling, convection heat transfer, and evaporation are all modes of heat transfer 
taking place in spray cooling (Lin and Ponnappan, 2003). Similar to pool boiling, spray cooling will also exhibit a limit in achievable heat flux bounded by CHF. However, CHF is usually much higher for spray cooling than for pool boiling because of the ability to rapidly remove the vapor forming on the surface of the heater (Kim, 2006).

\section{Section 2.3: $\quad$ Spray Behavior}

There have been a variety of explanations of the CHF limit in sprays. Certain aspects of spray impingement behavior will add to the possibility of the surface not being fully wetted and electronic burnout occurring. The first stems from nucleate boiling. As the liquid film on the heater surface is heated beyond the liquid saturation temperature, small vapor bubbles are generated (Chow, 1997). These bubbles tend to move toward the free surface of the film, where they will burst, or re-condense because the top of the liquid film is cooler than that in contact with the heater surface. When the vapor bubble bursts two distinct effects occur. Liquid is ejected from the surface of the thin film, and a void is created where the vapor bubble was. In this new region the liquid film is made even thinner. At this point evaporation happens very efficiently and local dry-out occurs. Eventually a new spray droplet or droplets will fill in the void and rewet the heater surface.

Spray behaviors are not always beneficial to achieving high heat transfer rates. The momentum of the spray droplets can cause adverse effects to the liquid film on the heater surface. Droplets will impinge on the liquid surface, causing the liquid layer present to displace locally in the impingement region. As the droplet expands outward along the surface a ripple is created, and as a result liquid can be expelled from the liquid 
layer. Figure 2.6 shows schematically how both types of spray interaction will cause liquid splashing to take place and expel liquid from the heater surface.

According to Tilton (1989), liquid splashing is a major problem when heating is taking place. About two percent of the impinging liquid splashes off the surface in normal no heat conditions, increasing to more than 87 percent of the fluid splashing off the surface under moderate heated conditions; this can be seen in Figure 2.7 (Bernardin et al., 1996) for individual drops impacting on a dry polished surface. Also, in both cases a region of very thin liquid film is created, which can contribute to localized dry-out of the heated surface. The effects of splashing can be reduced or controlled through the use of a confining cap that encloses the spray impingement region (Yerkes et al., 2006). The present work uses an unconfined flow without the use of a cap.

a)
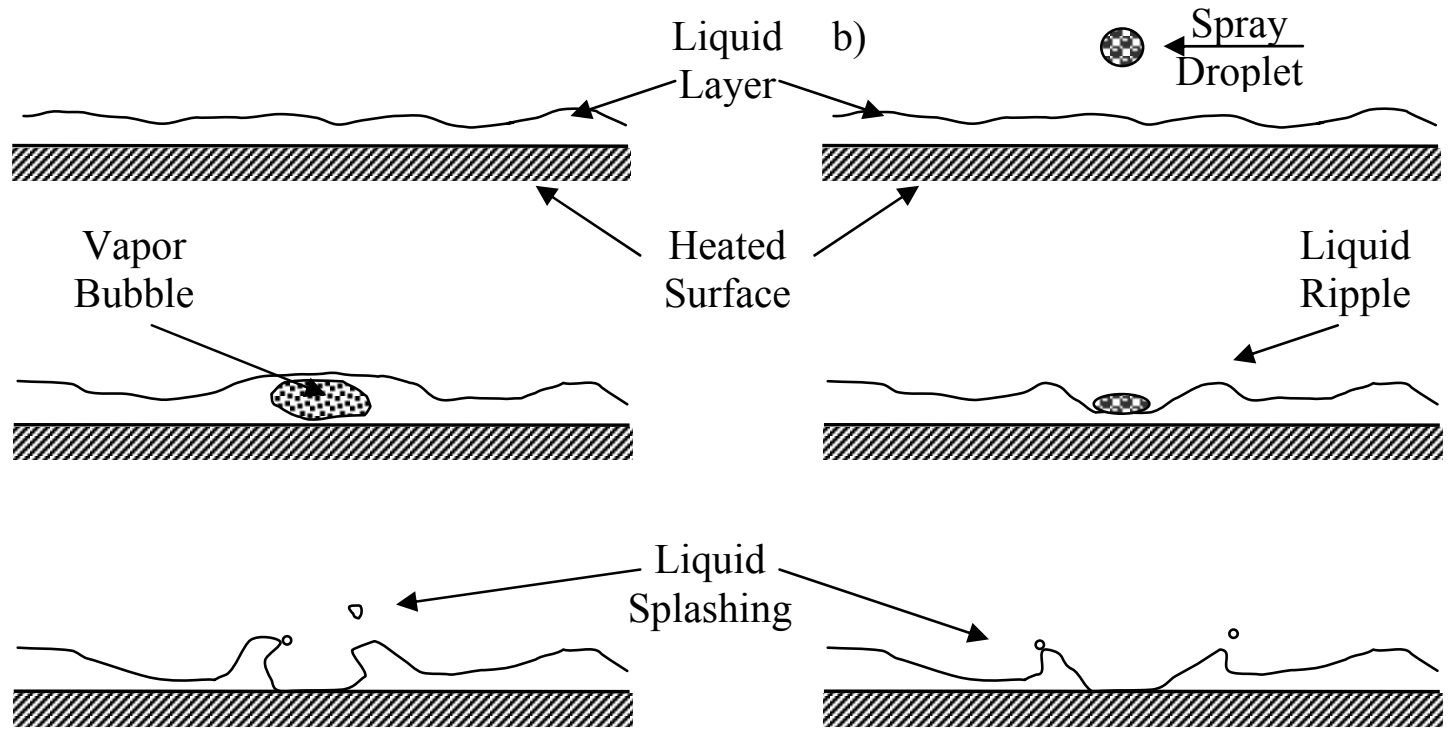

Figure 2.6: Liquid Interactions Resulting in Splashing due to, a) Vapor Bubble Expansion, b) Droplet Impact 


\begin{tabular}{|c|c|c|c|c|c|c|}
\hline $\mathbf{T}_{\mathrm{s}}$ & \multicolumn{6}{|c|}{ Polished Surface, $\mathrm{We}=220$} \\
\hline \multicolumn{7}{|l|}{$\begin{array}{c}280 \\
{ }^{\circ} \mathrm{C}\end{array}$} \\
\hline & $\mathrm{t}=1 \mathrm{~ms}$ & $2 \mathrm{~ms}$ & $3 \mathrm{~ms}$ & $4 \mathrm{~ms}$ & $5 \mathrm{~ms}$ & $6 \mathrm{~ms}$ \\
\hline \multicolumn{7}{|l|}{180} \\
\hline & $\mathrm{t}=1 \mathrm{~ms}$ & $2 \mathrm{~ms}$ & $3 \mathrm{~ms}$ & $4 \mathrm{~ms}$ & $5 \mathrm{~ms}$ & $8 \mathrm{~ms}$ \\
\hline \multicolumn{7}{|c|}{$\begin{array}{c}125 \\
{ }^{\circ} \mathrm{C}\end{array}$} \\
\hline & $\mathrm{t}=2 \mathrm{~ms}$ & $3 \mathrm{~ms}$ & $5 \mathrm{~ms}$ & $11 \mathrm{~ms}$ & $13 \mathrm{~ms}$ & $45 \mathrm{~ms}$ \\
\hline
\end{tabular}

Figure 2.7: Splashing as a Function of Temperature (Bernardin et al., 1996)

\section{Section 2.3.1: $\quad$ Effects of Electric Fields on Fluid Behavior}

Having steady predictable heat transfer is important to maximizing the efficiency of spray cooling. Up to 90 percent of the liquid can be ejected from the surface of the liquid layer during high heat fluxes. Therefore, to improve heat transfer it becomes very desirable to try to control the behavior of the liquid droplets and/or vapor bubbles. There have been several studies that have dealt with the use of electrode charging to influence how the spray droplets and vapor bubbles move.

Other industries use this technology quite frequently; for example it has been used in agricultural processes. Spraying a crop field with pesticides is very inefficient and often only covers the top of the plant leaf (Law, 1978). However, when the droplets are electrically charged the spray will tend to cover the entire leaf top and bottom with less 
overspray. One of the beneficial aspects of this technology is that far less pesticide has to be used to properly cover the crops.

There are potentially two fluid flow mechanisms that an electrical field may enhance in the performance of sprays. First, with the ability to control how droplets will impinge on a heated surface it may be possible to help control the characteristics of the heat transfer and make the droplet mass flux to surface more uniform. Secondly, if an external body force is applied to the liquid layer predictable and controllable behavior of the liquid layer may be obtained.

Certain liquids react to outside stimuli such as magnetic or electric fields in an expected fashion. Kuhlman et al. (2005) explain that a paramagnetic fluid in the presence of a magnetic field will experience an attractive force between the fluid and the magnet. The experiment was performed by simulating pool boiling by injecting air bubbles into a concentrated Manganese-Chloride solution. The experiment showed that the magnetic Kelvin force resulted in a much larger attraction of the liquid than the surface tension attachment force for bubbles present and therefore caused the bubbles to detach and to move away from the surface in the absence of a gravitational buoyancy force. Figure 2.8 shows a representative image from Kuhlman et al. (2005), showing the magnet case and the control case. For the case with the magnet a steady stream of air bubbles moves away from the injection surface, while the bubble in the no magnet case continues to grow in the absence of a buoyancy force. 


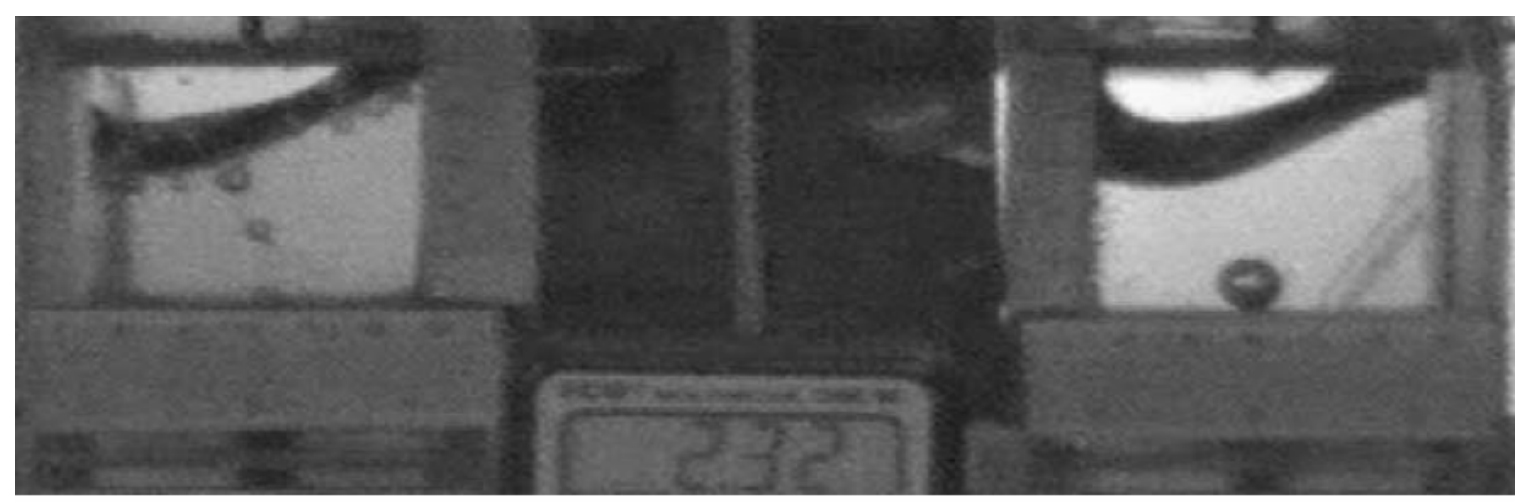

Magnet

No Magnet

Figure 2.8: Bubble Trajectory and Flow Patter as Affected by the Magnetic Kelvin Force (Kuhlman et al., 2005)

A similar principle can be used with sprays; however, there are limits to the magnetic Kelvin force. As the distance from the magnet is increased, the strength of the attractive force decreases rapidly. A suitable substitute for the magnetic Kelvin force in a spray cooling application is the electric Coulomb force. This force is uniform as long as the electric field is uniform. Law (1978) used this concept in the form of electrostaticinduction to charge the droplets of a spray used for agricultural processes, but it has also been used for xerography, textile flocking, sandpaper manufacture, and inkjet printing.

Electrostatic-induction will take place if the time to charge each droplet is smaller than the time for each droplet to pass through the region of high electric field. The time to form a charge on the droplet can be calculated by the charge relaxation time $\tau$.

$$
\tau=\frac{\varepsilon}{\sigma}
$$

Here, $\varepsilon$ is the permittivity and $\sigma$ is the electrical conductivity of the fluid in the liquid jet. This can be rewritten in more readily available terms,

$$
\tau=k \rho \varepsilon
$$


Here, $\mathrm{k}$ is the liquid's dielectric constant, and $\rho$ is the liquid's resistivity. This process has proven to be very effective in past applications. Similar techniques have been used in heat transfer research at the University of Pisa (Di Marco and Grassi, 2002) as explained in Section 2.5.

\section{Section 2.3.2: $\quad$ Effects of Electric Field on Heat Transfer}

Di Marco and Grassi (2002) from the University of Pisa have used an electric field to control bubble detachment from a heated wire in pool boiling. The results of this research show that the heat transfer coefficient can be significantly changed by using an electric field. According to Cipriani et al. (2004) the heat transfer coefficient can be increased by as much as 400 percent in the presence of an electric field, and an improvement has been seen in the efficiency of bubble motion away from the wire due to the electric field.

Di Marco and Grassi's (2002) research was primarily focused in reduced gravity; however, terrestrial gravity experiments show that a similar trend existed for both the reduced gravity data and the terrestrial data with the application of an electric field. Figure 2.9 shows that as a higher voltage was applied to the wire, the critical heat flux values increased. This research represents a large step in the field of controlling and improving heat transfer efficiency with an external force, in this case an electric field. The equation that represents the electrical force applied to a fluorinert fluid without the presence of magnetic fields is defined by Di Marco and Grassi (2002).

$$
F_{e}=\rho_{E} E-\frac{1}{2} E^{2} \operatorname{grad}\left(\varepsilon_{0} \varepsilon\right)+\frac{1}{2} \operatorname{grad}\left[E^{2} \rho\left(\frac{\partial\left(\varepsilon_{0} \varepsilon\right)}{\partial \rho}\right)_{T}\right]
$$


Here,

$$
\begin{array}{ll}
\rho_{E} & \text { Free electric charge density, } \mathrm{C} / \mathrm{m}^{3} \\
\mathrm{E} & \text { Electric potential gradient, N/C } \\
\varepsilon_{0} & \text { Vacuum dielectric permittivity, } \mathrm{F} / \mathrm{m} \\
\varepsilon & \text { Relative dielectric permittivity } \\
\rho & \text { Density, } \mathrm{kg} / \mathrm{m}^{3} \\
\mathrm{~T} & \text { Temperature, }{ }^{\circ} \mathrm{C}
\end{array}
$$

The right hand side of the equation is broken down into three terms. The first term represents the Coulomb force and for spray cooling techniques can be used to control the spray droplets. The second term is the permittivity gradient force, which in most applications where a fluorinert fluid is used is neglected because the permittivity is proportional to the gradient of the electric field and the dielectric constant of the working fluid. Finally, the third term is the electrostricitve force, which can also be neglected.

In most cases the Coulomb force usually outweighs the other electrical forces, and therefore is the force of primary concern (Di Marco and Grassi, 2002). Advantages of this force can be seen in many different environments. For example the reduced gravity experiments of Di Marco and Grassi (2002) were concerned with how the electric field compensated for the lack of a buoyancy force. This caused the liquid and vapor to behave in such a fashion as to enhance the heat transfer that took place. Advantages were also seen in terrestrial conditions. The Coulomb force combined with the force of gravity and thus enhanced the heat transfer. 


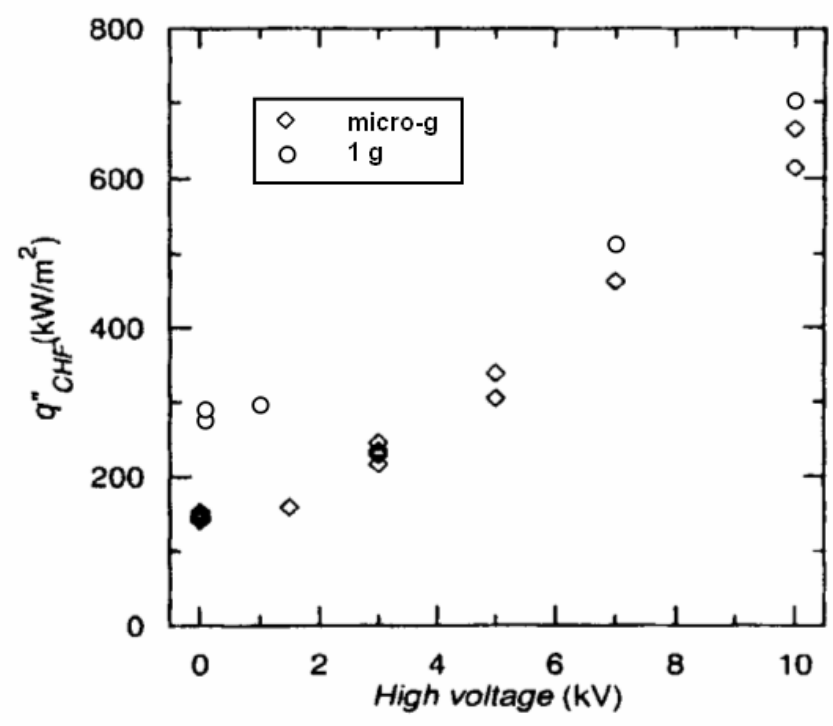

Figure 2.9: Critical Heat Flux Values Vs. High Voltage for FC-72 in 1-g and micro-g Conditions (Di Marco and Grassi, 2002)

Di Marco and Grassi (2002) used the Coulomb force to effect bubble detachment from a heated wire. Therefore, an electric field could also be used to enhance the heat transfer in many different cooling applications. During spray cooling on a thin film, there are small vapor bubbles that are created on the heater surface due to nucleate boiling. Controlling the movement of the bubbles that form in this region may ultimately help with the heat transfer on the surface. With the formation of the small nucleation sites, a void of liquid occurs. This may be hazardous over time because there might be a buildup of vapor adjacent to the surface leading to a lack of heat transfer and ultimately burnout. Another possibility is that with an electric field present the droplets could be directed to a specific location on the heater surface in such a way to make the vapor pockets dissipate. Thirdly, perhaps droplet splashing after droplet impingement could be reduced. 


\section{Section 2.4: $\quad$ Other Effects on Heat Transfer}

Previous pool boiling research has shown that changing different experimental parameters will also affect the heat transfer from the heater surface. Pressure, subcooling, dissolved gas content and surface roughness have all been studied by Rainey et al. (2003), You et al. (1995) and Kim (2006). Other parameters that could affect the heat transfer of sprays are droplet Sauter-mean diameter, droplet velocity, and droplet flux (Chen et al., 2002).

During pool boiling, the effects of pressure can enhance the heat transfer coefficient and the CHF in the nucleate boiling regime (Rainey et al., 2003). The effects of pressure and surface roughness can be seen in Figure 2.10. Subcooling can affect the thickness of the superheated liquid layer forming on the heater surface. Note the shift in the curves representing the onset of nucleation that occurs as two-phase heat transfer starts to occur. This can increase natural convection and thus increase the Marangoni heat transfer. Marangoni effects create bubble movement according to surface tension as a function of the surface temperature (Straub, 2001).

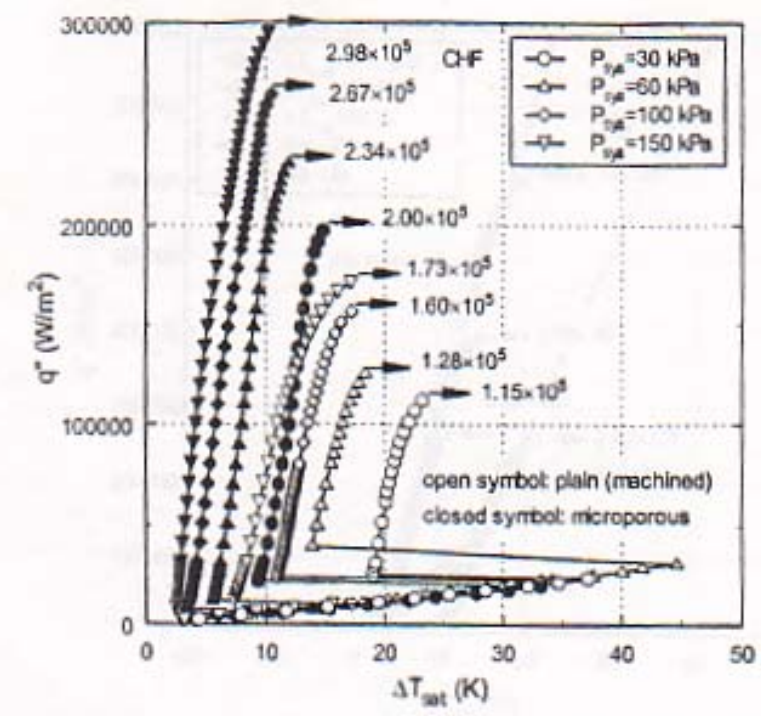

Figure 2.10: Effects on Heat Flux as a function of Pressure and Surface Roughness (Rainey et al., 2003) 
Dissolved gas content in the cooling fluid also affects the CHF. Since the CHF is a function of vapor building up on the surface of the heater, it is expected that the amount of gas that can come out of the fluid would affect such occurrences. According to You et al. (1995), as the dissolved gas content increases in the working fluid so does the CHF. However, the presence of more dissolved gas yields a higher surface temperature (Kim, 2006). Figure 2.11 shows an example of how the gas content affects the nucleate boiling curve (You et al., 1995). Case 1 represents a saturated fluid baseline, case 2 contains a low gas level, and case 3 represents even less dissolved gas content. From this figure one can say that as the dissolved gas level decreases, the wall superheat decreases at a given heat flux.

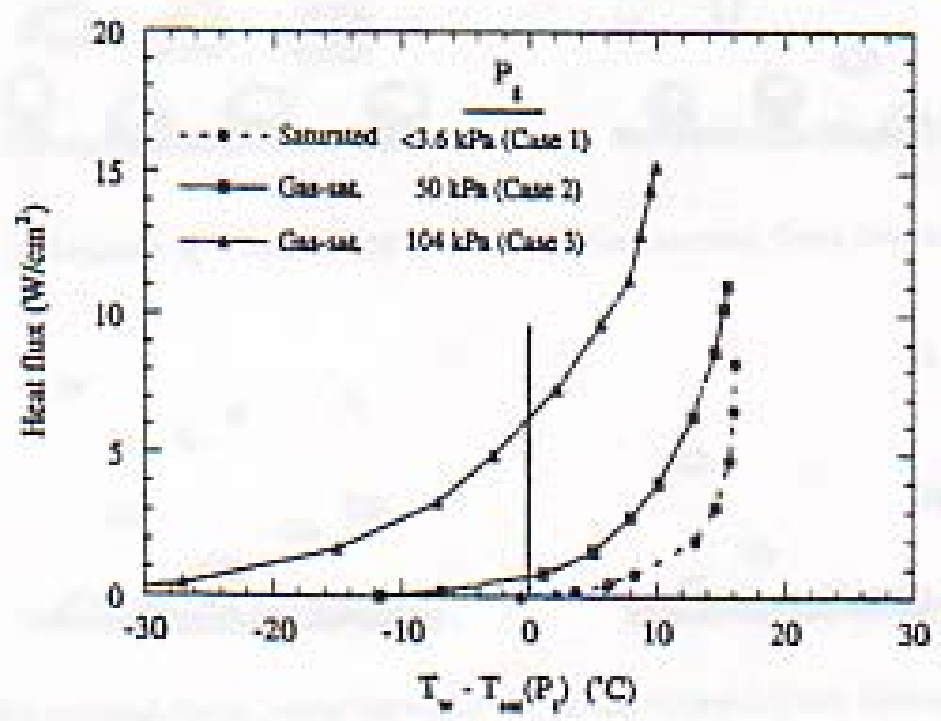

Figure 2.11: Nucleate Boiling Curve as a Function of Dissolved Gas (You et al., 1995)

With the advances in electronics made over the past decade it is becoming more and more necessary to remove large amounts of heat from electronics efficiently. 
Understanding what parameters affect the heat transfer rates that can be reached will ultimately aid the removal of high heat fluxes.

In order to understand the effects of altering the velocity, $\mathrm{v}$, droplet diameter, $\mathrm{d}_{32}$ and number flux, N, Chen et al. (2002) studied more than 20 full-cone nozzles. The nozzles tested were manufactured by Hago, Bete, and Delavan. Varying the three parameters for each nozzle yielded more than 3000 different combinations. The effect of $\mathrm{N}$ on $\mathrm{CHF}$ and $\mathrm{h}$ was studied by holding $\mathrm{v}$ within $7.5 \mathrm{~m} / \mathrm{s} \pm 10 \%$ and $\mathrm{d}_{32}$ within $56 \mu \mathrm{m} \pm$ $3 \%$ while varying $\mathrm{N}$ as shown in

Table 2.1 (Chen et al., 2002). It can be seen that increasing N from $7.30 \times 10^{6}$ to $29.00 \mathrm{x}$ $10^{6} 1 / \mathrm{cm}^{2} \mathrm{~s}$ increases the CHF about $30 \%$, and the heat transfer coefficient increases about $20 \%$.

Table 2.1: Experimental effect of varying N on CHF and h (Chen et al., 2002)

\begin{tabular}{|c|c|c|c|}
\hline Nozzle Type & B37 & B50 & Bete \#2 \\
\hline $\mathrm{N}\left(1 / \mathrm{cm}^{2} \mathrm{~s}\right)$ & $7.30 \times 10^{6}$ & $15.25 \times 10^{6}$ & $29.00 \times 10^{6}$ \\
\hline $\mathbf{d}_{32}(\mu \mathrm{m})$ & 57.3 & 55.4 & 54.7 \\
\hline $\mathrm{V}(\mathrm{m} / \mathrm{s})$ & 6.9 & 7.3 & 8.0 \\
\hline $\mathrm{CHF}\left(\mathrm{W} / \mathrm{cm}^{2}\right)$ & 610.7 & 761.9 & 780.2 \\
\hline$h\left(W / \mathbf{c m}^{2} K\right)$ & 5.94 & 7.01 & 7.15 \\
\hline
\end{tabular}

Similarly, the effects of the droplet Sauter-mean diameter were studied by holding $\mathrm{v}$ within $7.2 \mathrm{~m} / \mathrm{s} \pm 7 \%$ and $\mathrm{N}$ within $8.00 \times 10^{6} 1 / \mathrm{cm}^{2} \mathrm{~s} \pm 10 \%$ as shown in Table 2.2 . However, this test did not show a clear trend for either CHF or $\mathrm{h}$ versus $\mathrm{d}_{32}$.

Table 2.2: Experimental effect of varying $d_{32}$ on CHF and h (Chen et al., 2002)

\begin{tabular}{|l|c|c|c|}
\hline Nozzle Type & B37 & B200 & Bete \#1 \\
\hline $\mathbf{N}\left(\mathbf{1} / \mathbf{c m}^{2} \mathbf{s}\right)$ & $7.30 \times 10^{6}$ & $8.62 \times 10^{6}$ & $8.50 \times 10^{6}$ \\
\hline $\mathbf{d}_{32}(\boldsymbol{\mu m})$ & 57.3 & 86.5 & 115.7 \\
\hline $\mathbf{V}(\mathbf{m} / \mathbf{s})$ & 6.9 & 6.7 & 7.8 \\
\hline CHF $\left(\mathbf{W} / \mathbf{c m}^{2}\right)$ & 610.7 & 621.6 & 651.1 \\
\hline $\mathbf{h}\left(\mathbf{W} / \mathbf{c m}^{2} \mathbf{K}\right)$ & 5.94 & 6.04 & 6.01 \\
\hline
\end{tabular}


Finally, the effects of varying the droplet velocity were studied by holding $\mathrm{N}$ within $15.0 \times 10^{6} 1 / \mathrm{cm}^{2} \mathrm{~s} \pm 10 \%$ and $\mathrm{d}_{32}$ within $68.0 \mu \mathrm{m} \pm 2 \%$ as shown in Table 2.3. For this case it can be seen that the CHF increases from 636.7 to $945.7 \mathrm{~W} / \mathrm{cm}^{2}$, an increase of nearly $50 \%$. The heat transfer coefficient increases nearly $40 \%$, from 5.94 to $8.38 \mathrm{~W} / \mathrm{cm}^{2} \mathrm{~K}$.

Table 2.3: Experimental effect of varying $\mathrm{v}$ on $\mathrm{CHF}$ and $\mathrm{h}$ (Chen et al., 2002)

\begin{tabular}{|l|c|c|c|}
\hline Nozzle Type & B150 & B200 & Bete \#3 \\
\hline $\mathbf{N}\left(\mathbf{1} / \mathbf{c m}^{2} \mathbf{s}\right)$ & $16.40 \times 10^{6}$ & $13.51 \times 10^{6}$ & $15.12 \times 10^{6}$ \\
\hline $\mathbf{d}_{\mathbf{3 2}}(\boldsymbol{\mu m})$ & 67.2 & 70.2 & 68.7 \\
\hline $\mathbf{V}(\mathbf{m} / \mathbf{s})$ & 4.64 & 5.97 & 21.4 \\
\hline $\mathbf{C H F}\left(\mathbf{W} / \mathbf{c m}^{2}\right)$ & 636.7 & 645.1 & 945.7 \\
\hline $\mathbf{h}\left(\mathbf{W} / \mathbf{c m}^{2} \mathbf{K}\right)$ & 5.94 & 6.01 & 8.38 \\
\hline
\end{tabular}

Chen et al. (2002) shows that changing the droplet velocity while holding the other parameters constant has the greatest effect on the resulting CHF and heat transfer coefficient. From the studies presented in this section there are several parameters that have been shown to affect both the CHF and the heat transfer coefficient. However, from one study to another, results may vary in magnitude and even be contradictory (Kim, 2006). 


\section{CHAPTER 3 : EXPERIMENTAL APPARATUS}

\section{Section 3.1: Introduction}

The present research efforts can be broken down into two major experimental aspects. First, modifications were made to the WVU experimental apparatus designed and fabricated by Hunnell (2005). Second, an electrode configuration was designed that would be easily implemented with the WVU experimental rig. The research in this thesis will focus on the work performed on the WVU laboratory rig, the schematic is shown in Figure 3.1 and photographs shown in Figure 3.2a.

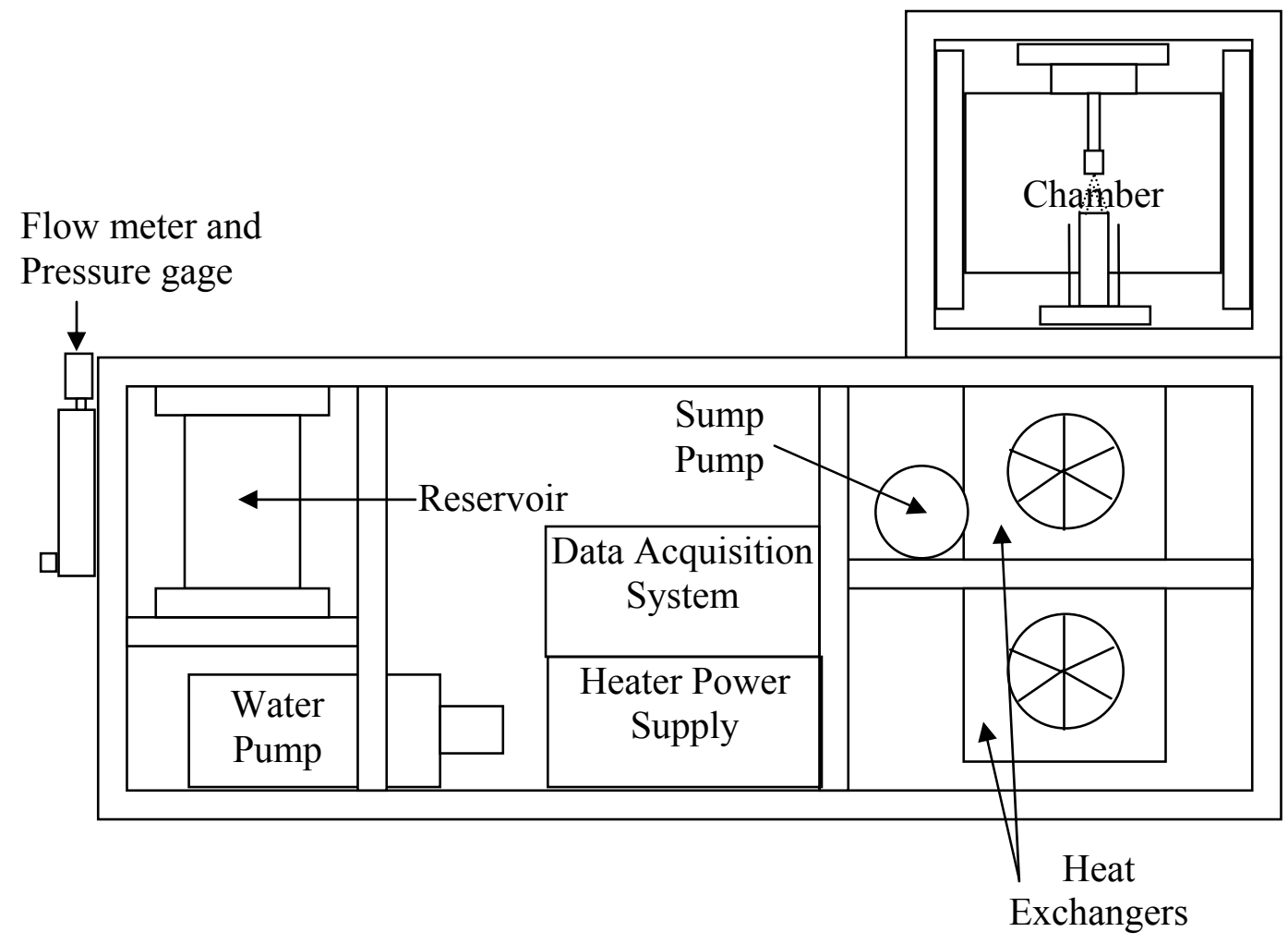

Figure 3.1: Schematic of WVU Laboratory Rig 

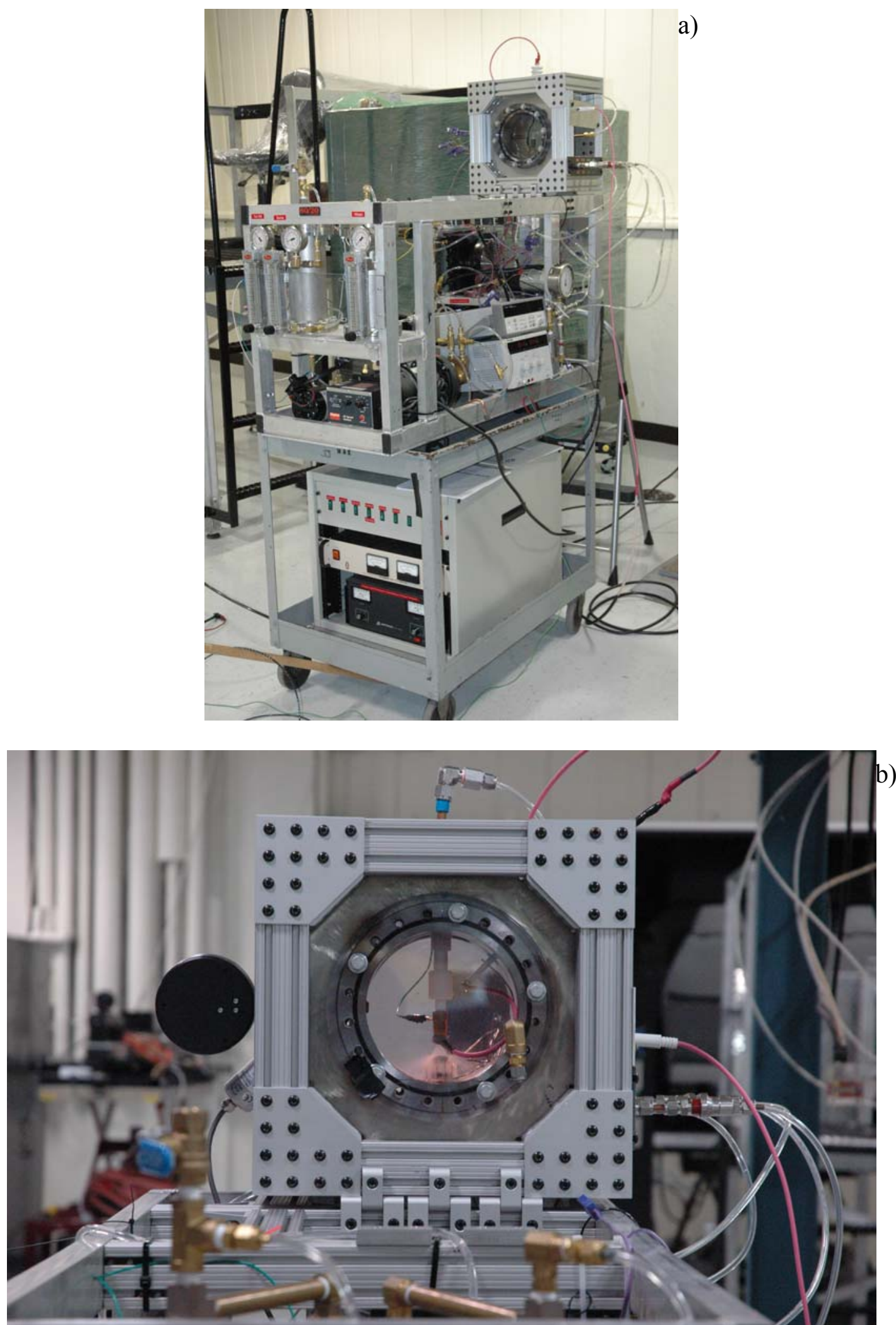

Figure 3.2: $\quad$ Photograph of a) WVU Experimental Rig b) Experimental Spray Chamber 
The experimental apparatus contains two primary components; the first is the flow management system, which consists of a supply and a drain loop to manage the working fluid and a water flow loop to allow temperature control of the spray test chamber. The second component is the experimental spray chamber, Figure 3.2b, containing a spray nozzle, heater, primary condenser surface, and sump configuration to collect the working fluid and condensate. The chamber also includes an electrode that was designed to control the working fluid at the heated surface. The following chapter will discuss both aspects of the experiment.

The experiment was operated by applying electrical power to an indium tin oxide (ITO) heater or a thick film resistance (TFR) heater inside the test chamber generating heat on the surface of the pedestal. A high voltage power supply was used to create an electric field around the nozzle and pedestal configuration, enabling control of the impinging spray. Under these conditions the heater surface was sprayed with the working fluid and spray cooling of the heaters was studied. Data was collected on the heat transfer performance and thermophysics of spray cooling of the heater in environments both with and without an electric field.

\section{Section 3.2: $\quad$ WVU Laboratory Spray Cooling Rig Flow Management System}

One outcome of the study by Hunnell (2005) was a series of suggestions of how to make the experiment better. The majority of this chapter is devoted to describing these suggested changes and how they were implemented. The most important change suggested by Hunnell (2005) was to take data using a data acquisition system. Several 
other suggestions were also made by committee members and will be elaborated upon in the following text.

The purpose of the WVU laboratory spray cooling rig is to provide a platform for performing laboratory testing of the different electrode configurations. Validation of this research will occur by comparing the baseline results, without an electric field, to the results obtained by the research team directed by Dr. Kirk Yerkes at Wright Patterson Air Force Base (WPAFB). Therefore, it is important for the two experimental rigs to be as similar as possible and, whenever possible, for the same components to be used. The largest portion of the experimental apparatus is the flow management system. Figure 3.3 shows a schematic representing the WVU laboratory spray cooling flow loop. In this flow management system there are two sub-systems, the water loop and the working fluid loop.

\section{Section 3.2.1: $\quad$ Water Flow Loop}

The purpose of the water flow loop is to regulate the temperature inside the spray chamber. This section will describe the water flow loop components starting with the reservoir. The reservoir is a five and three-quarter inch vertical MDC vacuum nipple with flanges welded to the top and bottom, enabling a water tight seal to be created. Inlet and outlet fittings, at the top and bottom of the reservoir, allow the flow to enter and exit the reservoir respectively. The water travels from the reservoir to the spray chamber where copper tubing covers as much surface area of the external portion of the spray chamber as possible, shown in Figure 3.4. Masterbond, EP21ANHT, thermally conductive epoxy was used to secure the copper tubing carrying the fluid around the chamber. 


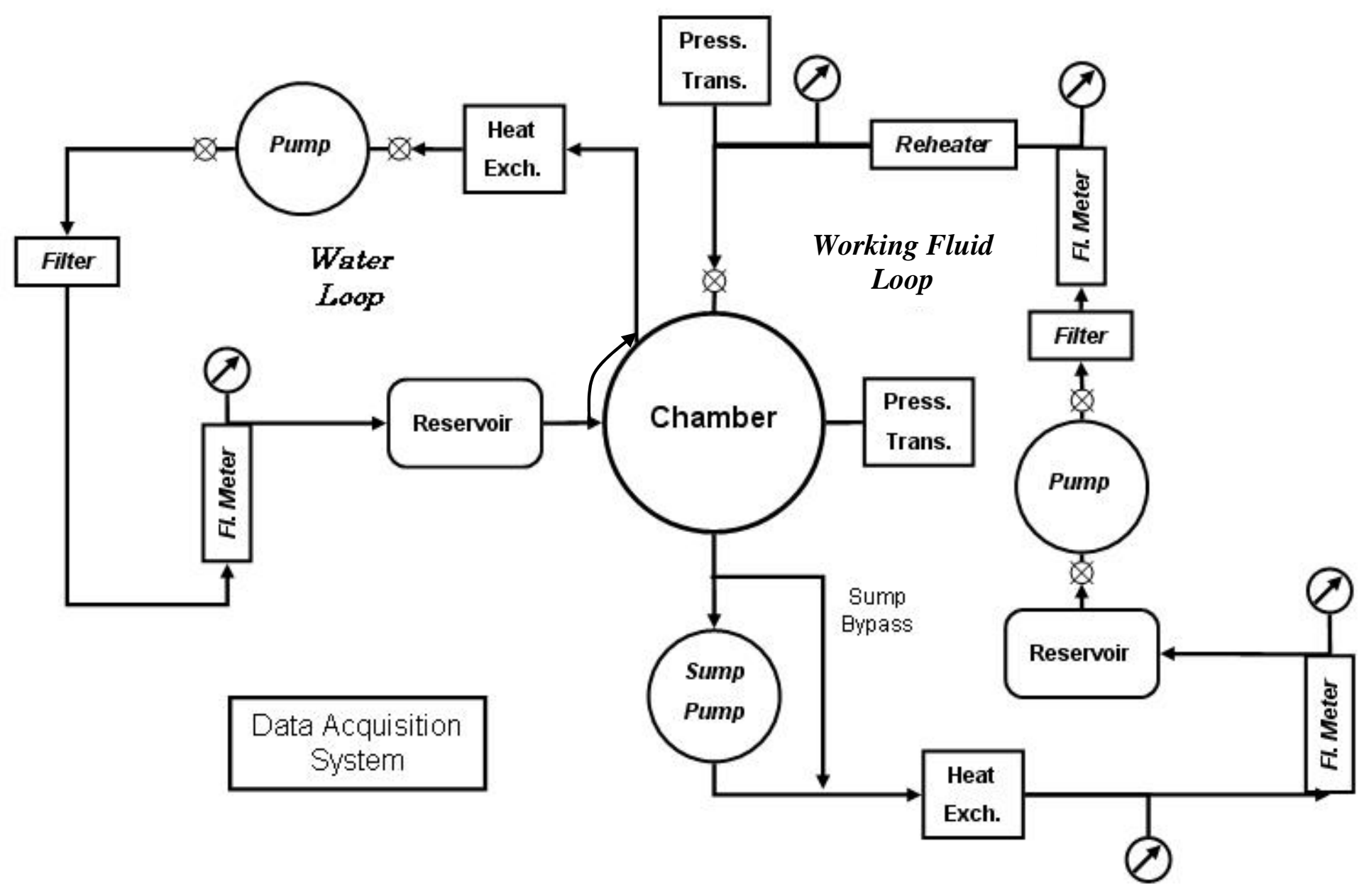

Figure 3.3: Schematic of WVU Lab Flow Loops 
From the chamber the water travels to a Lytron liquid-to-air heat exchanger, where the excess heat is removed from the fluid, preventing the system temperature from continually rising. Located on either side of the water heat exchanger are Omega MSQQ type $\mathrm{E}$ thermocouples to monitor the temperature of the fluid entering and exiting the heat exchanger.

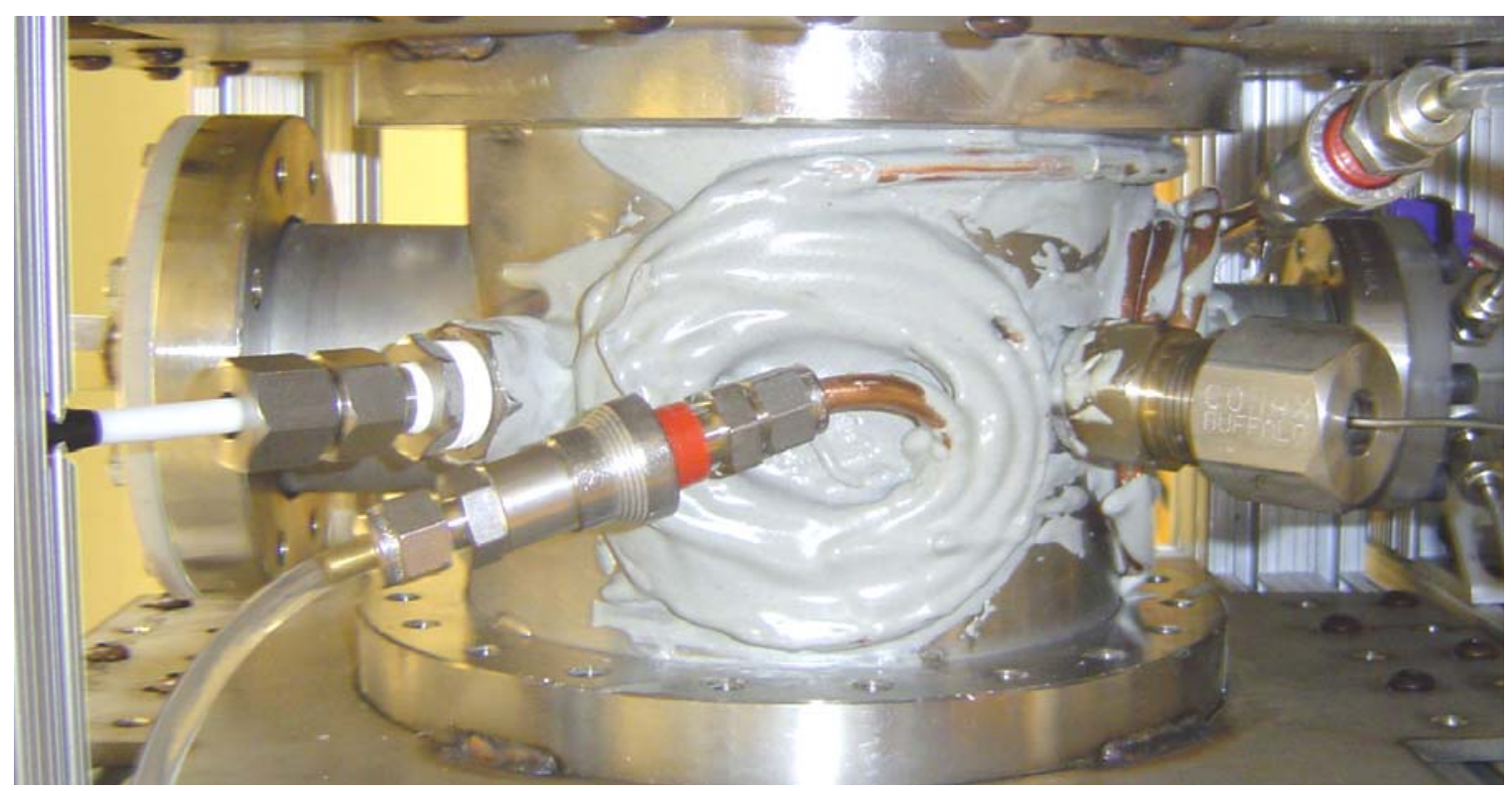

Figure 3.4: Photograph of Copper Tubing Covering Spray Chamber

The water then travels through a Grainger vane pump powered by a Dayton speed controller which regulates the flow rate at which the water moves around the loop. On either side of the pump there are valves, which serve as fill and drain valves respectively. The water then travels through a 40 micron filter that removes any sediment from the flow loop. Filters must be cleaned periodically to ensure steady clean flow. Next, the fluid moves through a $20 \mathrm{GPH}$ Dwyer RMB-82-SSV rotameter and past a pressure gauge, where the characteristics of the flow are monitored visually (due to monetary constraints automated readings for the water loop have not been included in the data 
acquisition system). Finally, the water travels back into the reservoir completing the loop.

\section{Section 3.2.2: $\quad$ Working Fluid Flow Loop}

The second sub-system of the fluid management system is the working fluid flow loop, shown in Figure 3.3. For these experiments, the working fluid is either FC-72 or HFE-7000, both produced by $3 \mathrm{M}$. This loop is more complicated than the water flow loop and is directly linked to the inside of the chamber where it delivers the working fluid to the heater surface. Several major modifications have been made to this loop in the present work from that described by Hunnell (2005). Major changes include inserting a bypass for the sump, eliminating the air/vapor problem that was associated with the air accumulator. Also a custom-built re-heater has been added to control the temperature of the fluid entering the nozzle inlet of the chamber. In addition, two Omega PX303 pressure transducers and a Sponsler MF90 flow meter were added to monitor flow conditions more accurately. Finally, a data acquisition system has been added to make data taking faster, more reliable and more repeatable.

Beginning with the reservoir to describe this flow loop, an identical MDC vacuum nipple with flanges on the top and bottom was used as the working fluid reservoir. Exiting a fitting in the bottom of the reservoir, the flow travels through a Tuthill D-series miniature magnetically coupled gear pump that controls the flow rate. Again drain and fill valves are located on either side of the pump. Next, the fluid travels through a 15 micron filter. In this loop, filters are more important because any sediment in the fluid could interfere with the generation of the electric field in the chamber, or even worse, clog the nozzle, stopping the spray and resulting in burnout of the heater. From this 
point, the fluid travels into a $20 \mathrm{GPH}$ Dwyer RMB -82-SSV rotameter and past a McMaster-Carr glycerin-filled pressure gauge giving a readable indication of the flow rate and pressure without the data acquisition system.

Next, the fluid goes through the custom-built re-heater, which is described in Section 3.2.2.1. The purpose of the re-heater is to control the temperature of the working fluid entering the nozzle, and thus the amount of subcooling of the working fluid. Next, the flow moves past a McMaster-Carr pressure gauge, and an Omega PX303-100A5V pressure transducer with an output voltage that is read by the data acquisition system. An Omega MSQQ type E thermocouple is also in line to monitor the temperature of the fluid as it enters the chamber. This signal is sent to the re-heater PID controller as well as the data acquisition system. At this point there is a bulkhead connection that allows the spray chamber to be interchanged with a second. The spray chamber will be described in detail in Section 3.3.

Next, the working fluid flow loop continues with the two drain lines that come from the spray chamber. One line comes from the front of the chamber, and is used only when the chamber is rotated on its side. This line meets up with the main line coming directly from the sump, located in the bottom of the spray chamber, where both lines can be opened or closed based on the orientation of the spray chamber. After the two lines come together the flow enters the sump pump, which is an Aquatec DDP diaphragm pump. This pump has a constant setting and is only used to help pull the fluid from the chamber and send it back to the reservoir. The diaphragm pump acts as a sump pump that operates at a constant speed; this requires a bypass to control the flow rate from the spray chamber through the diaphragm sump pump, see section 3.2.2.2. 
After the bypass, the fluid enters a Lytron liquid-to-air heat exchanger with the intended purpose of cooling the working fluid. Located on either side of the heat exchanger are Omega MSQQ type E thermocouples to monitor the temperature of the fluid entering and exiting the heat exchanger. The working fluid exits the heat exchanger and travels past a McMaster-Carr pressure gauge to monitor the pressure at this point in the flow loop. Next, the fluid travels through another 40 micron filter to remove any sediment that might have been picked up in the chamber during an equipment change of the pedestal, cap, nozzle, or electrode. The fluid then passes through another $20 \mathrm{GPH}$ Dwyer RMB -82-SSV rotameter. After the filter the fluid travels back up and into the reservoir completing the working fluid loop.

\section{Section 3.2.2.1: $\quad$ Re-heater Design}

The re-heater was custom-built for this application using an 18 " long $1 / 2$ " diameter copper tube for transporting the working fluid flow through the re-heater. Mica insulation was then wrapped around a 12" long section of the tube, creating the base layer for the re-heater. Next, 18 gauge Nickel Chromium wire was wrapped around the mica insulation as shown in Figure 3.5 and Figure 3.6. To create evenly spaced wire coils, insulated 18 AWG (American wire gauge) wire was used as a spacer in between each coil of the conductive wire. To regulate the speed and ensure the wire was wrapped tightly a portable low speed lathe was used to spin the copper tube at a rate of one revolution every three seconds. Once the wire was wrapped tightly around the tube and tied off, the spacing wire was removed. Ten inches of wire were left at either end of the tube for power control leads. 


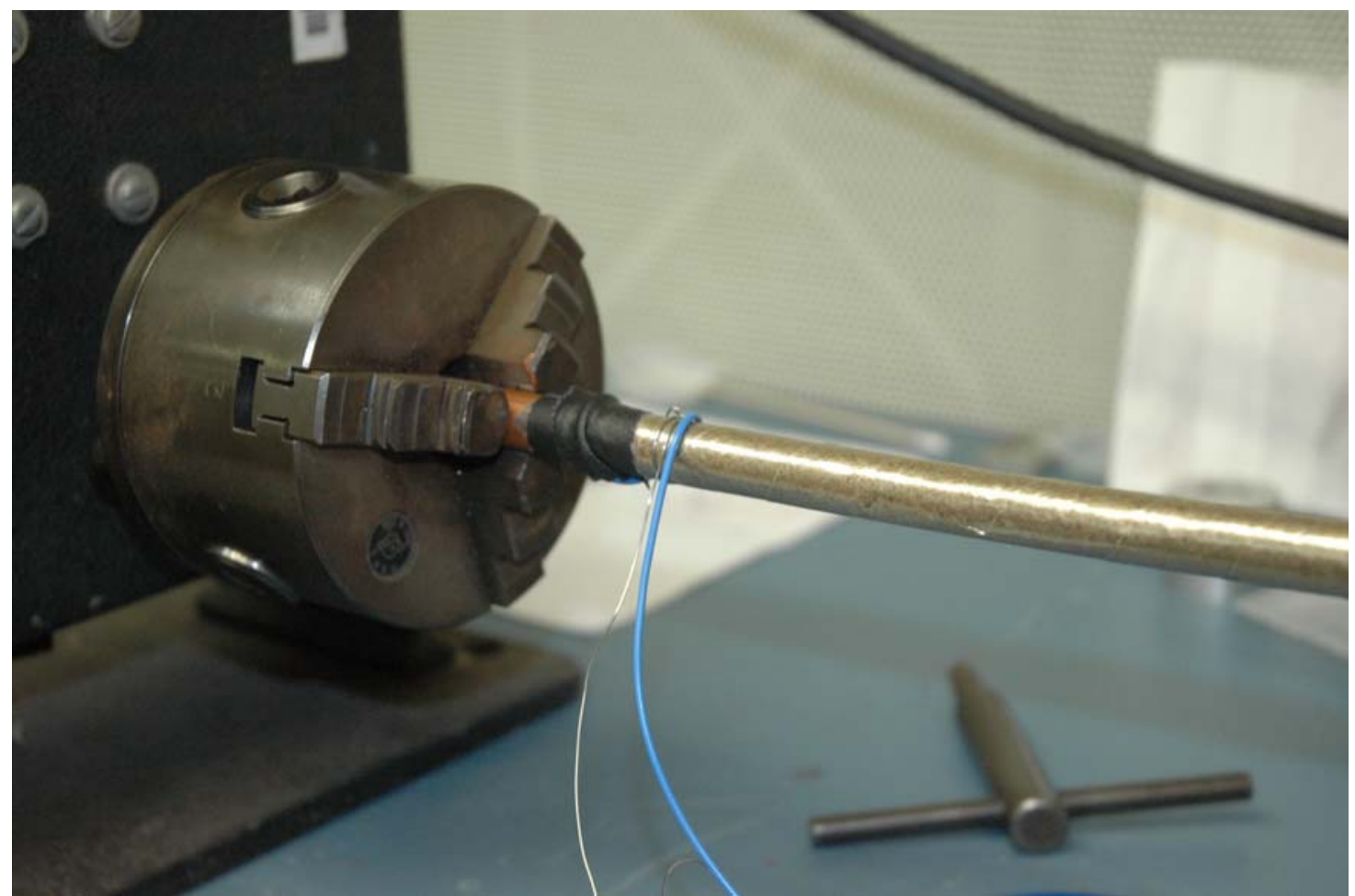

Figure 3.5: Copper Tube Wrapped in Mica Insulation

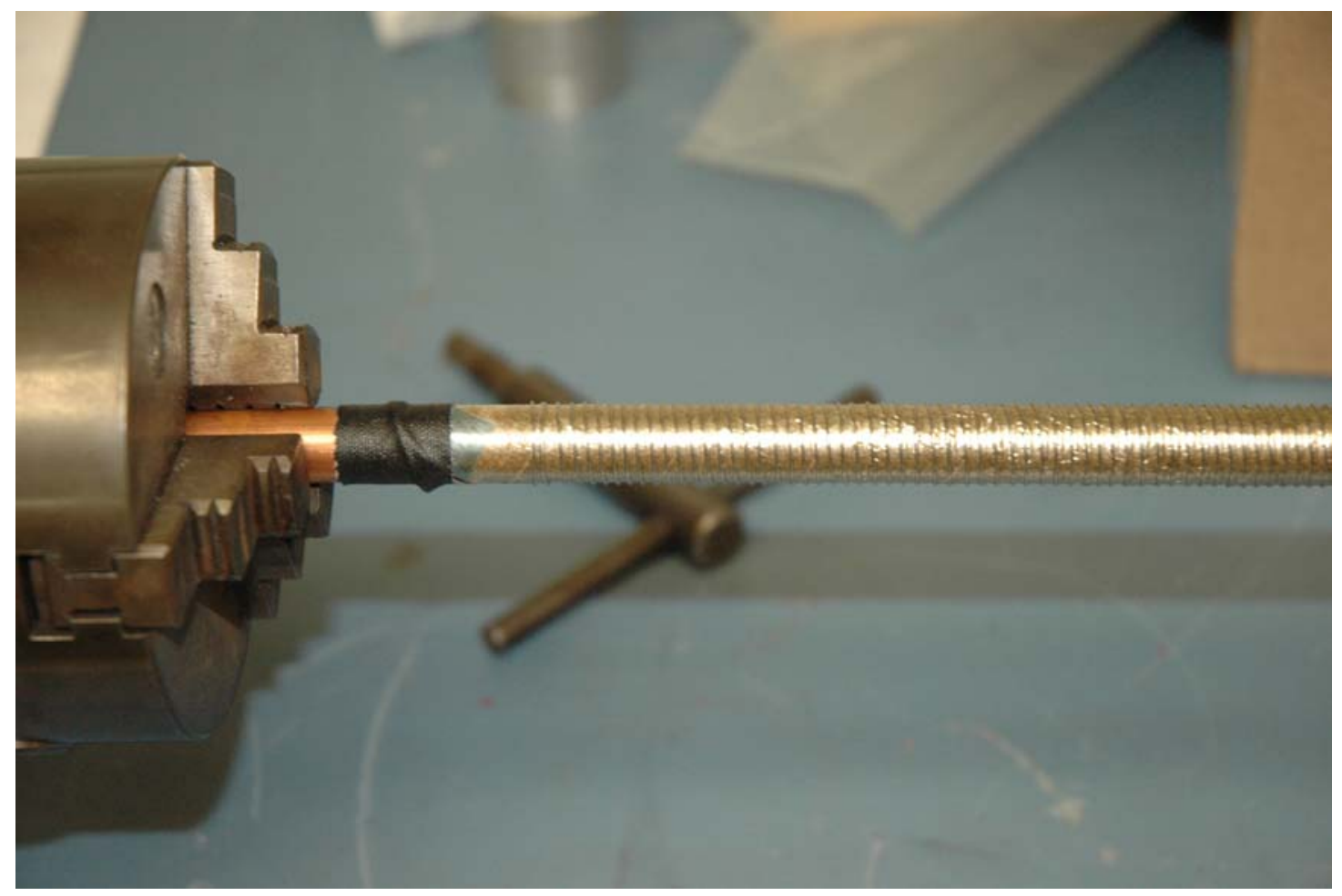

Figure 3.6: Nichol Chromium Wire Wrapped around Copper Tube 
High temperature Permatex RTV was then spread over the surface of the tube covering the Nickel Chromium wire as shown in Figure 3.7. After this was allowed to cure, the re-heater was wrapped with $1 / 2$ inch thick Fiberfrax insulation several times creating a three inch diameter. To finish the re-heater, a 1/16 inch sheet of aluminum was spot welded securely around the side and ends of the insulation, shown in Figure 3.8, making sure that the control leads were allowed to exit either end of the re-heater, so that a voltage could be applied. The resistance in the internal wires creates resistive heating at a level of up to $500 \mathrm{~W}$ with an applied voltage of $110 \mathrm{~V}$. This design matches that of the re-heater developed at AFRL for their apparatus.

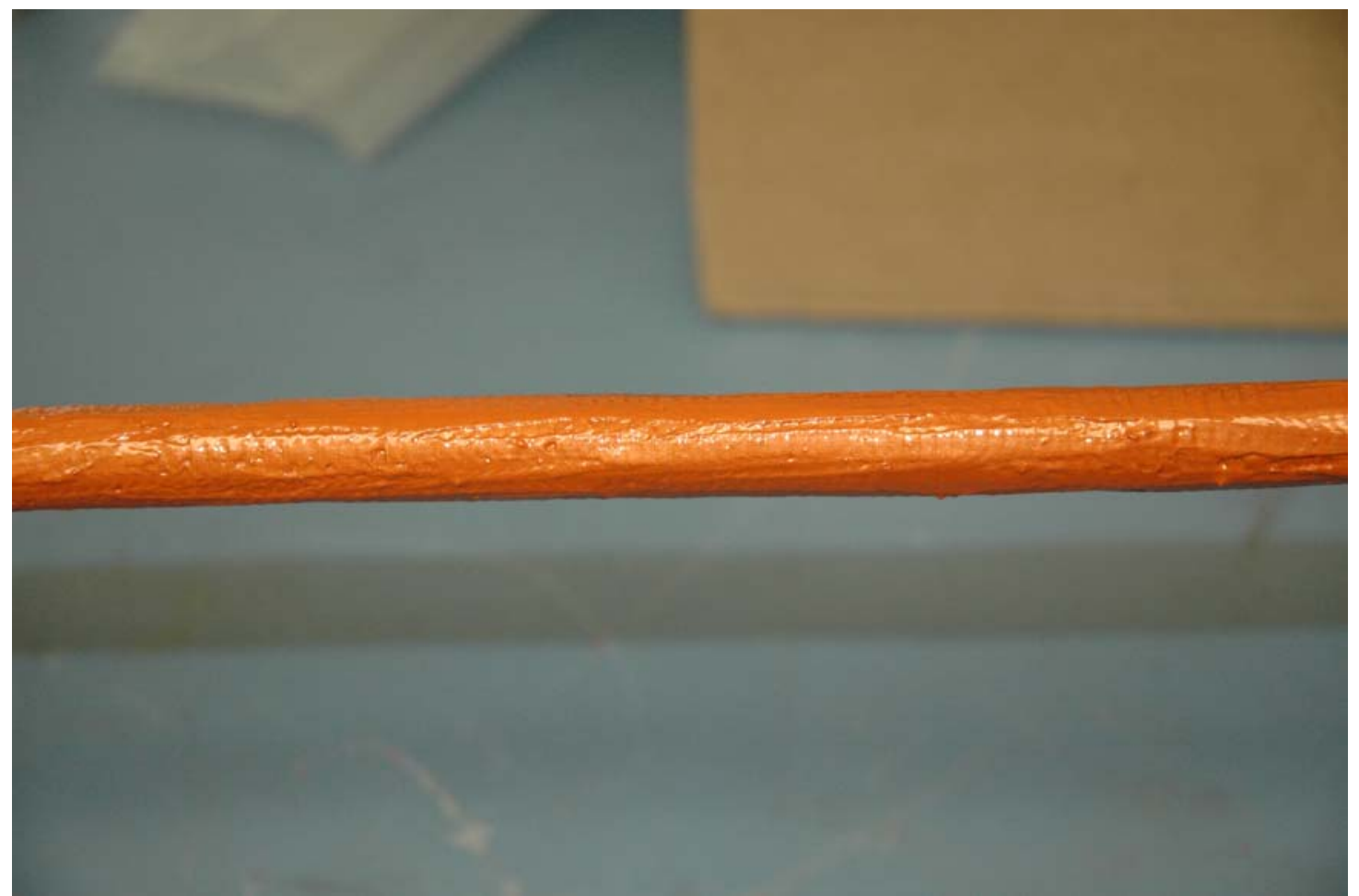

Figure 3.7: Copper Tube Covered with High Temperature Permatex RTV

To control the level of heat input to the working fluid a Fuji Electric PXR3 temperature controller is used. A PID controller allows the user to set a desired temperature to be maintained. The temperature of the working fluid, was measured at the 
nozzle inlet using an Omega Type-E thermocouple, and then wired into the controller. Converting an input $\mathrm{AC}$ power to a DC voltage switches the re-heater on and off by means of a solid state relay. Incrementally turning the re-heater on and off generates the necessary heating level to maintain the temperature set-point.

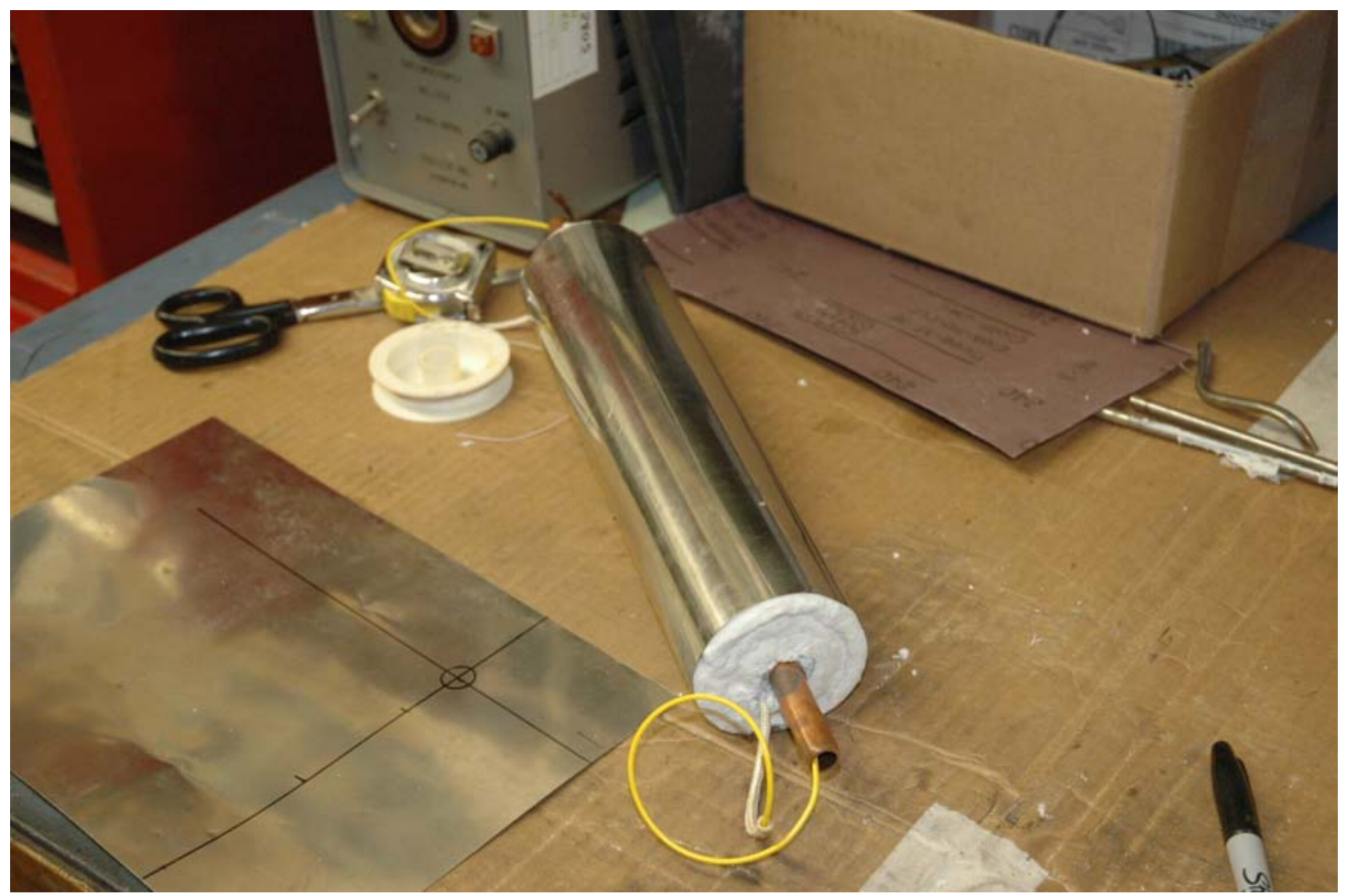

Figure 3.8: Completed Re-heater with Ends Exposed to Show Insulation

\section{Section 3.2.2.2: $\quad$ Sump Bypass}

One of the biggest problems experienced by Hunnell (2005) was keeping the system flow steady. Since two-phase flow is present in the chamber, the sump pump will draw both liquid and vapor from the spray chamber. This mixture could cause problems due to the vapor moving through the lines. If any vapor reaches the inlet of the spray nozzle the spray will be interrupted causing a "burp" in the spray. If the flow is interrupted while the heater is on, the surface temperature of the heater increases, and 
dry-out could occur or CHF could be reached prematurely due to the reduced flow of liquid working fluid. As a result the heater could overheat and burnout could occur, permanently damaging the heater.

Previously the method used to alleviate this problem was an air accumulator that was placed in the flow loop after the sump. Opening and closing this valve would enable control of the system flow. The way the vapor accumulator worked was by creating a small reservoir directly after the sump pump. Separating the two-phases in the vapor accumulator, by gravity, enabled the air to periodically be bled off the top. However, the vapor accumulator was also bleeding the working fluid vapor into the atmosphere. Thus, over time the system fluid levels decreased. Another problem inherent with the air accumulator was an inability to keep the system pressure truly steady and reliable.

This problem has been solved by installing a bypass in the line between the chamber and the heat exchangers as shown in Figure 3.9. After the two drain lines converge and pass through the sump pump, the line splits and goes back to the other side of the sump pump, as well as traveling into the heat exchanger. The bypass controls the amount of liquid vapor mixture recirculating before it moves through the heat exchangers. A throttling valve controls the amount of fluid vapor mixture allowed to cycle back into the bypass. Adjusting the bypass then controls the fluid flow rate from the constant speed sump pump. 


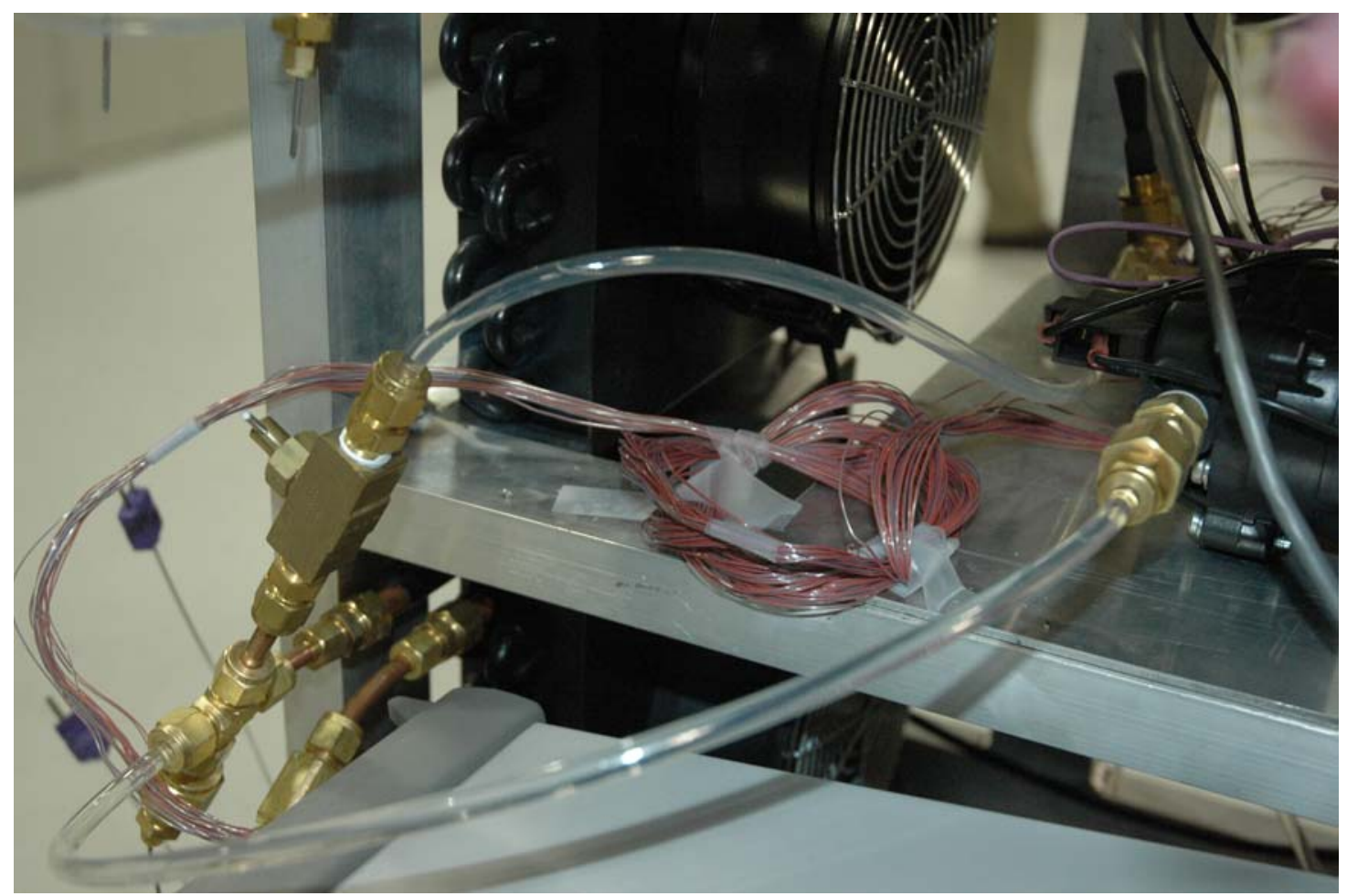

Figure 3.9: $\quad$ Sump Bypass

\section{Section 3.2.2.3: Data Acquisition System}

Taking data manually was troublesome and potentially subject to human bias in reading the instruments. To eliminate this problem an Agilent 34970A data acquisition switch unit was selected for use in the experimental data taking, based on recommendation from WPAFB. This unit has three slots for different data acquisition control modules. Three Agilent 34902A - 16 channel multiplexer modules were chosen because of their ability to sample data at rates of up to 250 channels per second. Each one of the 16 channels can be set to read one of 11 different signal types, including different thermocouple types, DC voltage, and frequency. In order to transfer data from the data acquisition system to a computer two different computer interfaces can be used: either a GPIB interface or an RS-232 interface. To maximize the performance an Agilent 
82357A USB/GPIB interface was used to connect the data acquisition system to the computer. For the present experiments a Dell Inspiron 700m laptop has been used to record the data into Excel spreadsheets.

The first and most important data that needed to be measured with the data acquisition system were the thermocouples. Next, the pressure transducers, and flow meter had to be read. Another very important parameter that needed to be tracked is the pedestal power; but this parameter could not be measured directly. Instead, a current and voltage were measured and thus the power could be calculated. However, the measurement was made even more complicated because the current could not be measured directly either. Therefore, a precision power PLV5 shunt resistor with a known resistance was wired in series with the heater. Then by measuring a voltage drop across the resistor a current was calculated. The calculated current multiplied by the voltage applied to the pedestal heater, gives the pedestal heater power. Each individual channel read by the data acquisition system can be seen in Table 3.1 below. Note that the interface temperature for each of the pedestals is referred to as TC \#1 and only one of the two pedestals is used at one time. Therefore either channels $101-106$ or $107-113$ are not in use during a particular test run.

To ensure that the readings by the data acquisition system are accurate according to national standards, each of the measurement devices had to be set up and calibrated for use in the system. Appendix A has a full explanation of the set up and calibration process for the thermocouples used in the present work. 
Table 3.1: Data Acquisition System Card Layout

\begin{tabular}{|c|c|}
\hline \multicolumn{2}{|c|}{ 100 Card } \\
\hline 101 & Old TFR Interface \\
\hline 102 & Old TFR \#2 \\
\hline 103 & Old TFR \#3 \\
\hline 104 & Old TFR \#4 \\
\hline 105 & Old TFR \#5 \\
\hline 106 & Old TFR \#6 \\
\hline 107 & New TFR Interface \\
\hline 108 & New TFR \#2 \\
\hline 109 & New TFR \#3 \\
\hline 110 & New TFR \#4 \\
\hline 111 & New TFR \#5 \\
\hline 112 & New TFR \#6 \\
\hline 113 & New TFR \#7 \\
\hline 114 & Sump Up Temp \\
\hline 115 & Sump Down Temp \\
\hline 116 & Nozzle Inlet Temp \\
\hline
\end{tabular}

\begin{tabular}{|l|c|}
\hline \multicolumn{2}{|c|}{ 200 Card } \\
\hline 201 & Chamber Pressure V \\
\hline 202 & Nozzle Pressure V \\
\hline 203 & Nozzle Flow Rate \\
\hline 204 & Heater Voltage Before \\
\hline 205 & Heat Voltage After \\
\hline 206 & \\
\hline 207 & \\
\hline 208 & \\
\hline 209 & \\
\hline 210 & \\
\hline 211 & \\
\hline 212 & \\
\hline 213 & \\
\hline 214 & \\
\hline 215 & \\
\hline 216 & \\
\hline
\end{tabular}

\begin{tabular}{|c|c|}
\hline \multicolumn{2}{|c|}{ 300 Card } \\
\hline 301 & Chamber Temp \\
\hline 302 & Wall Temp \\
\hline 303 & Nozzle Temp \\
\hline 304 & Sump Wall Temp \\
\hline 305 & Working Fluid HX in \\
\hline 306 & Working Fluid HX out \\
\hline 307 & H2O HX in \\
\hline 308 & H2O HX out \\
\hline 309 & Ambient Temp \\
\hline 310 & \\
\hline 311 & \\
\hline 312 & \\
\hline 313 & \\
\hline 314 & \\
\hline 315 & \\
\hline 316 & \\
\hline
\end{tabular}

\begin{tabular}{|c|c|}
\hline \multicolumn{2}{|c|}{900 Computed Channels } \\
\hline 900 & Chamber Pressure \\
\hline 901 & Nozzle Pressure \\
\hline 902 & Heater Current \\
\hline 903 & Heater Power \\
\hline
\end{tabular}

To ensure accurate temperature measurements a thermocouple calibration was conducted at WPAFB. This calibration lowered the uncertainty of the thermocouples from $\pm 0.6{ }^{\circ} \mathrm{C}$ observed during previous calibrations to $\pm 0.1{ }^{\circ} \mathrm{C}$. An in depth explanation of the calibration process is presented in Appendix A.

\section{Section 3.3: $\quad$ WVU Spray Chamber}

The second major component of the experimental apparatus is the spray chamber. The spray chamber houses the nozzle, pedestal, heater, sump, and the electrode. Figure 3.10 shows a schematic of how the spray interacts with the pedestal without the electrode present. 
Figure 3.11 shows a photograph of the spray chamber with electrode 1 in place. Complete construction and testing details for the spray chamber can be found in Hunnell (2005).

Multiple spray chambers could be used with the WVU experimental test rig: one chamber for the present work and the second chamber for the work of Glaspell (2006). The different chambers housed different electrode configurations that were tested. Since only one flow management system is being used for the two different experiments being conducted, it was necessary to make it easy to exchange the spray chambers. To accomplish this, bulkheads were created for both the plumbing as well as the chamber and pedestal thermocouples. To switch between chambers, these bulkhead fittings are simply removed from one chamber and connected to the other, taking less than thirty minutes, as opposed to several days if only one spray chamber had been used.

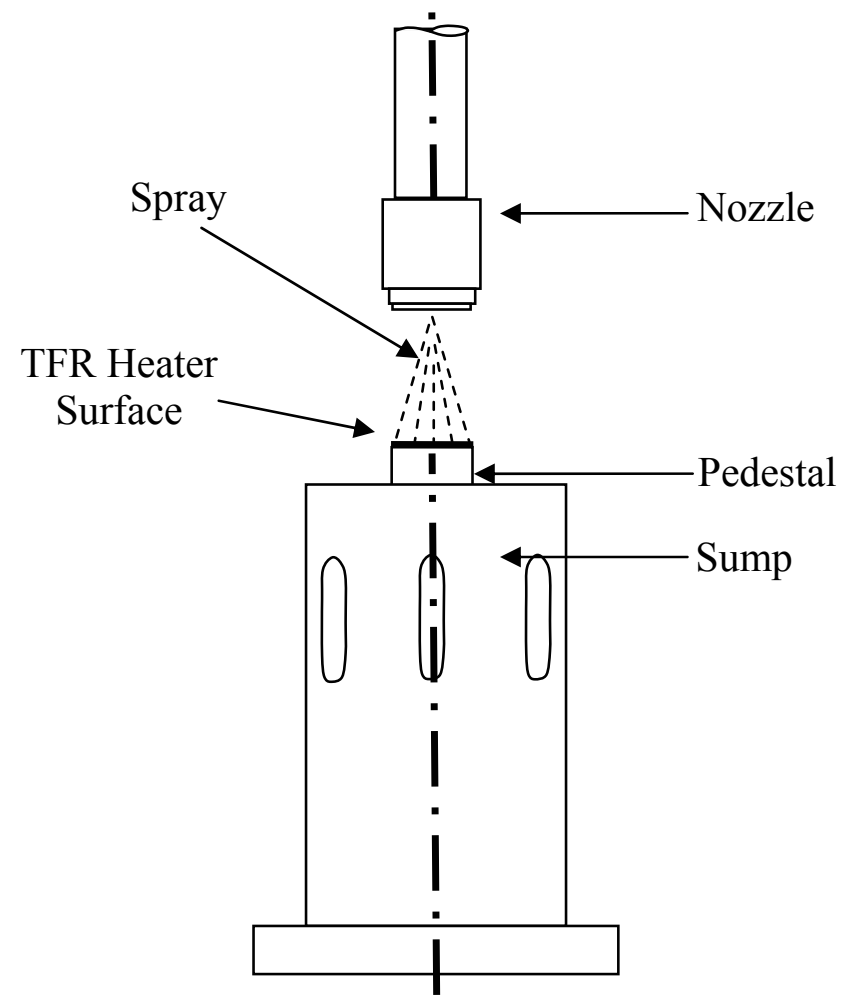

Figure 3.10: Chamber Configuration, without Electrode 
The spray chamber consists of a five and three-quarter inch diameter horizontal MDC vacuum nipple, with flanges attached for input ports for equipment. To make the inside of the chamber visible, the two end flanges are sealed off using one inch thick poly carbonate view ports. These view ports were bolted in place and sealed with a gasket to make the chamber accessible for changes and adjustments. A four and a half inch diameter flange was welded to the top of the chamber, to provide access for the nozzle. At the bottom of the chamber there is a similar one and one half inch diameter flange to provide access for the sump. Various other bulkhead fittings were used for thermocouples and the high voltage feed throughs.

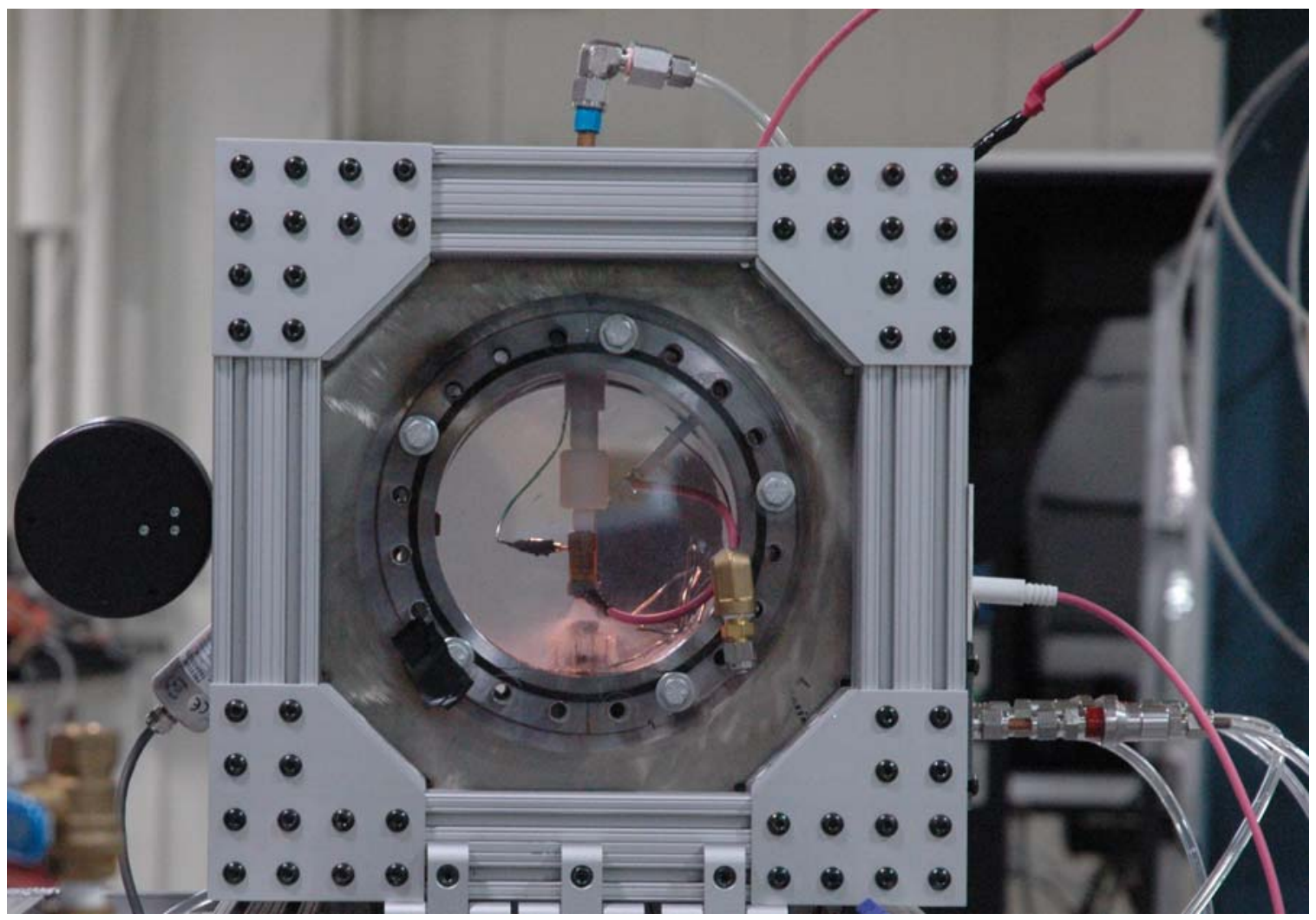

Figure 3.11: Photograph of Chamber Configuration with Electrode

In order to mount the chamber onto the flow management system, a framework was made to support the chamber. The framework was built around the spray chamber out of 2020 extrusions from 80/20 Inc. Various 80/20 connectors were used to hold the 
lengths of extrusion together. The connectors were secured in place using 1/4-20 bolts and T- nuts that were torqued to 100 in-lbs. Two stainless steel mounting plates were welded to the chamber and then fastened to the $80 / 20$ framework. Hinges have been used to connect the chamber to the base rig, enabling the chamber to be rotated 90 degrees. Additional structural analysis and fatigue testing for the spray chamber have been performed to meet flight test requirements.

\section{Section 3.3.1: $\quad$ Spray Nozzle Design}

Nozzle design is an integral part of spray cooling. Work done by Baysinger (2004) has helped define the proper nozzle selection for the present application. Yerkes (2006) shows average droplet diameter and average droplet velocity at various flow rates for the Spraying Systems Inc. nozzle. A two-axis phase Doppler anemometer was used to determine droplet size and distribution for a wide range of spray nozzles. Typical droplet velocity and volumetric flux distributions can be seen in Figure 3.12 and Figure 3.13. Based on this study a Spraying Systems Incorporated FullJet 1/8-G nozzle was selected. The chosen nozzle sprays a full cone with a cone angle of 60 degrees.

Table 3.2: $\quad$ Nozzle Performance Data (Yerkes, 2006)

\begin{tabular}{|c|c|c|c|}
\hline $\begin{array}{c}\text { Volumetric Flow } \\
\text { Rate, } V \\
\left(\mathbf{m}^{3} / \mathbf{s}\right) /(\mathbf{G P H})\end{array}$ & $\begin{array}{c}\text { Nozzle } \\
\text { Pressure } \\
\text { (kPa)/(psig) }\end{array}$ & $\begin{array}{c}\text { Average Droplet } \\
\text { Diameter, } D_{p}(\mu \mathrm{m})\end{array}$ & $\begin{array}{l}\text { Average Droplet } \\
\text { Velocity, v (m/s) }\end{array}$ \\
\hline $7.36 \times 10^{-6} / 7.0$ & $248 / 36$ & 48 & 9.0 \\
\hline $1.01 \times 10^{-5} / 9.6$ & $324 / 47$ & 48 & 12.0 \\
\hline $1.21 \times 10^{-5} / 11.5$ & $469 / 68$ & 47 & 15.0 \\
\hline
\end{tabular}




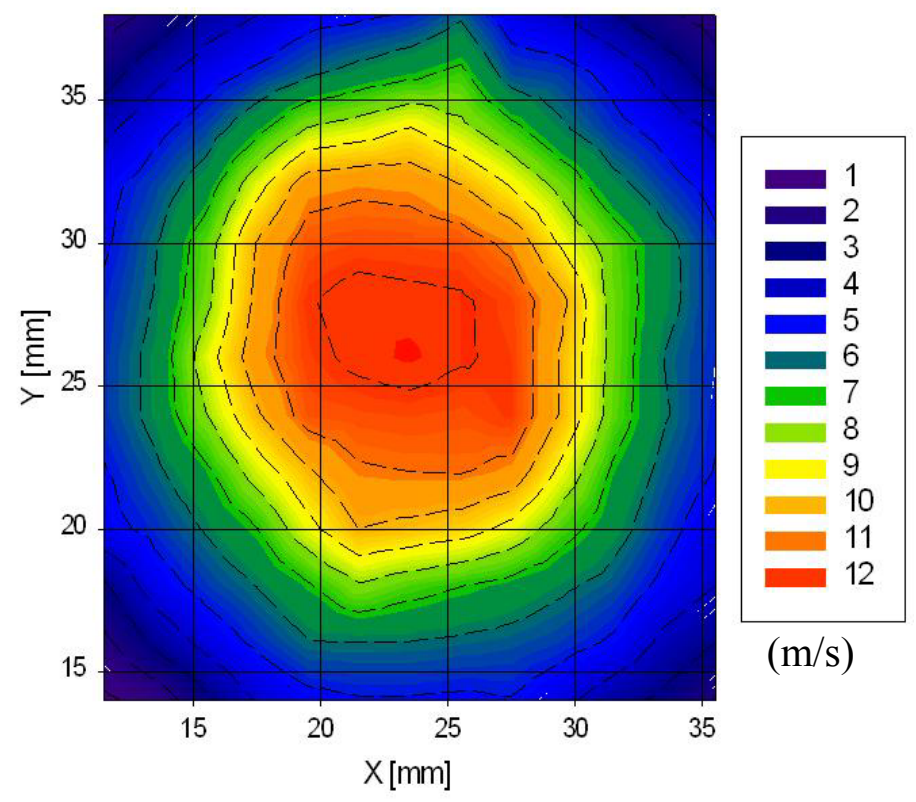

Figure 3.12: Velocity Distribution for Spraying Systems Full Jet 1 Nozzle at 9.0 GPH, 40 psig, 15 mm (Baysinger, 2004)

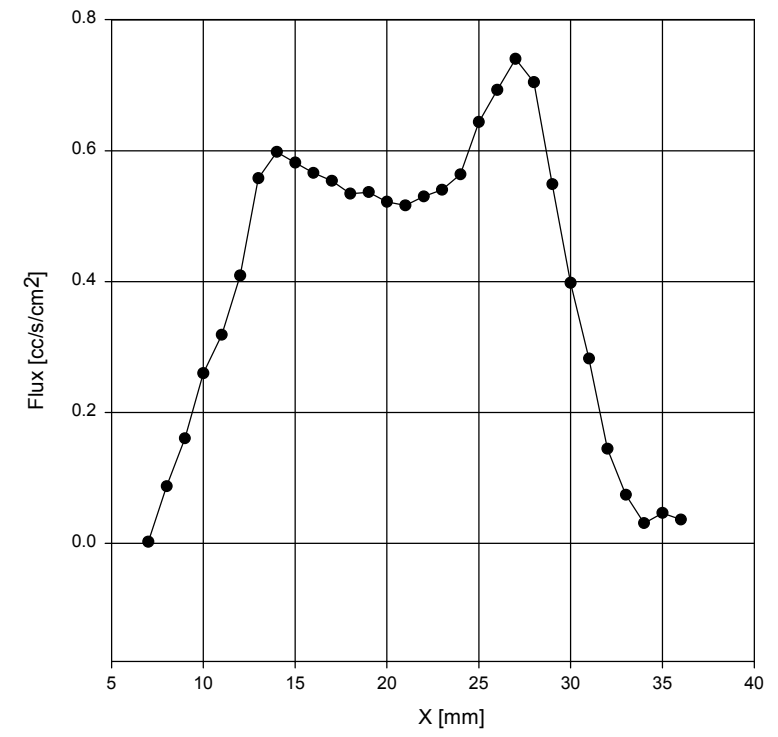

Figure 3.13: Volumetric Flux vs. Position Across the Center of the Spray for a Spraying Systems FullJet 1 Nozzle (Baysinger, 2004)

Chow (1997) states that it is rarely possible to obtain precisely the same spray distribution from a variety of the same nozzles under the same spray conditions. With the use of two different nozzle materials this information becomes important. Therefore, a 
comparison of several different Spraying Systems nozzles was conducted that revealed different results under the same test conditions. Test results for the nozzle comparison can be found in Section 5.8 and Appendix B. A typical schematic and photograph of a nozzle and spray cone can be seen in Figure 3.14 and Figure 3.15.

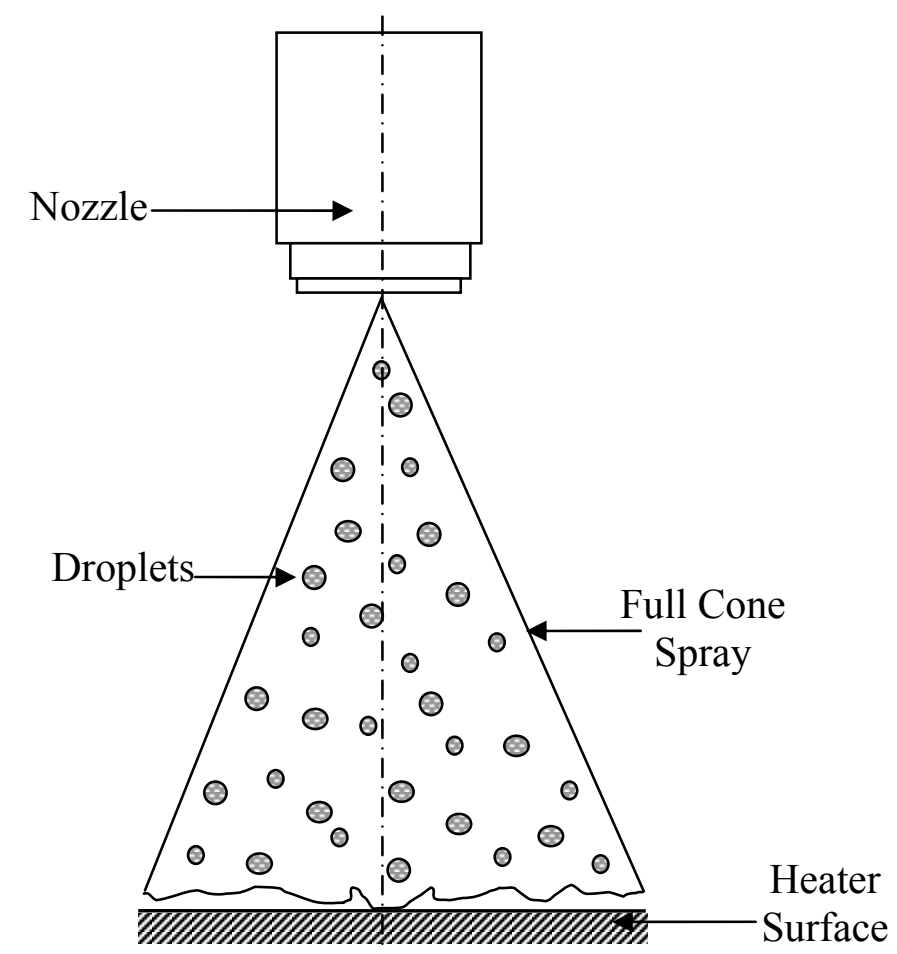

Figure 3.14: Schematic of Full Cone Spray with a Spraying Systems 1/8-G Nozzle 


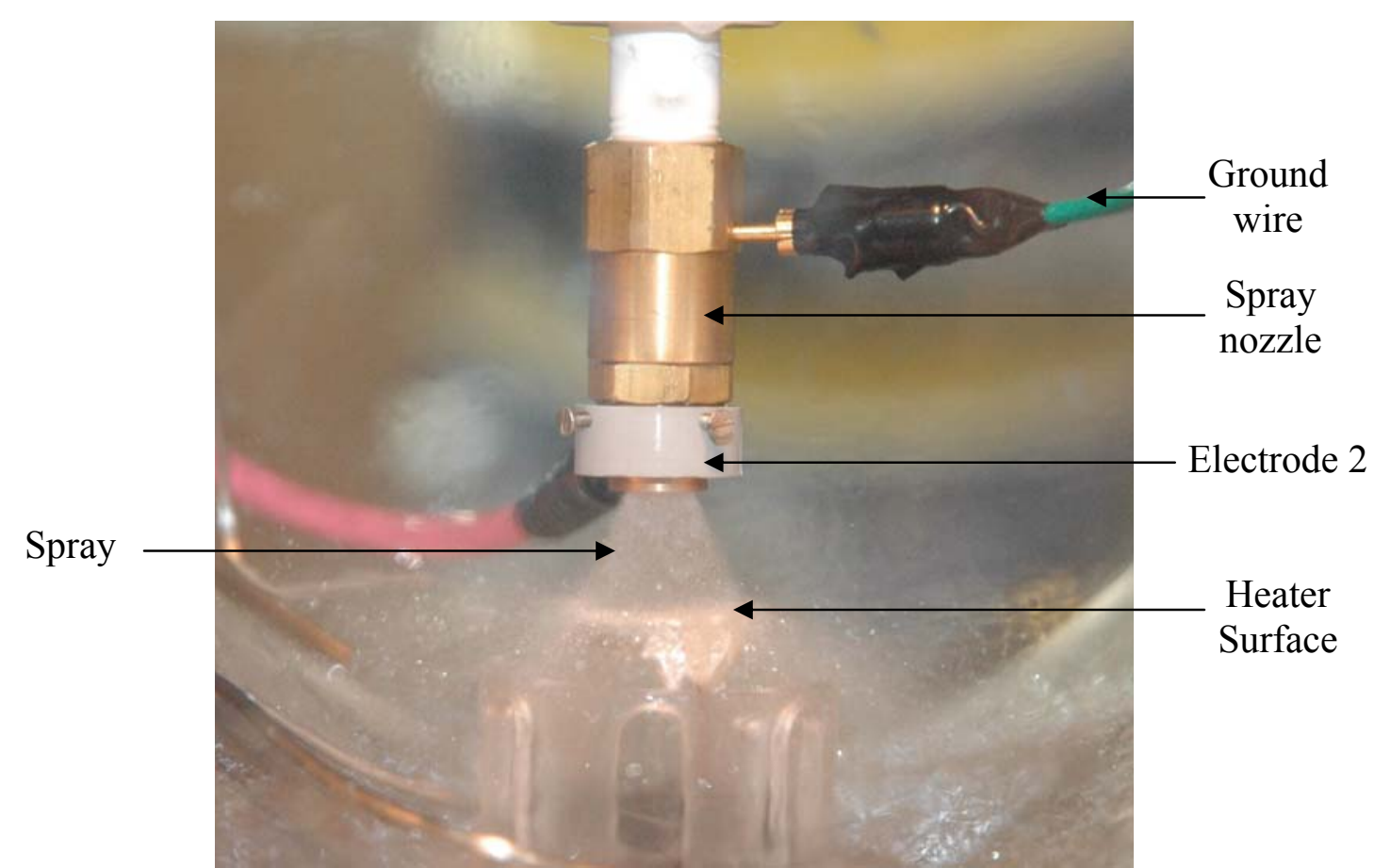

Figure 3.15: Photograph of Full Cone Spray with a Spraying Systems 1/8-G Nozzle with Electrode 2

The location of the electrode with respect to the nozzle, thermocouples and pedestal was important due to the presence of a high voltage power source. For the electrode designs, care had to be taken to ensure that no arcing would take place in the chamber when voltage was applied to the electrode. In order to achieve this, all metal components intruding into the chamber had to be moved as far away from the electrode as possible. To accomplish this several changes had to be made.

For the electrode design tested by Glaspell (2006), the brass nozzle used by Hunnell (2005) had to be replaced. Spraying Systems makes an identical $1 / 8-G$ nozzle out of PVC. Since identical spray patterns are not predictably the same even with the same nozzle, a comparison between the brass nozzle and the PVC nozzle had to be performed, and the test results can be found in Section 5.8 and Appendix B. The rest of the nozzle assembly was altered so that no metal nozzle components were located within the inner diameter of the spray chamber. 
It was important that the distance between the nozzle and the heater surface not be closer than $13 \mathrm{~mm}$. A spacing comparison performed by Glaspell (2006) showed that as the nozzle was traversed in the axial direction, performance degraded as the nozzle was moved closer to the heater surface. Moving the nozzle further away would cause the spray to overshoot the heater surface and thus lower the amount of spray droplets hitting the heater surface. Therefore, the ideal distance between the nozzle and the heater surface was determined by the spray cone angle.

Several of the chamber thermocouples had to be moved to a distance such that arcing would not occur. Many vital data values were measured from the thermocouples located in the spray chamber. These data values were used to calculate the heat flux, the subcooling amount, and the interface pedestal temperature (TC \#1). As a result, the location of each of the thermocouples in the spray chamber was critical. Thirteen thermocouples were located inside the spray chamber, with seven of those imbedded inside the pedestal, and six more of those located around the spray chamber in different locations, and one additional thermocouple is located in the nozzle supply line just upstream of the chamber. Figure 3.16 shows how the thermocouples are placed inside the spray chamber. 


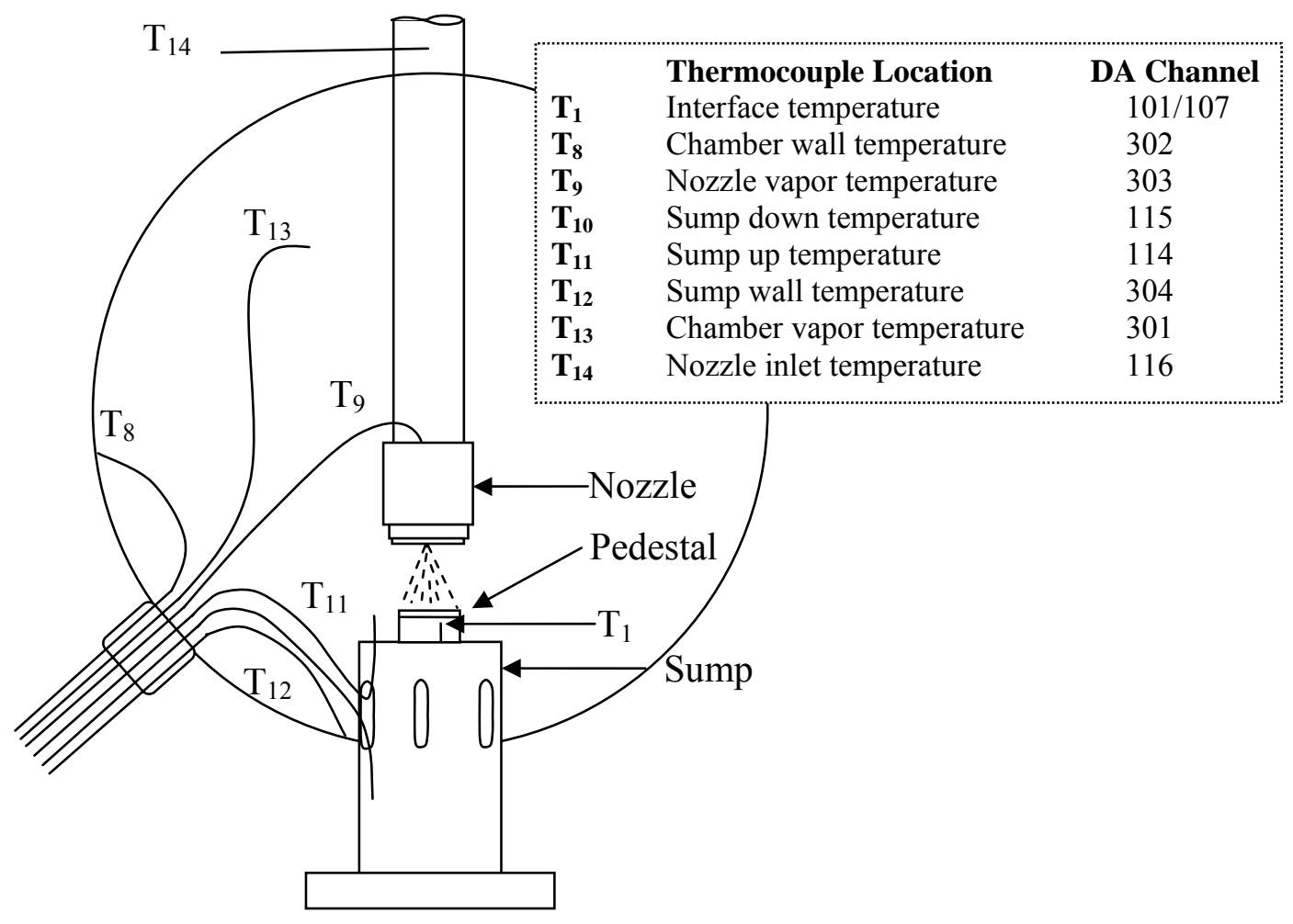

Figure 3.16: Chamber thermocouple locations

\section{Section 3.3.2: $\quad$ Pedestal Design}

The design of the sump and pedestal comes from the design used by Baysinger (2004) at WPAFB. The sump was manufactured by Devall Brothers Inc. machine shop in Sabraton, West Virginia to the dimensions shown in Figure 3.17. Likewise, the initial glass pedestal matches the WPAFB design, and was constructed with the help of Mr. Richard Harris at WPAFB, and can be seen in Figure 3.18. 

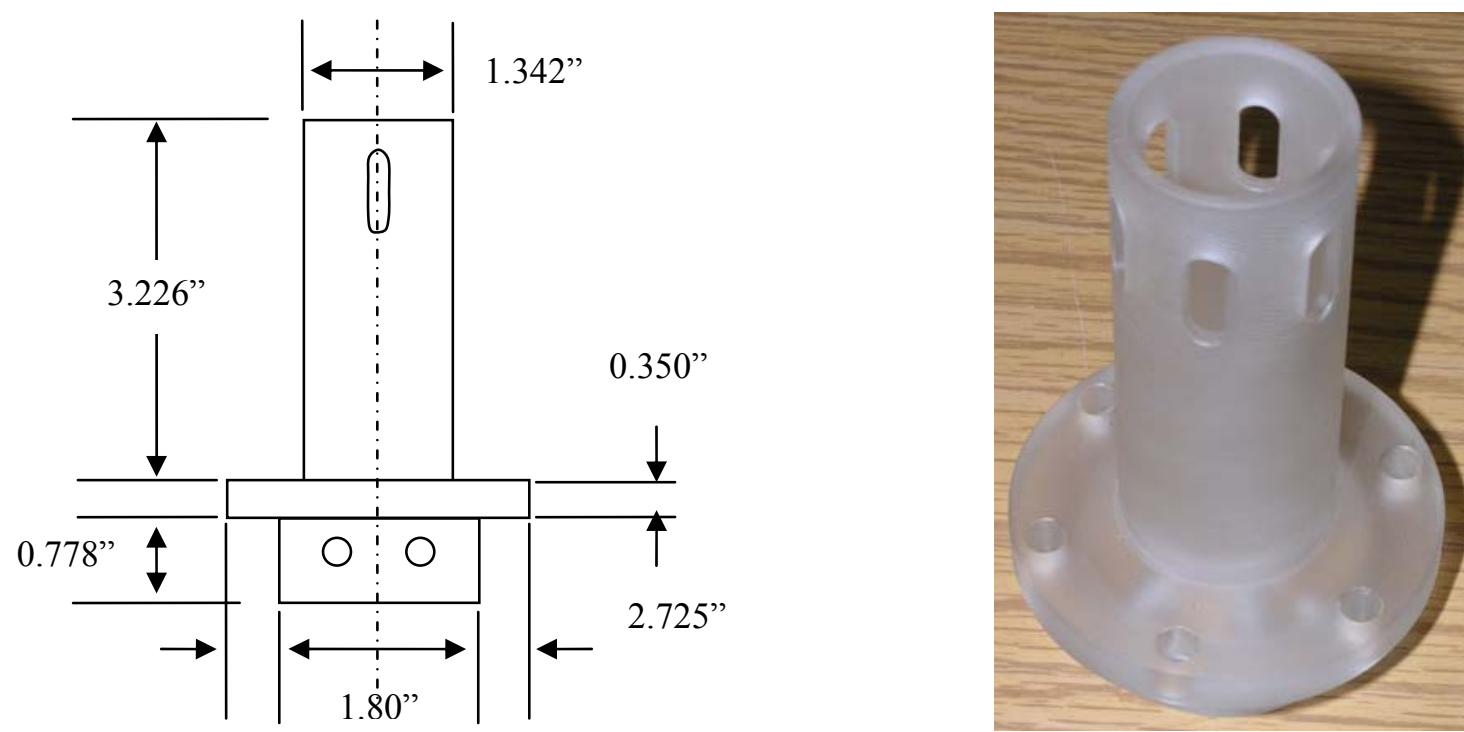

Figure 3.17: Sump Schematic and Photograph
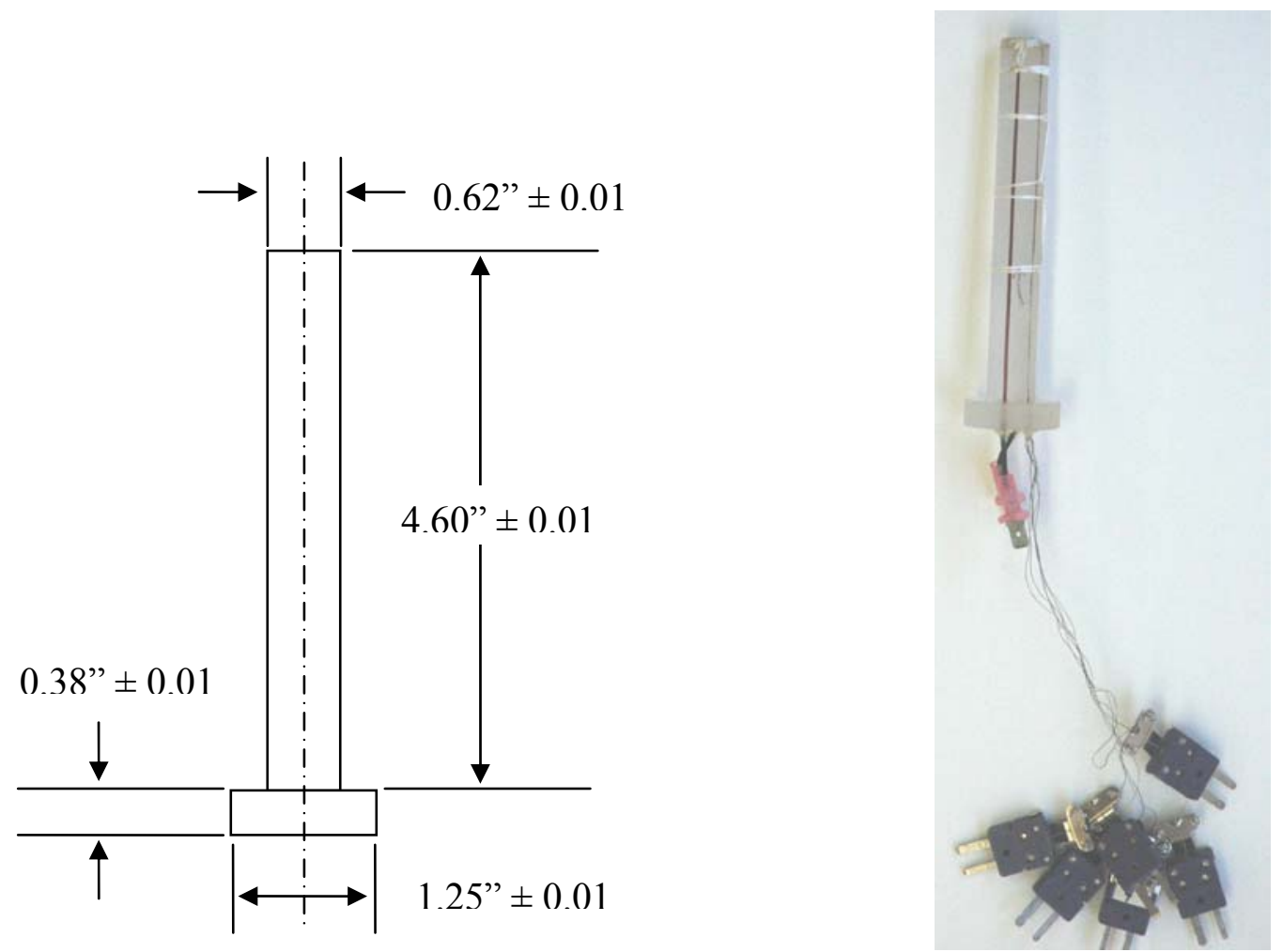

Figure 3.18: Glass Pedestal Schematic and Photograph

A schematic of the pedestal with a TFR heater with a glass coating present is shown in Figure 3.19. The only difference between this and the non-glass TFR is the absence of the $\delta_{\mathrm{g}}$ layer. In this figure $\delta_{1}$ and $\delta_{2}$ are $1 \mathrm{~mm}$ thick wafers of the glass 
pedestal sliced so that thermocouples can be placed between layers. $\delta_{\text {sub }}$ is the thickness of the alumina substrate, $\delta_{\mathrm{r}}$ is the thickness of the resistor, $\delta_{\mathrm{g}}$ is the thickness of the glass. $\mathrm{T}_{\text {Int }}$ is located at the interface of the TFR heater with the top layer of the pedestal post and $\mathrm{T}_{\mathrm{S}}$ is the calculated surface temperature.

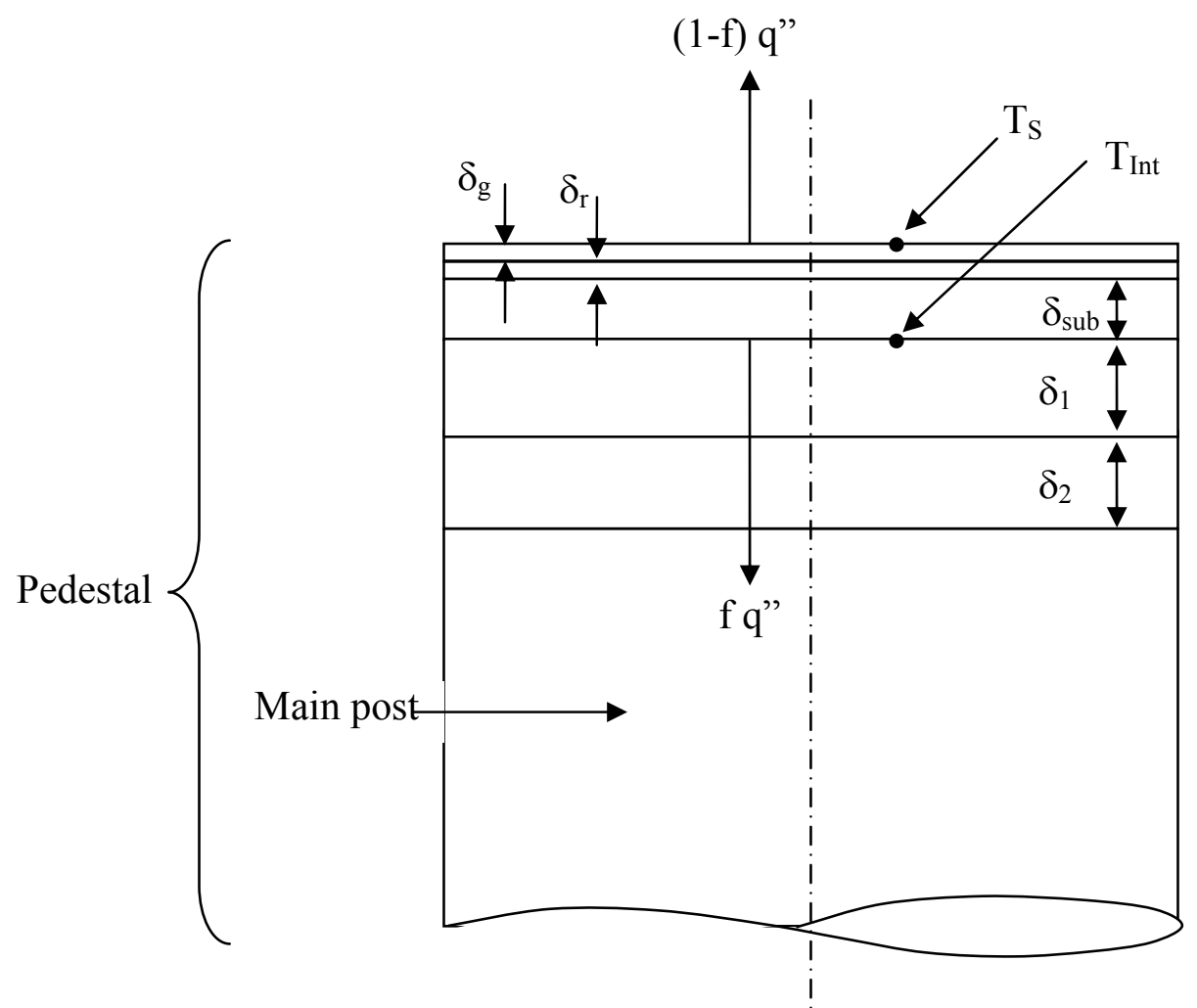

Figure 3.19: Schematic of Pedestal Design

The glass pedestal is constructed in several sections. First a Pyrex disk is used to provide a seal when inserted into the bottom of the sump. Next a glass rod with longitudinal notches in the side, for thermocouples and power leads, is secured to the disk. The rod is composed of 3 layers: the main post and two $1 \mathrm{~mm}$ thick layers $\delta_{1}$ and $\delta_{2}$. Finally a thick film resistive heater is secured in place. Figure 3.20 shows the assembly of a glass pedestal using a transparent ITO heater. The entire assembly is called the pedestal. Thermocouples are located in between each layer at different angles 
and radial positions. Figure 3.21 shows the layout of the seven thermocouples in the pedestal.

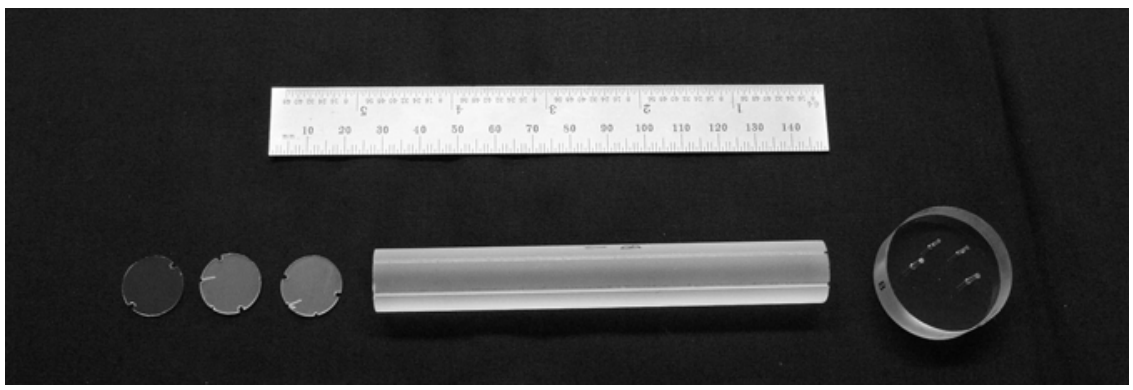

a)

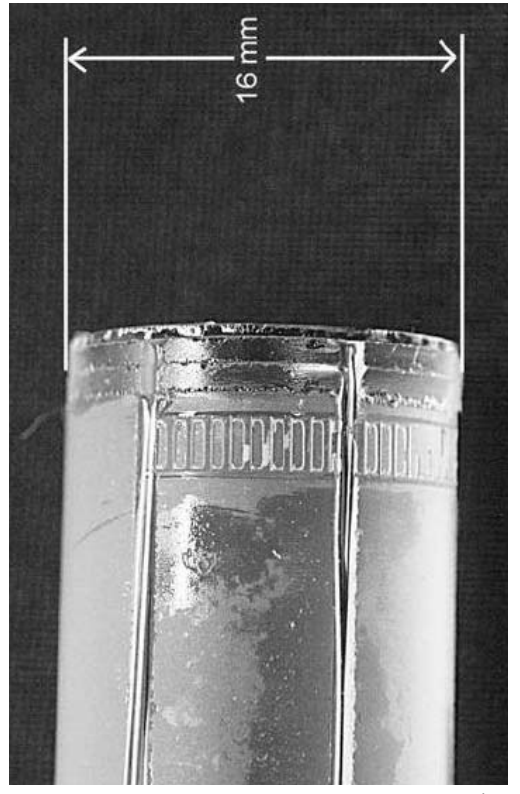

b)

Figure 3.20: Glass Pedestal Close up Photographs a) Assembly b) Side View c) Top View (Baysinger 2004) 
Section at top surface

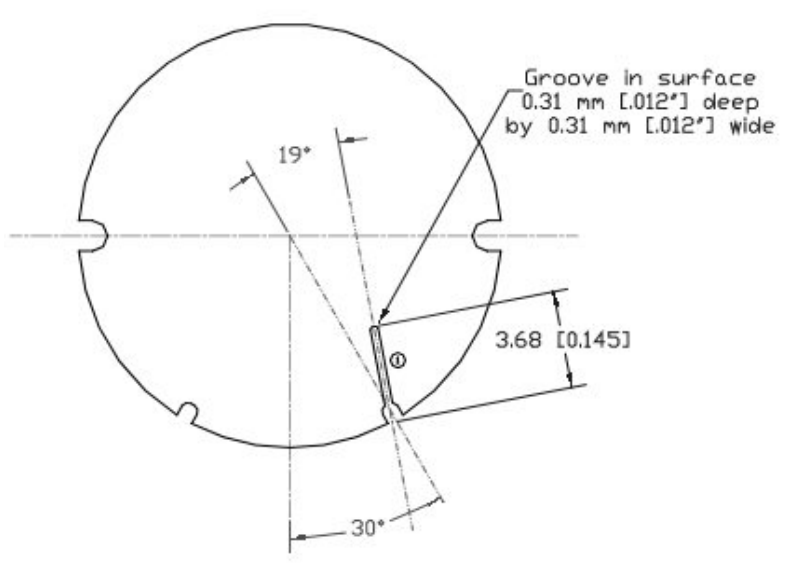

Section at $1 \mathrm{~mm}$ depth

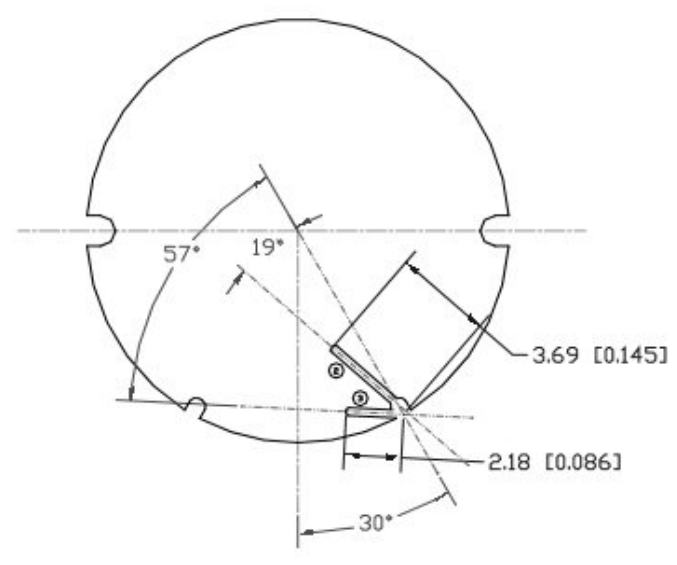

Section at $50 \mathrm{~mm}$ depth

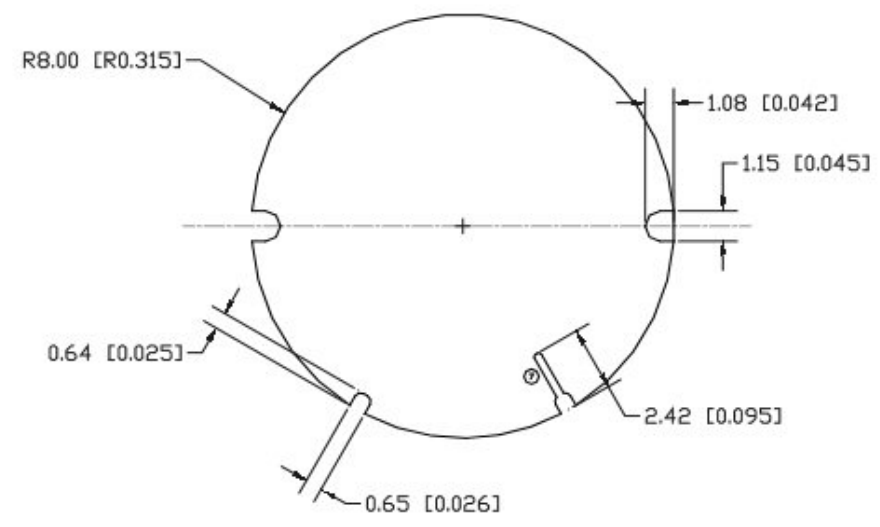

Section at $2 \mathrm{~mm}$ depth

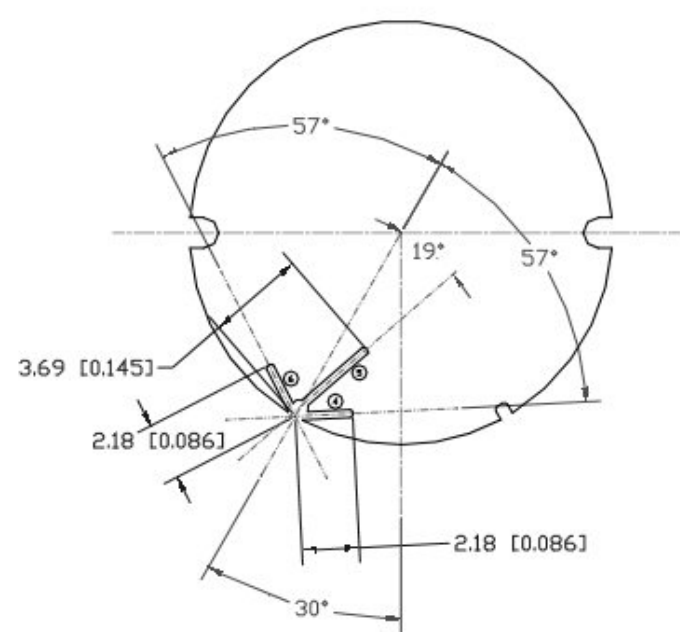

Figure 3.21: Pedestal Thermocouple Locations 
There are two different types of TFR heaters that have been used throughout the current study. The first consists of three separate layers: an alumina base substrate material onto which a resistor is spray deposited followed by a glass layer. The second has only the alumina substrate and resistor layers. A manufacturer drawing of the TFR heater can be seen in Figure 3.22. The layers of the TFR heater were broken down into three separate sections and a scanning electron microscope (SEM) was used to determine the thickness or each layer (Glaspell, 2006). Table 3.3 shows the thickness of each layer according to the SEM measurements, along with thermal conductivities of each layer that are used for data reduction (Glaspell, 2006).

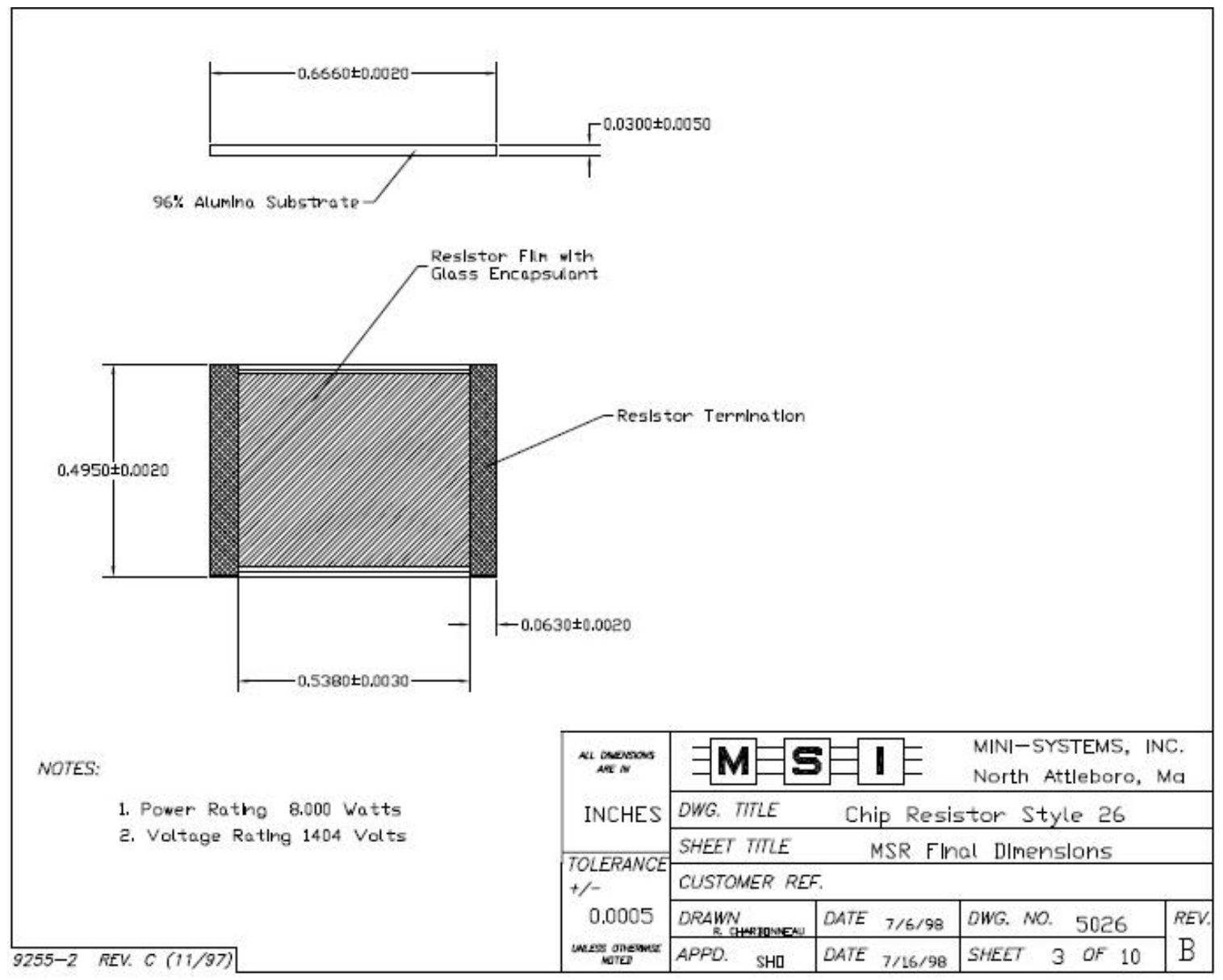

Figure 3.22: Manufacturer Drawing from Data Sheets of TFR Heater 
Table 3.3: Thickness and Thermal Conductivity of TFR Layers (Glaspell,

\begin{tabular}{|c|c|c|c|}
\hline Layer & $\begin{array}{c}\text { TFR with Glass } \\
\text { Layer, } \boldsymbol{\delta}(\boldsymbol{\mu m})\end{array}$ & $\begin{array}{c}\text { TFR without Glass } \\
\text { Layer, } \boldsymbol{\delta}(\boldsymbol{\mu m})\end{array}$ & $\mathbf{k}(\mathbf{W} / \mathbf{m}-\mathbf{K})$ \\
\hline Glass & $40 \pm 5$ & --- & 1.04 \\
\hline Resistor & $8 \pm 2$ & $20 \pm 5$ & 1.04 \\
\hline Substrate & $634 \pm 10$ & $634 \pm 10$ & 27.0 \\
\hline
\end{tabular}

Similar to the design of the glass pedestal, an additional second pedestal was designed and manufactured out of PTFE (Glaspell 2006). The new pedestal design allowed replacement parts to be manufactured at WVU instead of relying on the expertise and equipment at WPAFB. The new pedestal design is essentially the same, except for the materials used, and the locations of the thermocouples. Referring to Figure 3.21 the thermocouple of greatest importance is TC \#1 located directly under the TFR. To enhance the measurements taken at this level five thermocouples were placed at the level at various positions around the pedestal as seen in Figure 3.23, with TC \#1 still located in the same position. Relating the thermal conductivities of PTFE with glass, the fractional heat loss down the PTFE pedestal due to conduction should be approximately one fourth as large as the 1.5 percent loss assumed by Yerkes et al. (2006). 


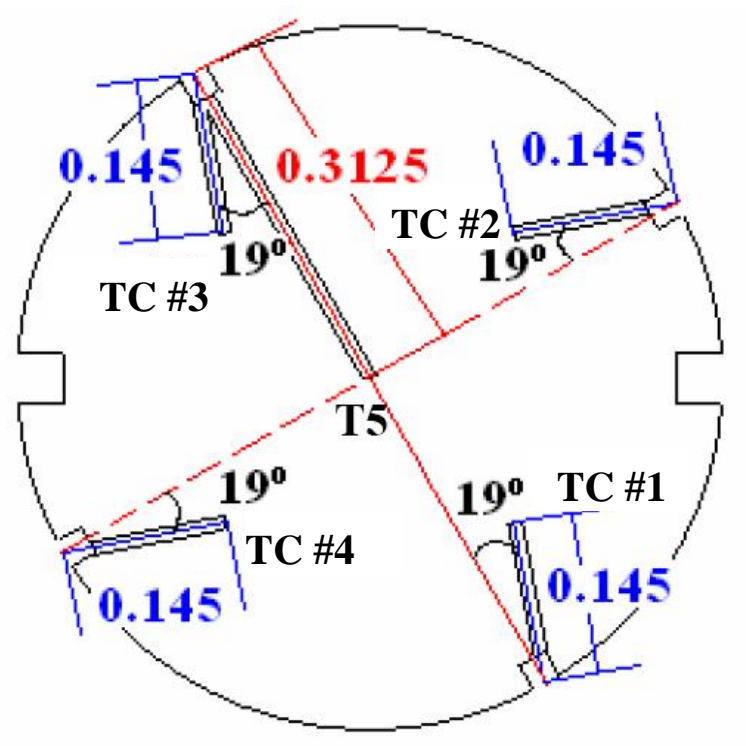

Figure 3.23: PTFE Thermocouple Locations (Glaspell 2006)

\section{Section 3.3.3: $\quad$ Electrode Design}

The central goal of this research is to compare spray cooling performance with and without the influence of an electric field. The two electrodes have been designed in such a way as to maximize the useful electric field generated, and at the same time, be as unobtrusive to the system as possible. To accomplish this task the electrode was secured to the bottom of the spray nozzle. This type of design is desired because Law (1978) suggested that inductive spray charging occurs, when the working fluid leaves the nozzle and forms into spray droplets. Calculated charging results for the electrode designs can be found in Section 5.10.

A cylindrical electrode was designed to inductively charge the spray droplets as they pass through a hollow cylinder electrode. Figure 3.24 shows a schematic of the liquid-particulate charging electrode designed by Law (1978). According to Law (1978), applying a positive potential to the electrode by attaching a voltage source to $\mathrm{L}_{1}$ and $\mathrm{L}_{2}$ will cause an accumulation of negative charge to build up on the liquid jet assuming the 
liquid has a non-zero electrical conductivity. This negative charge will then remain on the spray droplets, assuming that they do not impinge on $\mathrm{L}_{2}$, and that the droplets form from the liquid jet inside of electrode $\mathrm{L}_{2}$.

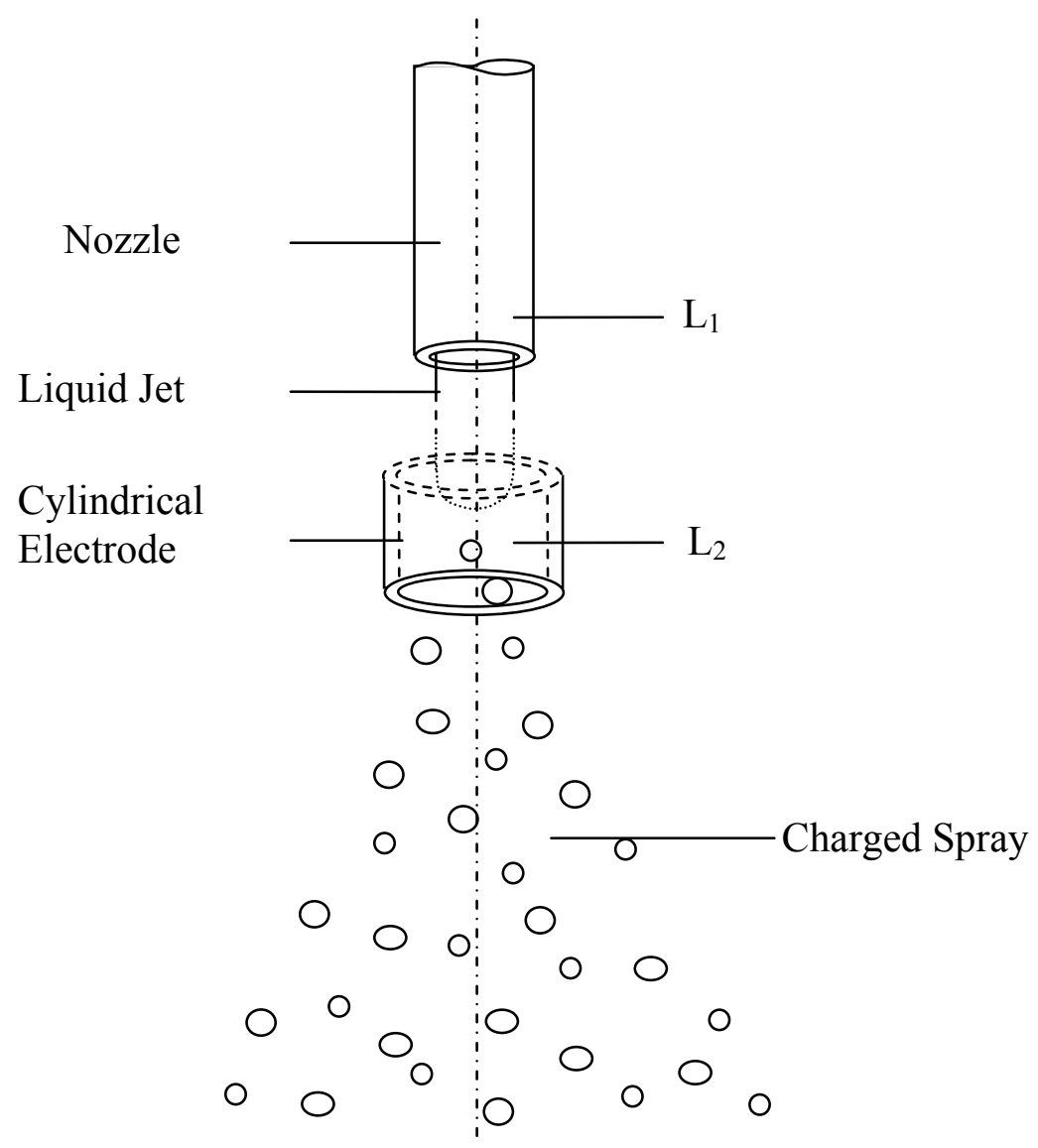

Figure 3.24: Schematic of a Liquid-Particulate Charging Electrode Designed and tested by Law (1978), modified and redrawn

The electrode design is constructed with a PVC connector that uses set screws to secure it directly to the nozzle. Imbedded within the connector is the cylindrical brass ring electrode, with a hole in the middle for the spray to pass through, and a lead for a high voltage input line. The ring electrode was designed from a similar electrode used by Law (1978), and uses electrostatic-induction to charge the spray droplets as they pass 
through the brass ring after they have come out of the nozzle. Figure 3.25 shows the nozzle and pedestal with electrode 1 installed.

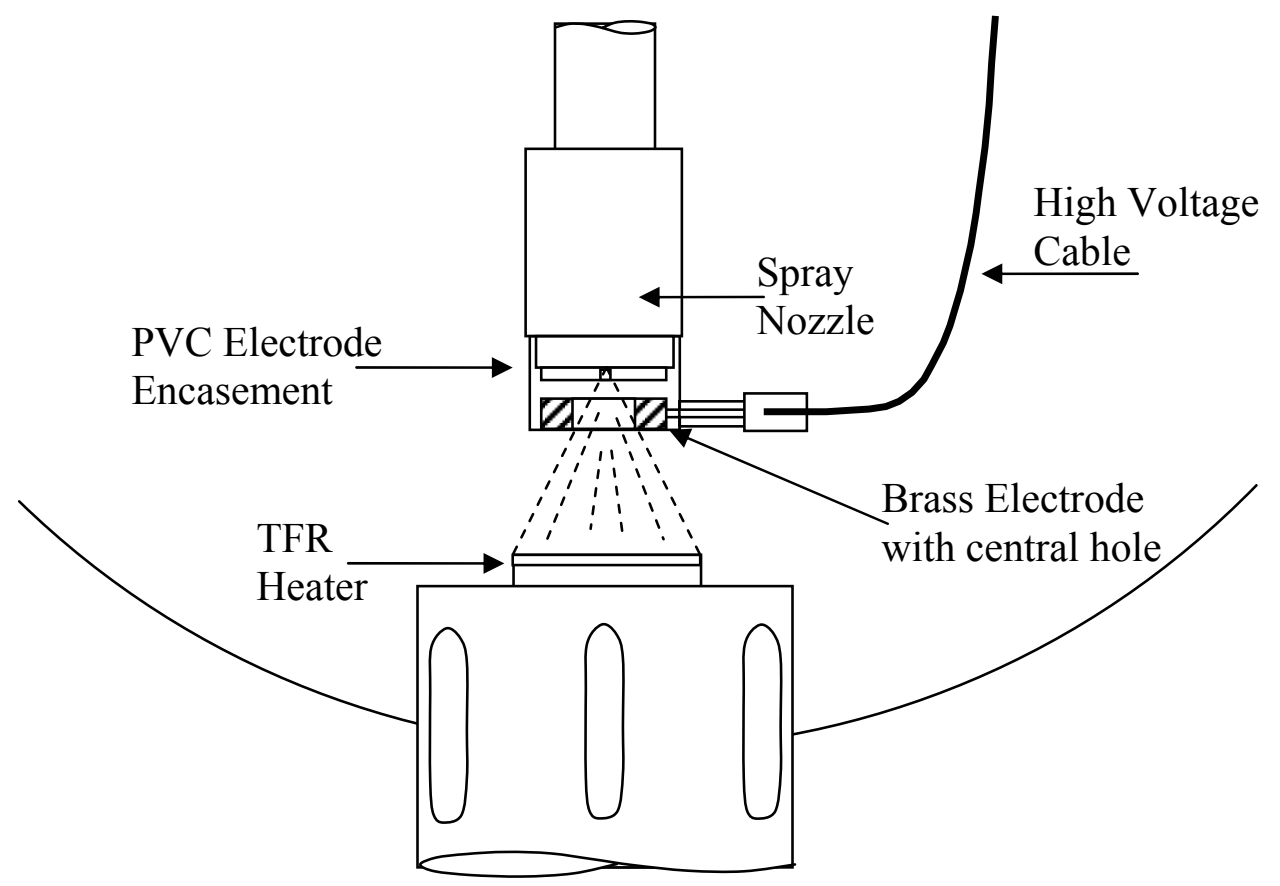

Figure 3.25: Electrode 1 Configuration

Designing the electrode configuration based on the work of Law (1978) required knowing several geometrical aspects of the spray nozzle and the behavior of the exiting spray. Documentation from Spraying Systems Inc. reports a spray cone angle of 60 degrees for the $1 / 8-\mathrm{G}$ nozzle. Using this spray angle, lines of spray motion could be drawn from the outlet hole of the nozzle to the outer edge of the pedestal heater. The electrode configuration could not obstruct these lines or else the spray would be redirected and charge would be lost from the spray droplets.

PVC was chosen as a connector material because it is a non-conductor and because of the ease with which it can be machined. The electrode connector is directly 
attached to the spray nozzle using set screws. An electrode was designed to attach to a Spraying Systems Inc. nozzle as can be seen in Figure 3.26.

Electrode 1 was designed based on the agricultural electrode designed by Law (1978) as seen in Figure 3.24. The idea behind this electrode is to inductively charge the individual spray droplets as they pass through the brass electrode. For this electrode configuration a brass nozzle was selected. The brass nozzle is attached to the spray chamber in order to ground the liquid stream before it passes through the electrode. The electrode then uses a high voltage source to inductively charge the spray droplets as they are expelled from the nozzle. A schematic of electrode 1 is shown in Figure 3.26 and a cross cut view of the electrode as attached to the spray nozzle is shown in Figure 3.27.

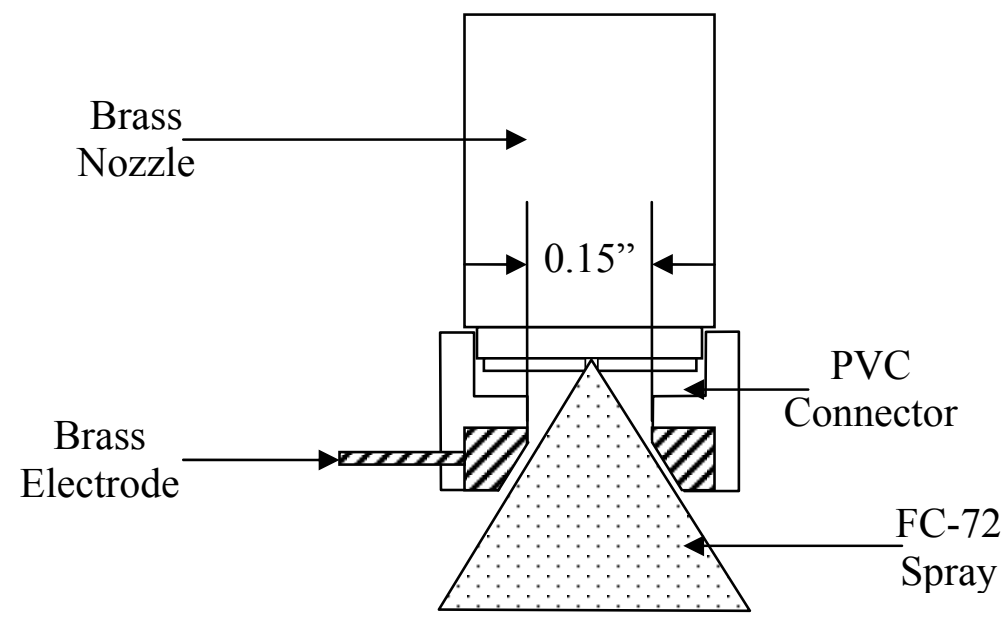

Figure 3.26: Schematic of Electrode 1 Configuration 


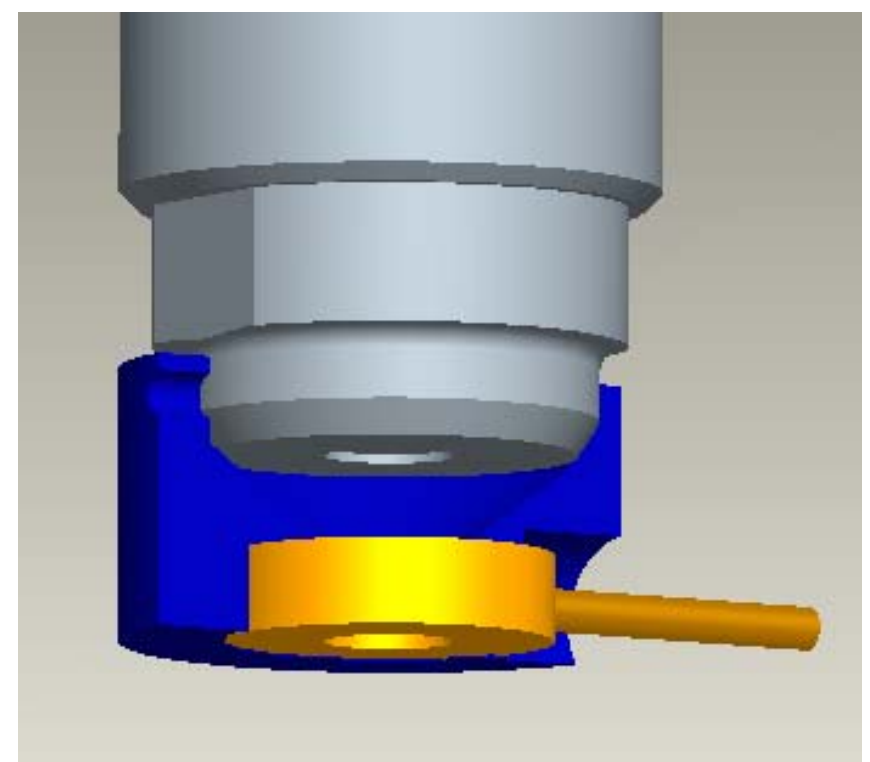

Figure 3.27: Pro-E Drawing of Electrode 1 Configuration

Electrode 2 is a modified version of Electrode 1. Originally the second electrode was designed to have PVC connected to the bottom, so that the only exposed portion of the electrode was the cylindrical area the spray passes through. However, after observing the initial success of the design of electrode 1 and then the subsequent failure to observe any effects when the original pedestal was damaged and repaired, it was decided that interaction of the spray with the electrode might be the problem. In an effort to fix this problem electrode 2 was bored out to have a larger diameter hole and the bevel was increased to allow the spray to pass through without coming in contact with the electrode. As a result, electrode 2 differs from electrode 1 by three main differences. Comparing Figure 3.28 to Figure 3.26 it can easily be seen that the inside diameter of the second electrode is larger, the bevel on the bottom of the electrode is more pronounced, and the PVC connector does not completely cover the electrode. Electrode 1 and Electrode 2 are shown in Figure 3.29 below. 


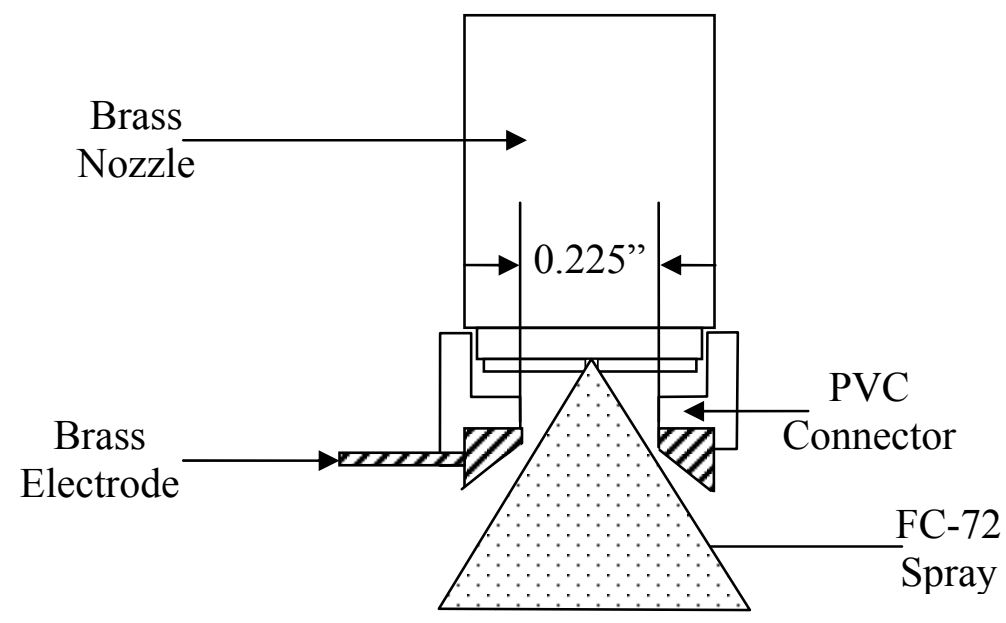

Figure 3.28: Schematic of Electrode 2 Configuration

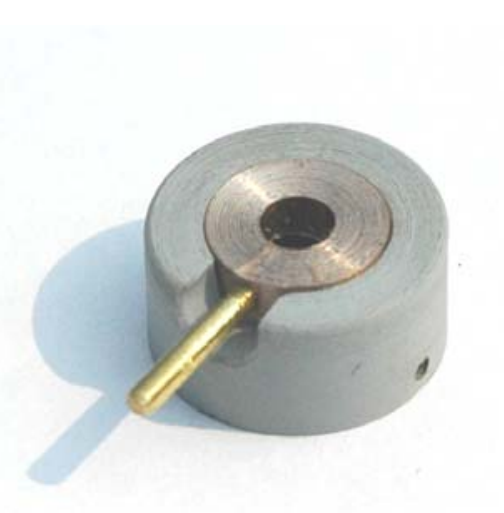

a)

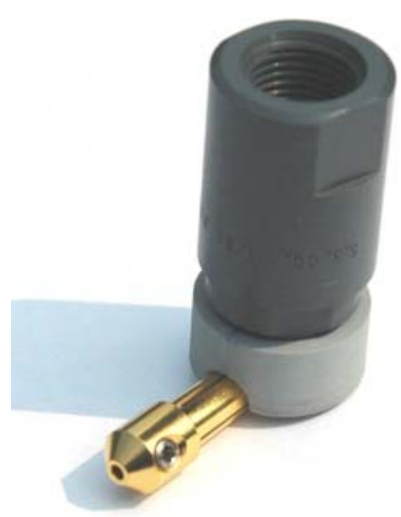

b)

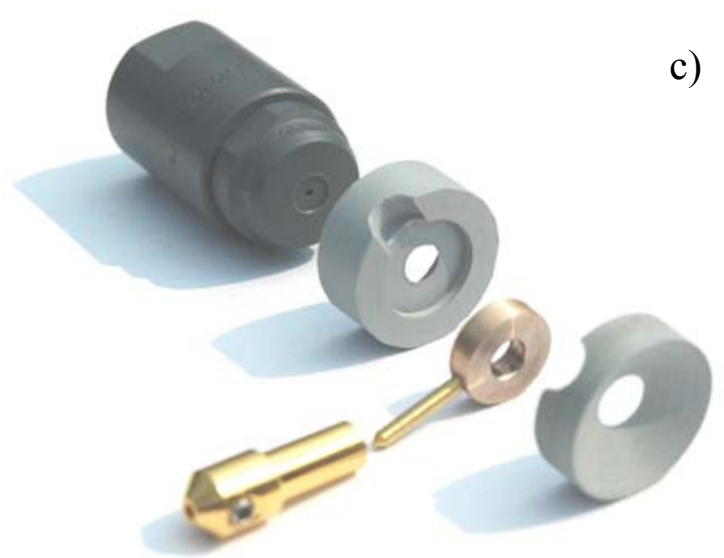

Figure 3.29: Photographs of Electrode Configurations a) Electrode 1 Bottom View b) Electrode 1 with Nozzle c) Electrode 2 Exploded View 


\section{ChAPTER 4 : Procedure ANd Data Reduction}

\section{Section 4.1: $\quad$ Introduction}

Proper experimental procedures have to be followed in order to ensure that repeatability is possible and therefore, valid experimental results will be obtained. This chapter will explain the procedures that were followed throughout the experimental process.

\section{Section 4.2: $\quad$ Initial setup}

The spray apparatus can now be run efficiently by one person, due to the implementation of an automated digital data acquisition system. Since the experiment is on a movable cart, the first step in operating the experiment is connecting all the proper power and ground lines. The rig is wired in such a way that only two external electrical lines have to be connected. First the $110 \mathrm{~V}$ main power line has to be connected, and secondly the ground wire for the high voltage power supply must also be connected. All pumps and power supplies are run from the $110 \mathrm{~V}$ main line. To ensure ultimate control over the different components of the rig, on / off switches have been connected, so that individual components can be turned on or off using the control panel.

Hunnell (2005) advises following a strict set of guidelines to prevent damaging the test equipment. The present author wishes to take that statement one step farther and add that a checklist should be followed to ensure consistent repeatability. When running an experiment on a daily basis it is easy to become complacent and forget to check every aspect of the experiment. Therefore, to minimize the risk of damage or injury, and to

ensure the highest data quality, the experiment turn on checklist in Table 4.1 must be 
followed. Once the checklist is completed the experiment is ready for data taking according to the developed test matrix.

Table 4.1: $\quad$ Experiment Turn on Checklist

\begin{tabular}{|r|l|}
\hline 1 & $\begin{array}{l}\text { MAKE SURE HIGH VOLTAGE POWER SUPPLY IS OFF AND } \\
\text { VOLTAGE CONTROL AT ZERO VOLTS }\end{array}$ \\
\hline 2 & Make sure all switches are in off position \\
\hline 3 & Plug in 110V main power \\
\hline 4 & Connect ground wire \\
\hline 5 & Turn on laptop \\
\hline 6 & Plug in data acquisition system \\
\hline 8 & Start Agilent data acquisition software \\
\hline 9 & $\begin{array}{l}\text { Make sure rotameters are fully open; the pumps speed will be used to } \\
\text { regulate the flow rates } \\
\text { the flow loop }\end{array}$ \\
\hline 10 & $\begin{array}{l}\text { Turn on the thermocouple reader to monitor the system temperature } \\
\text { externally in case something happens to the data acquisition system }\end{array}$ \\
\hline 11 & $\begin{array}{l}\text { Turn on the Astron power supply that powers the Tuthill pump and } \\
\text { pressure transducers }\end{array}$ \\
\hline 12 & Switch on Tuthill pump \\
\hline 13 & Switch on sump pump \\
\hline 14 & $\begin{array}{l}\text { Monitor flow pattern to make sure both pumps are working correctly, } \\
\text { adjust the bypass setting to achieve optimum flow behavior }\end{array}$ \\
\hline 15 & Switch on heat exchanger fans \\
\hline 16 & Switch on water pump \\
\hline 17 & Monitor flow conditions until steady state is reached ( $~ 10$ min) \\
\hline 18 & Check to make sure pedestal power is at 0 W \\
\hline 19 & Check pedestal temperature alarm \\
\hline 20 & Switch on Protek power supply to power pedestal heater \\
\hline 21 & Check all high voltage supply lines \\
\hline 22 & Turn on high voltage power supply \\
\hline 23 & $\begin{array}{l}\text { Vary pedestal heater power and electrode voltage according to test matrix } \\
\text { (Note: high voltage power supply should be turned off for all runs of } 0 \mathrm{~V} \\
\text { electrode voltage) }\end{array}$ \\
\hline &
\end{tabular}

\section{Section 4.3: $\quad$ Experimental Test Procedure}

Once the experiment is successfully turned on, an operational procedure must be followed to parametrically change the different variables of the test matrix. The test 
matrix in Table 4.2 and represents the different data sets taken. The main parameters that were or could be changed throughout this research were flow rate, nozzle temperature, saturation temperature, electrode voltage and heater power. The nozzle temperature sets the subcooling for a given saturation temperature, which is controlled by the chamber pressure. Other parameters were recorded, including fluid type, air content, and saturation temperature. Each test run was conducted using a new black TFR heater without a glass layer on top of the resistive layer.

Table 4.2: $\quad$ Experimental Test Matrix

\begin{tabular}{|c|c|c|c|c|}
\hline $\begin{array}{l}\text { Flow } \\
\text { Rate } \\
\text { (GPH) }\end{array}$ & $\begin{array}{l}\text { Saturation } \\
\text { Temp }\left({ }^{\circ} \mathrm{C}\right) \\
\text { and fluid }\end{array}$ & $\begin{array}{c}\text { Sub- } \\
\text { Cooling } \\
\left({ }^{\circ} \mathrm{C}\right)\end{array}$ & $\begin{array}{l}\text { Electrode } \\
\text { Voltage } \\
\text { (Volts) }\end{array}$ & $\begin{array}{c}\text { Pedestal } \\
\text { Power (W) }\end{array}$ \\
\hline \multirow{5}{*}{$10 \pm 0.5$} & \multirow{3}{*}{$\begin{array}{c}36-39 \\
(\text { HFE-7000) }\end{array}$} & \multirow{5}{*}{$14 \pm 2$} & 0 & \multirow{5}{*}{20} \\
\hline & & & 2500 & \\
\hline & & & 5000 & \\
\hline & \multirow{2}{*}{$\begin{array}{c}57-60 \\
(\text { FC-72) }\end{array}$} & & 2500 & \\
\hline & & & 0 & \\
\hline \multirow{5}{*}{$10 \pm 0.5$} & \multirow{3}{*}{$\begin{array}{c}36-39 \\
(\text { HFE-7000) }\end{array}$} & \multirow{5}{*}{$14 \pm 2$} & 0 & \multirow{5}{*}{50} \\
\hline & & & 2500 & \\
\hline & & & 5000 & \\
\hline & \multirow{2}{*}{$\begin{array}{l}57-60 \\
(\mathrm{FC}-72)\end{array}$} & & 2500 & \\
\hline & & & 0 & \\
\hline \multirow{5}{*}{$10 \pm 0.5$} & \multirow{3}{*}{$\begin{array}{c}36-39 \\
(\text { HFE-7000) }\end{array}$} & \multirow{5}{*}{$14 \pm 2$} & 0 & \multirow{5}{*}{70} \\
\hline & & & 2500 & \\
\hline & & & 5000 & \\
\hline & \multirow{2}{*}{$\begin{array}{c}57-60 \\
(\mathrm{FC}-72) \\
\end{array}$} & & 2500 & \\
\hline & & & 0 & \\
\hline \multirow{5}{*}{$10 \pm 0.5$} & \multirow{3}{*}{$\begin{array}{c}36-39 \\
(\text { HFE-7000) }\end{array}$} & \multirow{5}{*}{$14 \pm 2$} & 0 & \multirow{5}{*}{100} \\
\hline & & & 2500 & \\
\hline & & & 5000 & \\
\hline & \multirow{2}{*}{$\begin{array}{c}57-60 \\
(\text { FC-72) }\end{array}$} & & 2500 & \\
\hline & & & 0 & \\
\hline
\end{tabular}


Table 4.2: $\quad$ Experimental Test Matrix (continued)

\begin{tabular}{|c|c|c|c|c|}
\hline $\begin{array}{c}\text { Flow } \\
\text { Rate } \\
\text { (GPH) }\end{array}$ & $\begin{array}{l}\text { Saturation } \\
\text { Temp }\left({ }^{\circ} \mathrm{C}\right) \\
\text { and fluid }\end{array}$ & $\begin{array}{c}\text { Sub- } \\
\text { Cooling } \\
\left({ }^{\circ} \mathrm{C}\right)\end{array}$ & $\begin{array}{l}\text { Electrode } \\
\text { Voltage } \\
\text { (Volts) } \\
\end{array}$ & $\begin{array}{c}\text { Pedestal } \\
\text { Power (W) }\end{array}$ \\
\hline \multirow{5}{*}{$8 \pm 0.5$} & \multirow{3}{*}{$\begin{array}{c}36-39 \\
(\mathrm{HFE}-7000)\end{array}$} & \multirow{5}{*}{$14 \pm 2$} & 0 & \multirow{5}{*}{20} \\
\hline & & & 2500 & \\
\hline & & & 5000 & \\
\hline & \multirow{2}{*}{$\begin{array}{l}57-60 \\
(\mathrm{FC}-72)\end{array}$} & & 2500 & \\
\hline & & & 0 & \\
\hline \multirow{5}{*}{$8 \pm 0.5$} & \multirow{3}{*}{$\begin{array}{c}36-39 \\
(\mathrm{HFE}-7000)\end{array}$} & \multirow{5}{*}{$14 \pm 2$} & 0 & \multirow{5}{*}{50} \\
\hline & & & 2500 & \\
\hline & & & 5000 & \\
\hline & \multirow{2}{*}{$\begin{array}{l}57-60 \\
(\mathrm{FC}-72)\end{array}$} & & 2500 & \\
\hline & & & 0 & \\
\hline \multirow{5}{*}{$8 \pm 0.5$} & \multirow{3}{*}{$\begin{array}{c}36-39 \\
(\mathrm{HFE}-7000)\end{array}$} & \multirow{5}{*}{$14 \pm 2$} & 0 & \multirow{5}{*}{70} \\
\hline & & & 2500 & \\
\hline & & & 5000 & \\
\hline & \multirow{2}{*}{$\begin{array}{l}57-60 \\
(\mathrm{FC}-72)\end{array}$} & & 2500 & \\
\hline & & & 0 & \\
\hline \multirow{5}{*}{$8 \pm 0.5$} & \multirow{3}{*}{$\begin{array}{c}36-39 \\
(\mathrm{HFE}-7000)\end{array}$} & \multirow{5}{*}{$14 \pm 2$} & 0 & \multirow{5}{*}{100} \\
\hline & & & 2500 & \\
\hline & & & 5000 & \\
\hline & \multirow{2}{*}{$\begin{array}{l}57-60 \\
(\mathrm{FC}-72)\end{array}$} & & 2500 & \\
\hline & & & 0 & \\
\hline
\end{tabular}

\begin{tabular}{|c|c|c|c|c|}
\hline \multirow{5}{*}{$6 \pm 0.5$} & $36-39$ & \multirow{5}{*}{$14 \pm 2$} & 0 & \multirow{5}{*}{20} \\
\hline & (HFE-7000) & & 2500 & \\
\hline & \multirow{3}{*}{$\begin{array}{l}57-60 \\
(\mathrm{FC}-72)\end{array}$} & & 5000 & \\
\hline & & & 2500 & \\
\hline & & & 0 & \\
\hline \multirow{5}{*}{$6 \pm 0.5$} & $36-39$ & \multirow{5}{*}{$14 \pm 2$} & 0 & \multirow{5}{*}{50} \\
\hline & (HFE-7000) & & 2500 & \\
\hline & \multirow{3}{*}{$\begin{array}{l}57-60 \\
(\mathrm{FC}-72)\end{array}$} & & 5000 & \\
\hline & & & 2500 & \\
\hline & & & 0 & \\
\hline \multirow{5}{*}{$6 \pm 0.5$} & \multirow{3}{*}{$\begin{array}{c}36-39 \\
\text { (HFE-7000) }\end{array}$} & \multirow{5}{*}{$14 \pm 2$} & 0 & \multirow{5}{*}{70} \\
\hline & & & 2500 & \\
\hline & & & 5000 & \\
\hline & \multirow{2}{*}{$\begin{array}{l}57-60 \\
(\mathrm{FC}-72)\end{array}$} & & 2500 & \\
\hline & & & 0 & \\
\hline \multirow{5}{*}{$6 \pm 0.5$} & \multirow{3}{*}{$\begin{array}{c}36-39 \\
(\mathrm{HFE}-7000)\end{array}$} & \multirow{5}{*}{$14 \pm 2$} & 0 & \multirow{5}{*}{100} \\
\hline & & & 2500 & \\
\hline & & & 5000 & \\
\hline & \multirow{2}{*}{$\begin{array}{l}57-60 \\
(\mathrm{FC}-72)\end{array}$} & & 2500 & \\
\hline & & & 0 & \\
\hline
\end{tabular}


The process for changing the variables in the test matrix is outlined in the experimental operating procedure checklist of Table 4.3. To obtain data the parameters that were changed are the spray flow rate, pedestal heater power, electrode voltage, and subcooling level. Before analyzing any data steady state tests were run to see how the experimental parameters varied over time at a constant pedestal interface temperature and subcooling; see Figure 4.1 for data from a sample steady state run.

Table 4.3: $\quad$ Experimental Operation Procedure Checklist

\begin{tabular}{|r|l|}
\hline 1 & $\begin{array}{l}\text { Adjust Tuthill pump level to correspond to the desired flow rate for that } \\
\text { test run }\end{array}$ \\
\hline 2 & Make sure system has come to steady state \\
\hline 3 & Start data acquiring via laptop \\
\hline 4 & $\begin{array}{l}\text { Adjust pedestal power level to that desired in the test matrix (watch data } \\
\text { acquisition display to monitor pedestal interface temperature) }\end{array}$ \\
\hline 5 & $\begin{array}{l}\text { Perform first run of test matrix (at a constant temperature and subcooling, } \\
\text { vary the electrode voltage) }\end{array}$ \\
\hline 6 & Power on high voltage power supply \\
\hline 7 & $\begin{array}{l}\text { Adjust } 10 \text { turn potentiometer on high voltage power supply to proper } \\
\text { voltage level, and record the elapsed time (the same number of turns } \\
\text { yields the same voltage every time) }\end{array}$ \\
\hline 8 & Let system balance out ( 1 min) \\
\hline 9 & Repeat steps 7 and 8 for each step of the test run \\
\hline 10 & Turn off high voltage power supply \\
\hline 11 & Adjust pedestal temperature with the Protek power supply \\
\hline 12 & Repeat steps 5 - 11 until the test matrix is completed \\
\hline
\end{tabular}

A baseline test run was conducted to show how the electrode affects the heater surface temperature without any pedestal heating taking place. The baseline showed no change in surface temperature with the application of a voltage level to the electrode. During this baseline experimental test run, the rig was first brought to steady state at the desired spray flow rate. Part of the test matrix was to change the flow rate of the spray. The flow rate was varied by changing the one turn potentiometer located directly on the Tuthill pump. The flow rate was then monitored with a rotameter located directly down 
line from the pump. For these experiments the flow rate was varied nominally between 6 GPH and $10 \mathrm{GPH}$. Then the HV power supply is turned on in order to control the electrode voltage. The voltage is increased in a stepwise fashion from $0 \mathrm{~V}$ to $6000 \mathrm{~V}$, and decreased back to $0 \mathrm{~V}$ by the same steps. For the present work a maximum of 6000 $\mathrm{V}$ was chosen to avoid breakdown in air. Each step was monitored until steady state was reached $(\sim 15 \mathrm{sec})$ and then observed for 30 additional seconds. The data acquisition program displays an elapsed time, which was a running time started with the start of data taking. Every time the HV power supply was adjusted, the elapsed time was written down so that the data can be properly sorted later. When the electrode voltage was returned back to $0 \mathrm{~V}$ the $\mathrm{HV}$ power supply was turned off.

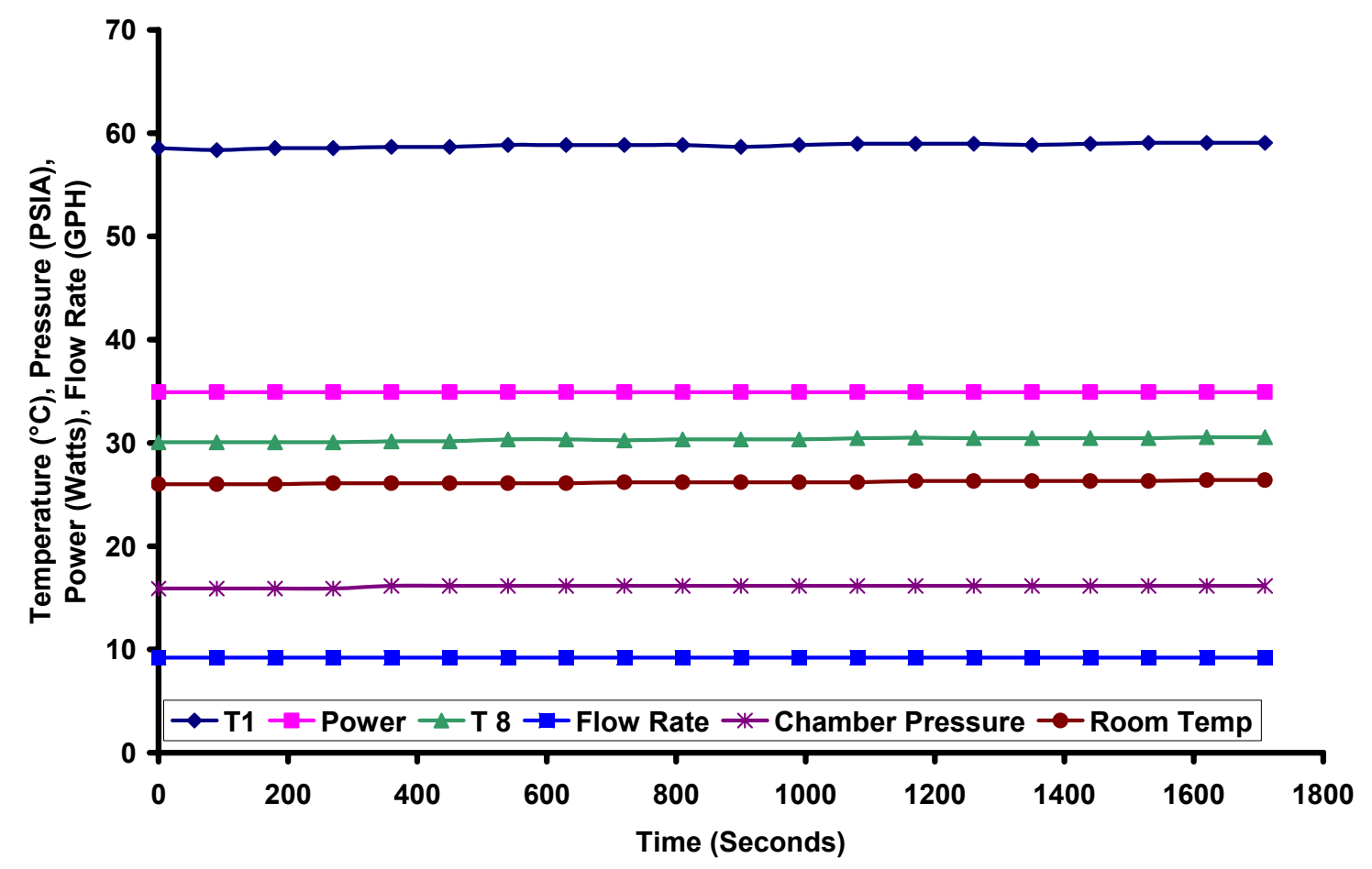

Figure 4.1: $\quad$ Sample Steady state data plot over time

Once the baseline experiment is conducted, an experimental test run with pedestal heating and thus a change in surface temperature is performed. First, the pedestal power 
supply is adjusted to yield the desired pedestal interface temperature. After the proper temperature is reached, and steady state for that temperature is reached, the HV power supply is turned on. The electrode voltage is again varied in a stepwise fashion. Once the data set is taken and the electrode voltage returned to $0 \mathrm{~V}$ the HV power supply is turned off. The process is repeated across the desired pedestal heater power range in a stepwise fashion for that particular flow rate. Adjusting the flow rate varying from 10 GPH to $6 \mathrm{GPH}$ will yield a complete data set. Once the test matrix is completed data reduction and analysis may begin.

\section{Section 4.4: $\quad$ Data Analysis and Reduction}

The implementation of the data acquisition system has helped the efficiency of the data taking immensely. The effects of the data acquisition system can also be realized when reducing the data. Thousands more data points have to be analyzed for each run; however, macros can be set up to perform this automatically upon obtaining the data. From the work done by Hunnell (2005) several important parameters have been identified as critical to this research. The rest of this section will describe how to obtain the proper reduced data values.

\section{Section 4.4.2: Data Analysis}

The implementation of the data acquisition system did not take all of the work out of analyzing data. After a data set has been taken time must still be devoted to separating the data corresponding to different flow rates and electrode voltage levels. Since, at the time of data taking the Sponsler turbine flow meter was inoperable and out for repairs, 
manual flow rates had to be recorded. To monitor the flow rates, the rotameters mounted in each of the flow lines were monitored visually and recorded in a data log book.

This process had to be used for adjusting the HV power supply as well. The program used to record the data taken by the data acquisition system has an elapsed time that represents the amount of time since the onset of data acquisition. Each time the spray flow rate, the subcooling level, or the electrode voltage was adjusted, the corresponding elapsed time was recorded. Once the data run was complete, data analysis could be performed by inserting the changes into the spread sheet. Data points that were logged during an adjustment in the operational levels of the experimental system were neglected.

\section{Section 4.4.2: Data Reduction}

Data reduction is an important step in any research project. First, it converts the raw data into useful performance parameters that can then be compared to related work presented in the literature. Second, these computed results are useful to quantify system performance and to understand the physical performance of the system. For this research one of the most important parameters that needs to be calculated is the heat flux. This section will explain how the data taken is transformed into heat flux and many other useful parameters that document the spray cooling system performance.

Each of the thermocouples used was calibrated according to the process described in Chapter 3 and Appendix A. To obtain the heater power one must also obtain the voltage and current supplied across it. These quantities cannot be measured directly, since the power supply does not have monitor output channels. Therefore, Ohm's Law was used to calculate first the current and then the heater power as shown in Equations 
4.1 and 4.2. To obtain the current, a Precision Resistor Company PLV5, $0.1 \Omega$ shunt resistor, was placed in series with the power supply and the pedestal. Using the voltage measuring channels in the data acquisition system, the voltage drop across the resistor was measured. By knowing the resistance of the resistor, a current was calculated from Equation 4.1. A benefit of this particular data acquisition system is its ability to do simple calculations like this one for the user. Once the current is known it can be used to calculate the power as shown in Equation 4.2.

$$
\begin{gathered}
I=\frac{V}{R} \\
Q=I V
\end{gathered}
$$

Once the heater power, Q, is known along with the surface area, A, of the heater Equation 4.3 can be used to obtain the heat flux.

$$
q^{\prime \prime}=\frac{Q}{A}
$$

Several other important values that must be calculated are the reference temperatures that are referred to in the literature. The reference temperatures include the saturation temperature, which is the temperature at which the working fluid starts to boil. The saturation temperature is a function of the spray chamber pressure and is found by thermo-physical property data supplied by $3 \mathrm{M}$.

Next, the heater surface temperature must be calculated. Because of the geometry of the pedestal, heater, and thermocouple design, the surface temperature does not correspond to the interface temperature which can be measured. Throughout the research process there were three different heaters used. The Indium Tin Oxide (ITO) heater is a transparent heater and was mostly used to validate data against Hunnell (2005). The ITO 
heater was not very robust and cracked easily at higher heat fluxes. There were two types of TFR heater used: an older type that has a thin glass layer on top (Figure 3.19), and a newer typed with no top glass layer. However, due to pedestal failure, all of the present tests were run with the second type of heater, a thick film resistor (TFR).

Using the seven thermocouples located at various levels of the pedestal it is possible to know the temperature directly below the heater. However, it is desired to know what the surface temperature is, in order to understand how the fluid is interacting with the heater surface. By estimating the amount of heat from the pedestal that conducts down the pedestal, neglecting heat generation, and assuming the rest is transferred out the top surface of the heater, a heater surface temperature can be calculated as follows (Baysinger, 2004).

$$
T_{s}=T_{\text {Int }}+\left(\frac{f q^{\prime \prime} \delta_{\text {sub }}}{k_{\text {sub }}}\right)-\left(\frac{(1-f) q^{\prime \prime} \delta_{g}}{k_{g}}\right)
$$

Here, f represents the fraction of heat lost down the pedestal due to conduction, q" is the heat flux, $\mathrm{H}_{2}$ is the substrate thickness, $\mathrm{k}_{\text {sub }}$ is the thermal conductivity of the substrate, $\delta_{\mathrm{g}}$ is the thickness of the glass layer, and $\mathrm{kg}_{\mathrm{g}}$ is the thermal conductivity of the glass. For the present work $f$ has been estimated as 1.5 percent based on the study by Baysinger (2004). However, in the case of a TFR without the glass layer, the third term on the right hand side must be neglected, $\delta_{\mathrm{g}}=0$. A detailed formulation of this process is found in Appendix D.

Reference temperatures are needed to put the data into non-dimensional terms. These reference temperatures are termed $\mathrm{T}_{\infty}$ top, $\mathrm{T}_{\infty}$ wall, $\mathrm{T}_{\text {sat }}$ and $\mathrm{T}_{\text {sub. }}$ Equations 4.5 
through 4.8 explain how values for each are determined (refer to Chapter 3 for thermocouple numbers and locations within the spray chamber).

$$
\begin{aligned}
& T_{\infty_{\text {Top }}}=\frac{T_{10}+T_{14}}{2} \\
& T_{\infty_{\text {Wall }}}=T_{10} \\
& T_{\text {sat }}(F C-72)=\frac{-1562}{\log _{10}(P)-9.729} \\
& T_{\text {sat }}(H F E-7000)=\frac{-3548.6}{\ln (P)-22.978} \\
& \Delta T_{\text {sub }}=T_{\text {sat }}-T_{\infty_{\text {top }}}
\end{aligned}
$$

$\mathrm{T}_{\text {sat }}$ represents the saturation temperature for the working fluid, and corresponds to the temperature $(\mathrm{K})$ for the onset of two-phase flow characteristics. Here, $\mathrm{P}$ is measured in Pascals. $\Delta \mathrm{T}_{\text {sub}}$, represents the amount of subcooling between the fluid temperature just off the surface of the pedestal with the saturation temperature. These definitions differ from those of Yerkes et al. (2006), because the presence of the high voltage electrode in the present work required the elimination of the thermocouple located at the top of the sump at the outer radius of the heater surface, labeled as $T_{11}$ in Figure 3.16. Using these present reference temperatures a non-dimensional temperature, $\theta$, can be defined and computed as follows.

$$
\begin{gathered}
\theta_{S}=\frac{T_{s}-T_{\infty_{\text {wall }}}}{T_{\text {Sat }}-T_{\infty_{\text {Wall }}}} \\
\theta_{\infty_{\text {Top }}}=\frac{T_{\infty_{\text {top }}}-T_{\infty_{\text {wall }}}}{T_{\text {Sat }}-T_{\infty_{\text {Wall }}}}
\end{gathered}
$$

Next, a heat transfer coefficient can be determined for the fluid (Yerkes et al., 2006): 


$$
h=\frac{(1-f) Q}{A_{\text {TFR }}\left(T_{s}-T_{\infty_{\text {Top }}}\right)}
$$

Likewise a value can be calculated for the thermal conductivity of the fluid based on information provided by $3 \mathrm{M}$.

$$
\begin{aligned}
& k_{f}(F C-72)=0.060-0.00011\left(T_{\infty_{\text {Tор }}}\right) \\
& k_{f}(H F E-7000)=0.0798-0.000196\left(T_{\infty_{\text {Tор }}}\right)
\end{aligned}
$$

Here, $\mathrm{T}_{\infty}$ top is in ${ }^{\circ} \mathrm{C}$. The heat flux must be put into non-dimensional terms as follows (Yerkes et al., 2006):

$$
G \Delta=\frac{(1-f) Q}{\pi b\left(T_{\text {sat }}-T_{\text {owall }}\right) k_{h t r}}
$$

Another non-dimensional numbers that is commonly used in the literature is the Nusselt number:

$$
N u=\frac{h_{f} b}{k_{f}}
$$

Here, $d$ represents the droplet diameter and $\sigma$ represents surface tension. Once the pertinent values have been calculated they are plotted and compared to previous results. The following chapter will present the data results in graphical form and explain the physical meaning of each plot.

\section{Section 4.4.3: $\quad$ Error Analysis}

Experimental calculations are only as precise as the equipment used to take the measurements and the people performing the experiments. Errors inherent in reading a gauge will be propagated down to the final result and the presented data is often off as much as 30 percent when dealing with heat transfer calculations. The following section 
will explain the error associated with each measurement device shown in Table 4.4 and explain how it affects the resulting equations.

Random error is also present in experimentation. Comparing different nozzle materials yielded a repeatability problem between three nozzles of the same type as discussed in Section 5.8. Equipment setup for this research can cause results under supposedly identical test conditions to range as much as $14 \%$. Comparing supposedly identical spray nozzles with different materials has shown a difference in results ranges from $5 \%$ to $14 \%$. This variance is attributed to the alignment of the nozzles. This random error due to variations in equipment setup must be added to the equipment error to obtain an overall error for each parameter calculated. However, this error is expected to be greatly reduced during any single continuous data set, since no changes or variations are made to the nozzle position. Any remaining errors would be due to variations in the ambient room temperature; these have not been quantified in the present work, but efforts have been made to keep them to a minimum.

Table 4.4: $\quad$ Error Levels of Different Experimental Equipment

\begin{tabular}{|l|l|}
\hline Equipment & Error \\
\hline Thermocouples (calibrated) & $\pm 0.1^{\circ} \mathrm{C}$ \\
\hline Thermocouples (un-calibrated) & $\pm 0.6^{\circ} \mathrm{C}$ \\
\hline DA Thermocouple Reading & $\pm 0.1^{\circ} \mathrm{C}$ \\
\hline Pressure Transducer & $\pm 0.25 \%$ FS \\
\hline Rotameters & $\pm 2.5 \% \mathrm{FS}$ \\
\hline Pedestal Voltage & $\pm 0.0055 \% \mathrm{FS}$ \\
\hline Pressure Transducer Voltage & $\pm 0.0037 \% \mathrm{FS}$ \\
\hline Precision Resistor & $\pm 0.005 \%$ \\
\hline
\end{tabular}

For the present work two different pedestals were used. The first set of thermocouples were those mounted in the glass pedestal that were calibrated using a controlled temperature bath and a calibrated RTD probe as explained in Appendix A. 
Two different sets of data were collected using this pedestal, the original assembly and the assembly with the repaired TFR. Both cases used calibrated thermocouples and therefore are estimated to be accurate to $\pm 0.1{ }^{\circ} \mathrm{C}$. The second pedestal used was the newly designed PTFE pedestal. These thermocouples as well as the thermocouples located in the chamber and flow loop were not calibrated beyond the accuracy from the manufacturer, estimated as of $\pm 0.6^{\circ} \mathrm{C}$. This estimate comes from calibration data of 20 Omega type E thermocouples, for which the largest correction factor was $0.6{ }^{\circ} \mathrm{C}$, with most being corrected only $0.4{ }^{\circ} \mathrm{C}$ or less. Both conditions were measured using an Agilent data acquisition board with a temperature measurement accuracy of $\pm 0.1{ }^{\circ} \mathrm{C}$. Thus the overall estimated accuracy for each type is $\pm 0.2{ }^{\circ} \mathrm{C}$ for the calibrated thermocouples, and $\pm 0.7^{\circ} \mathrm{C}$ for the un-calibrated thermocouples.

The flow rate of the working fluid is measured using a rotameter calibrated by the manufacturer for water. Therefore, a transformation must be made to convert the measurement to the proper fluid. To perform this conversion, the flow rate measured \pm $2.5 \%$ FS must be multiplied by the square root of the density ratio of the working fluid to water. Since both the density of FC-72 and HFE-7000 depend on temperature of the liquid in the rotameter must be used. The rotameter is directly upstream of the nozzle, and therefore the nozzle temperature is used to calculate the density. Assuming the temperature to be constant the density calculations will vary $\pm 0.7 \%$. Thus the overall estimated error in flow rate is $\pm 3.2 \%$ of full scale or $\pm 0.64 \mathrm{GPH}$.

The heater power is calculated using the voltage supplied to the resistor multiplied by the current through the resistor. The current is calculated by measuring the voltage drop across a precision resistor of known resistance, $0.1 \Omega$, in series with the power 
supply and the pedestal heater. The precision resistor has a specified resistance uncertainty of $\pm 0.0005 \Omega$. The measurement of a voltage by the data acquisition system is $\pm 0.0055 \%$ for a voltage range reading up to $100 \mathrm{~V}$. Thus the estimated error in the calculated heater power level is $\pm 0.125 \%$.

Pressure transducers were used to measure the pressure at the nozzle as well as the pressure inside the spray chamber. The uncertainty of the pressure transducer itself according to the manufacturer is $\pm 0.0026 \mathrm{~V}$. This error is increased by the inherent error of the data acquisition system with an added error of $\pm 0.0037 \%$. Combining the two sources of error the overall error estimate on pressure measurements is $0.4 \%$. 


\section{CHAPTER 5 : RESULTS AND DISCUSSION}

\section{Section 5.1: $\quad$ Introduction}

In this chapter the present research results are presented in chronological order to describe the development and data taking process while searching for the optimal electrode configuration. Due to several setbacks and complications the data taking process had to be altered accordingly. The results in this chapter are for data runs using two different Coulomb force electrode geometries with unconfined flow and two different working fluids: FC-72 and HFE-7000. Initial test runs using the new TFR heater and electrode 1 showed results; however, this observed effect was an increase in the surface temperature and decrease in the heat transferred away from the heater surface.

\section{Section 5.2: $\quad$ Complications}

During the course of altering the rig used by Hunnell (2005) several complications arose. First and foremost, according to recommendations from AFRL an electronic turbine flow meter was to be implemented. However, the bearings in the flow meter did not operate properly from the time that it was first installed in the flow loop. Troubleshooting was followed according to company recommendations, but there was no improvement in performance and the problem persisted. The flow meter had to be returned to the manufacturer for further analysis. Therefore, for the present work the data regarding the flow rate of the system had to be read using a rotameter, and recorded by hand. The rotameters that were used were calibrated by the manufacturer for water, to an uncertainty of \pm 2.5 percent with an additional uncertainty of \pm 0.7 percent for the density in the conversion to the flow rate of the working fluid. 
Another complication occurred during the setup of the PID controller that regulated the amount of heat input to the working fluid flow loop by the re-heater. The PID was controlling the re-heater through a solid state relay. With improper use after a few minutes the re-heater overheated causing irreversible damage to the re-heater and the plumbing in direct contact with it. The re-heater had to be removed from the flow loop and as a result the amount of subcooling was not able to be independently varied as originally planned.

A third complication arose when the system would overheat and reach CHF, and several heaters placed on top of the pedestals were damaged and had to be replaced. As will be demonstrated in Section 5.8 and Appendix B, the radial positioning of the nozzle is very critical, and if not done properly the surface temperature will vary greatly. If the spray cone is misaligned the heater can overheat on one side before the alarm trips and cuts the power to the heater. This can cause onset of CHF and dry-out to take place uncontrolled and unmonitored. During this period of dry-out damage to the heater occurs. Mini-Systems Inc. recommends that the surface of the TFR resistor not exceed $150{ }^{\circ} \mathrm{C}$. Figure 5.1 and Figure 5.2 show how the TFR as well as the surface of the pedestal can be damaged if the temperature is allowed to exceed $150{ }^{\circ} \mathrm{C}$ and dry-out occurs. 

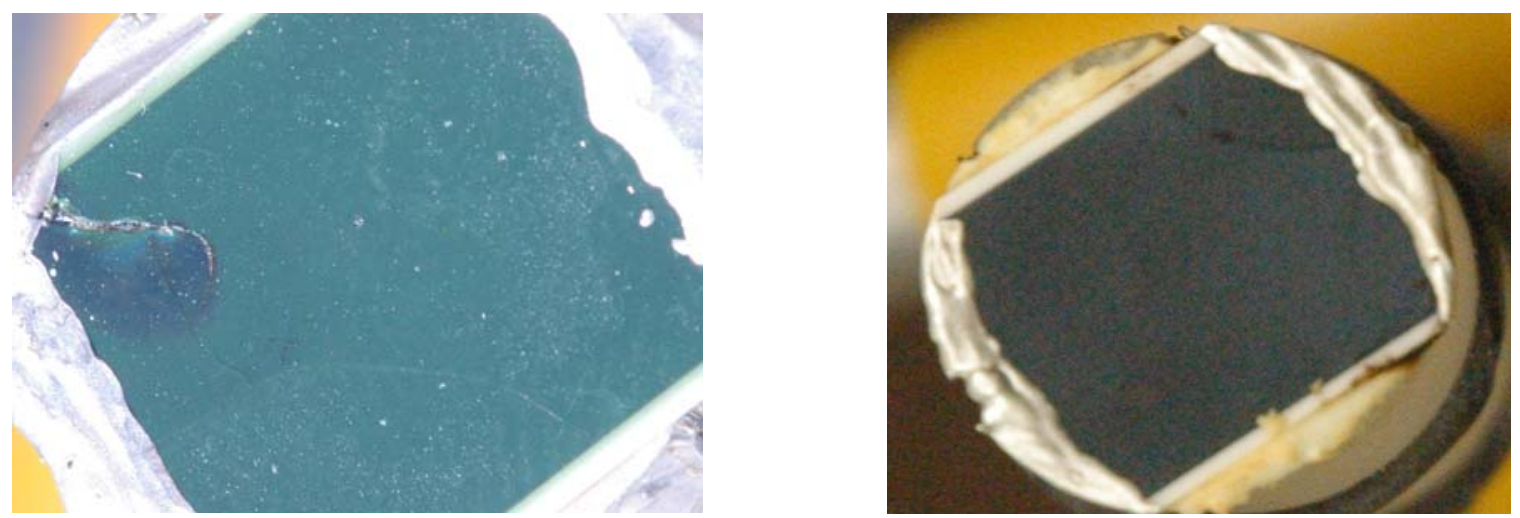

Figure 5.1: $\quad$ Damaged TFR Heaters, a) TFR with glass layer, b) TFR without glass layer

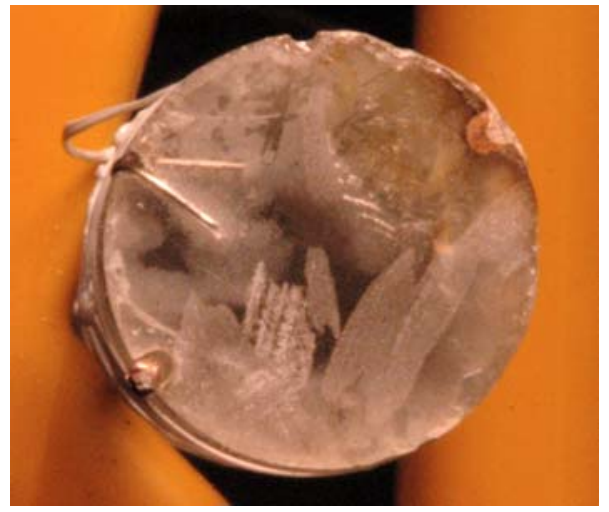

Figure 5.2: $\quad$ Damage to Top Glass Pedestal Layer Under the TFR

\section{Section 5.3: $\quad$ Data Overview}

Throughout the course of this work several different pedestals, electrodes, and fluids were used in an effort to maximize the effects of the Coulomb force. The two fluids used during testing were FC-72 and HFE-7000. The two different electrodes as well as the different pedestals used have been described in Chapter 3. According to the procedure and test matrix described in Chapter 4 the working fluid flow rate was adjusted to the desired level, then the pedestal heater power was adjusted in a stepwise fashion between $0 \mathrm{~W}$ and up to a maximum of $120 \mathrm{~W}$ depending on the working fluid and pedestal used. The air content for all tests using FC-72 was computed to be $22 \%$ by volume based on Mercury Aire-ometer testing performed at WPAFB. The air content for 
the HFE-7000 was not calculated during the testing process. The electrode voltage was also applied in a stepwise fashion for each power setting. The $250 \mathrm{~Hz}$ data acquisition system acquires a continuous data record for the entire length of the test. In most cases this data record varied between 14 and 30 minutes in length, resulting in up to two hundred thousand data points, depending on test length. As a result a large amount of data was collected for each run, but not all of it was usable, and so the data records had to be analyzed accordingly.

Figure 5.3 shows a typical data run described above for a constant flow rate and varying heater power and electrode voltage. During a test there are regions where the heater power level is being adjusted, and therefore those regions are not of interest during the data reduction since the experiment was not operating under steady state conditions. After each change was made to the system parameters, all variables were held constant for 45 seconds to allow the system to steady out.

For the particular data run shown in Figure 5.3 the flow rate was set to be $8 \pm 0.5$ GPH of HFE-7000. The heater power level was adjusted from $0 \mathrm{~W}$ to $80 \mathrm{~W} \pm 0.07 \%$ with a resulting interface temperature ranging from $25^{\circ} \mathrm{C}$ to $49{ }^{\circ} \mathrm{C} \pm 0.2{ }^{\circ} \mathrm{C}$ at the largest heater power. All power settings were monitored with the electrode voltage set to $0 \mathrm{kV}$, and the electrode was then adjusted to $5 \mathrm{kV} \pm 3 \%$ while the heater power levels were continuously monitored. Several data points on the heater power curve in Figure 5.3 deviate from the stepwise trend because a coarse one turn potentiometer was used to adjust the heater power level. 


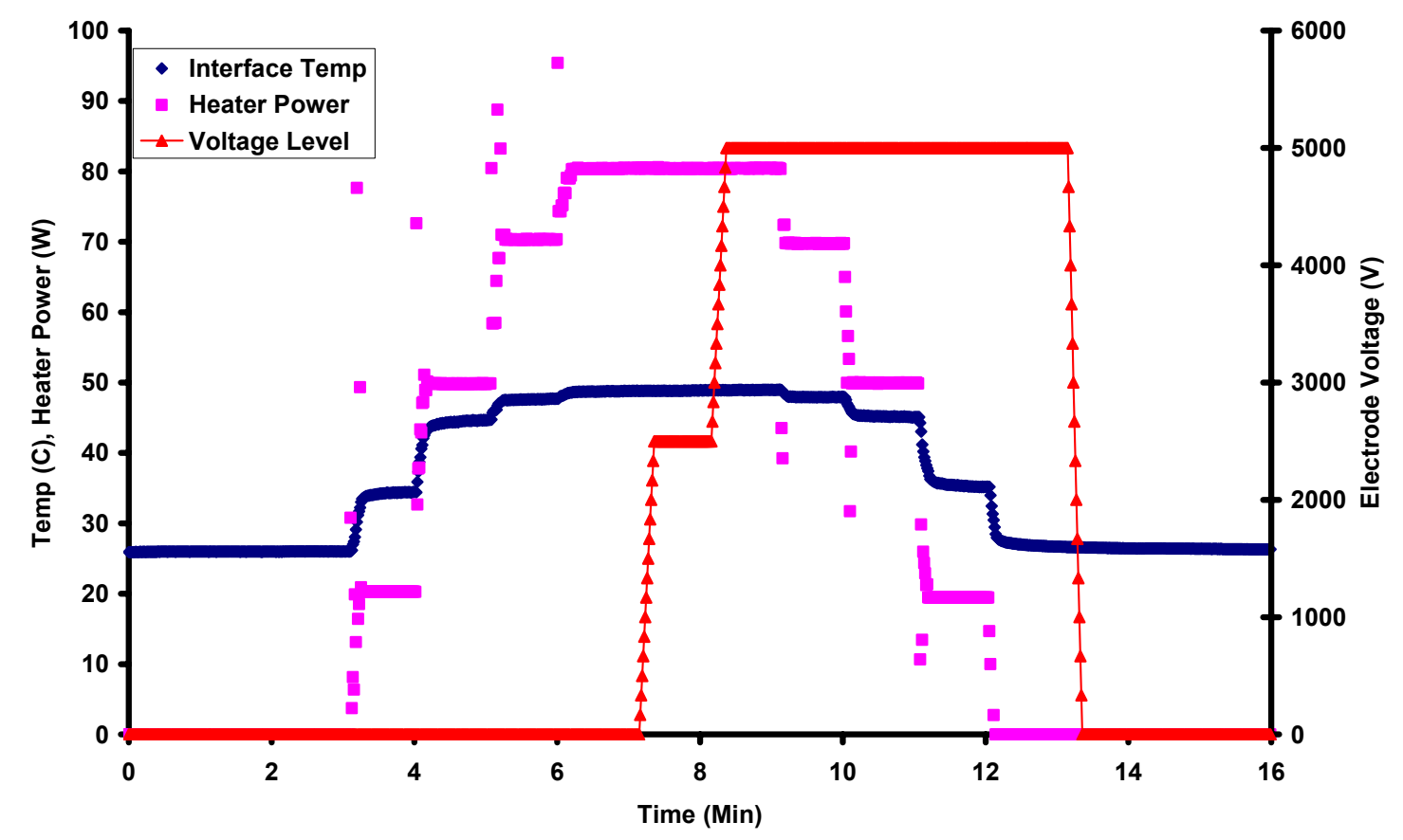

Figure 5.3: Typical Data Run using PTFE Pedestal, HFE-7000, 8 GPH, and Electrode 1

In order to present the data collected in an efficient and easily understandable form, the raw data had to be analyzed and sorted. In heat transfer one of the most important plots is the heat flux plotted as a function of temperature difference. There are two schools of thought on which temperatures to use. For single-phase heat transfer the temperature difference used would be $T_{S}-T_{\infty_{\text {top }}}$, where $T_{\infty_{\text {top }}}$ is the average liquid temperature on the heater surface. However, since there is interest in the present work in what is occurring in the two-phase region it is more acceptable to present the data in the form of $T_{S}-T_{\text {sat }}$, where $T_{\text {sat }}$ is the working fluid saturation temperature.

Figure 5.4 presents the heat flux plotted against the two-phase temperature difference for the raw data shown in Figure 5.3. This figure contains computed results for all data collected using the data acquisition system. This plot shows two regions: 
when the $\mathrm{x}$-axis is negative there is single-phase heat transfer taking place, and when the values are positive there is two-phase heat transfer taking place.

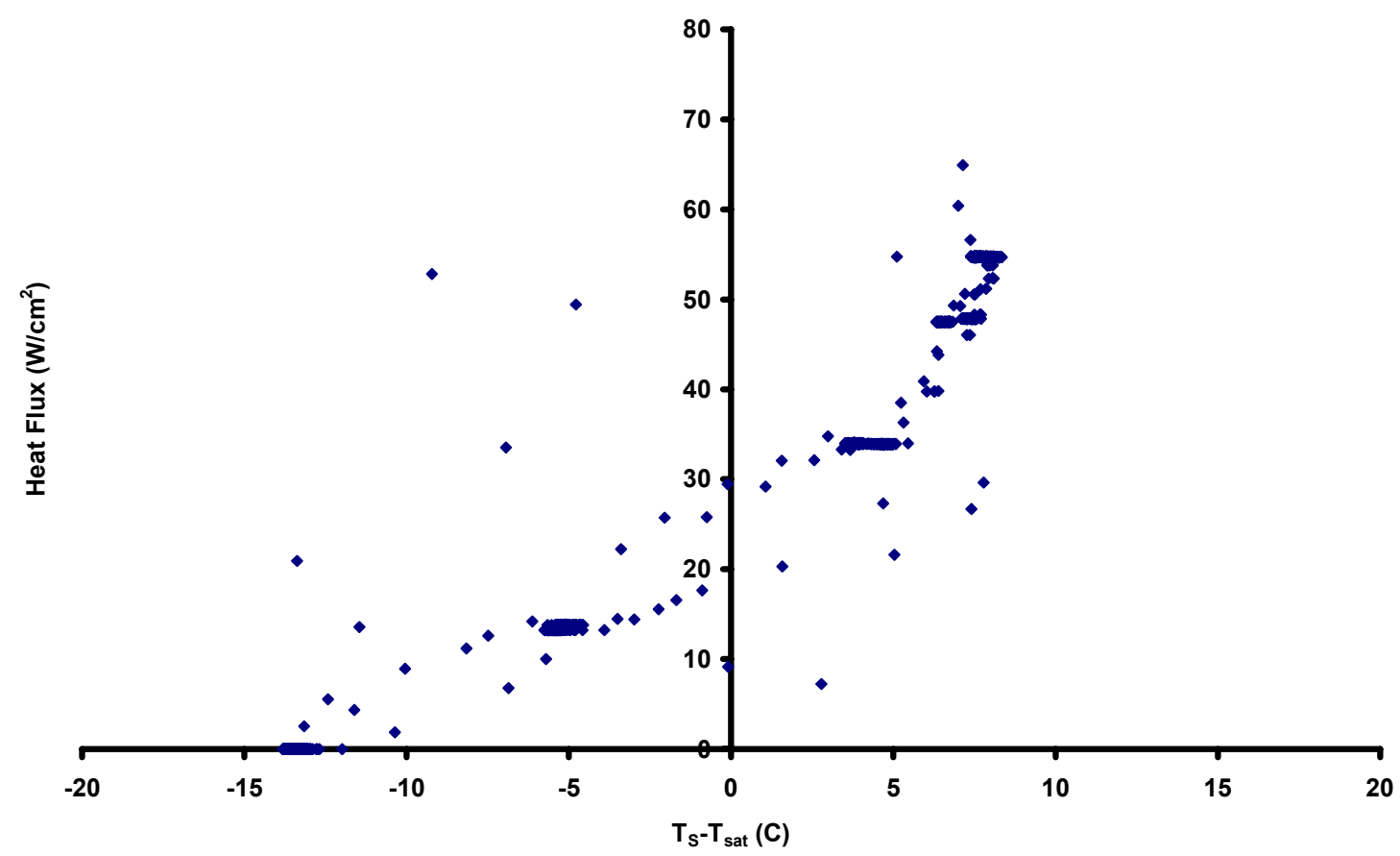

Figure 5.4: Heat Flux Plot with all Data Collected for PTFE Pedestal, HFE7000, $8 \mathrm{GPH}$, and Electrode 1

Sorting the data points used in this plot yields a plot without any of the noise due to the unsteady data collected during the changing of variables such as heater power and/or electrode voltage. With each power setting held constant for 45 seconds, allowing the system to reach steady state during the first 15 seconds of each power level, data taken during the remaining 30 seconds can be plotted. Figure 5.5 represents the data from Figure 5.3 acquired during the last 30 seconds of each heater power setting according to each electrode voltage setting. The blue symbols represent the data with 0 $\mathrm{kV}$ and the red symbols represent the data with $5 \mathrm{kV}$ applied to electrode 1.

To further simplify the plot, each of the groupings of data points in Figure 5.5 are averaged to yield a single data point for each heater power setting as well as for each 
electrode voltage setting. Plotting the data for $0 \mathrm{kV}$ together on a single curve and likewise for the $5 \mathrm{kV}$ data, an average heat flux plot is created as presented in Figure 5.6.

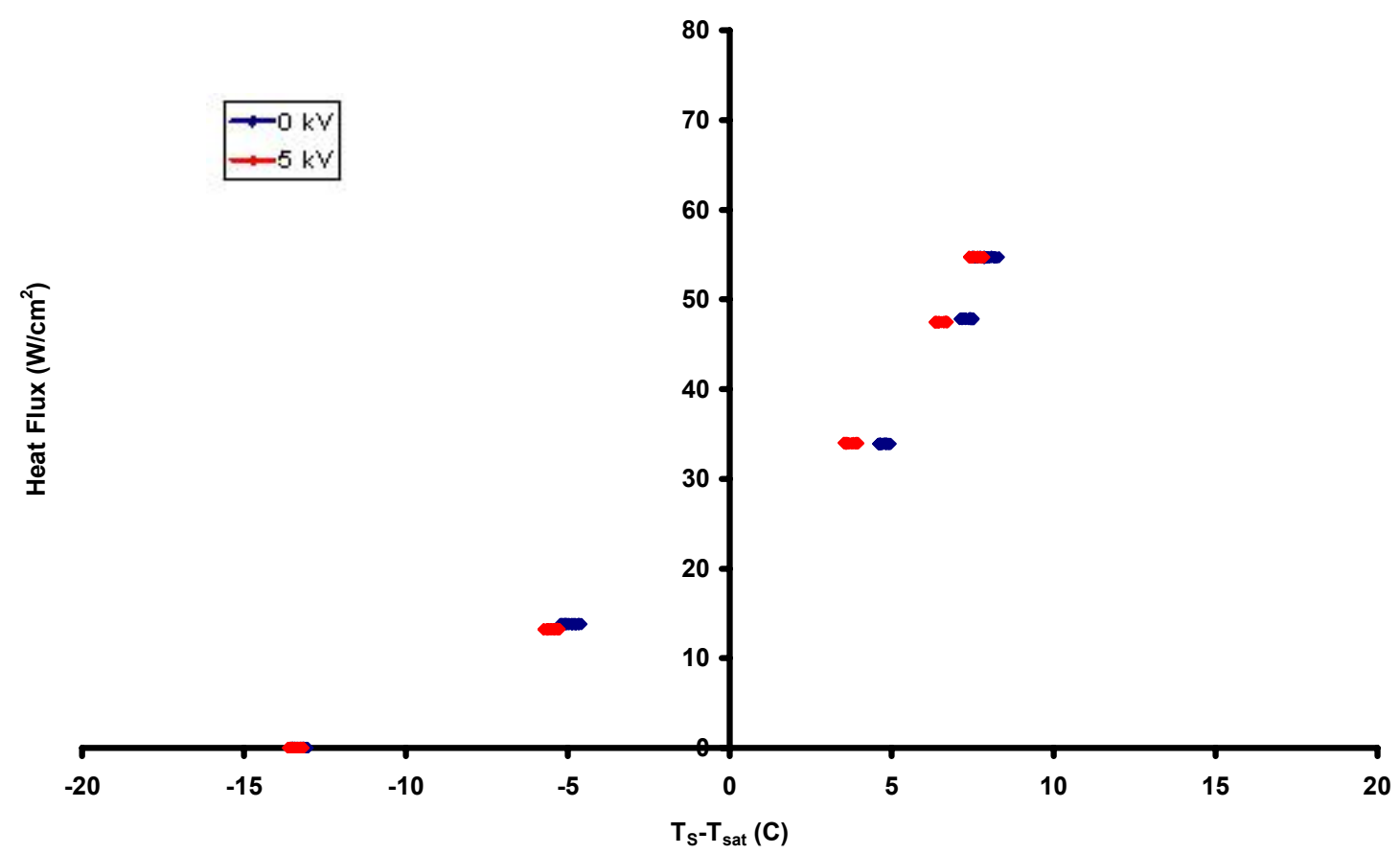

Figure 5.5: Heat Flux Plot with Variable Adjustments Removed for PTFE Pedestal, HFE-7000, 8 GPH, and Electrode 1

Looking at Figure 5.6 several important trends are noted. On the negative portion of the plot corresponding to single-phase heat transfer, the heat flux is linear. However, when a transition is noted in the two-phase region the data trends up more steeply. When CHF is reached the heat flux remains constant, but data points move horizontally to the right as the temperature begins to run away. There is also a slight deviation of the curves in the two-phase region that represents the deviation of the $5 \mathrm{kV}$ data from the $0 \mathrm{kV}$ curve. 


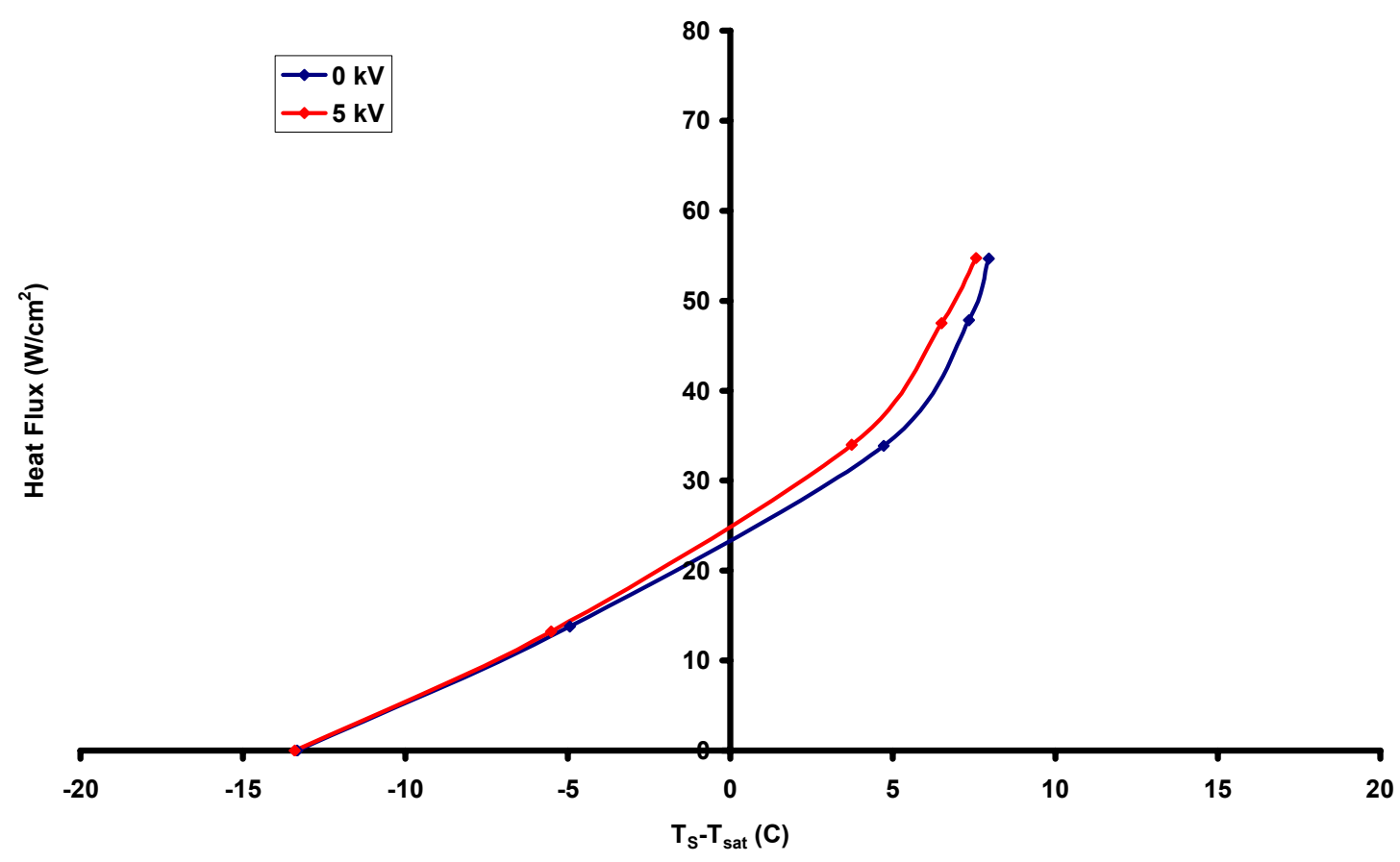

Figure 5.6: Heat Flux Plot Averaged at each Heater Power Level for PTFE Pedestal, HFE-7000, 8 GPH, and Electrode 1

\section{Section 5.4: $\quad$ FC-72 Data Results}

After the results of Hunnell (2005) had been verified in preliminary studies, the next step was to begin studying the effectiveness of the inductive spray charging electrode geometries to control the spray. Electrode 1 was installed in the chamber, and after data were observed with no effects on the interface heater temperature several changes were made. The PVC nozzle was removed and replaced by a brass nozzle which was grounded to the spray chamber. This was done to enhance the amount of electrons moving from the nozzle to or from the droplets of working fluid, depending on the polarity of the high voltage power supply. Several data runs were taken to see how the electrode affected the heat transfer rate from the heater surface. The next section presents data collected for one such data run that showed an effect of the electrode on the heat transfer from the heater surface. 


\section{Section 5.4.1: $\quad$ New TFR Pedestal with Electrode 1 using FC-72 Showing Effects due to Electrode 1}

For initial tests using a positive electrode polarity, an effect was seen, where the interface temperature of the heater increased as the electrode voltage level was increased. Since this trend decreased the heat transfer, the polarity of the high voltage power supply was changed from positive to negative. However, switching to negative polarity did not alter the effect of the trend of the interface temperature, thus a negative voltage was used for the remaining tests in the present work. Figure 5.7 shows the heat flux plot for the increasing heater power levels using electrode number 1 at $8 \pm 0.5 \mathrm{GPH}$ of FC-72 with the new TFR pedestal.

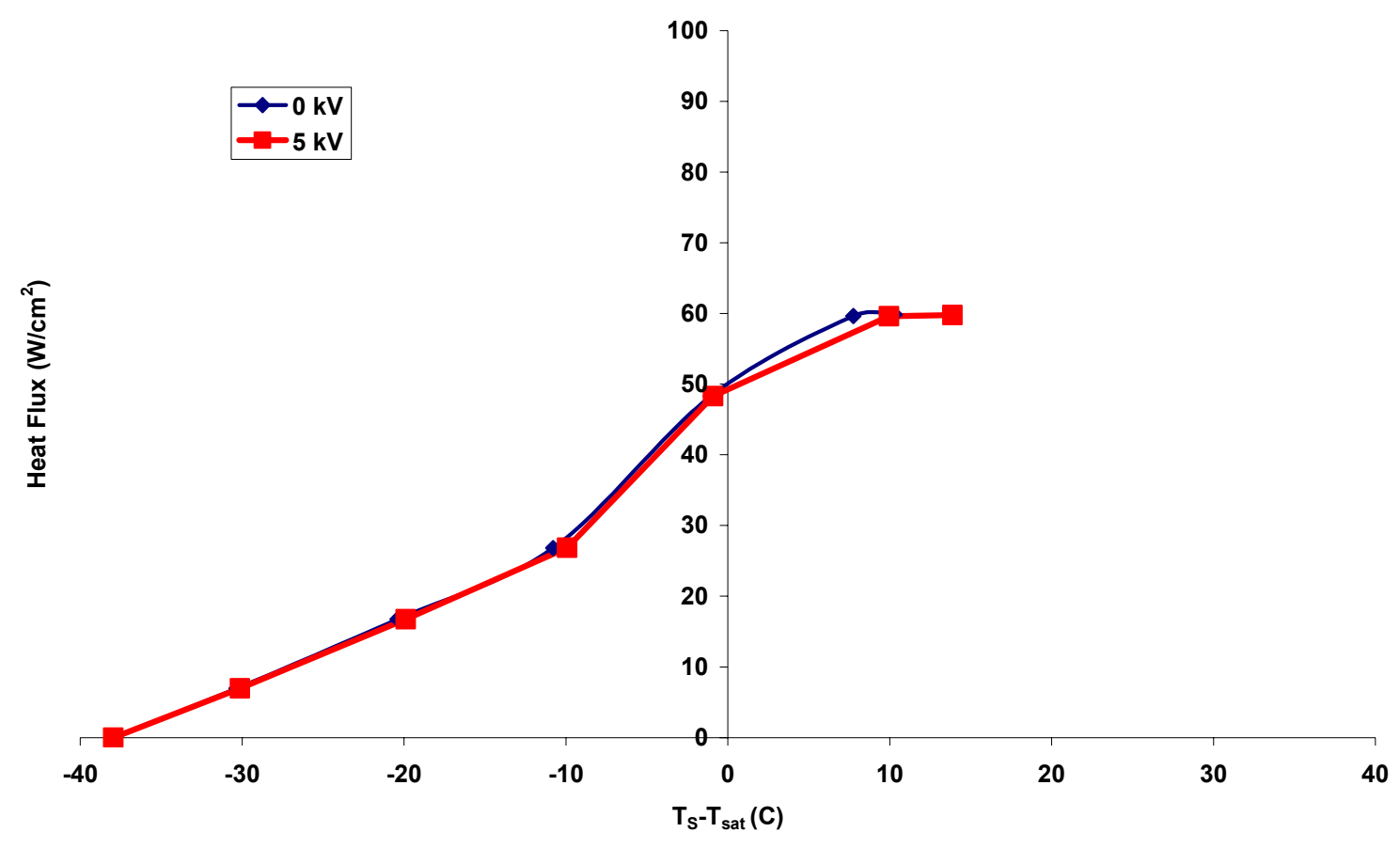

Figure 5.7: Heat Flux Plot for FC-72, 9.3 GPH, and Electrode 1 Data Run with Effects

During this test, effects due to the electrode voltage on heat transfer performance were observed. This can easily be seen in Figure 5.8. This Figure is a time history of the entire data run. Looking at the regions where the electrode voltage was the highest, it is 
possible to see that the interface temperature first increases as the voltage is increased and then decreases when the electrode voltage is reduced. This effect ranges from a temperature increase of several tenths of a degree Celsius at the lower power settings to as much as 4 degrees at the highest heater power settings. The rapid increase in temperature occurring at 16 minutes is the heater surface reaching CHF.

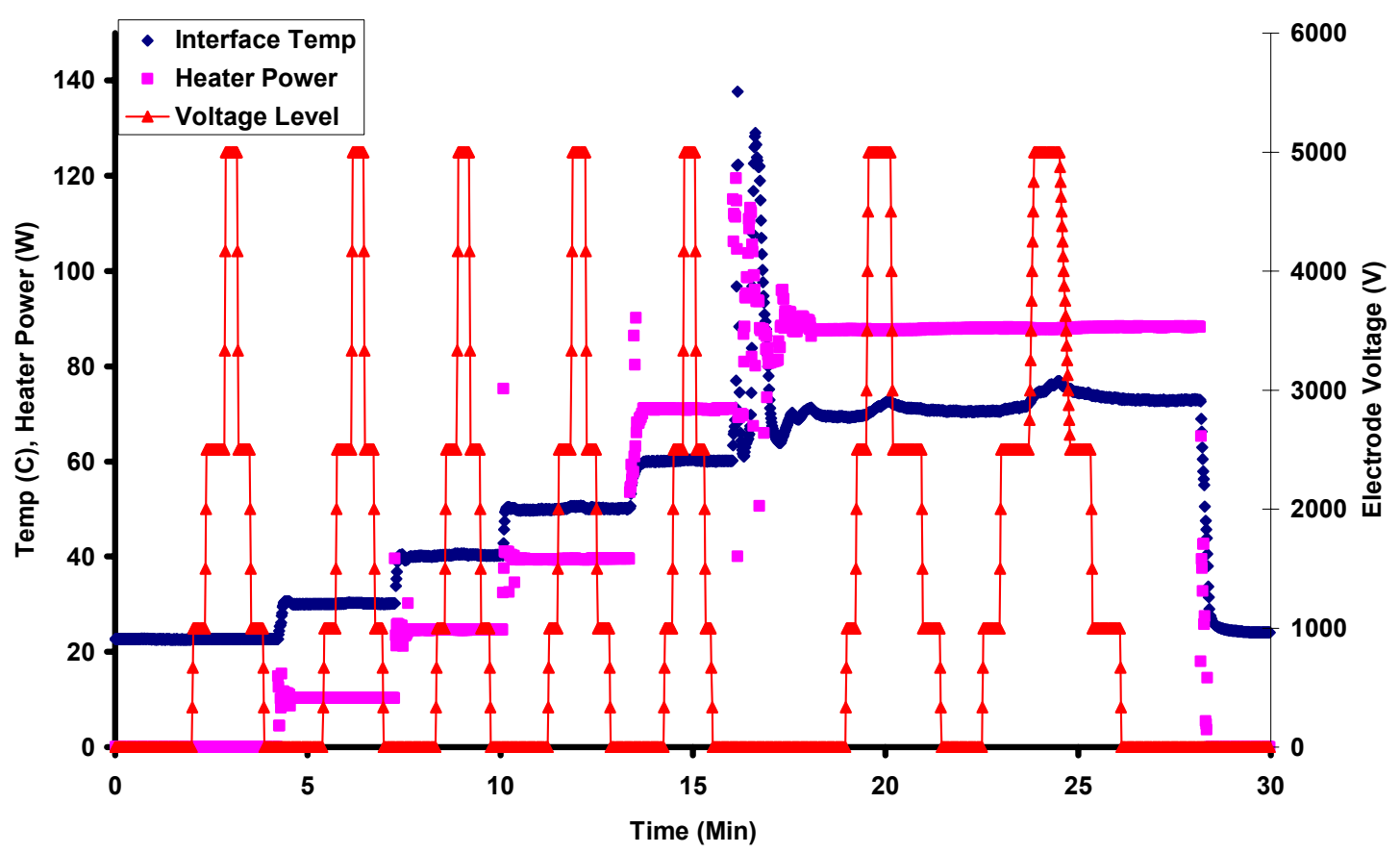

Figure 5.8: Time History of FC-72, $9.3 \mathrm{GPH}$, and Electrode 1 Data Run with Effects

Figure 5.9 zooms in on the region from 22 minutes to 27 minutes where the heater power level is $88 \mathrm{~W}$ and the heater interface temperature is nominally $70{ }^{\circ} \mathrm{C}$. The electrode voltage supply is also stepped up from $0.0 \mathrm{kV}$ to $1.0 \mathrm{kV}$ to $2.5 \mathrm{kV}$ to $5.0 \mathrm{kV}$. This region shows the greatest effect seen due to altering the voltage level of the electrode.

Examining Figure 5.9 it is possible to see that the average interface temperature before the electrode voltage is turned on is about $70.5^{\circ} \mathrm{C}$. After the electrode voltage is turned up to $5 \mathrm{kV}$ the average interface temperature increases to around $77.0^{\circ} \mathrm{C}$. When 
the electrode voltage level is returned to $0 \mathrm{kV}$ the average interface temperature reduces back to $73.0{ }^{\circ} \mathrm{C}$. This shows an increase of heater interface temperature of $6.5^{\circ} \mathrm{C}$ when the electrode voltage of $5 \mathrm{kV}$ was applied and a $4.0{ }^{\circ} \mathrm{C}$ decrease after the electrode is turned off. This hysteresis is likely due to heating up of the entire flow loop, perhaps due to an increase in the room temperature.

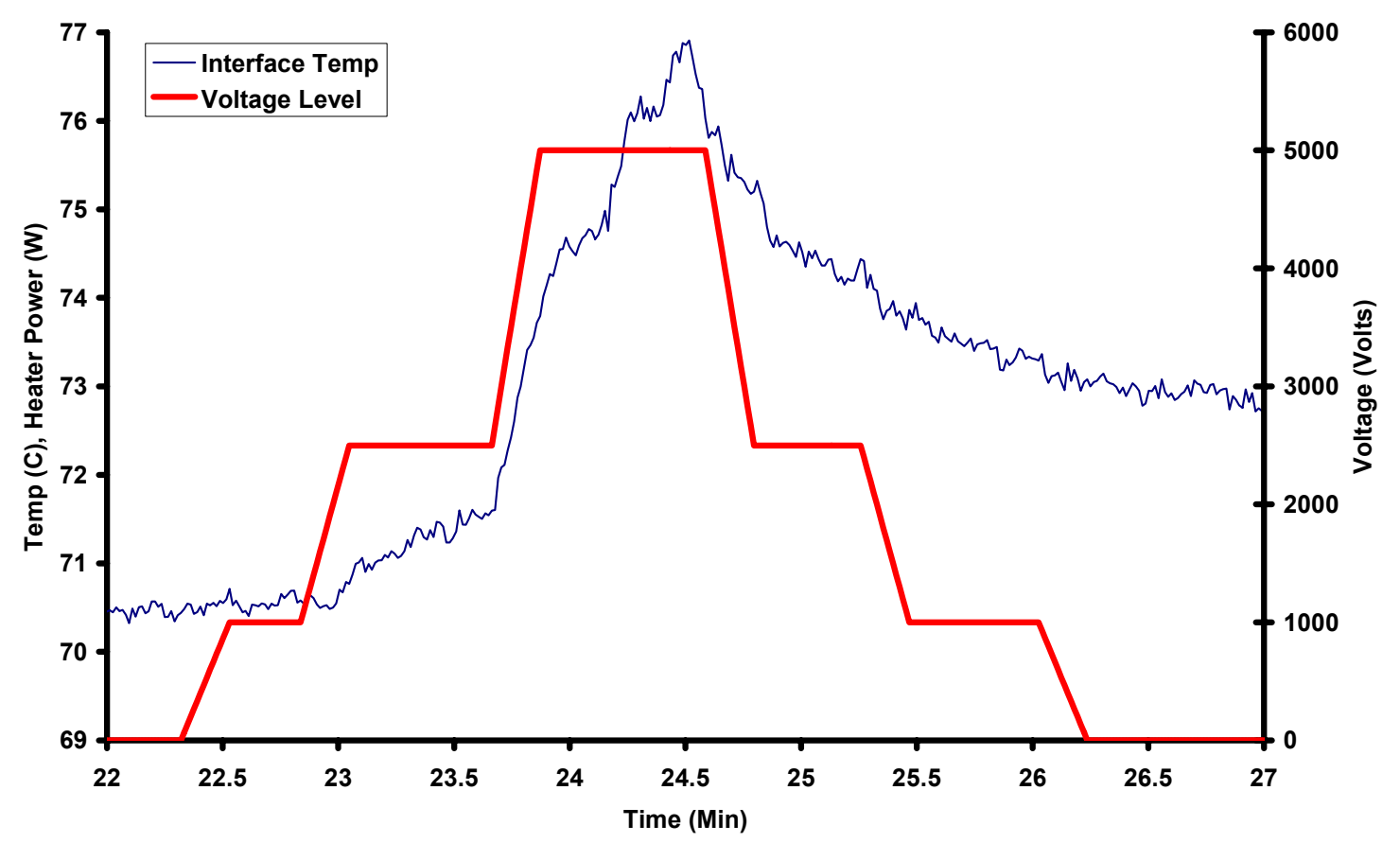

Figure 5.9: Zoom in on Region of Electrode Voltage for FC-72, $9.3 \mathrm{GPH}$, and Electrode 1 Data Run with Effects

Figure 5.10 zooms in on the region from 15.75 minutes to 17.40 minutes in Figure 5.8 where the heater power level is increasing in efforts to increase the interface temperature. However, CHF was reached. The heater power was immediately turned down before the interface temperature reached the temperature cut off value. A second attempt to increase the heater power resulted in the onset of CHF again. Adjusting the one turn potentiometer finally resulted in a stable heater power level and corresponding interface temperature. 


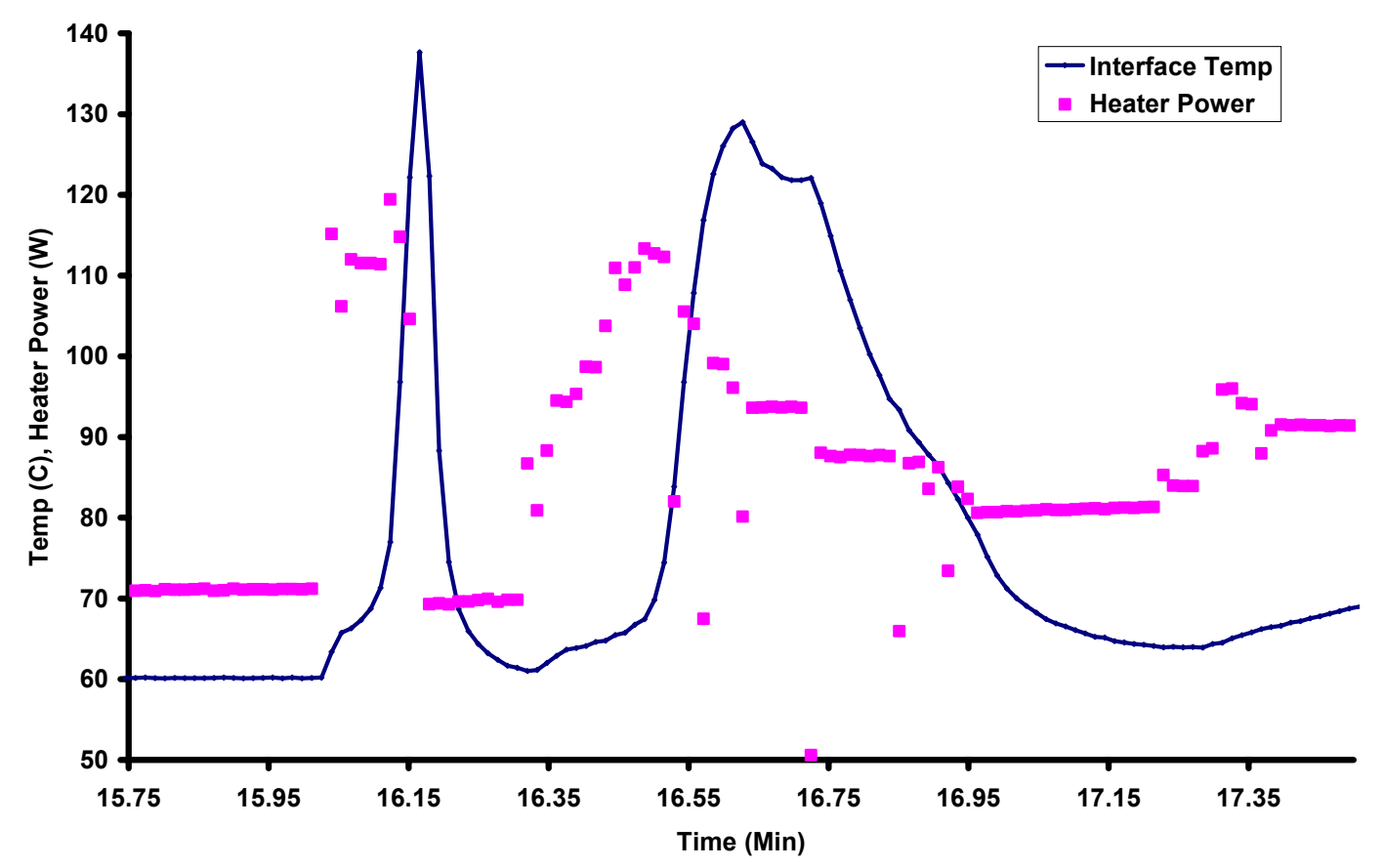

Figure 5.10: Zoom in on Region of Electrode Voltage for FC-72, 9.3 GPH, and Computed heat transfer characteristics for the raw data shown in Figure 5.8 are presented in both dimensional and non-dimensional forms in Figure 5.11 - Figure 5.13. First Figure 5.11 shows a non-dimensional form of the heat flux versus temperature difference plot of Figure 5.7. Figure 5.12 shows the heat transfer coefficient, $h\left(W / \mathrm{m}^{2}-K\right)$ plotted against heat flux. Finally Figure 5.13 shows a non-dimensional plot showing the Nusselt number plotted against the non-dimensional heat flux. 


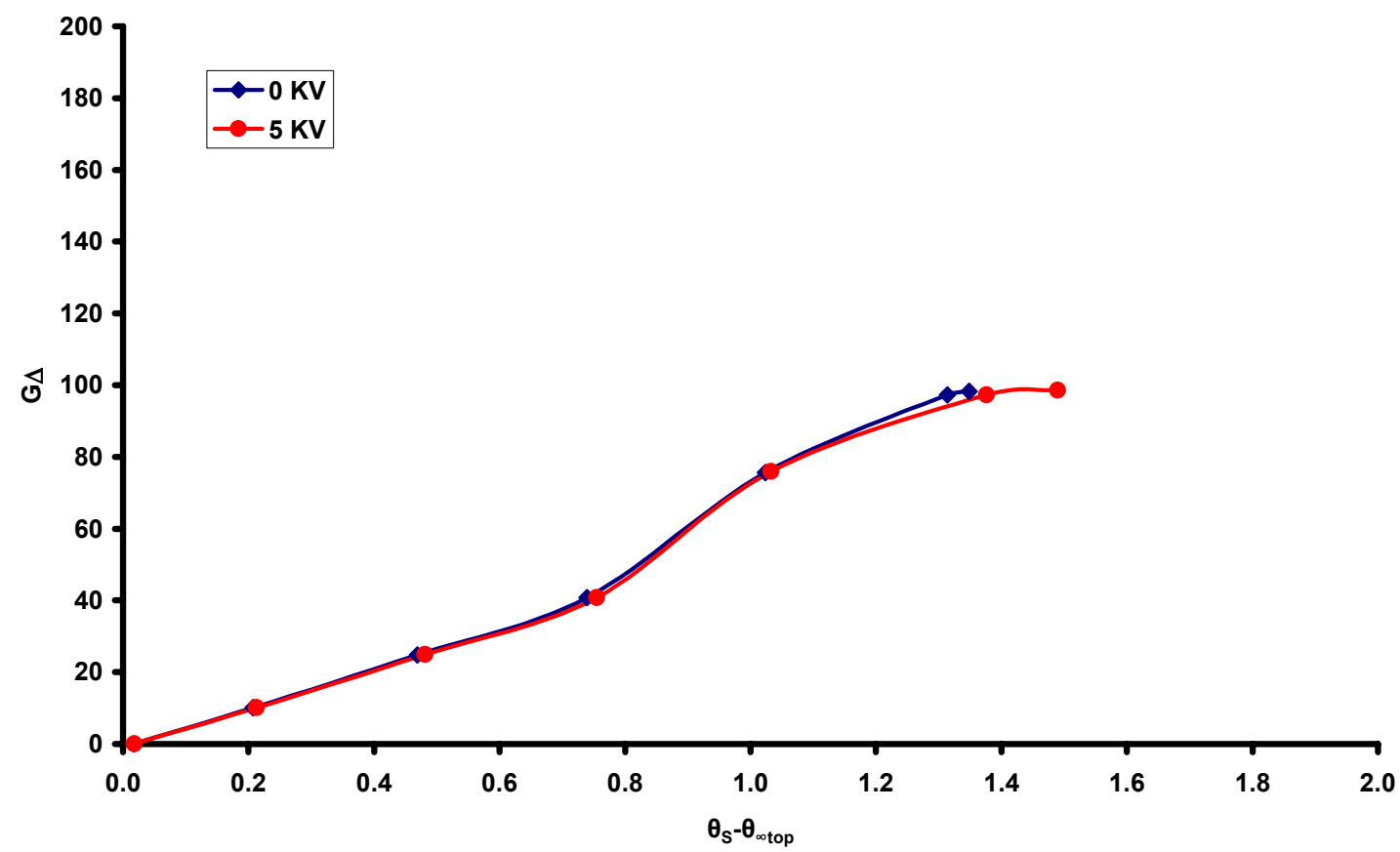

Figure 5.11: Non-dimensional Heat Flux versus Temperature Difference for FC-72, 9.3 GPH, and Electrode 1 Data Run with Effects

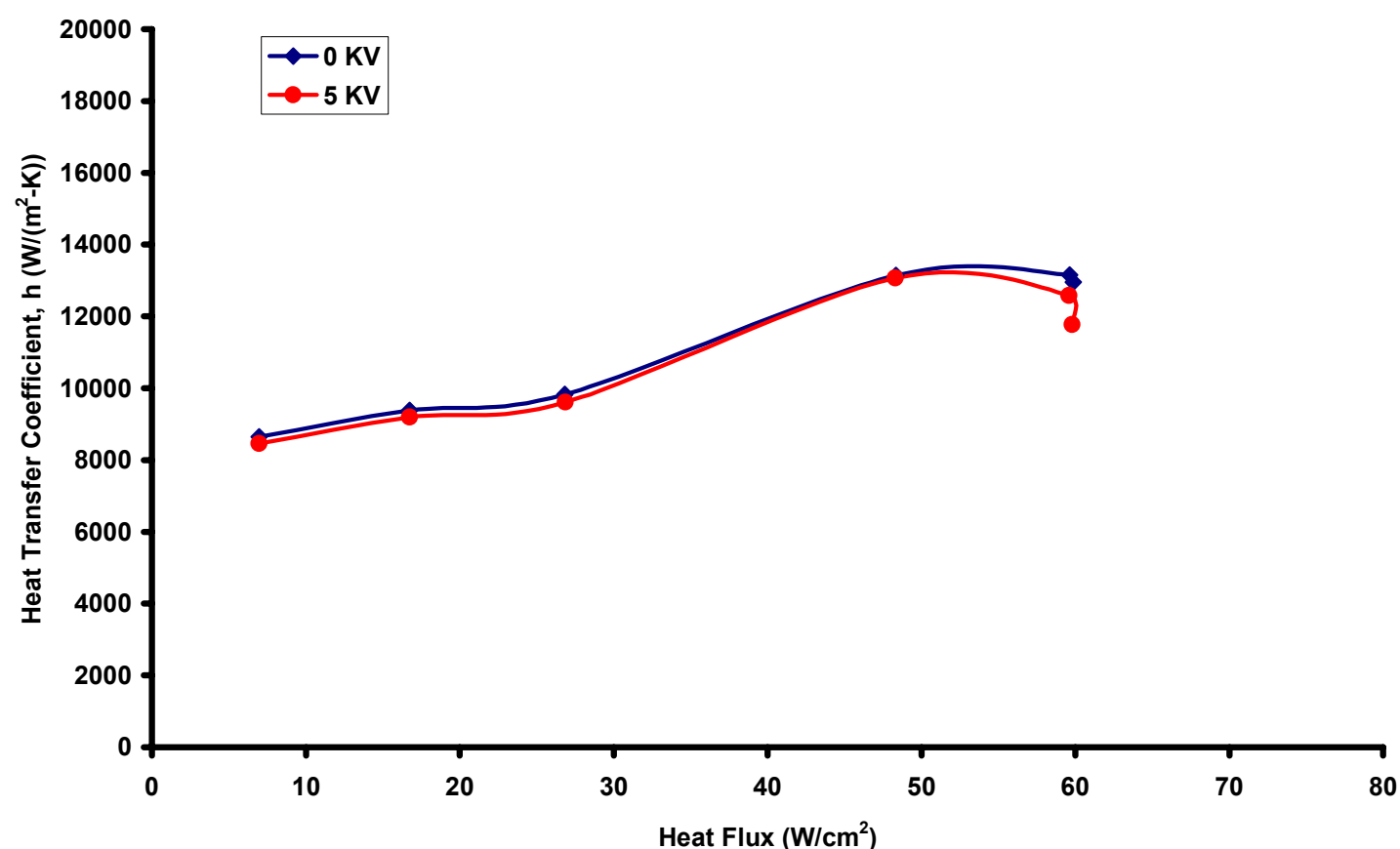

Figure 5.12: Heat Transfer Coefficient versus Heat Flux for FC-72, 9.3 GPH, and Electrode 1 Data Run with Effects 


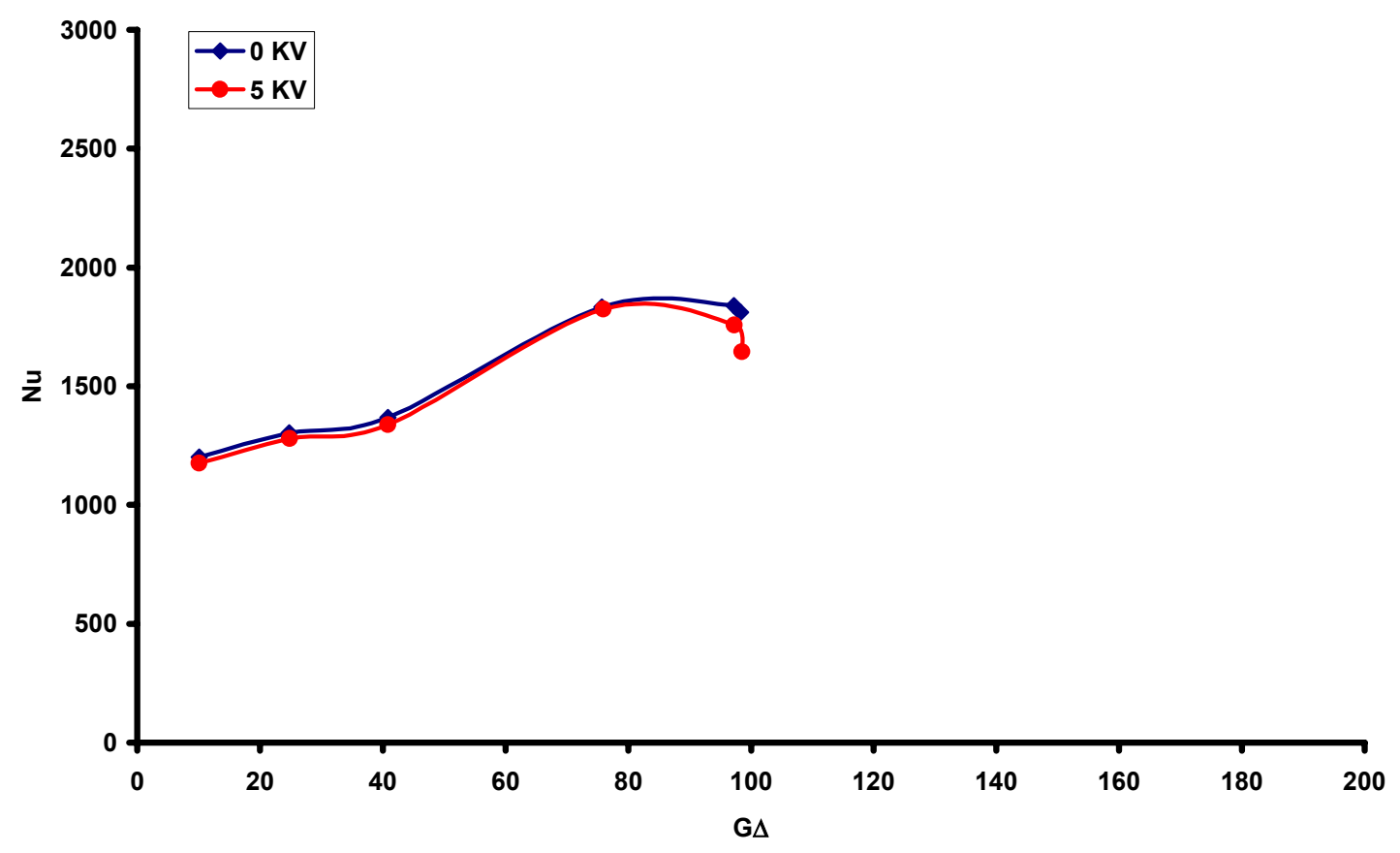

Figure 5.13: Nusselt number versus Non-dimensional Heat Flux for FC-72, 9.3 GPH, and Electrode 1 Data Run with Effects

Examining Figure 5.11 it is observed that the heat transfer coefficient increases with heat flux. The largest increases occur at the higher heat flux levels in the two-phase region closer to the $\mathrm{CHF}$. Looking a little closer it can be seen that the presence of electrode voltage decreased the heat transfer coefficient slightly at the highest heat flux level. Figure 5.12 shows that the heat transfer is also shifted to the right for the highest two levels of the nondimensional heat flux. Figure 5.13 also shows a negative effect on Nusselt number due to the presence of the electrode voltage at the highest heat flux (G $\Delta$ ) values.

Shortly after this test run was completed the heater and pedestal failed. A similar data test run was conducted on the following day, focusing on the regions that showed the greatest change in interface temperature. The run verified that a change in interface temperature was indeed taking place, and similar values were observed. During the second test, at a heater power of 90 W the heater interface temperature before the electrode was turned on was $71.6^{\circ} \mathrm{C}$, the interface 
temperature increased to $76.4{ }^{\circ} \mathrm{C}$, with the electrode voltage, and returned to $72.5{ }^{\circ} \mathrm{C}$ when the electrode was turned off again.

During this second test run examining the areas of greatest change in temperature for this electrode configuration a small crack was noticed that had formed on the surface of the TFR heater and as a result a small spot on the heater was observed to be glowing red (the resulting damage to the TFR heater can be seen in Figure 5.1a. Once this happened the resistance across the pedestal was altered and the highest heater power levels could no longer be achieved. Therefore, the pedestal had to be repaired by installing a new TFR heater. Figure 5.14 represents the resistance across the pedestal as a function of time for this data run. This figure shows that there was an increase in the resistance after the pedestal was put through CHF. Section 5.8 gives an explanation of how the pedestal might have been destroyed even though the interface temperature alarm was not tripped when critical temperatures were approached.

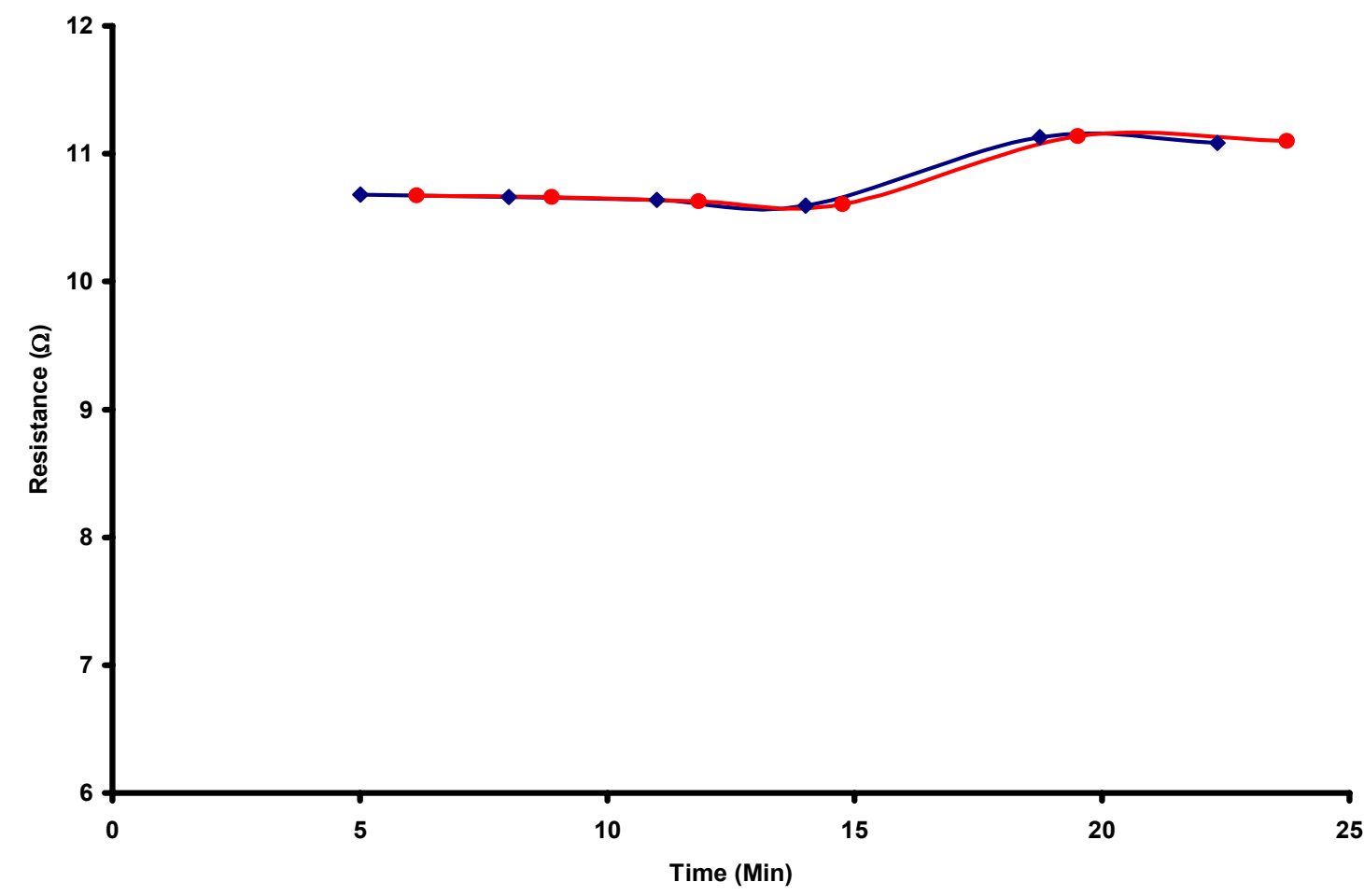

Figure 5.14: Resistance versus Time for FC-72, 9.3 GPH, and Electrode 1 Data Run with Effects 


\section{Section 5.4.2: $\quad$ Repaired TFR Pedestal with Electrode 1 and FC-72}

Unfortunately, after the original pedestal was repaired results of the same magnitude as those presented in the previous section were no longer obtainable. The test presented in the previous section was repeated with the only change being the pedestal that was used. Figure 5.15 represents the time history of the present data run. The test procedure was changed in order to make data reduction take less time. For the first portion of the test the heater power was stepped up from $0 \mathrm{~W}$ to $120 \mathrm{~W}$. The increase in the maximum applied heater power level is because the repaired pedestal performed differently than before it was repaired. However no significant changes in interface temperature due to the applied electrode voltage were observed for this configuration.

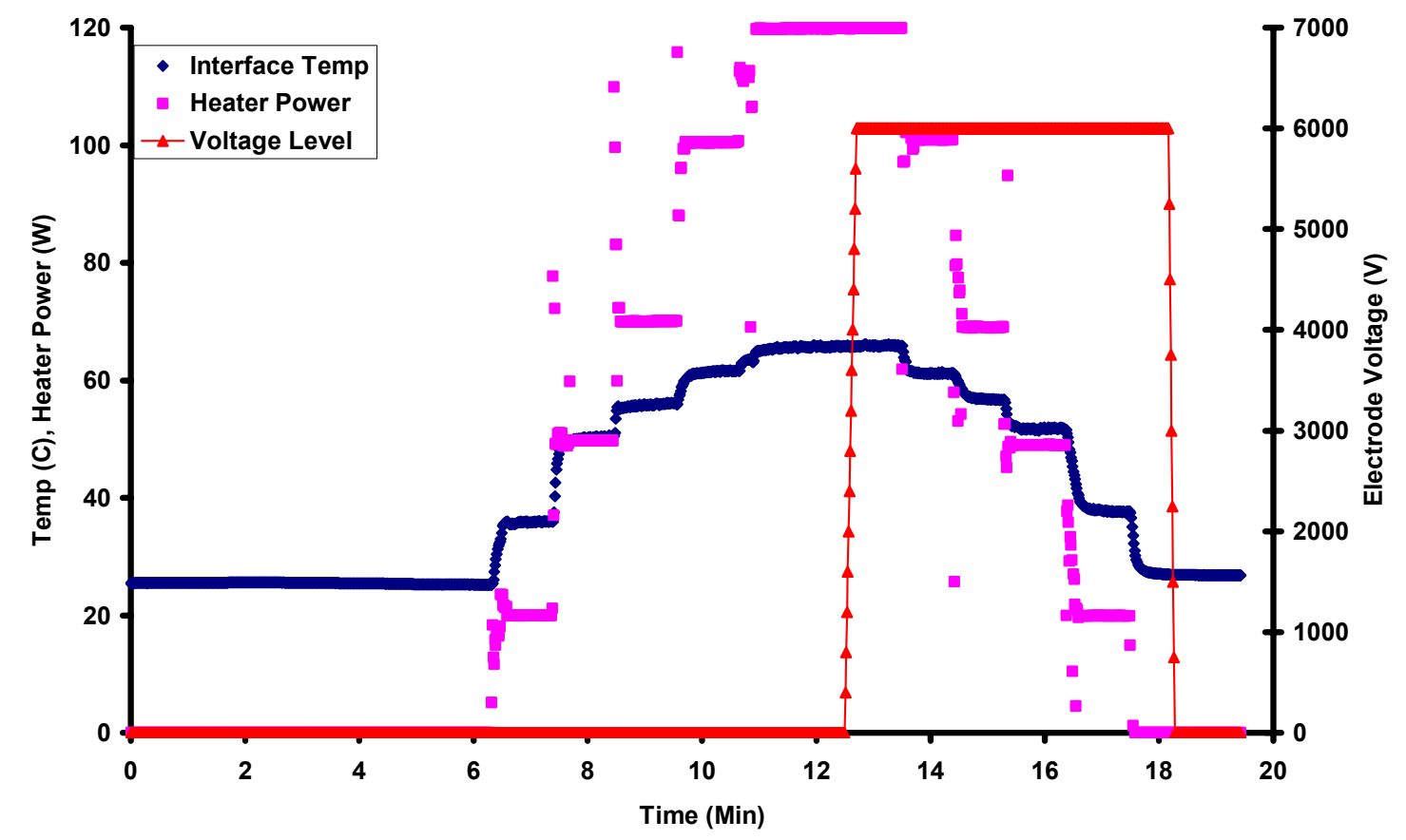

Figure 5.15: Time History for FC-72 Data Run using Repaired TFR Heater Pedestal with Electrode 1 at $9.3 \mathrm{GPH}$

Figure 5.16 - Figure 5.19 show little to no effect between the data taken with and without the electrode voltage and that taken with the electrode level increased to $6 \mathrm{kV}$. 
Figure 5.20 represents the monitored resistance of the pedestal heater versus time. It is possible to see that the resistance level during a normal data run without CHF does not change significantly. In hopes of seeing a greater effect it was decided to test the second electrode design to see if the interaction of the spray with the electrode was causing the lack of effects that were being observed.

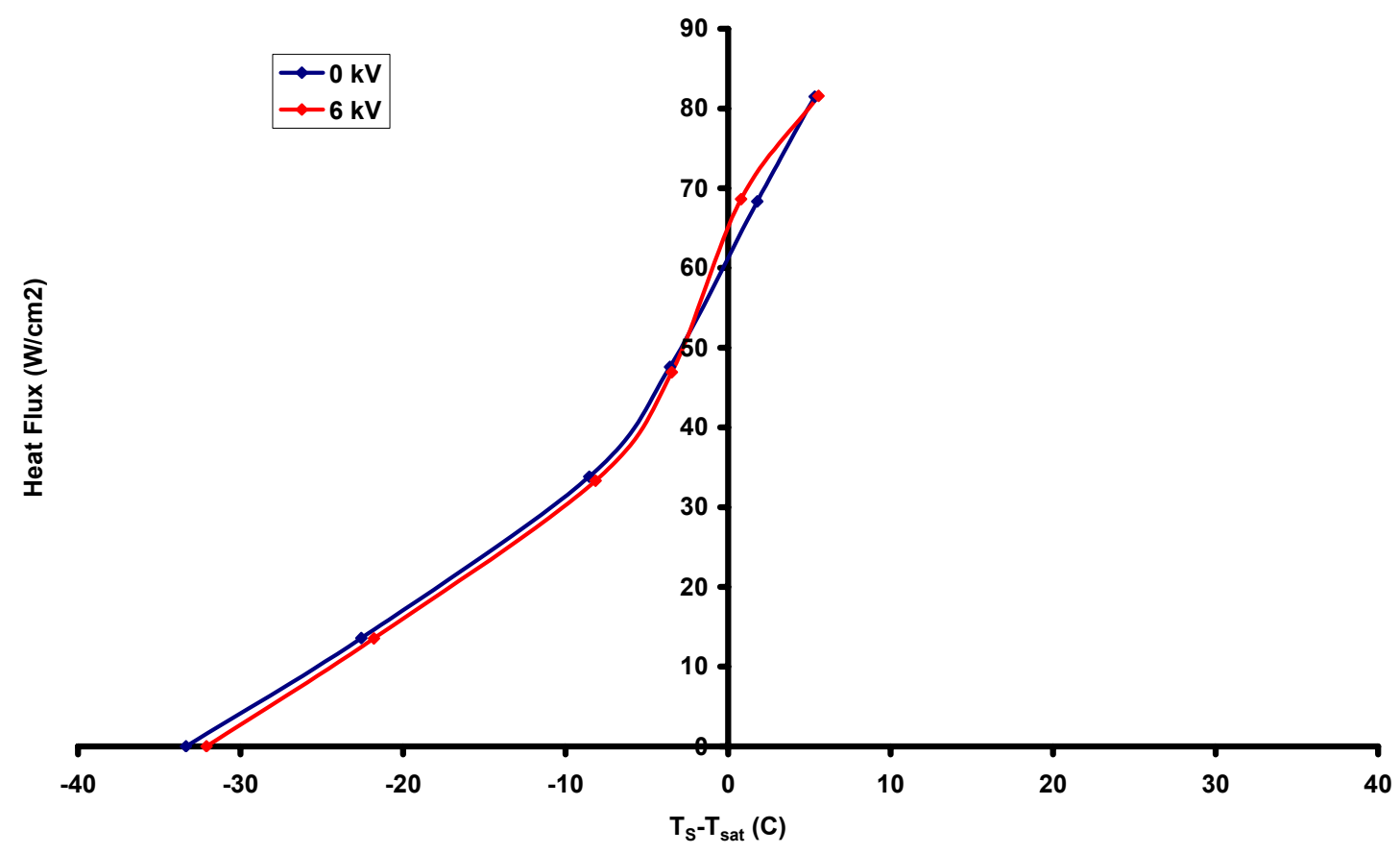

Figure 5.16: Heat Flux plot for FC-72 Data Run using Repaired TFR Heater Pedestal with Electrode 1 at $9.3 \mathrm{GPH}$ 


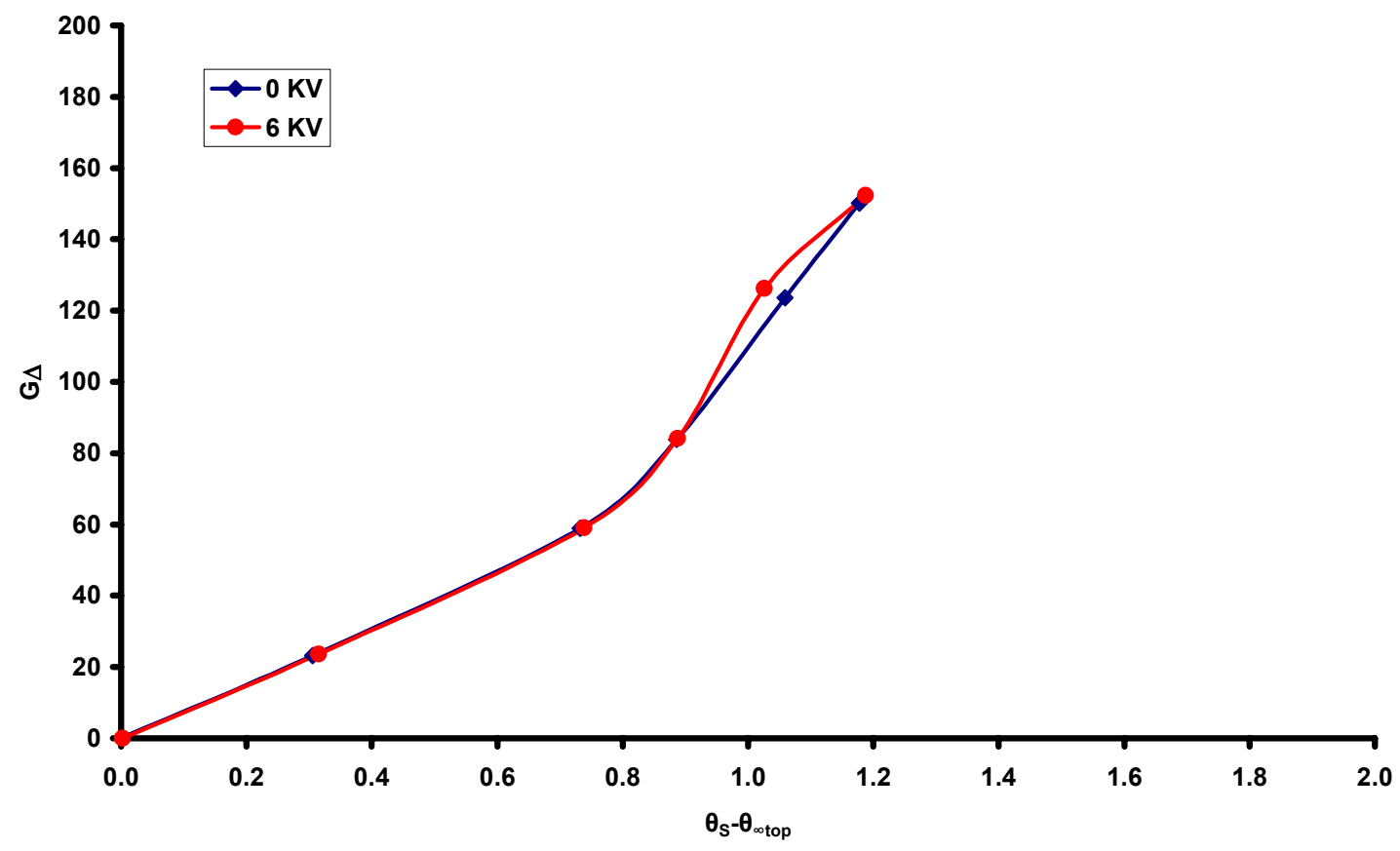

Figure 5.17: Non-dimensional Heat Flux versus Temperature Difference for FC-72 Data Run using Repaired TFR Heater Pedestal with Electrode 1 at $9.3 \mathrm{GPH}$

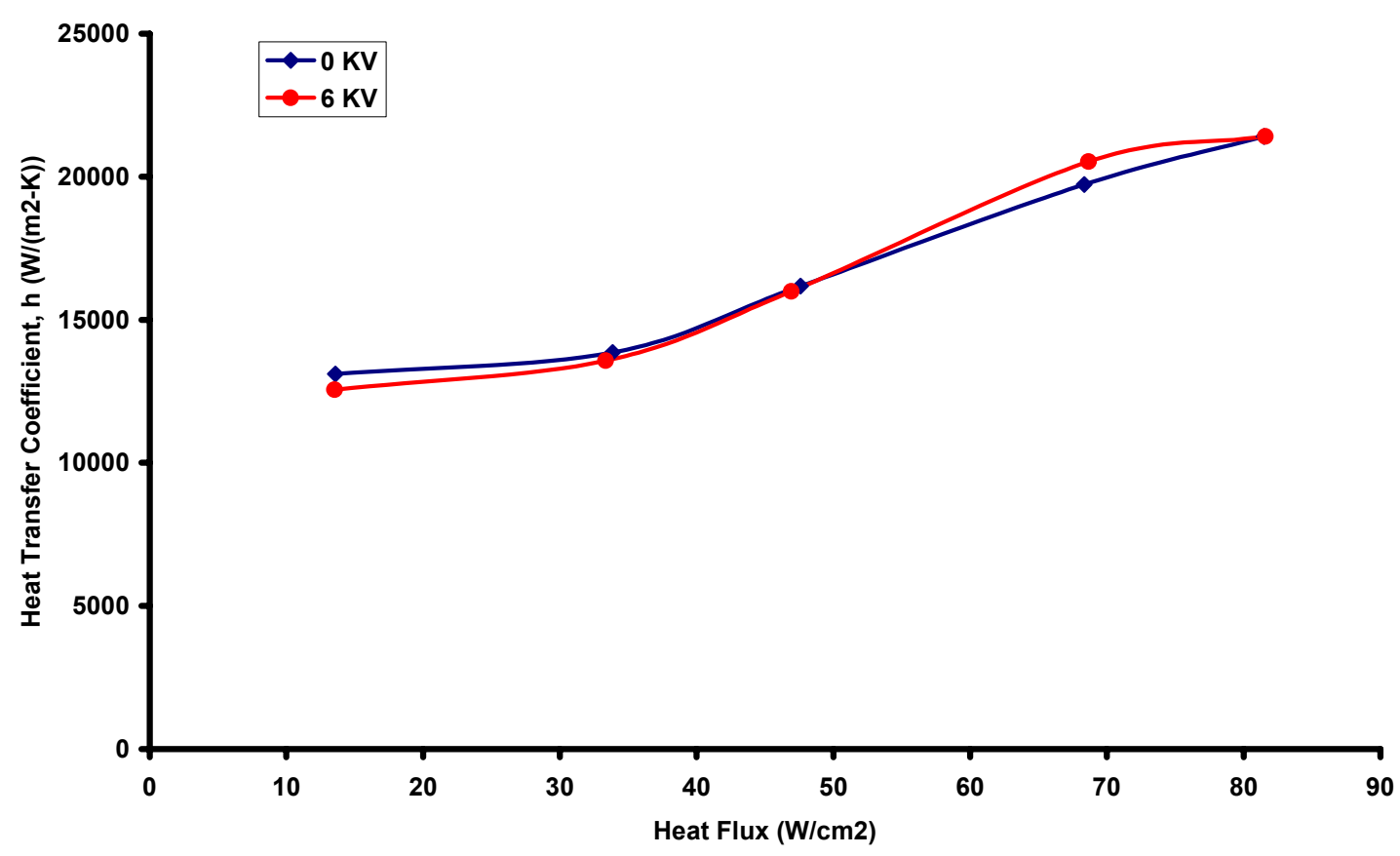

Figure 5.18: Heat Transfer Coefficient plot for FC-72 Data Run using Repaired TFR Heater Pedestal with Electrode 1 at $9.3 \mathrm{GPH}$ 


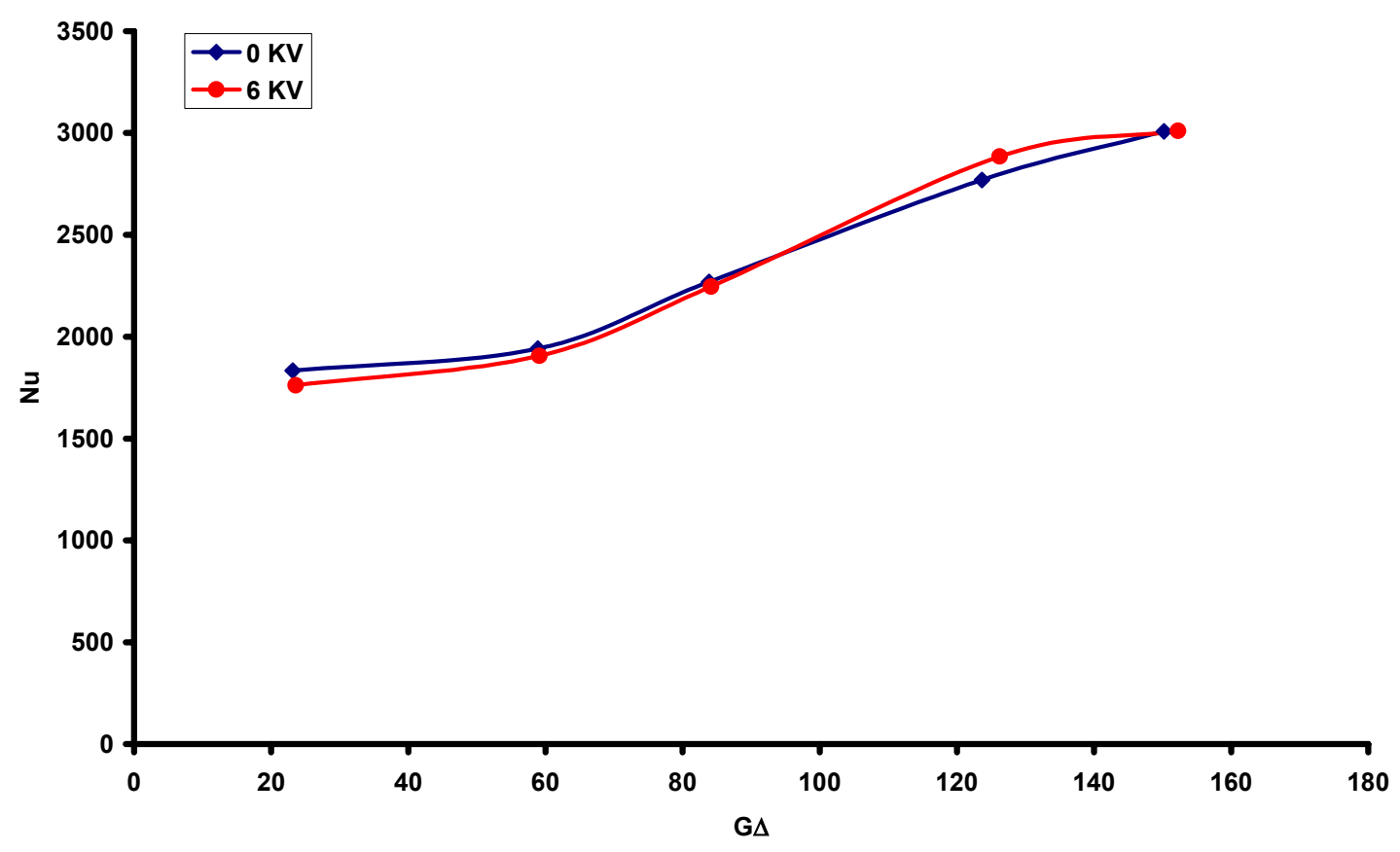

Figure 5.19: Nusselt number versus Non-dimensional Heat Flux for FC-72 Data Run using Repaired TFR Heater Pedestal with Electrode 1 at 9.3 GPH

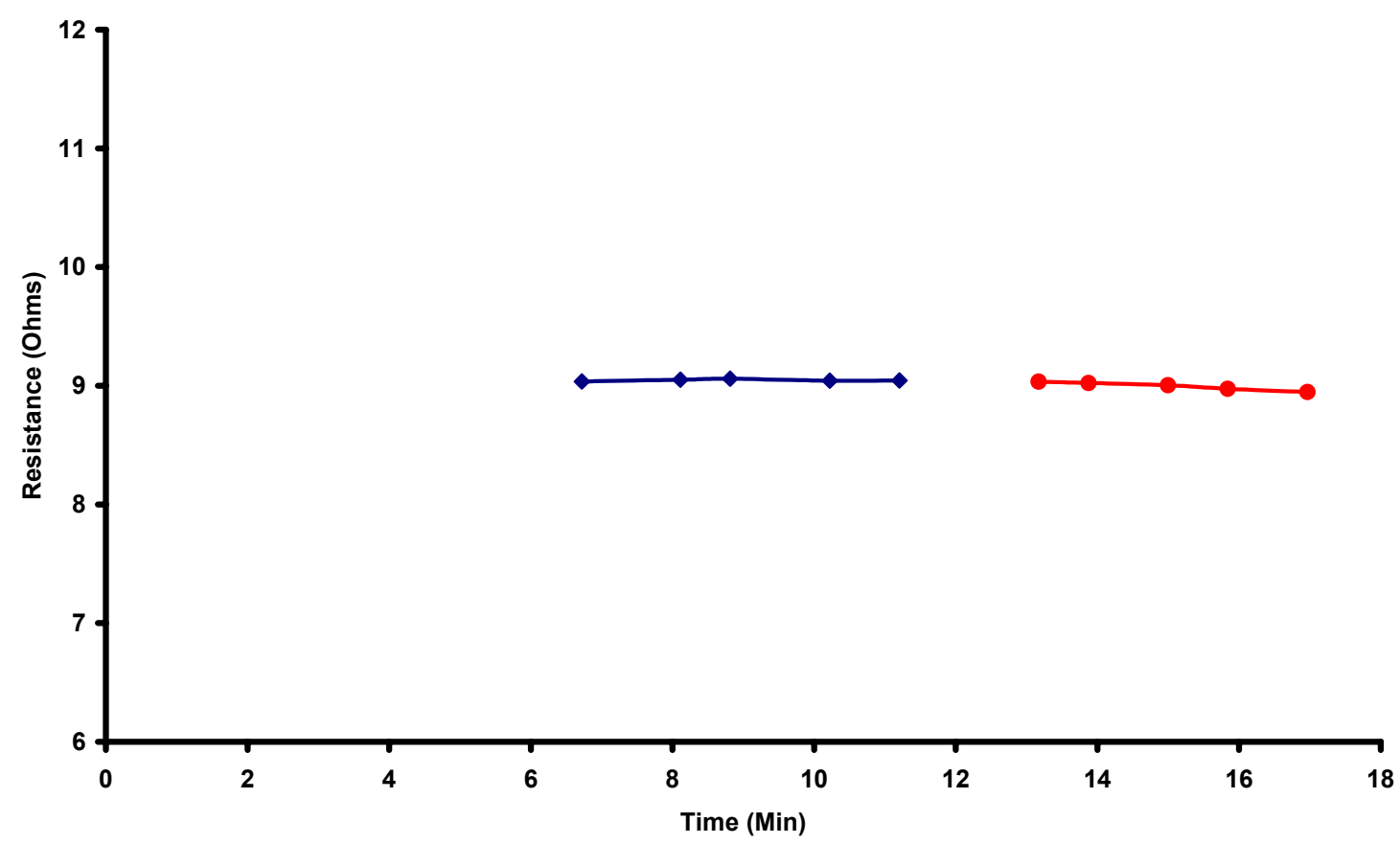

Figure 5.20: Resistance versus Time for FC-72 Data Run using Repaired TFR Heater Pedestal with Electrode 1 at $9.3 \mathrm{GPH}$ 


\section{Section 5.4.3: $\quad$ Repaired TFR Pedestal with Electrode 2 and FC-72}

The differences between electrode 1 and electrode 2 have been described in Chapter 3. The main difference between electrodes is the size of the central spray hole. However, changing to the second electrode configuration yielded similar results to those with the first electrode design, as shown by the performance comparison in Figure 5.21 Figure 5.24, that is, the electrode voltage has very little effect on the heat transfer performance.

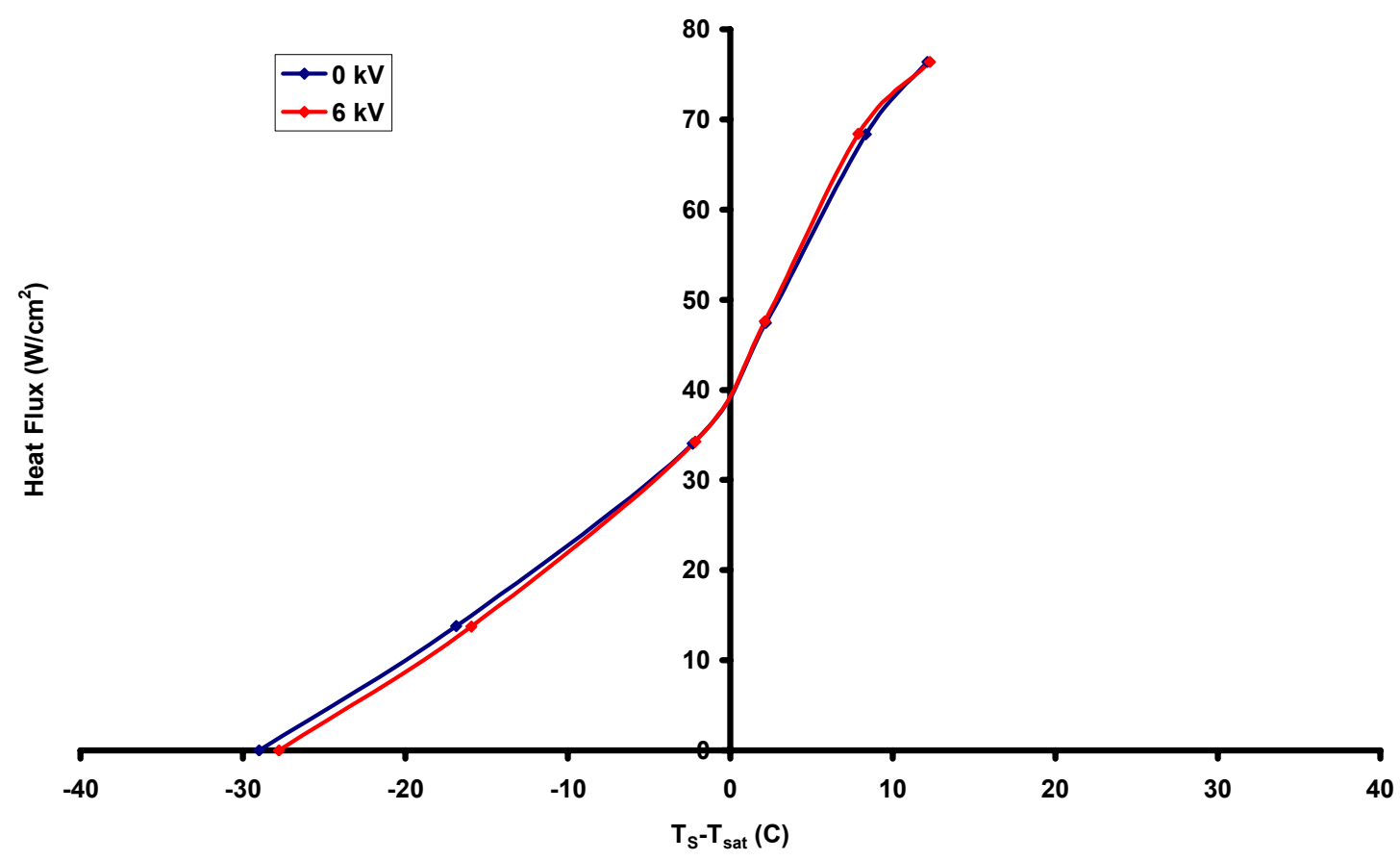

Figure 5.21: Heat Flux plot for FC-72 Data Run using Repaired TFR Heater Pedestal with Electrode 2 at $9.3 \mathrm{GPH}$ 


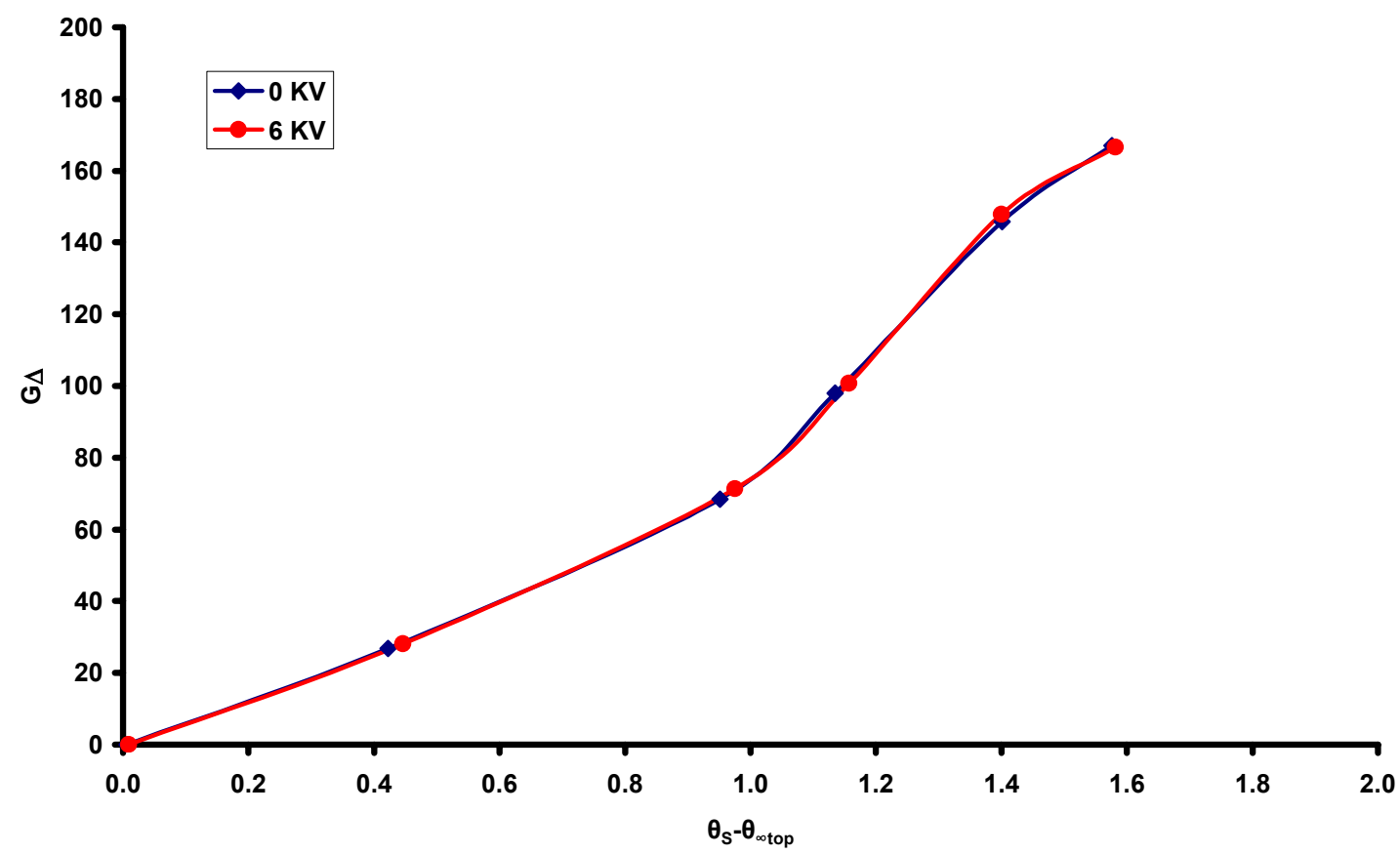

Figure 5.22: Non-dimensional Heat Flux versus Temperature Difference for FC-72 Data Run using Repaired TFR Heater Pedestal with Electrode 2 at $9.3 \mathrm{GPH}$

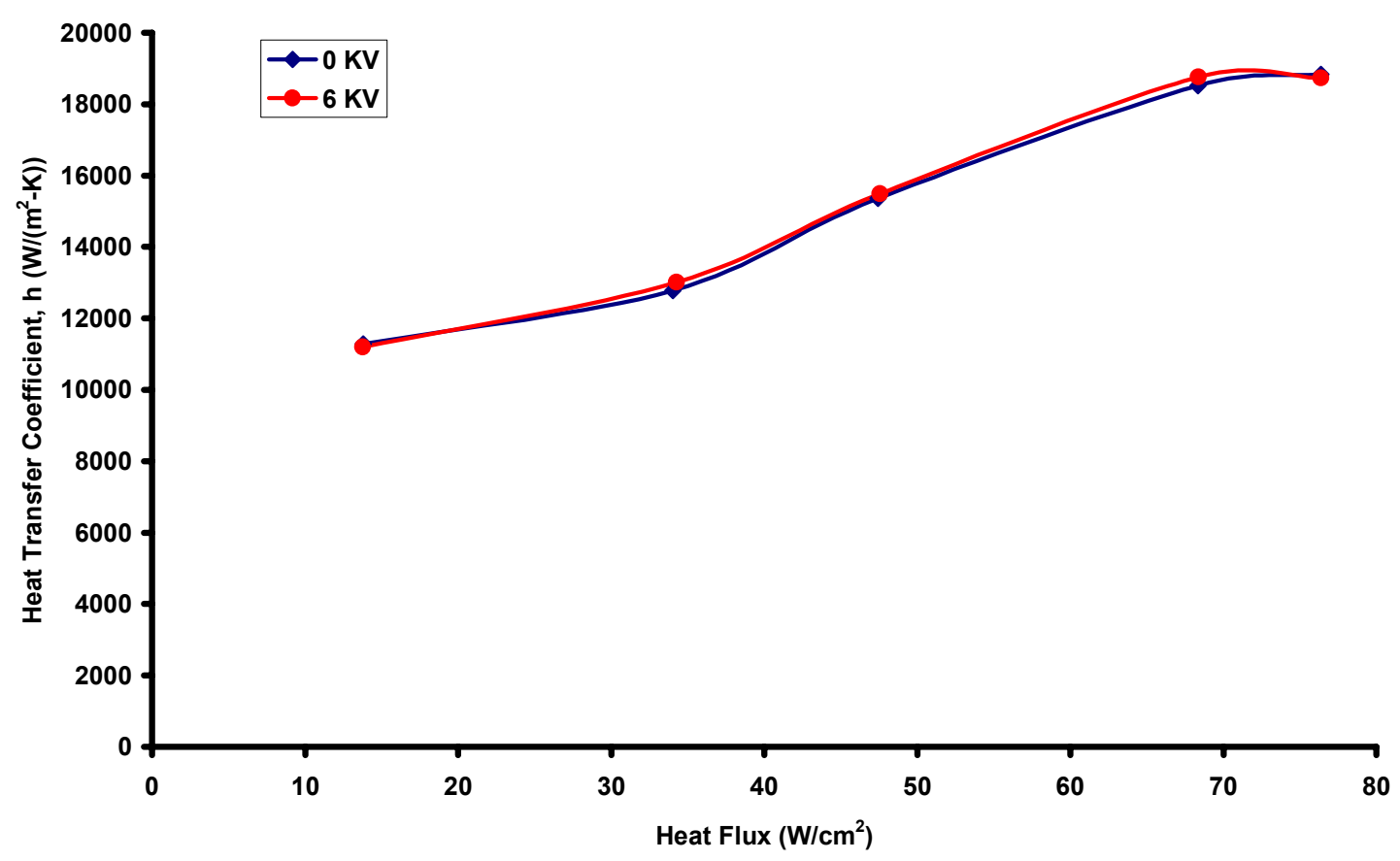

Figure 5.23: Heat Transfer Coefficient plot for FC-72 Data Run using Repaired TFR Heater Pedestal with Electrode 2 at $9.3 \mathrm{GPH}$ 


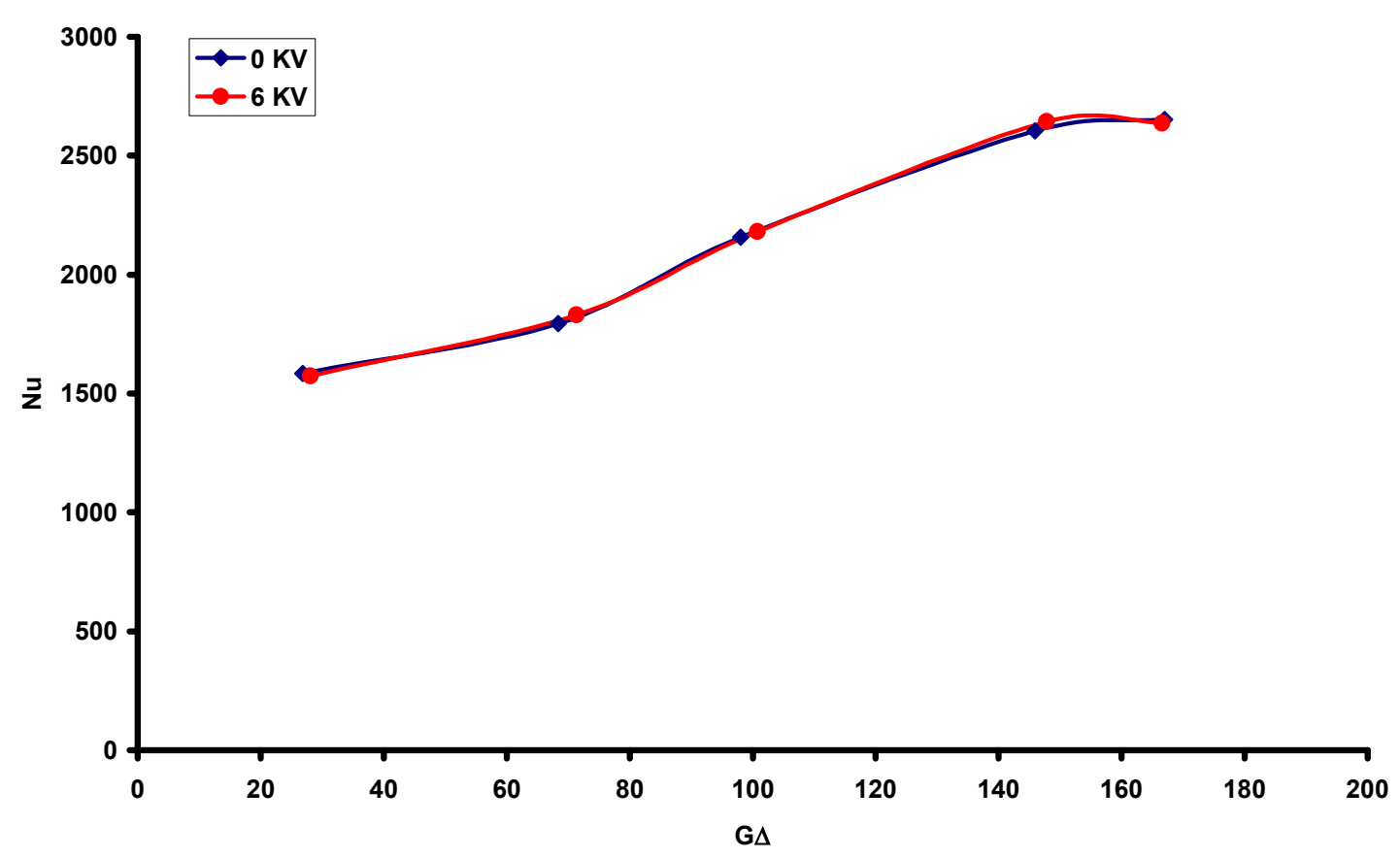

Figure 5.24: Nusselt number versus Non-dimensional Heat Flux for FC-72 Data Run using Repaired TFR Heater Pedestal with Electrode 2 at 9.3 GPH

\section{Section 5.5: $\quad$ Changing Fluids}

Since the results obtained after the pedestal was repaired did not show the same results as those taken earlier, adjustments had to be made. It was thought that changing the working fluid would cause the effects due to inductive spray charging using the Coulomb force to be stronger, because of the lower electrical resistivity of the HFE-7000. Both FC-72 and HFE-7000 have similar heat transfer characteristics, however the electrical characteristics for HFE-7000 are much better for inductive charging. According to Law (1978) the electrical resistivity of the working fluid greatly influences the amount of charge imparted onto the spray droplets. In this case the change from FC72 to HFE-7000 should enable a significant increase in the magnitude of the Coulomb force. Table 5.1 shows how parameters for these two working fluids compare at room 
temperature and standard atmospheric pressure. Note the decrease in electrical resistivity by seven orders of magnitude. This should make it easier to charge the HFE-7000 inductively.

Table 5.1: $\quad$ FC-72 and HFE-7000 Fluid Properties at $25^{\circ} \mathrm{C}$ unless otherwise stated

\begin{tabular}{|c|c|c|}
\hline & FC-72 & HFE-7000 \\
\hline Liquid Density & $1680 \mathrm{~kg} / \mathrm{m}^{3}$ & $1400 \mathrm{~kg} / \mathrm{m}^{3}$ \\
\hline Thermal Conductivity & $0.075 \mathrm{~W} / \mathrm{m}-\mathrm{K}$ & $0.057 \mathrm{~W} / \mathrm{m}-\mathrm{K}$ \\
\hline Kinematic Viscosity & $0.38 \mathrm{cSt}$ & $0.32 \mathrm{cSt}$ \\
\hline Boiling Point @ 1atm & $56^{\circ} \mathrm{C}\left(133^{\circ} \mathrm{F}\right)$ & $34^{\circ} \mathrm{C}\left(93^{\circ} \mathrm{F}\right)$ \\
\hline Surface Tension & $10 \mathrm{dynes} / \mathrm{cm}$ & $12.4 \mathrm{dynes} / \mathrm{cm}$ \\
\hline Molecular Weight & $338 \mathrm{~g} / \mathrm{mol}$ & $200 \mathrm{~g} / \mathrm{mol}$ \\
\hline Dielectric Strength & $38 \mathrm{kV}$ & $40 \mathrm{kV}$ \\
\hline Dielectric Constant & 1.75 & 7.4 \\
\hline Electrical Resistivity & $10^{15} \mathrm{ohm}-\mathrm{cm}$ & $10^{8} \mathrm{ohm}-\mathrm{cm}$ \\
\hline
\end{tabular}

In order to change from FC-72 to HFE-7000 the system had to be purged of FC72. To accomplish this, the drain valve just after the nozzle pump in the working fluid line was opened and most of the fluid was drained from the system. Once the fluid was removed, the working fluid loop was broken into sections. Compressed air was run through the sections forcing the remaining FC-72 out of the system. The filters were changed to alleviate the possibility of contaminants from entering the system. The used FC-72 was collected so that it could be used again.

Once the flow loop was purged all components were connected back together and filled with HFE-7000. Complications arose from the change of fluid. Even though HFE7000 is a less viscous fluid, it was pumped at a higher pressure, and thus the maximum flow rate of HFE-700 that could be achieved was $8.5 \pm 0.5 \mathrm{GPH}$. Additionally, the maximum interface temperature before the onset of CHF would be lower. 


\section{Section 5.6: HFE-7000 Data Results}

Once the working fluid was changed from FC-72 to HFE-7000 the test runs using the repaired pedestal and electrodes one and two were repeated. The system ran a little differently after the switch in working fluid was made, because of the difference in material properties listed above. Using the HFE-7000 most runs showed a slight increase in the heat transfer characteristics of up to $6 \%$.

\section{Section 5.6.1: $\quad$ Repaired TFR Pedestal with Electrode 1 and HFE- 7000}

The next set of tests used the repaired TFR pedestal, electrode 1 and HFE-7000. Because of the increased running pressure in the working fluid flow loop the maximum flow rate that was able to be reached was $8.02 \pm 0.5 \mathrm{GPH}$ of HFE-7000. One of the limitations causing this lower flow rate was the limited range of the pressure gauge installed to monitor the flow loop pressure directly after the nozzle pump.

Figure 5.25 graphically represents the increase in heat flux as the temperature difference increases. Figure 5.26 is the non-dimensional form of the same figure. Looking closer at Figure 5.25 and Figure 5.26 it can be seen that the case with $5 \mathrm{kV}$ electrode voltage there is a slight increase in the heat transferred from the heater surface. The effect gets larger as the amount of heat flux increases and the flow transitions into two-phase heat transfer, but then appears to become smaller again as CHF is approached. This is observed by a shift in the $5 \mathrm{kV}$ curve upwards and to the left. For this particular data run a $4 \%$ increase in the heat transfer coefficient from the heater surface is observable during the maximum shift in heat flux at a given temperature difference. 
Figure 5.27 represents the heat transfer coefficient as a function of heat flux. Figure 5.28 is the non-dimensional form of the same figure. From Figure 5.27 and Figure 5.28 both the heat transfer coefficient and the Nusselt number show an effect due to the transition from single to two-phase heat transfer. The trend in both of these plots shows an increase in the heat transfer coefficient due to application of the high voltage to the electrode with respect to an increase in heat flux.

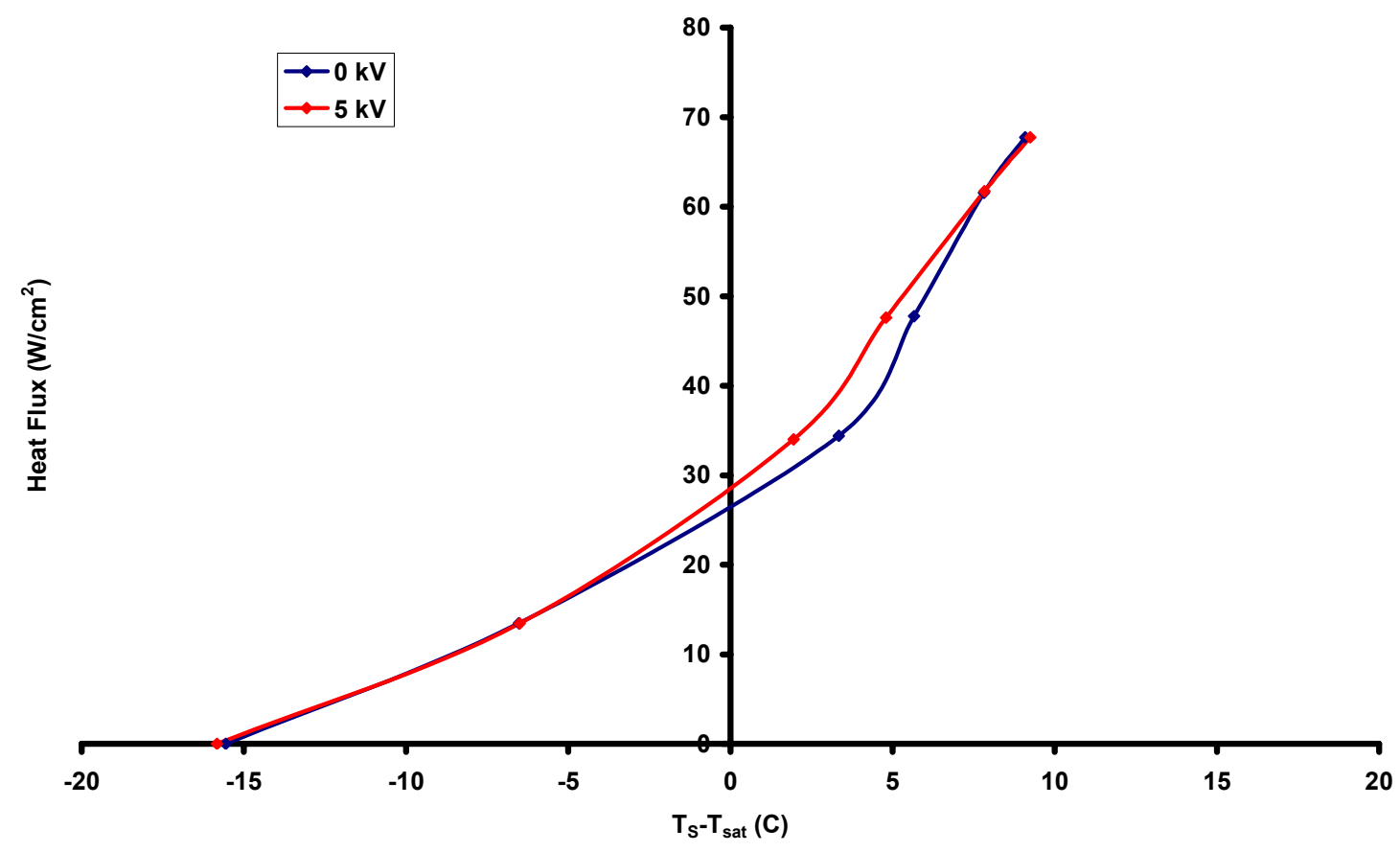

Figure 5.25: Heat Flux plot for HFE-7000 Data Run using Repaired TFR Heater Pedestal with Electrode 1 at $8.0 \mathrm{GPH}$ 


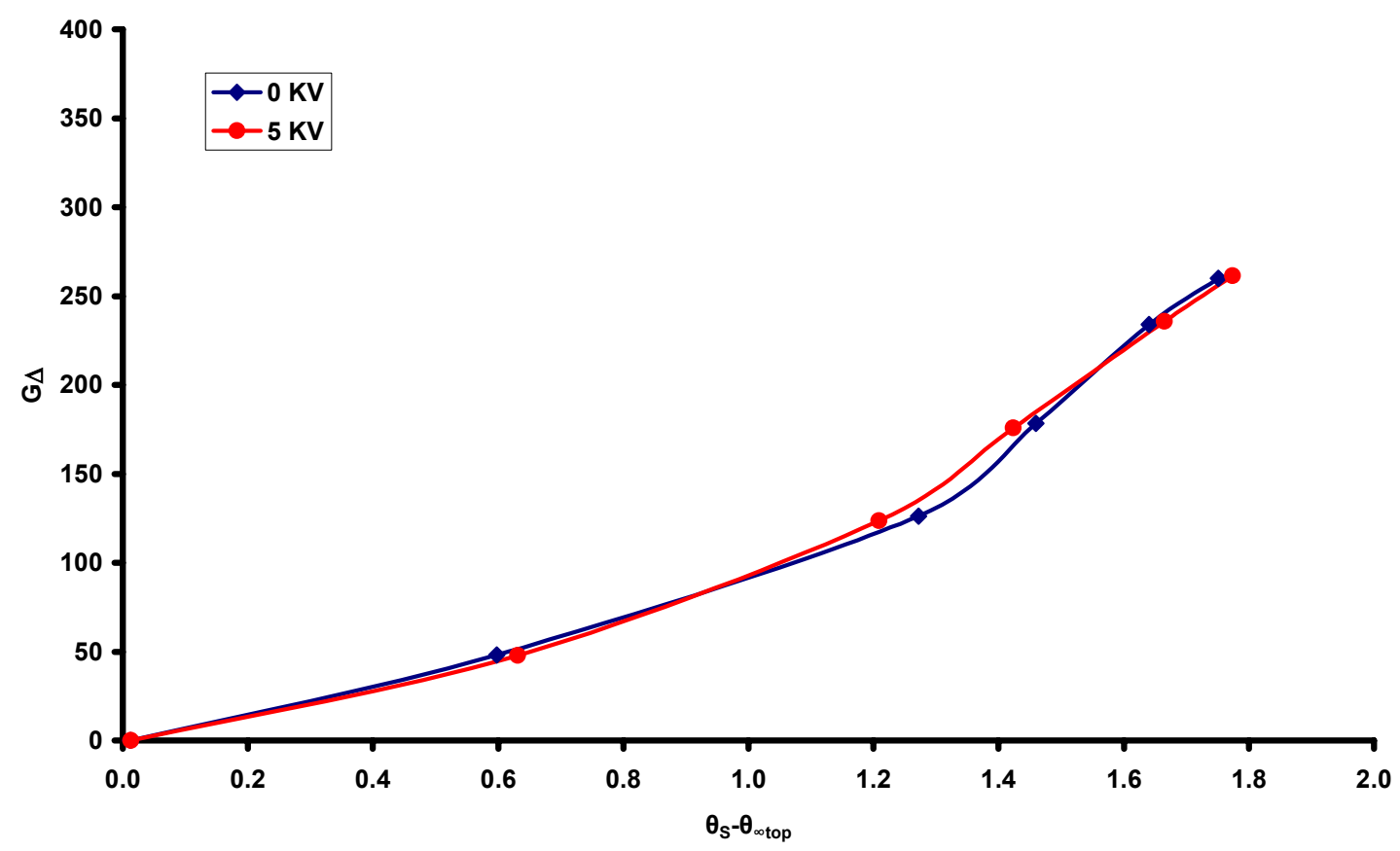

Figure 5.26: Non-dimensional Heat Flux versus Temperature Difference Heat Flux plot for HFE-7000 Data Run using Repaired TFR Heater Pedestal with Electrode 1 at $8.0 \mathrm{GPH}$

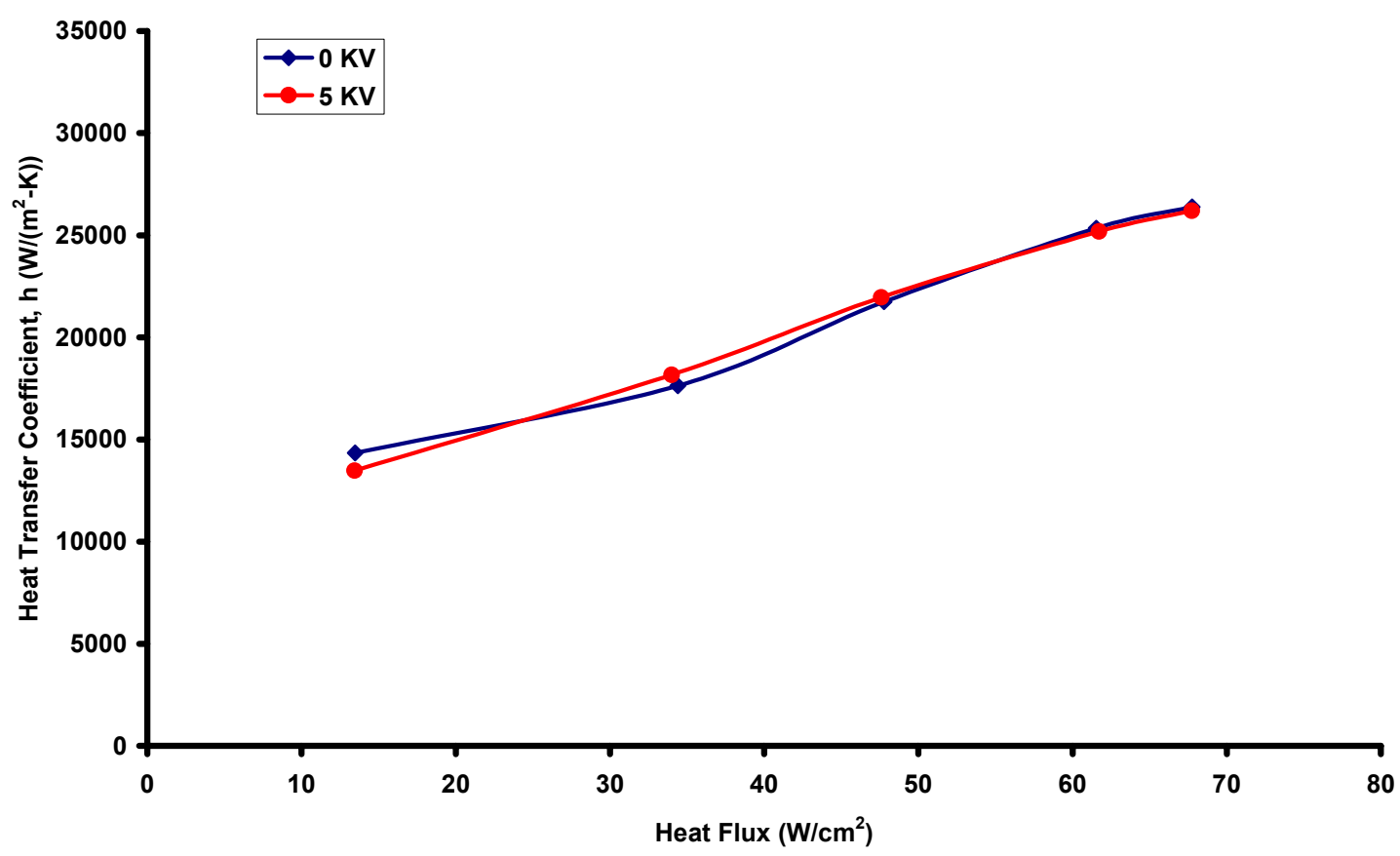

Figure 5.27: Heat Transfer Coefficient plot Heat Flux plot for HFE-7000 Data Run using Repaired TFR Heater Pedestal with Electrode 1 at 8.0 GPH 


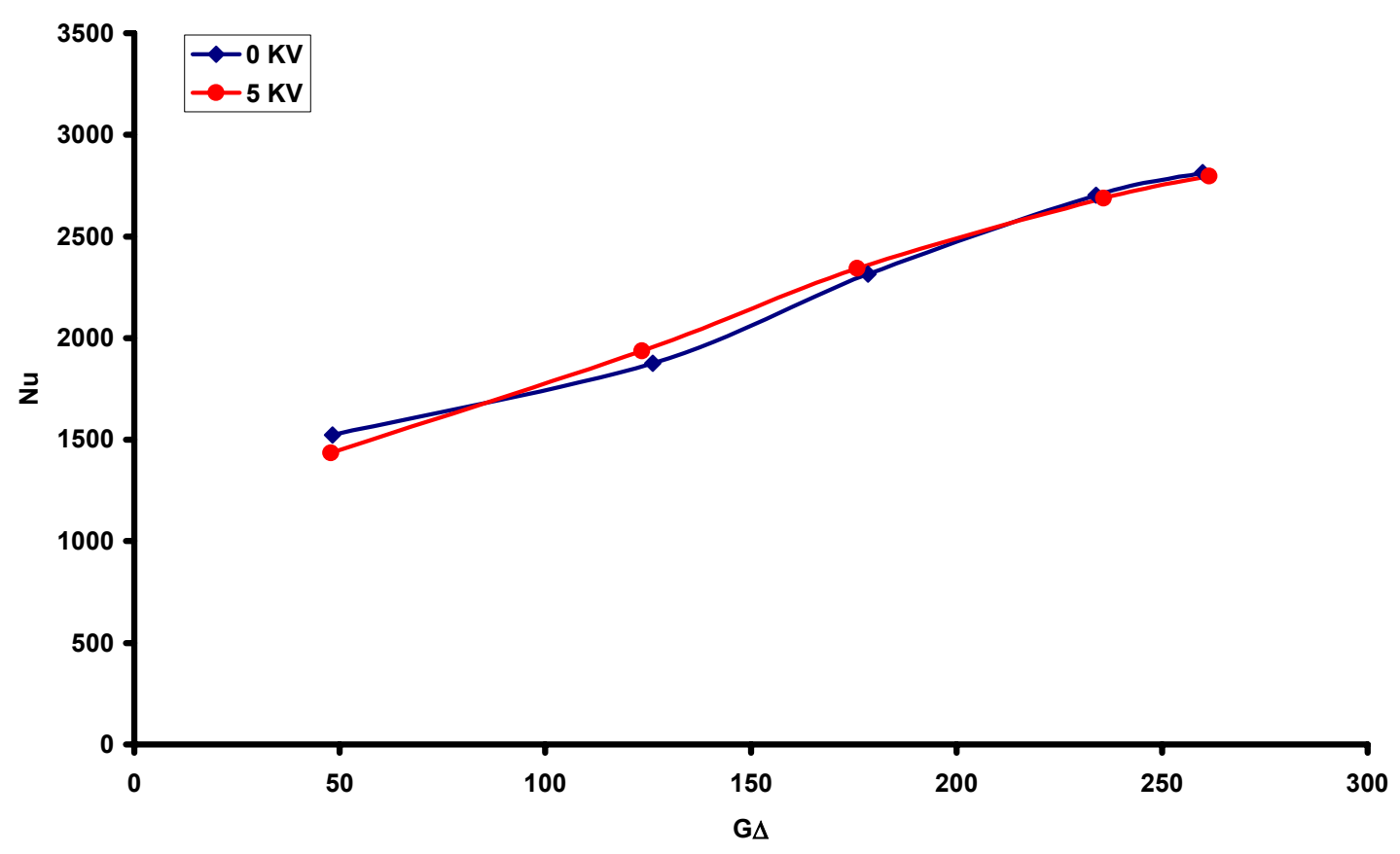

Figure 5.28: Nusselt number versus Non-dimensional Heat Flux Heat Flux plot for HFE-7000 Data Run using Repaired TFR Heater Pedestal with Electrode 1 at $8.0 \mathrm{GPH}$

\section{Section 5.6.2: $\quad$ Repaired TFR Pedestal with Electrode 2 and HFE- 7000}

The next set of tests differs from previous section only by the geometry of the electrode used. For this test run the repaired TFR pedestal, electrode 2 and HFE-7000 were used. The flow rate of the working fluid was again set to $8 \pm 0.5 \mathrm{GPH}$ of $\mathrm{HFE}-$ 7000. All results for this set of test runs Figure 5.29 - Figure 5.32 shows that there is little effect in the heat transferred when a voltage of $5 \mathrm{kV}$ is applied to the electrode. Concentrating on Figure 5.29 and Figure 5.30 the only consistent effect that is noticeable is the trend that occurs when the fluid shifts from single to two-phase heat transfer shown by an increase slope of the heat flux curve. 
Similar to the previous section Figure 5.31 represents the heat transfer coefficient as a function of heat flux, and Figure 5.32 is the non-dimensional form of the same figure. These figures correspond with the expected increase of heat transfer coefficient and the Nusselt number as the working fluid transitions from single to two-phase heat transfer. The trends showed in Figure 5.29 through Figure 5.32 show similar effects to those using electrode 1 , although the effect of the $5 \mathrm{kV}$ voltage is smaller for electrode 2 . Comparing both Figure 5.28 and Figure 5.32 the $5 \mathrm{kV}$ red curve is above the $0 \mathrm{kV}$ blue curve in the range $100 \leq \mathrm{G} \Delta \leq 170$ for both cases.

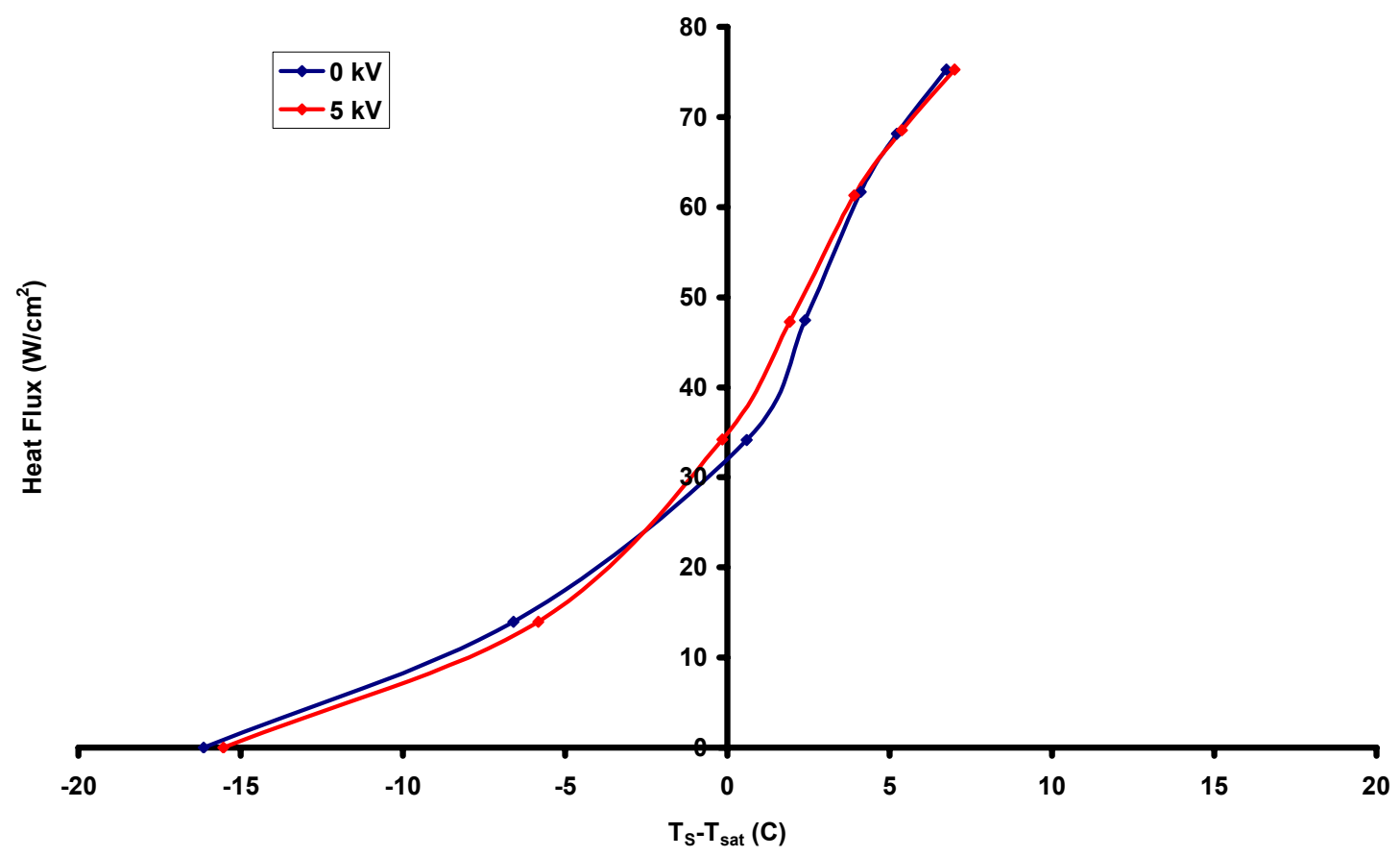

Figure 5.29: Heat Flux plot Heat Flux plot for HFE-7000 Data Run using Repaired TFR Heater Pedestal with Electrode 2 at $8.0 \mathrm{GPH}$ 


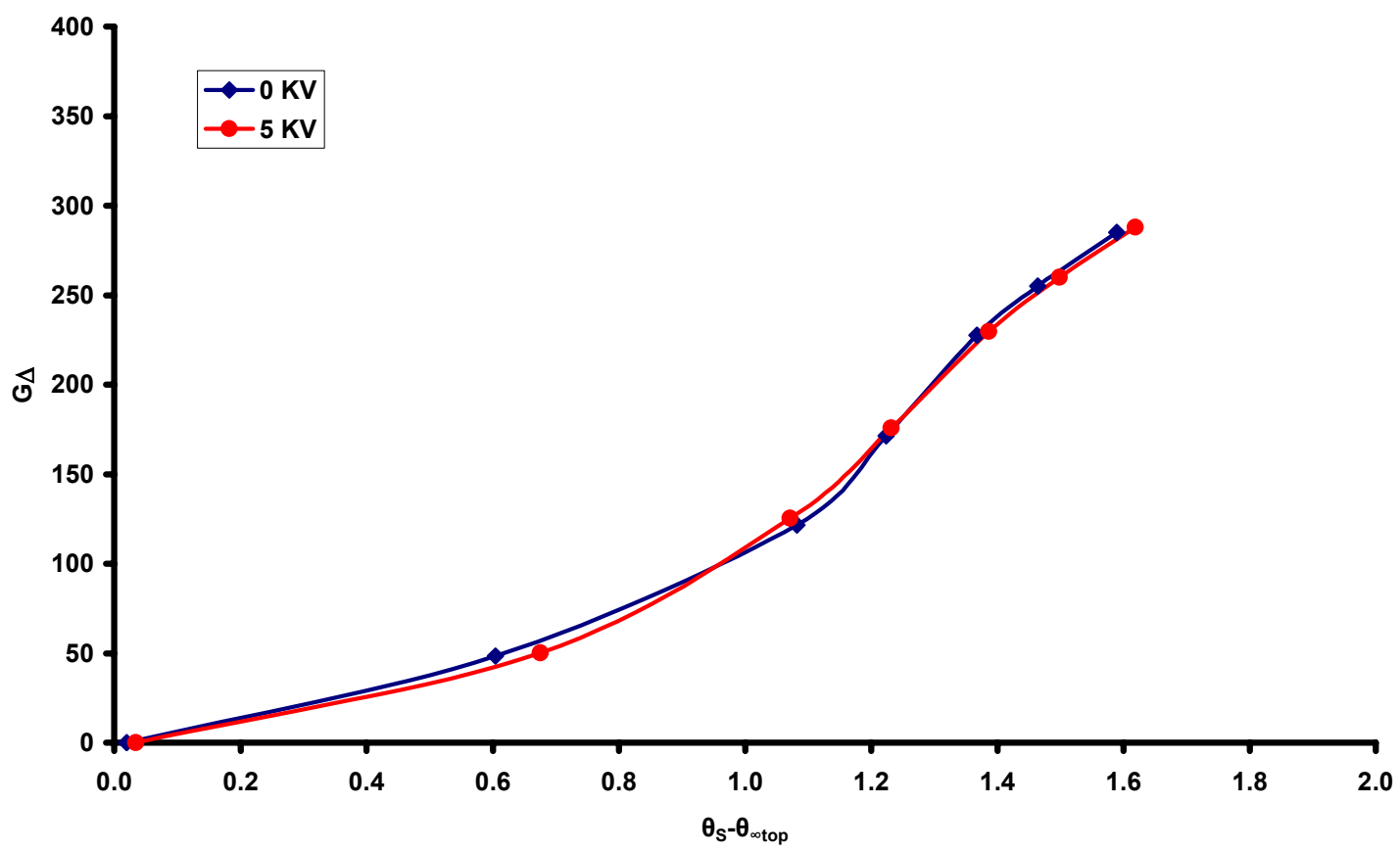

Figure 5.30: Non-dimensional Heat Flux versus Temperature Difference for HFE-7000 Data Run using Repaired TFR Heater Pedestal with Electrode 2 at $8.0 \mathrm{GPH}$

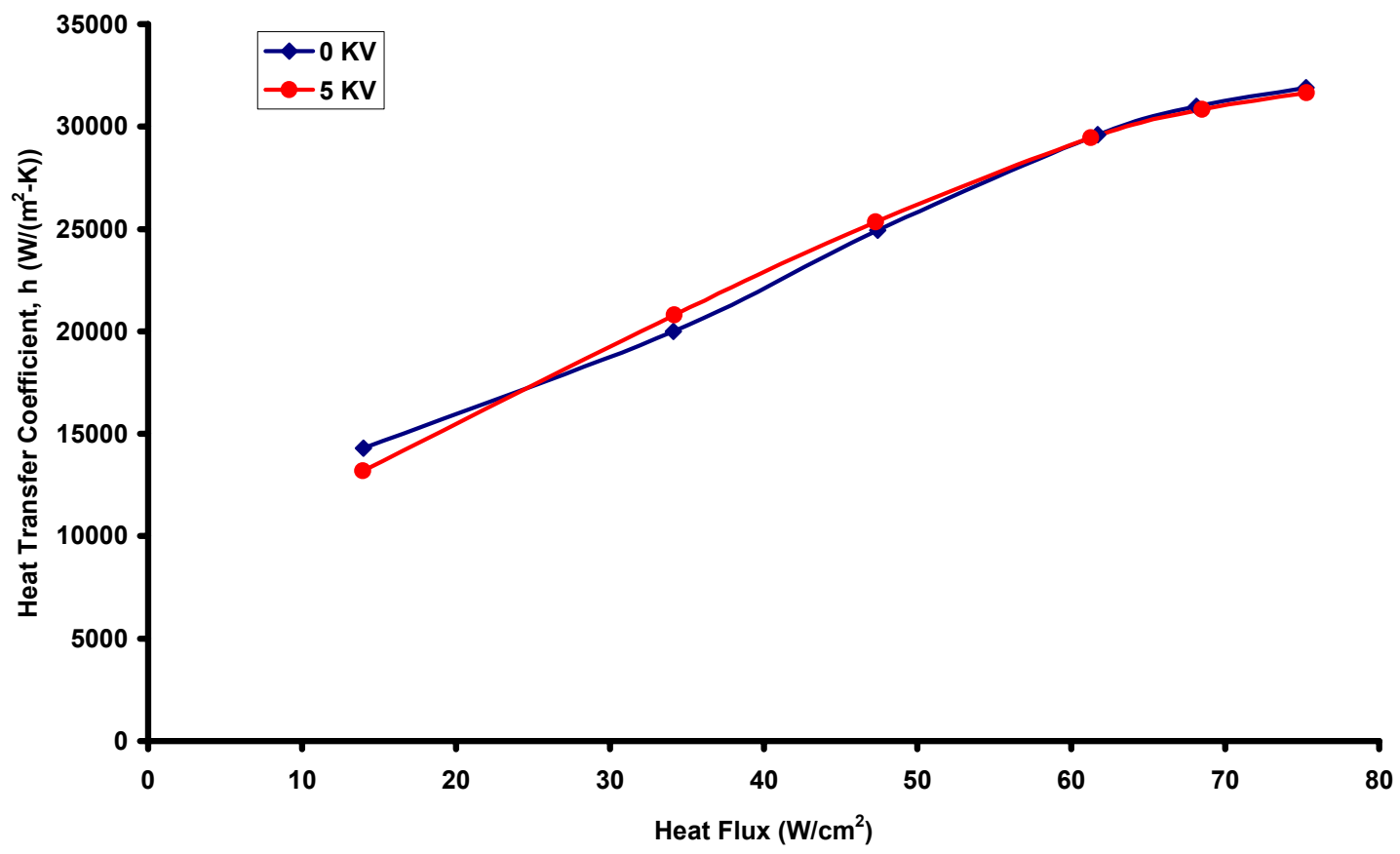

Figure 5.31: Heat Transfer Coefficient plot for HFE-7000 Data Run using Repaired TFR Heater Pedestal with Electrode 2 at 8.0 GPH 


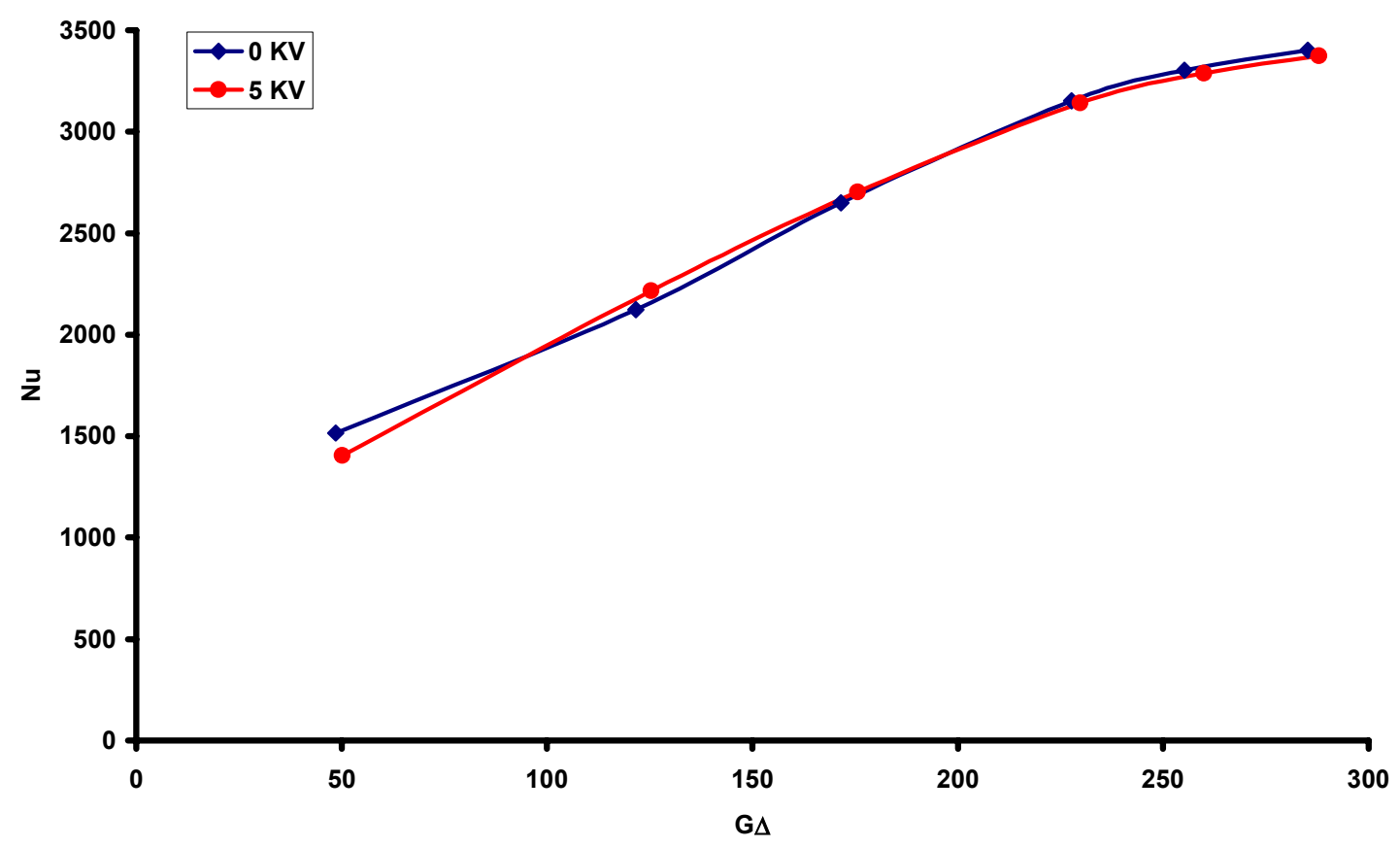

Figure 5.32: Nusselt number versus Non-dimensional Heat Flux for HFE-7000 Data Run using Repaired TFR Heater Pedestal with Electrode 2 at 8.0 GPH

\section{Section 5.7: $\quad$ PTFE Pedestal Results}

Since the effects seen during the first data set were not consistent with those using the repaired pedestal, an effort was made to determine if the damage sustained to the pedestal which required it to have to be replaced was altering the trends seen in the results. A new pedestal was created using PTFE as discussed in Chapter 3. A major advantage of this new pedestal is the ability to monitor the surface temperature at five different locations around the interface region as opposed to the single point used in the glass pedestals. 


\section{Section 5.7.1: $\quad$ PTFE Pedestal with Electrode 1 and HFE-7000}

Similar to the data taken in Section 5.6.1 corresponding to electrode 1 a stepwise increase in the heater power level was recorded for electrode voltages of both $0 \mathrm{kV}$ and 5 $\mathrm{kV}$. The heat transfer characteristics were monitored and are plotted below. Figure 5.33 and Figure 5.34 represent the heat flux as a function of temperature difference in both the dimensional and non-dimensional forms. The trends that were present in Figure 5.25 and Figure 5.26 are repeated in Figure 5.33 and Figure 5.34, but with a larger and more sustained effect. A nominally $13 \%$ increase in the heat flux from the heater surface at equal surface temperatures is represented in the shift of the curve up and to the left. Again, there appears to be a tendency for this effect to decrease as CHF is approached.

Similar trends are also seen in the plots representing the heat transfer coefficient and the non-dimensional Nusselt number plotted in Figure 5.35 and Figure 5.36. As expected the heat transfer increases as the heat flux increases. Comparing the results from the PTFE pedestal for electrode 1 with those obtained using the repaired pedestal and electrode 1, it can be determined that use of the repaired pedestal during the second set of tests did alter the trends for the heat transfer. 


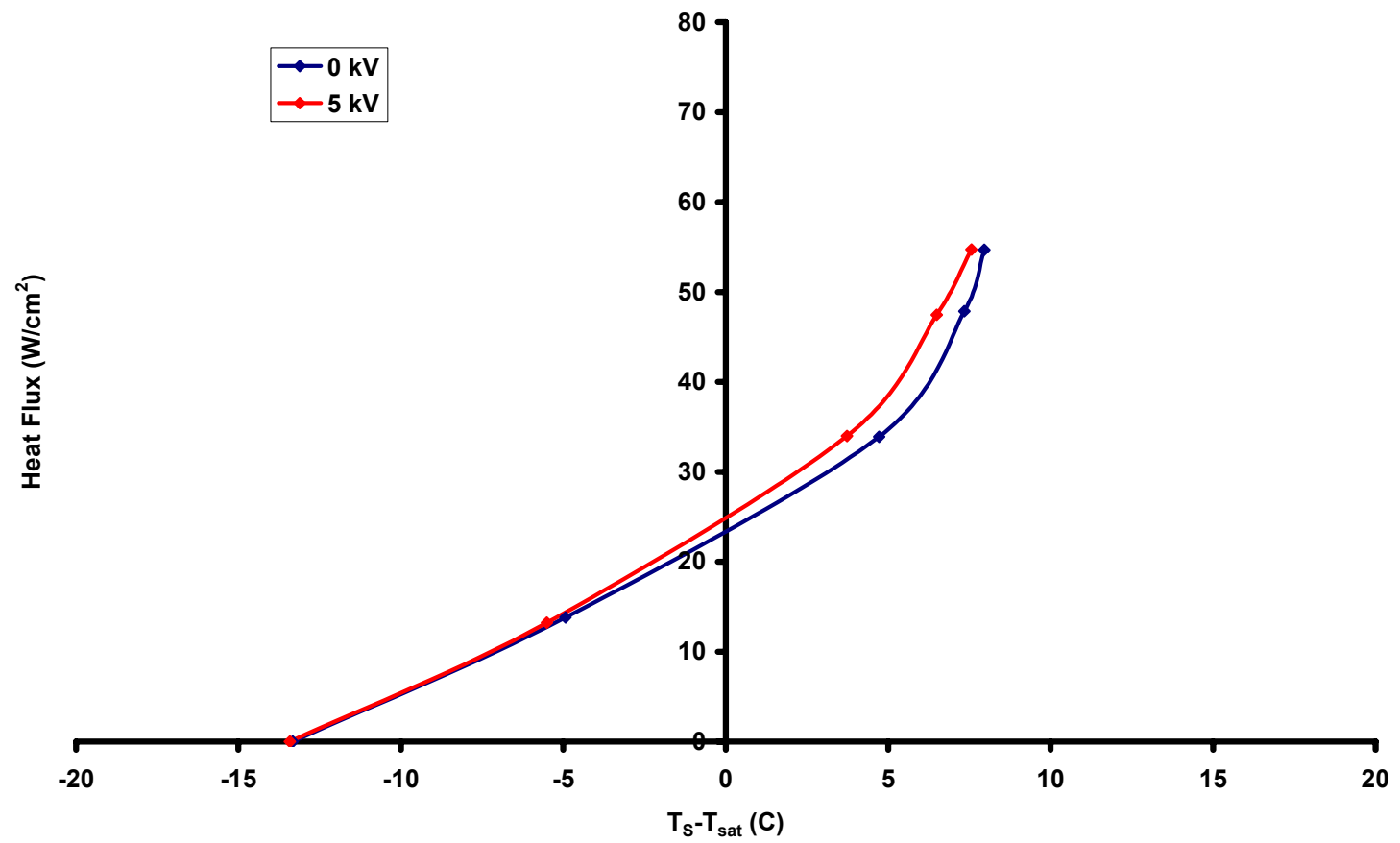

Figure 5.33: Heat Flux plot for HFE-7000 Data Run using PTFE Pedestal with TFR Heater and Electrode 1 at 8.0 GPH

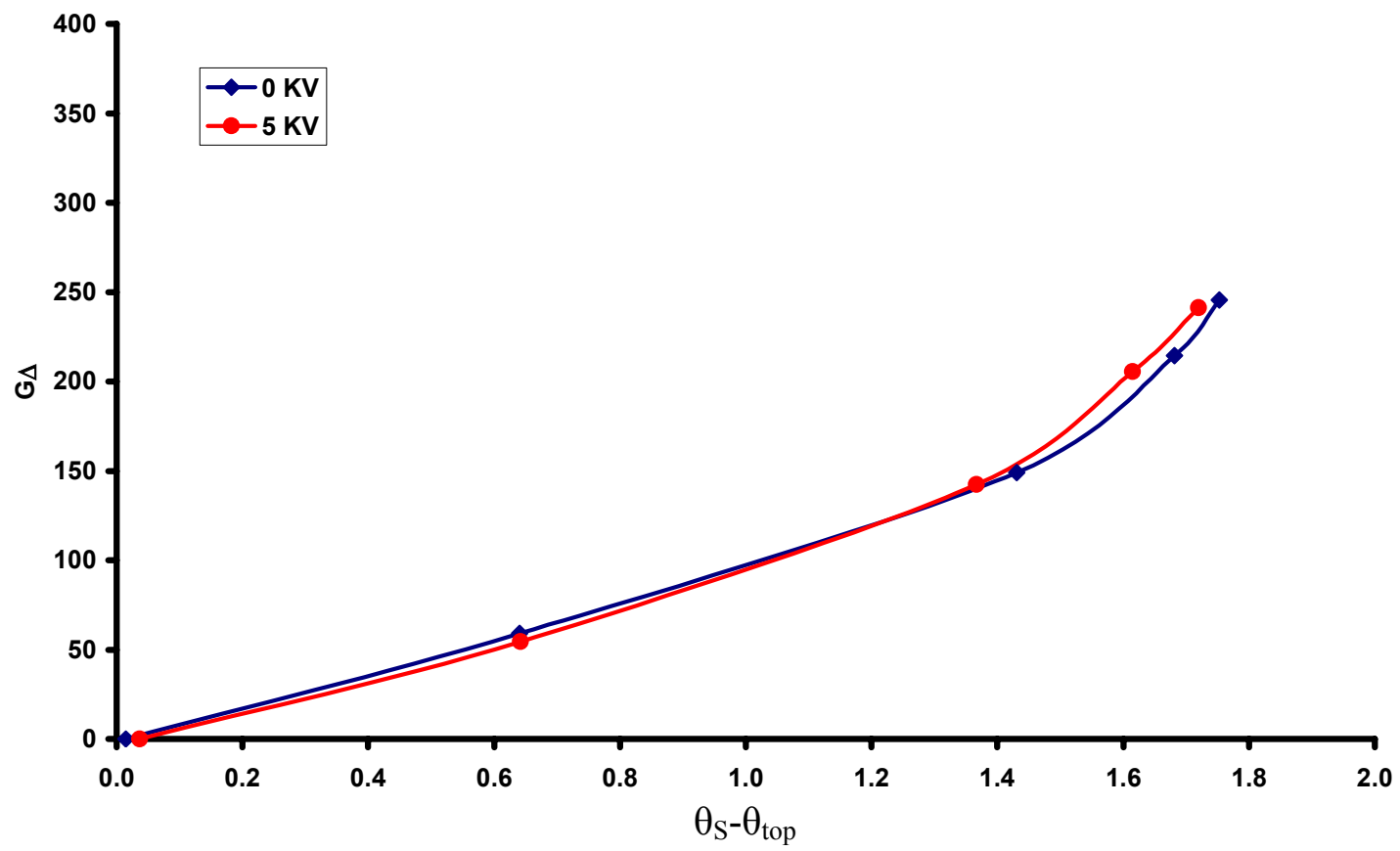

Figure 5.34: Non-dimensional Heat Flux versus Temperature Difference for HFE-7000 Data Run using PTFE Pedestal with TFR Heater and Electrode 1 at $8.0 \mathrm{GPH}$ 


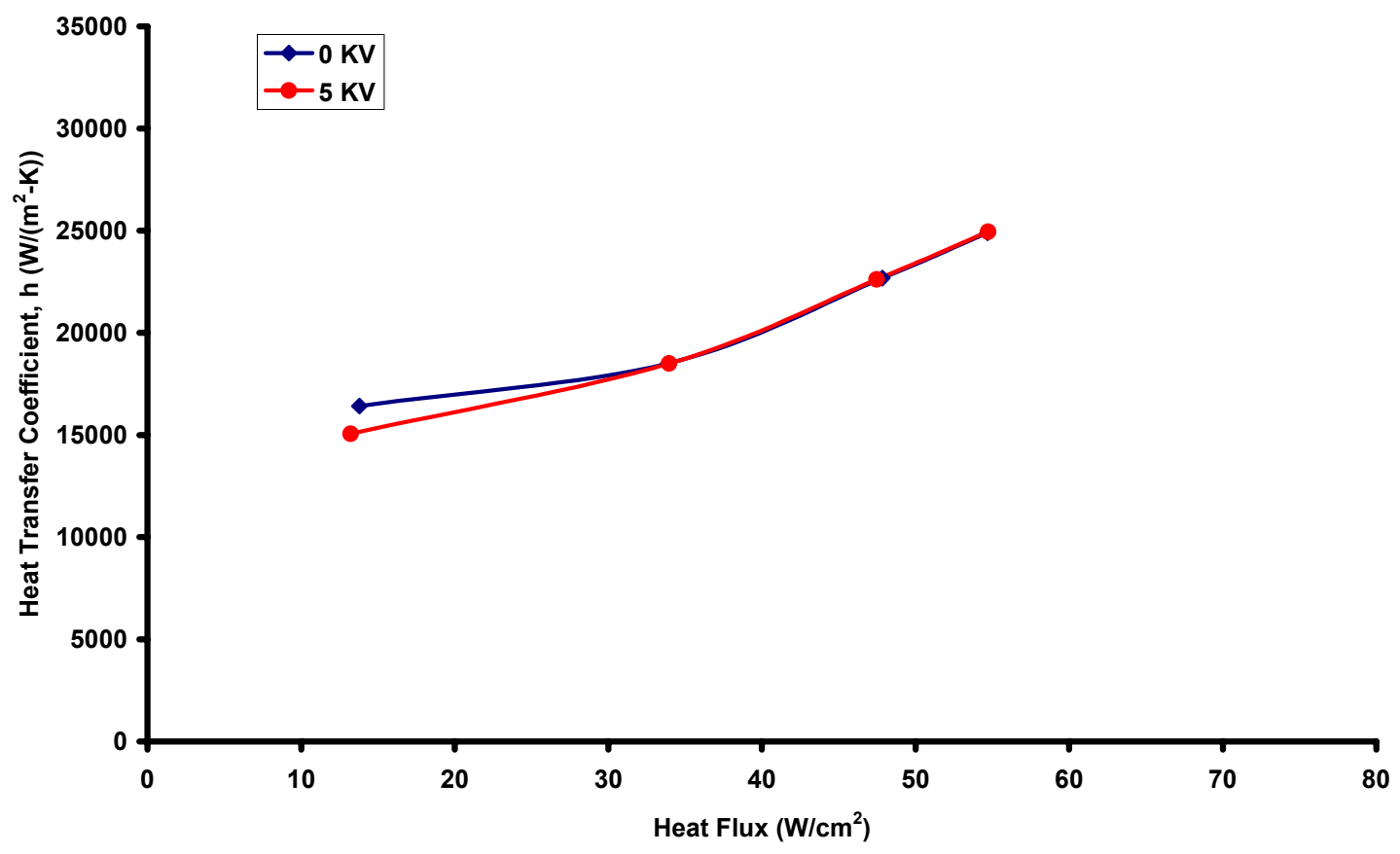

Figure 5.35: Heat Transfer Coefficient plot for HFE-7000 Data Run using PTFE Pedestal with TFR Heater and Electrode 1 at $8.0 \mathrm{GPH}$

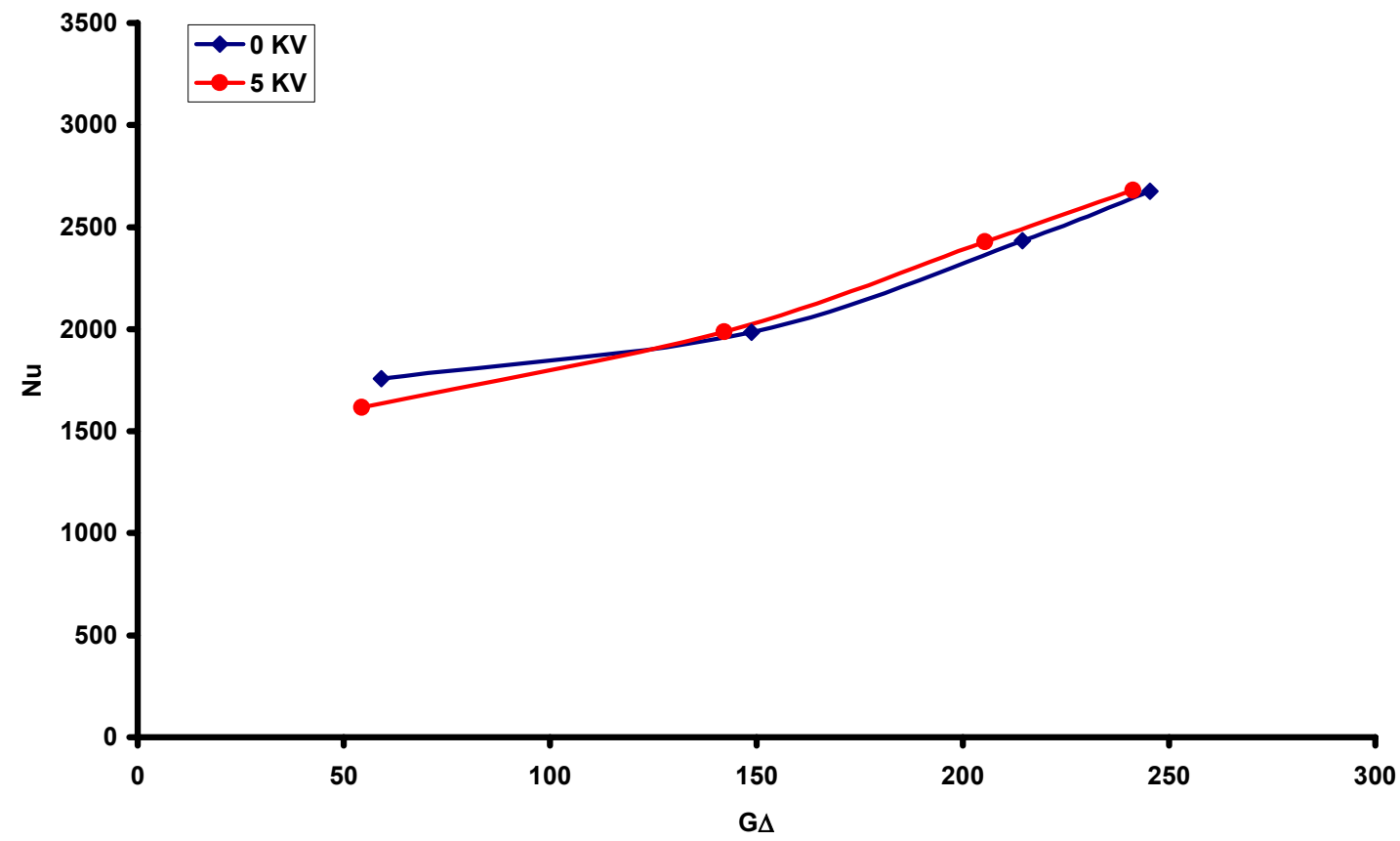

Figure 5.36: Nusselt number versus Non-dimensional Heat Flux for HFE-7000 Data Run using PTFE Pedestal with TFR Heater and Electrode 1 at 8.0 GPH 


\section{Section 5.7.2: $\quad$ PTFE Pedestal with Electrode 1 using HFE-7000 Comparing Two Flow Rates}

With the positive effects seen in Section 5.7.1 a second data set is plotted to compare the values obtained from two different flow rates. Two data runs were taken using the new PTFE pedestal with electrode 1 and HFE-7000. Figure 5.37 - Figure 5.38 shown below show how the performance at two different flow rates compare; the first plot represents the non-dimensional heat flux as a function of the non-dimensional temperature difference. Examining this figure, as the lower flow rate case reaches a higher level of heat flux, there is a shift in the $5 \mathrm{kV}$ curve compared to the $0 \mathrm{kV}$ curve.

Comparing the $13 \%$ increase of heat flux previously described for the $8 \mathrm{GPH}$ case with the $17 \%$ enhancement of the $6 \mathrm{GPH}$ case, a larger percentage increase is seen at the lower flow rate. This larger effect may be attributed to three different conditions. First, the maximum applied heat flux was higher for the data set acquired at the lower flow rate. Secondly, with the lower flow rate, there is less momentum pushing the liquid from the surface of the pedestal. This appears to allow the onset of boiling at a lower heat flux. Finally with the lower flow rate the droplets take longer to travel past the inductive charging electrode and allow a longer time for charge to be transferred from the nozzle to the working fluid. This would increase the magnitude of the Coulomb force.

Comparing Nusselt number as a function of non-dimensional heat flux for two different flow rates shows a noticeable difference between flow rates seen in Figure 5.38. The non-dimensional heat transfer coefficient is larger by as much as $14 \%$ for the higher flow rate at the same heat flux, which is to be expected due to more droplets hitting the heater surface. Comparing the curves of $5 \mathrm{kV}$ to those of $0 \mathrm{kV}$ for the two different flow rates the 5 $\mathrm{kV}$ curve begins lower and gets steeper as the flow transitions into two-phase flow for both 
flow rates. Both cases have a better heat transfer coefficient with the electrode voltage turned on in the two-phase heat transfer region.

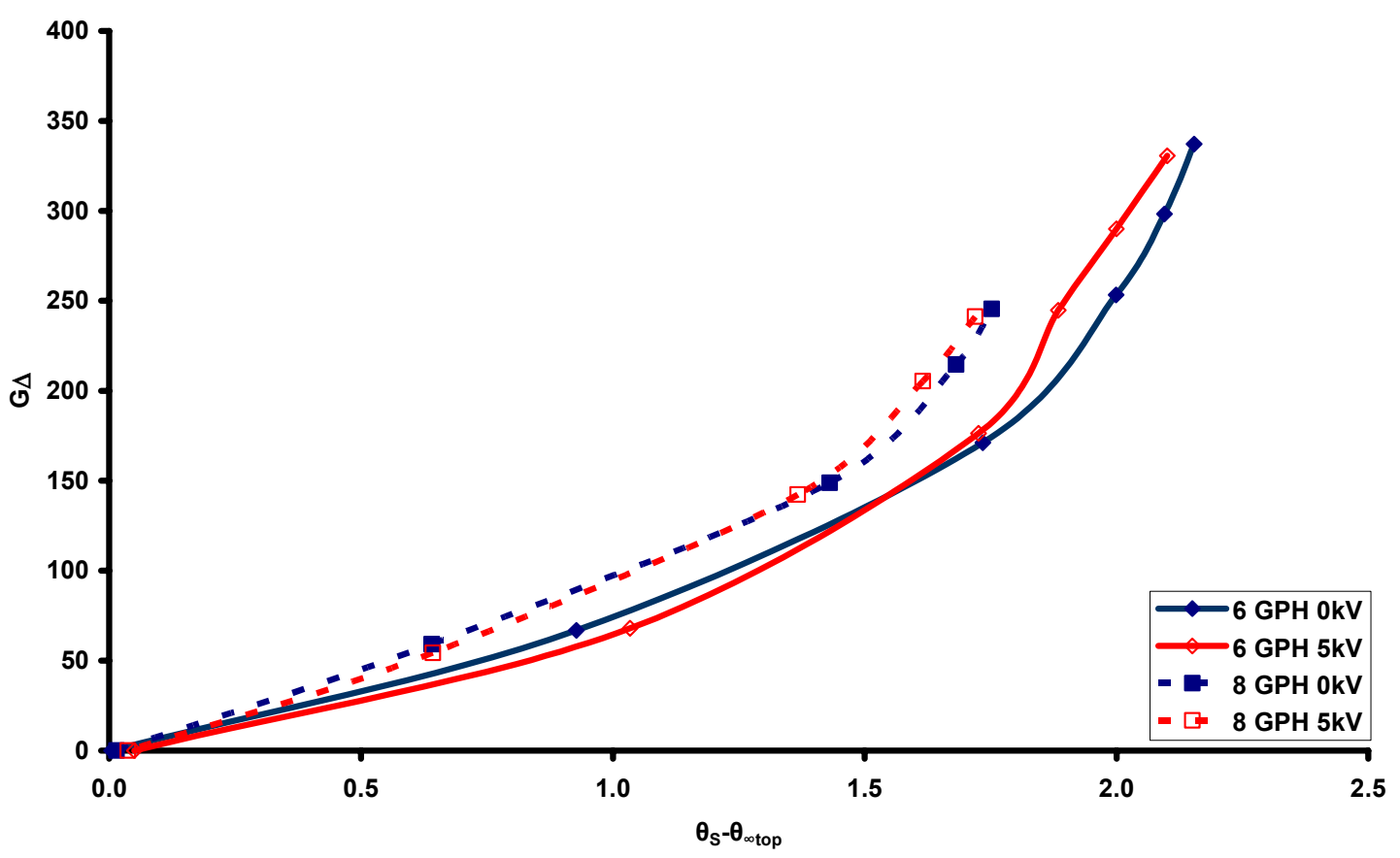

Figure 5.37: Non-dimensional Heat Flux versus Temperature Difference for HFE-7000 Data Run using PTFE Pedestal with TFR Heater and Electrode 1 Comparing Flow Rates 


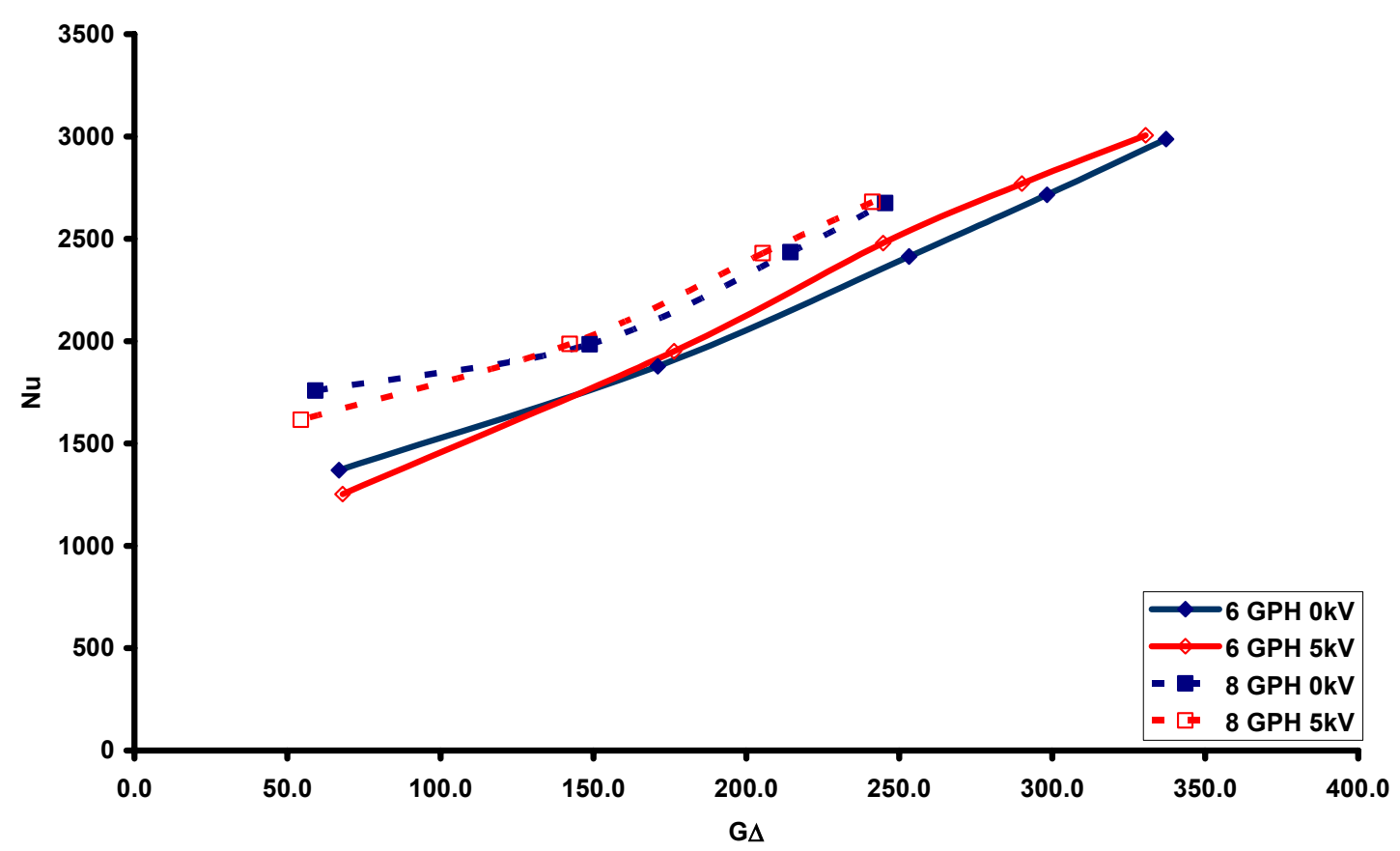

Figure 5.38: Nusselt number versus Non-dimensional Heat Flux for HFE-7000 Data Run using PTFE Pedestal with TFR Heater and Electrode 1 Comparing Flow Rates

\section{Section 5.8: Nozzle Selection and Alignment}

A critical portion of the data taking process is the correct alignment of the nozzle and the components used. For the present study two different types of spray nozzles were used. The two different spray nozzles were brass and PVC versions of the Spraying Systems Inc. 1/8-G full cone spraying nozzles. According to manufacturing specifications the only differences between the two types of nozzles were the manufacturing material. Section 5.8.1 explains how performance variations occur between the different nozzles tested. Section 5.8.2 shows how CHF occurs at different times across the pedestal. There is also evidence presented that shows how the resistance of the heater can be altered after an extreme CHF event takes place. 


\section{Section 5.8.1: $\quad$ PVC and Brass Nozzle Comparison}

This comparison of two different material spray nozzles demonstrates that there were significant variations in performance found from one material to another. This data series tests and compares a PVC nozzle to two separate (but supposedly identical) brass spray nozzles. Appendix B gives a full explanation of the comparison process. Looking at Figure 5.39 and Figure 5.40 it is seen that the heat transfer for the two brass nozzles are consistently higher than that of the PVC nozzle. However, the difference between the two brass nozzles, and the difference between the second brass nozzle and the PVC nozzle are of the same magnitude. The difference between the brass nozzles and the PVC nozzle range from $7 \%$ to $14 \%$ and the difference between brass nozzles is $5 \%$. There is also a significant (and expected) variation between flow rates, with $12 \%$ variation between $9.2 \mathrm{GPH}$ and $7.7 \mathrm{GPH}$ and $24 \%$ variation between $9.2 \mathrm{GPH}$ and $6.2 \mathrm{GPH}$.

From these results it is not possible to determine if the difference in performance for different nozzles at the same flow rate is due to the use of different spray nozzles, or to variations in the positioning of the nozzle assembly after the hardware changes were made. Section 5.8.2 explains the importance of centering the spray nozzle assembly to efficiently and uniformly cool the heater surface. 


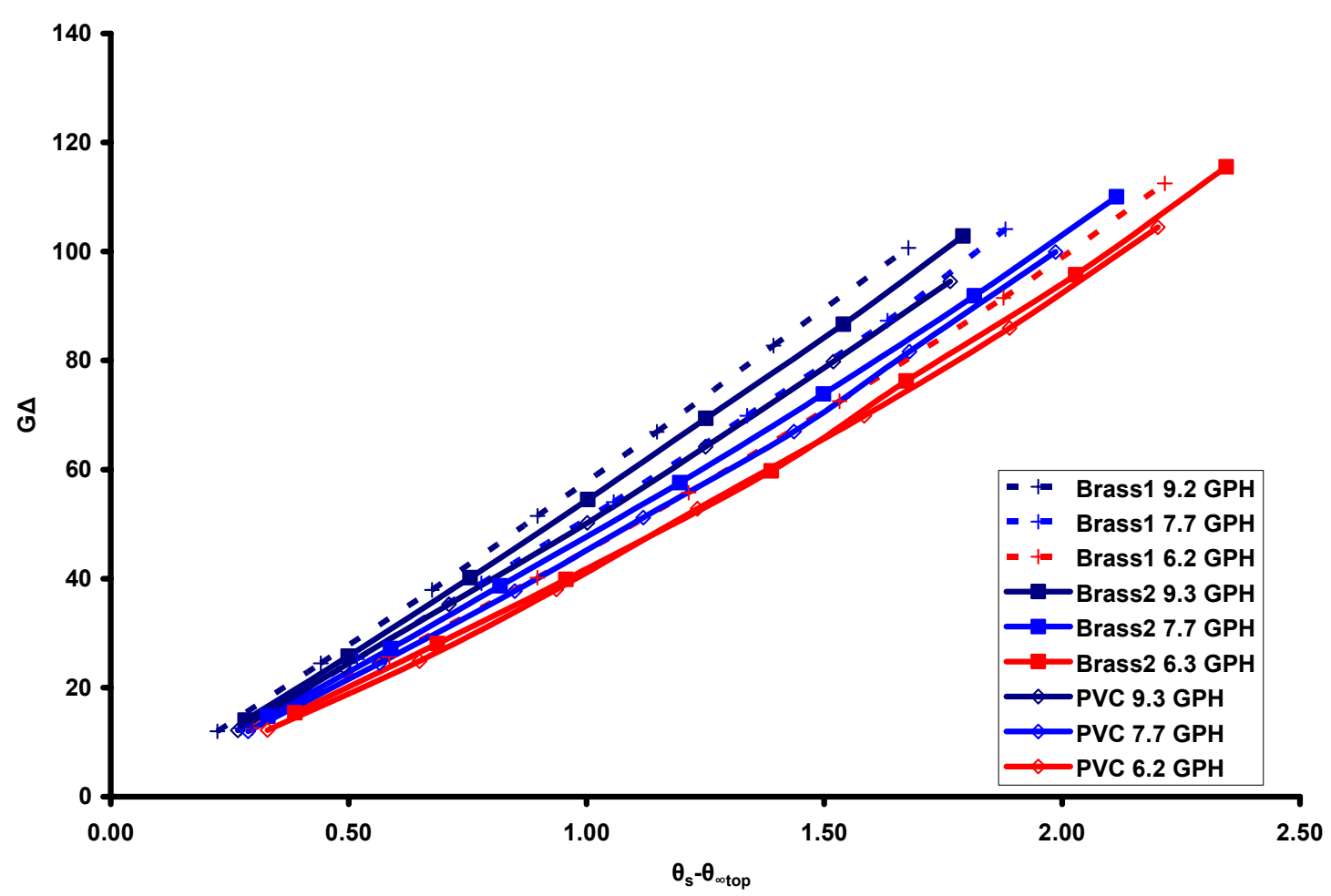

Figure 5.39: Non-dimensional Heat Flux versus Temperature Difference for Nozzle Comparison Data Run using FC-72 and no Electrode

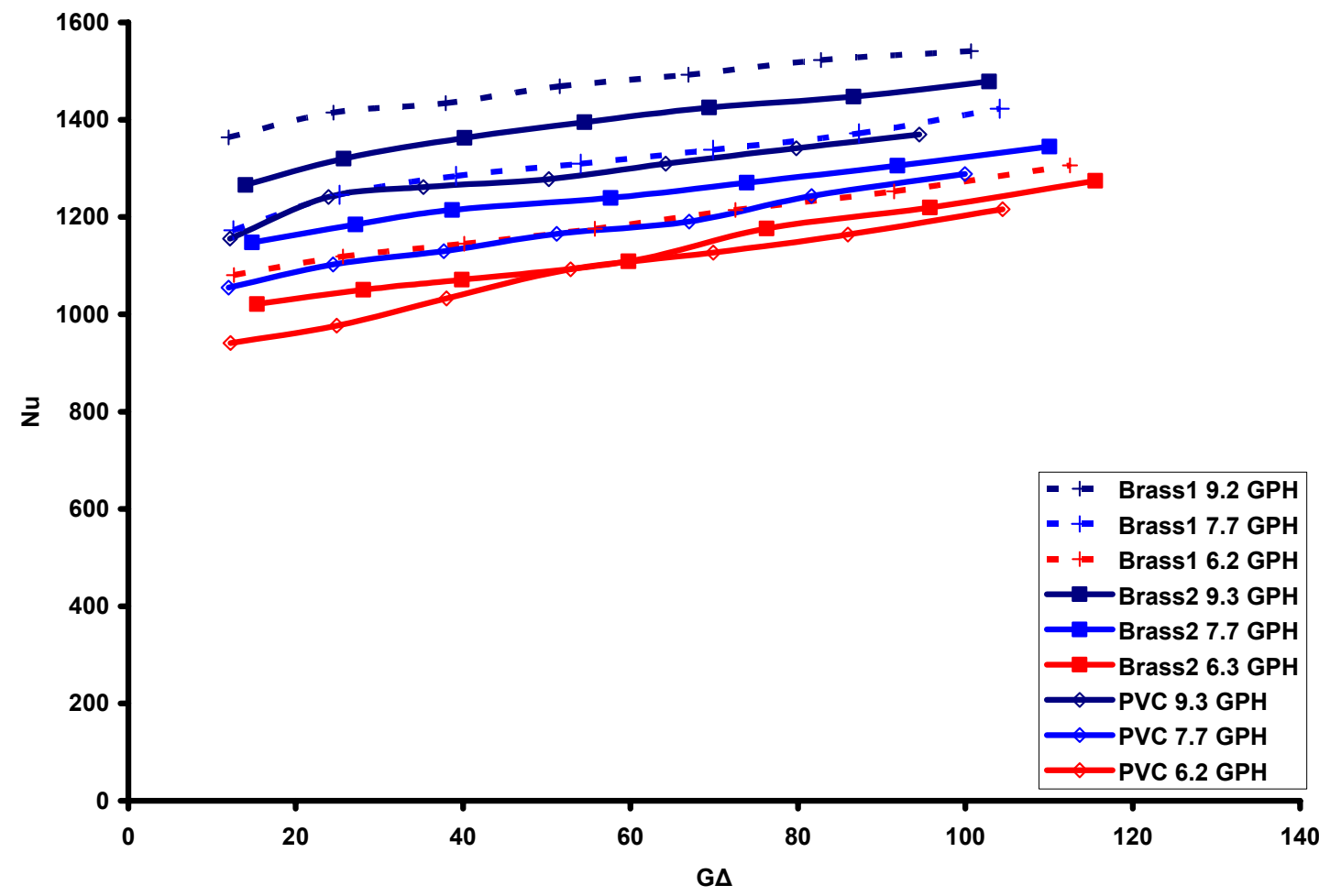

Figure 5.40: Nusselt number versus Non-dimensional Heat Flux for Nozzle Comparison Data Run using FC-72 and no Electrode 
Section 5.8.2: $\quad$ PTFE Pedestal Going Through CHF Using HFE-7000 at $8 \mathrm{GPH}$

After the desired data sets were taken an experiment to observe how CHF occurs along the surface was performed. Using the results from Section 5.7 the five thermocouples mounted beneath the TFR heater substrate were monitored to determine which thermocouple was reading the hottest. Figure 5.41 shows a consistent trend for this data set where the thermocouple labeled interface temperature was always at a higher temperature, and the range of temperatures across the pedestal was $\pm 2.5^{\circ} \mathrm{C}$ at the highest levels of heat flux. Based on the trends seen in Figure 5.41 the interface temperature was connected to the high-temperature cut out alarm, and the heat fluxes were turned up to higher levels to determine where CHF would occur for the PTFE pedestal and TFR heater.

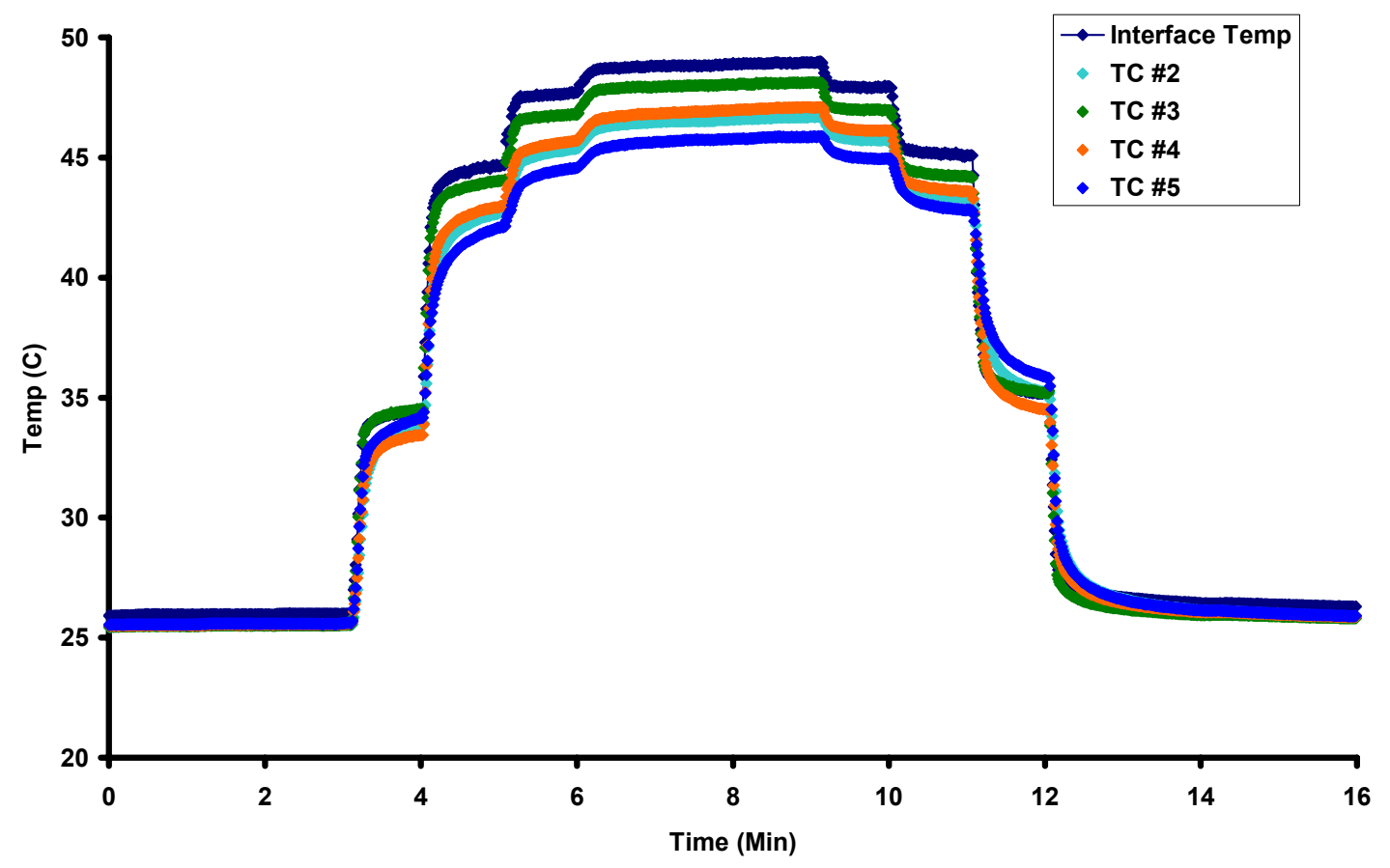

Figure 5.41: Temperature vs. Time for the Five Thermocouples Located below the TFR Heater of the PTFE Pedestal with Electrode 1 
To determine the temperature and heat flux level where CHF occurred, the heater power level was turned up in a stepwise fashion. Examining Figure 5.42 the first $\mathrm{CHF}$ event took place at 13 minutes into the data run and shows a maximum interface temperature of $280{ }^{\circ} \mathrm{C}$. Focusing on the $\mathrm{CHF}$ event that takes place between 12 minutes and 14 minutes it is possible to see that the onset of CHF is indicated much sooner by two thermocouples than the interface thermocouple that was connected to the alarm. The cut out alarm was set to turn off the heater power as the interface temperature exceeded 150 ${ }^{\circ} \mathrm{C}$.

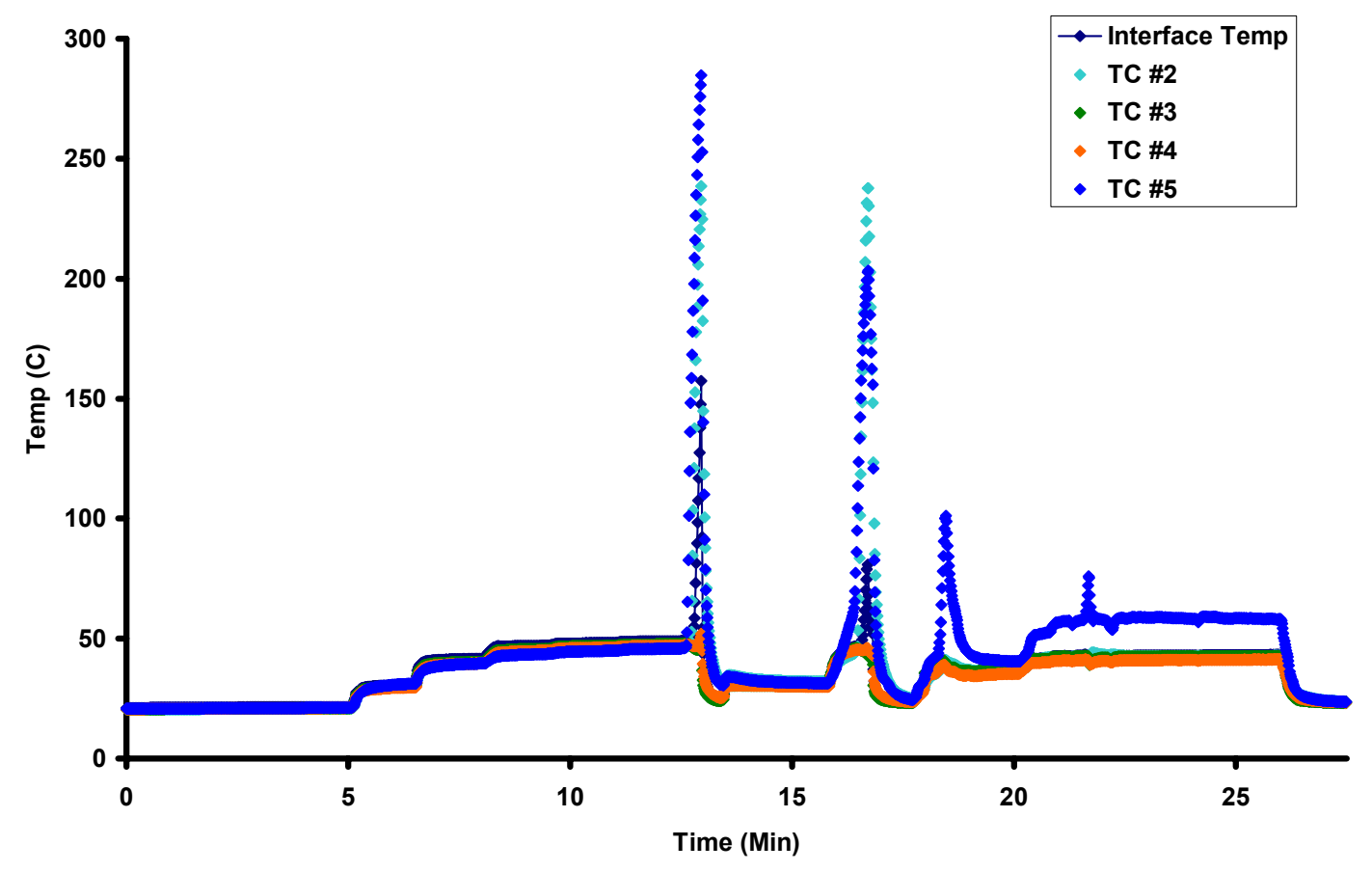

Figure 5.42: Temperature vs. Time for the Five Thermocouples Located below the TFR Heater of the PTFE Pedestal as CHF Occurs

From the zoomed-in data shown in Figure 5.43 it is seen that CHF was reached sooner by portions of the heater surface near to thermocouples TC \#2 and TC \#5, by as much as 12 seconds. The maximum measured peak temperature reached $280{ }^{\circ} \mathrm{C}$ directly before the alarm was triggered by the interface temperature and the heater power was cut 
off. Looking back at Figure 5.42, after CHF occurred the thermocouple reading TC \#5 was apparently damaged and reading changes in temperature without any change in the resistor power level. This effect could be explained by an effect observed during the death of a previous TFR heater and pedestal. After several CHF events had been experienced a small glowing red-orange spot was noticed on the heater surface. This could have been a local hot spot caused by damage sustained by the heater due to localized dry-out of the heater surface.

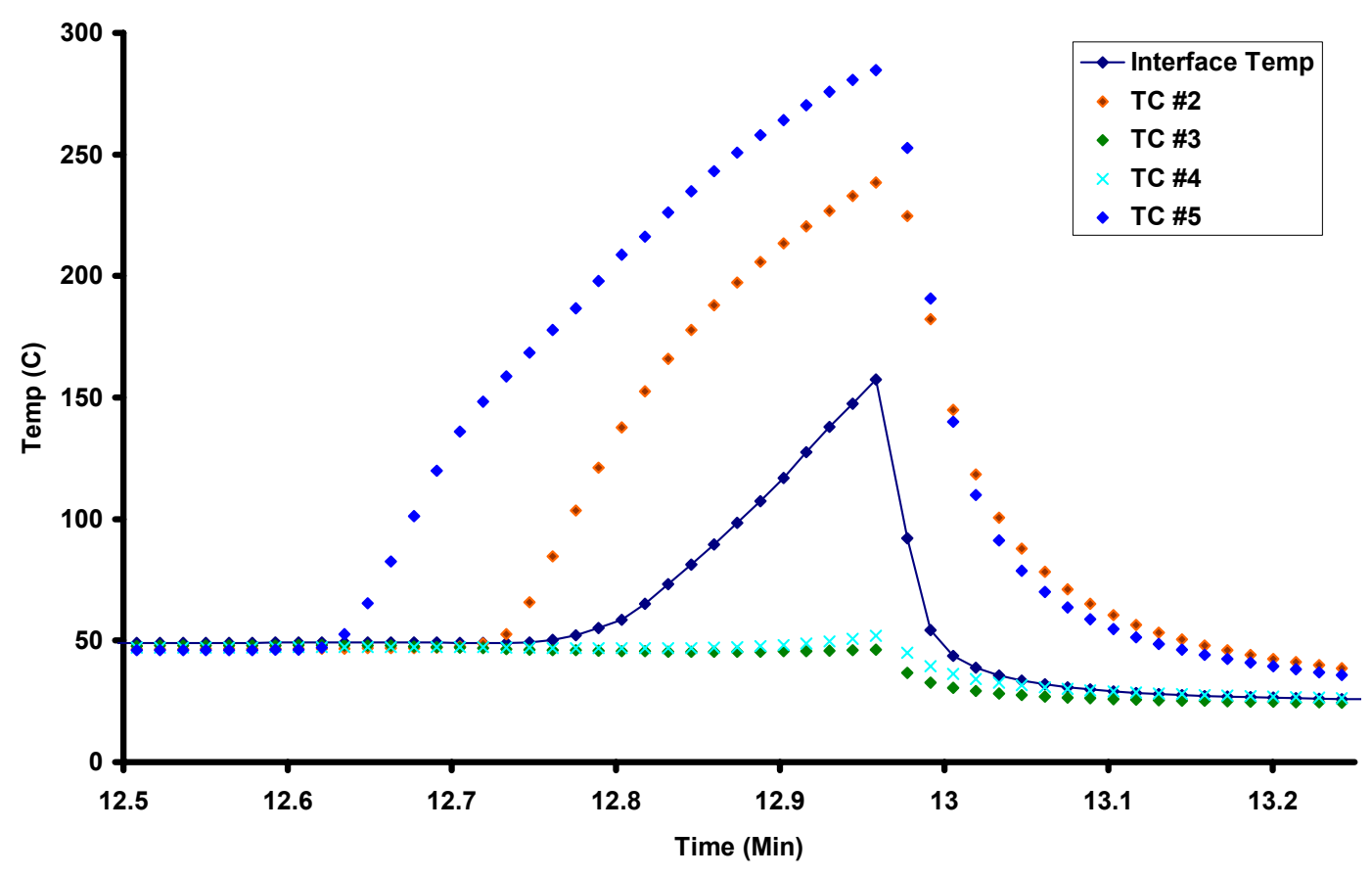

Figure 5.43: Temperature vs. Time for the Five Thermocouples Located below the TFR Heater of the PTFE Pedestal Focused on the CHF Event

Another important result observed with this test run is the change in resistance across the TFR that occurs with an extreme occurrence of CHF. Looking at Figure 5.44 the resistance initially was constant at $10 \Omega$. However three separate CHF events occurred and the resistance became significantly higher afterwards. After the first CHF 
event represented by the vertical line in Figure 5.44 or the first peak in Figure 5.40 the resistance increased to a level of $10.5 \Omega$. However, after two smaller CHF events occurred the resistance increased again to a level of $12 \Omega$, which is substantially higher. With this increased resistance across the TFR heat transfer characteristics will be altered such that different heat fluxes occur when the heater power is increased. The possibility of small cracks present may also lead to future damage to the pedestal.

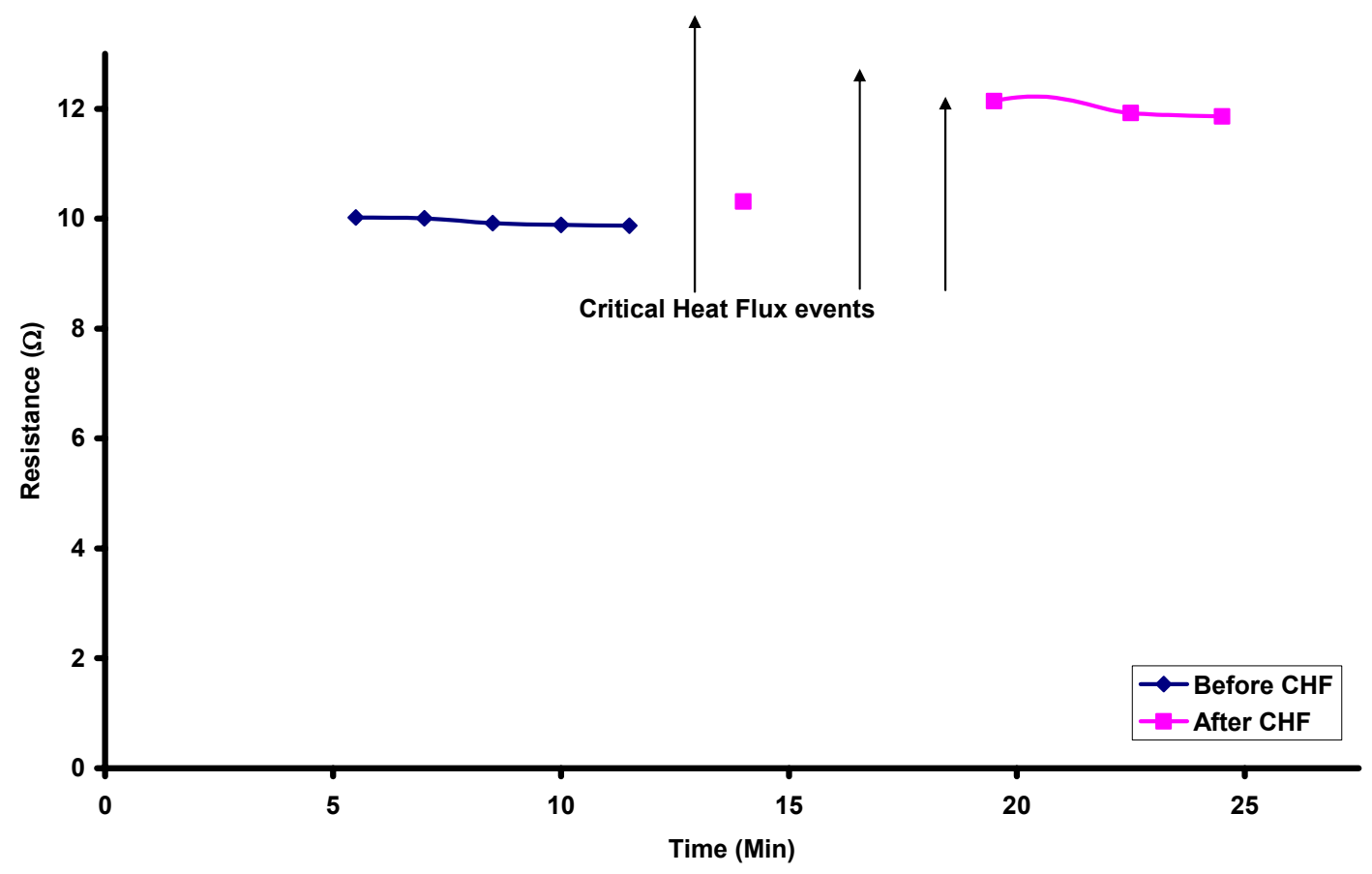

Figure 5.44: Resistance vs. Time for the PTFE Pedestal Showing CHF Events

\section{Section 5.9: Electrode Comparison}

Throughout this chapter a narrative of several results has been presented for various different pedestal and electrode configurations and two different working fluids. The first data run showed data taken using FC-72 and electrode 1 for the original TFR pedestal. The second set shows data for FC-72 with both electrode 1 and 2 using the repaired TFR pedestal. Next, results were obtained using HFE-7000 and both electrode 1 
and 2 for the repaired TFR pedestal. Finally data obtained using the PTFE pedestal was described using electrode 1 and HFE-7000.

Figure 5.45 plots the non-dimensional heat flux versus temperature difference for the data taken using both electrodes 1 and 2 and FC-72. The trend for this data starts in a similar fashion with small perturbations seen in the curves. Figure 5.46 shows the same plots for the HFE-7000 data using the repaired pedestal and both electrodes 1 and 2 . The curves start out identical, however once they begin to transfer into the two-phase region they separate based on electrode. This is believed to be because of the pedestal and heater that was used. Comparing the $0 \mathrm{kV}$ curve with the $5 \mathrm{kV}$ curve for each electrode, small differences are noticed with a slight enhancement just as the transition occurs to the two-phase region. Figure 5.47 shows the same plot with a sample of a typical data run of each type discussed within this chapter.

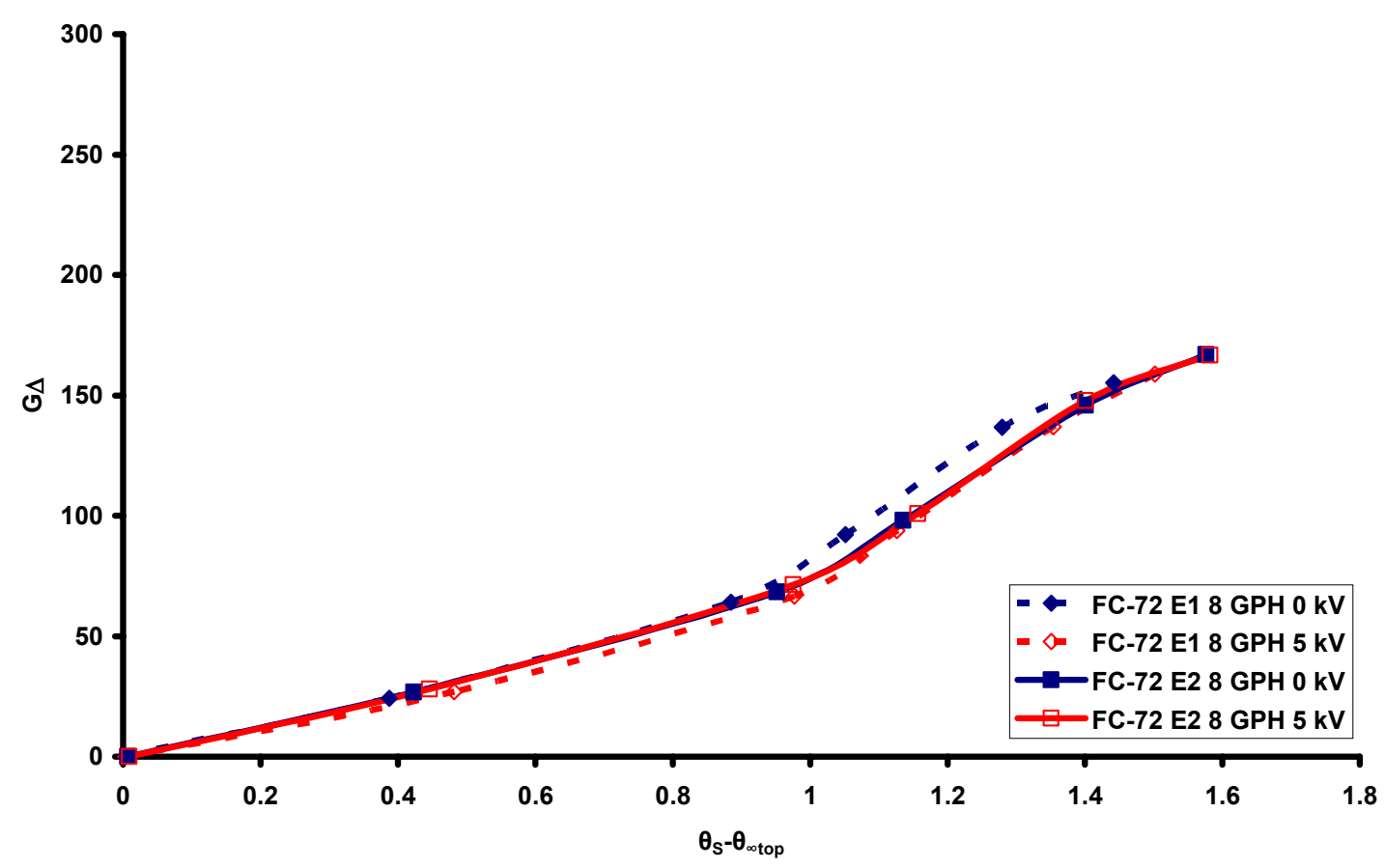

Figure 5.45: Non-dimensional Heat Flux versus Temperature Difference for Comparing FC-72 Data Runs 


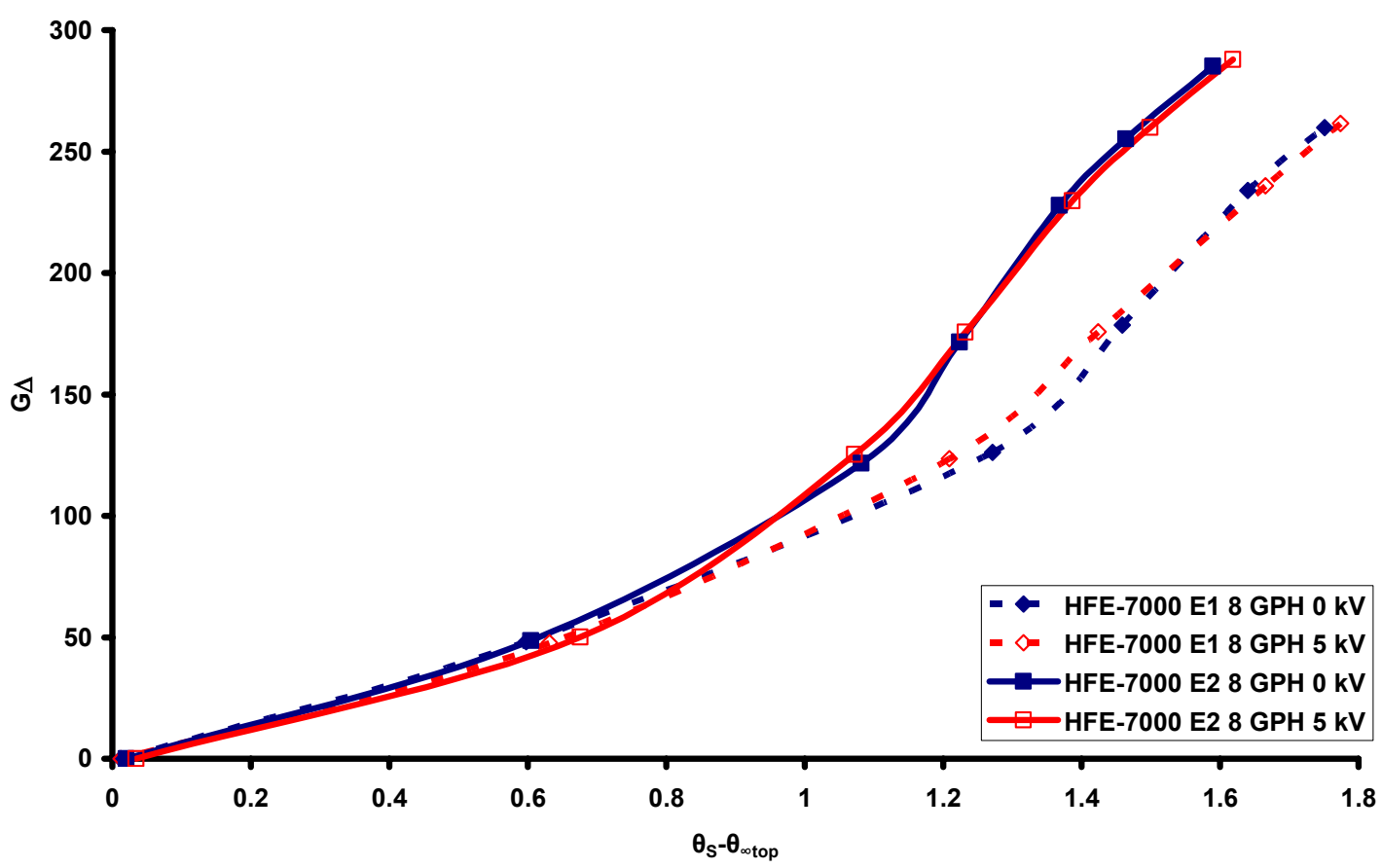

Figure 5.46: Non-dimensional Heat Flux versus Temperature Difference for Comparing HFE-7000 Data Runs

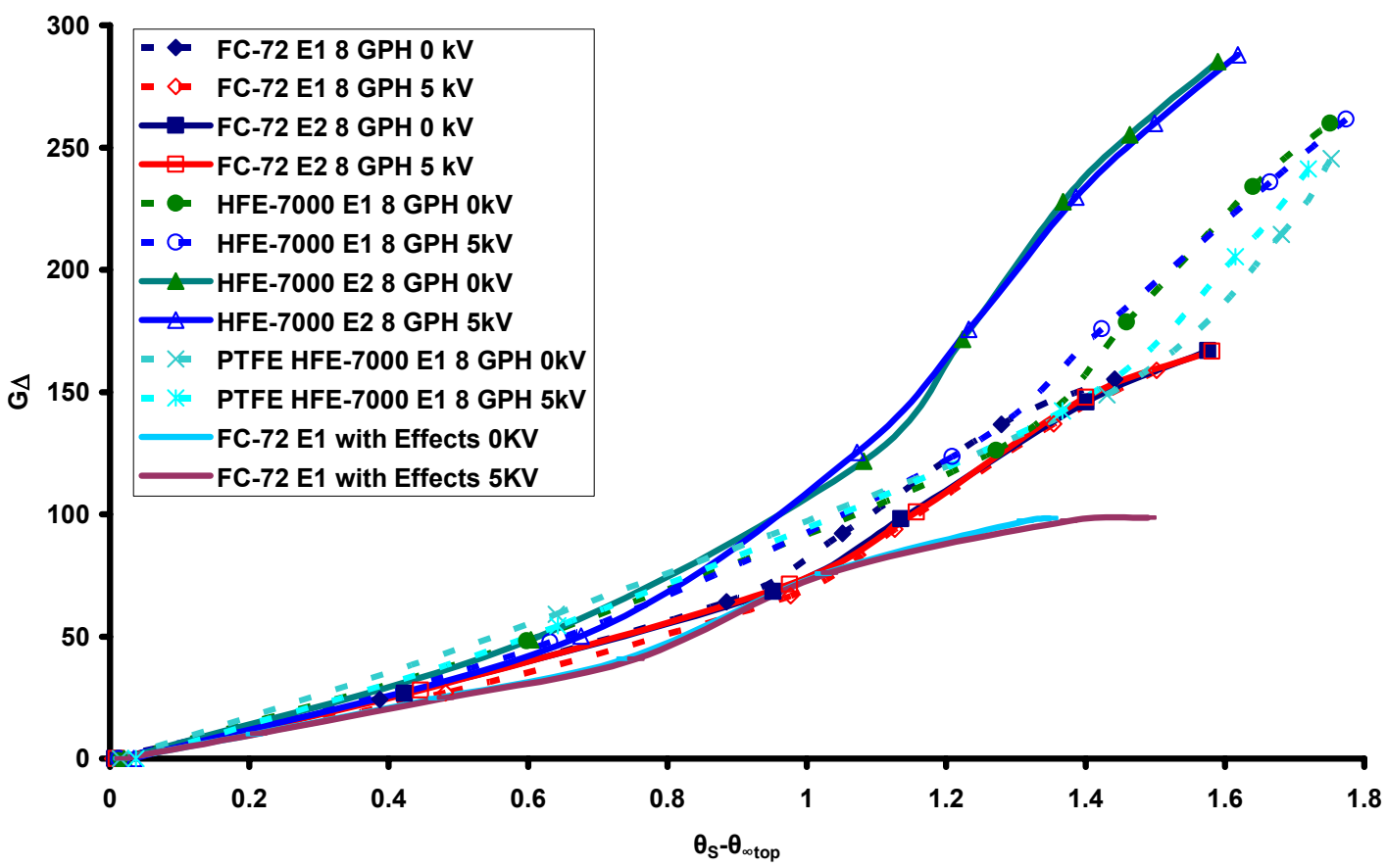

Figure 5.47: Non-dimensional Heat Flux versus Temperature Difference for Comparing All Data Runs 
Figure 5.48 plots the Nusselt number as a function of non-dimensional heat flux for FC-72 using both electrode 1 and 2. Overall a similar trend can be observed, with the non-dimensional heat transfer coefficient increasing with an increase in non-dimensional heat flux. No dramatic change is sustained throughout an entire data run. Figure 5.49 demonstrates the same figure with HFE-7000. Again no discernable trend is noticed throughout an entire data run. Figure 5.50 plots the Nusselt number as a function of nondimensional heat flux for a typical data run of each type. Appendix $\mathrm{C}$ shows dimensional and non-dimensional plots for every data series taken for the two different fluids and two tested pedestals.

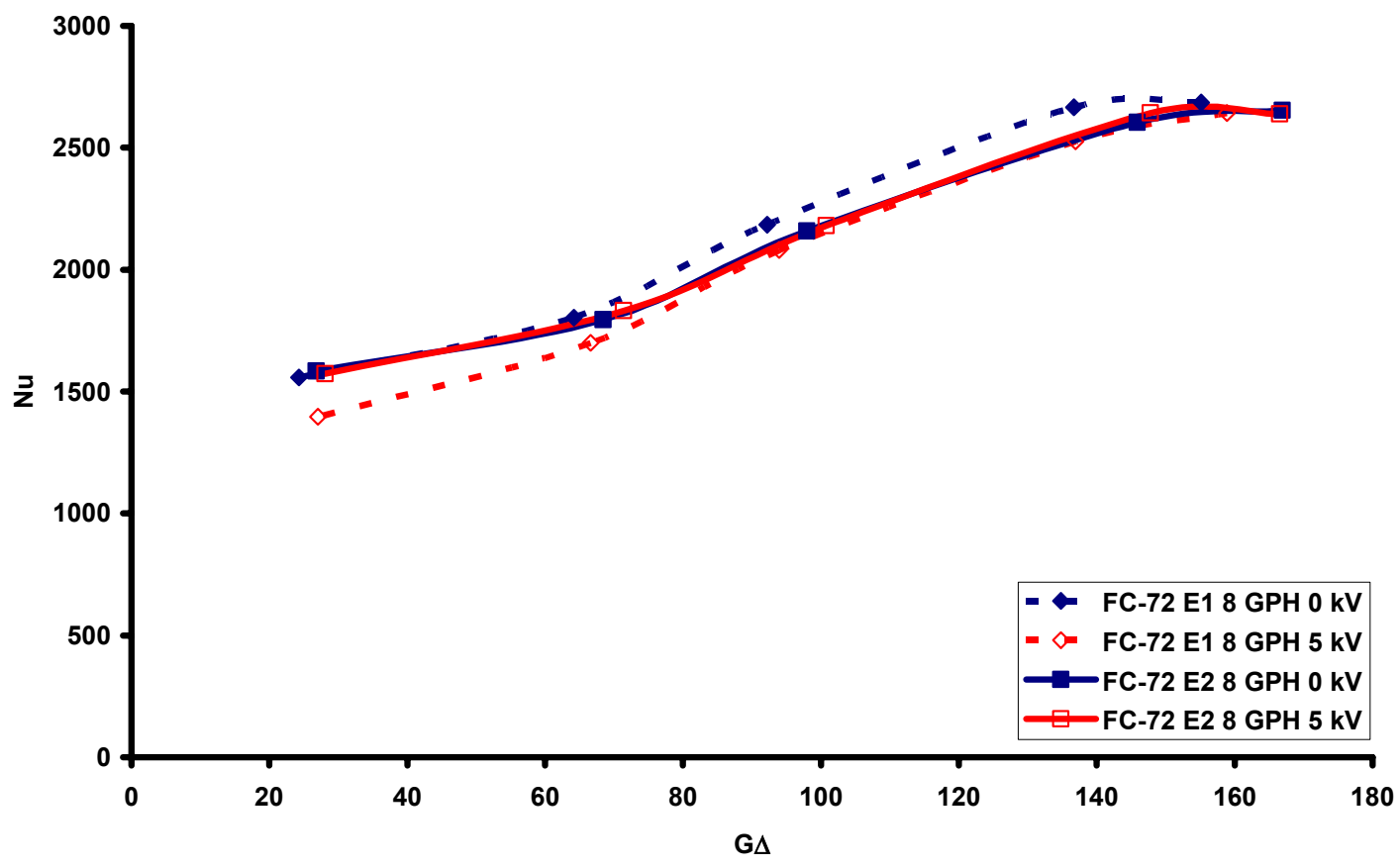

Figure 5.48: Nusselt number versus Non-dimensional Heat Flux for Nozzle Comparing FC-72 Data Runs 


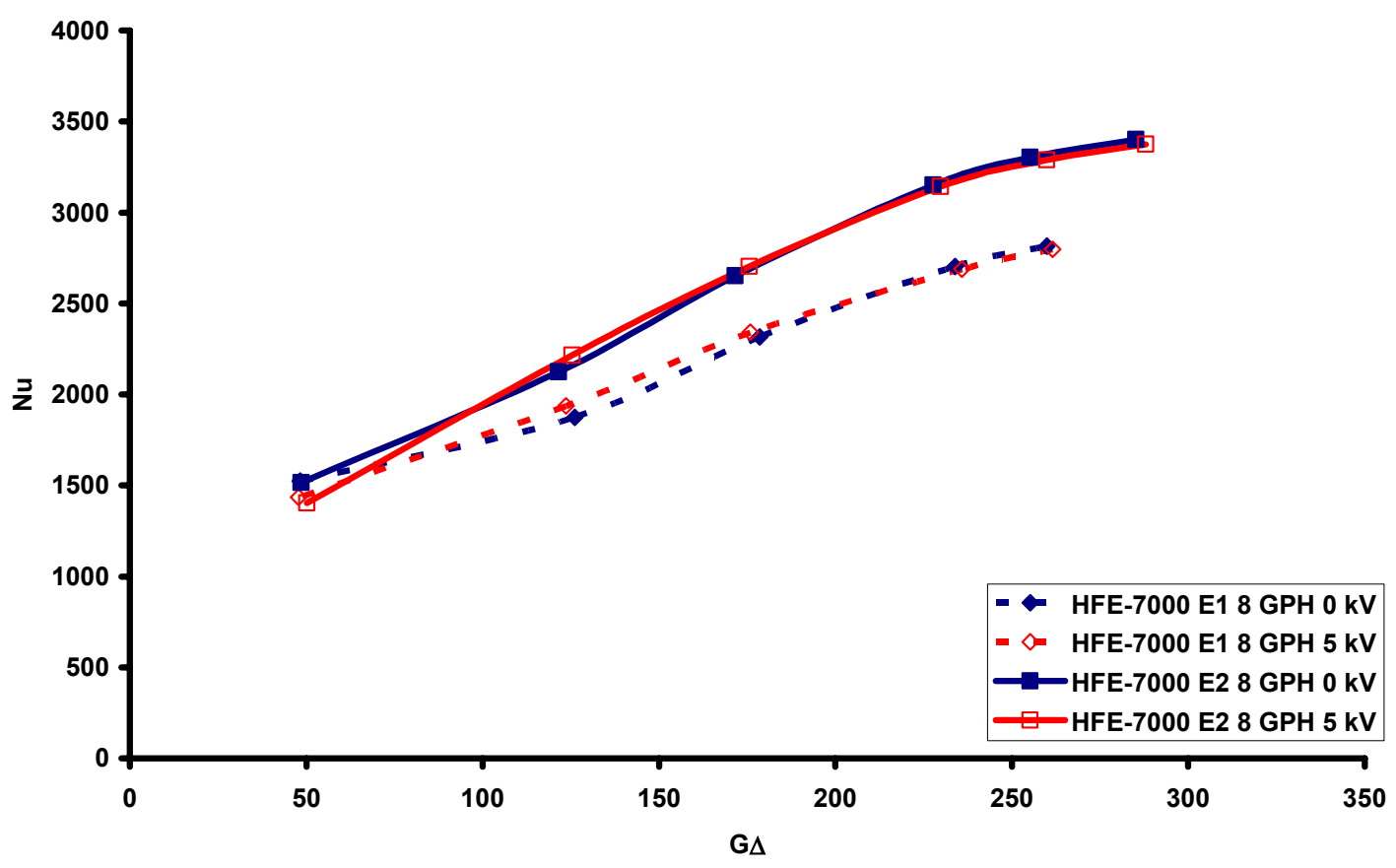

Figure 5.49: Nusselt number versus Non-dimensional Heat Flux for Nozzle Comparing HFE-7000 Data Runs

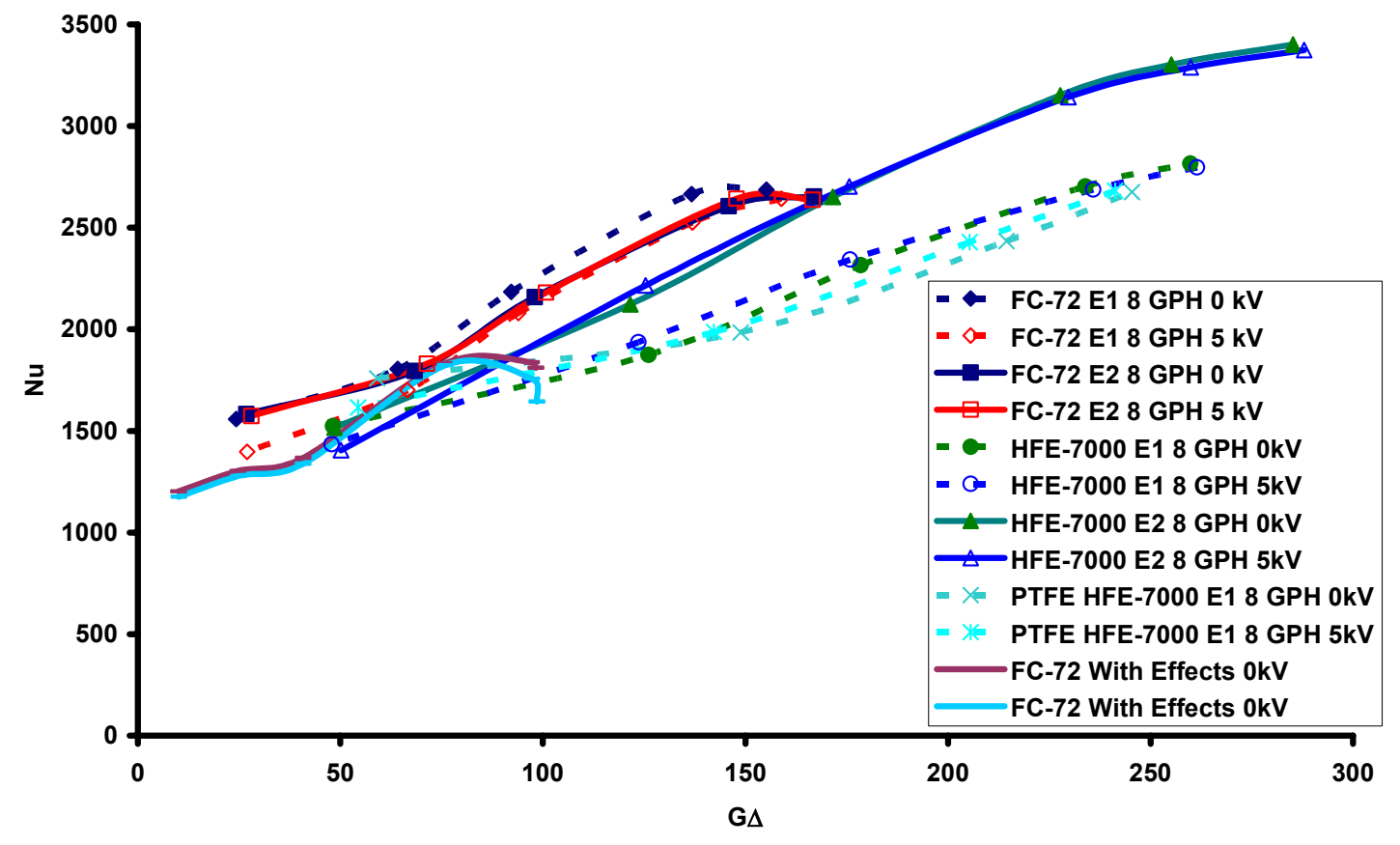

Figure 5.50: Nusselt number versus Non-dimensional Heat Flux for Nozzle Comparing All Data Runs 


\section{Section 5.10: $\quad$ Interpretation of Results}

To better understand the experimental results obtained in the previous sections of this chapter the predicted effects of the electric field exerted on the spray zone have been studied computationally. Figure 5.51 and Figure 5.52 represent the electric potential exerted by both electrodes, as calculated by Mehra (2006) using the CFD-Ace+ multiphysics code. For these simulations the electrode was held at $5 \mathrm{kV}$ and the nozzle and pedestal were fixed at $0 \mathrm{kV}$. As to be expected for an electrode using inductive charging the maximum potential is found directly below the nozzle outlet in the middle of the electrode.

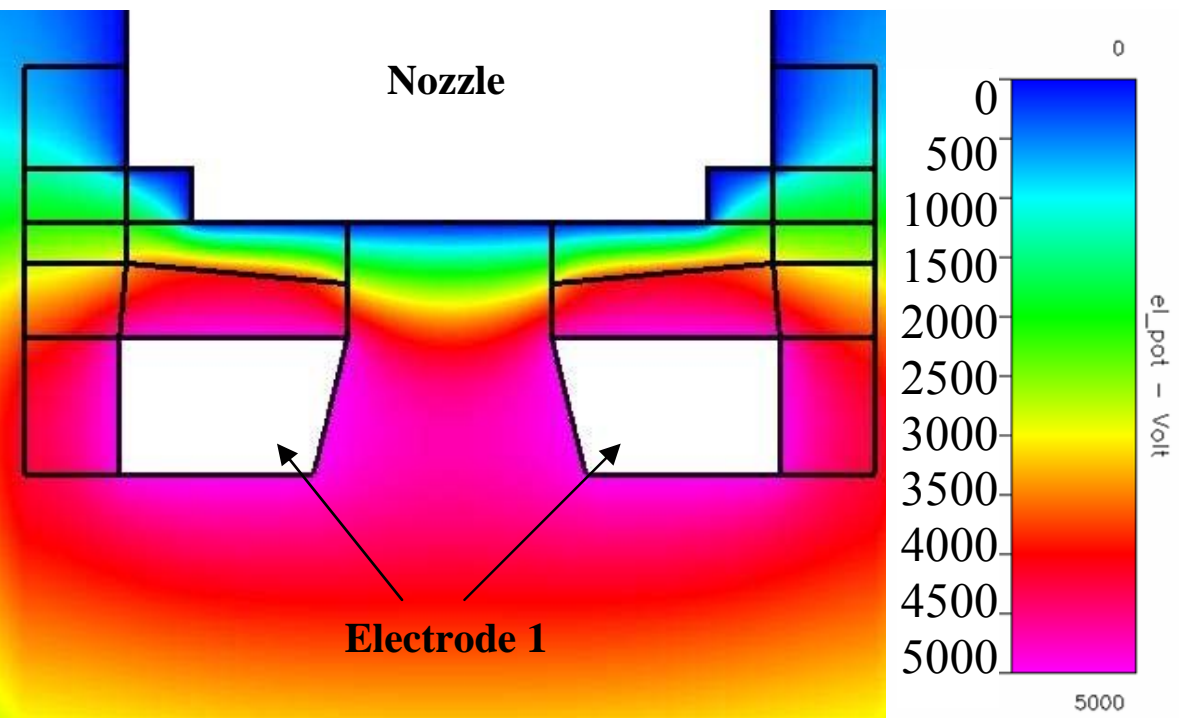

Figure 5.51: Electrode 1 Electric Potential (Mehra, 2006) 


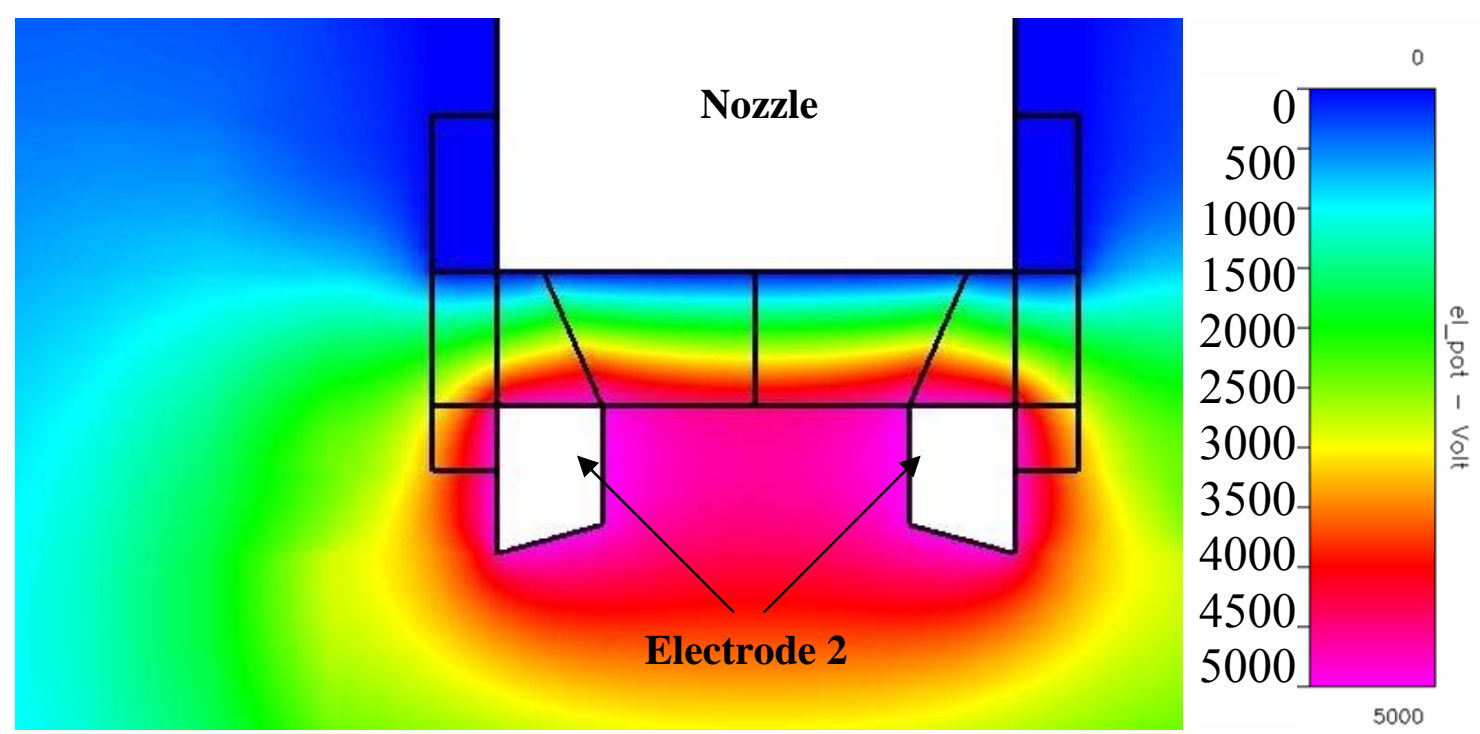

Figure 5.52: Electrode 2 Electric Potential (Mehra, 2006)

The resultant forces exerted on the spray droplets would either be due to the electric Kelvin force or the Coulomb force. The predicted Kelvin force in the X-direction obtained using CFD-Ace+ (Mehra, 2006) can be seen in Figure 5.53 and Figure 5.54 for electrodes 1 and 2 respectively. The Kelvin force is quite small. The predicted Kelvin forces per mass vary in magnitude from -0.05 to $0.05 \mathrm{~N} / \mathrm{kg}$. However, in order to obtain useful plots, the imaging program used was adjusted manually thus omitting some of the extremes.

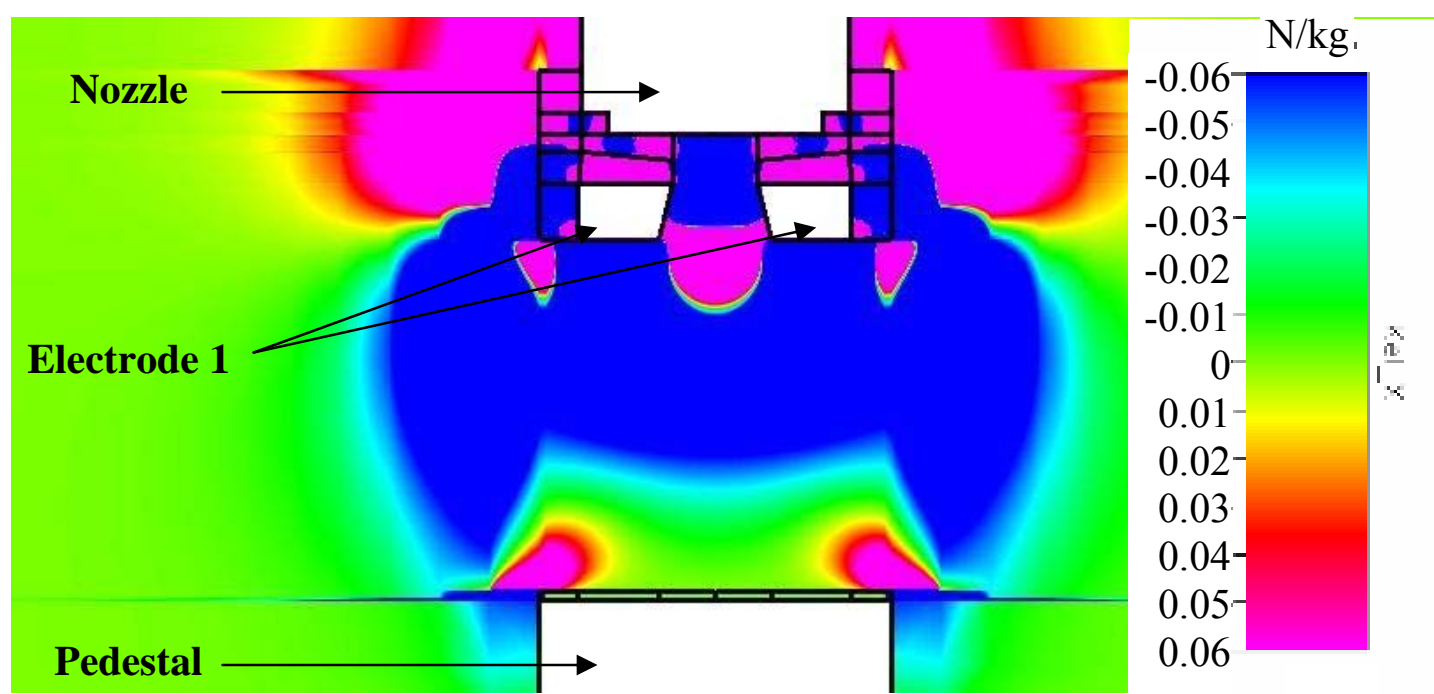

Figure 5.53: Calculated Axial Kelvin Force/Mass for Electrode 1 Presented in $\mathrm{N} / \mathrm{kg}$ (Mehra, 2006) 


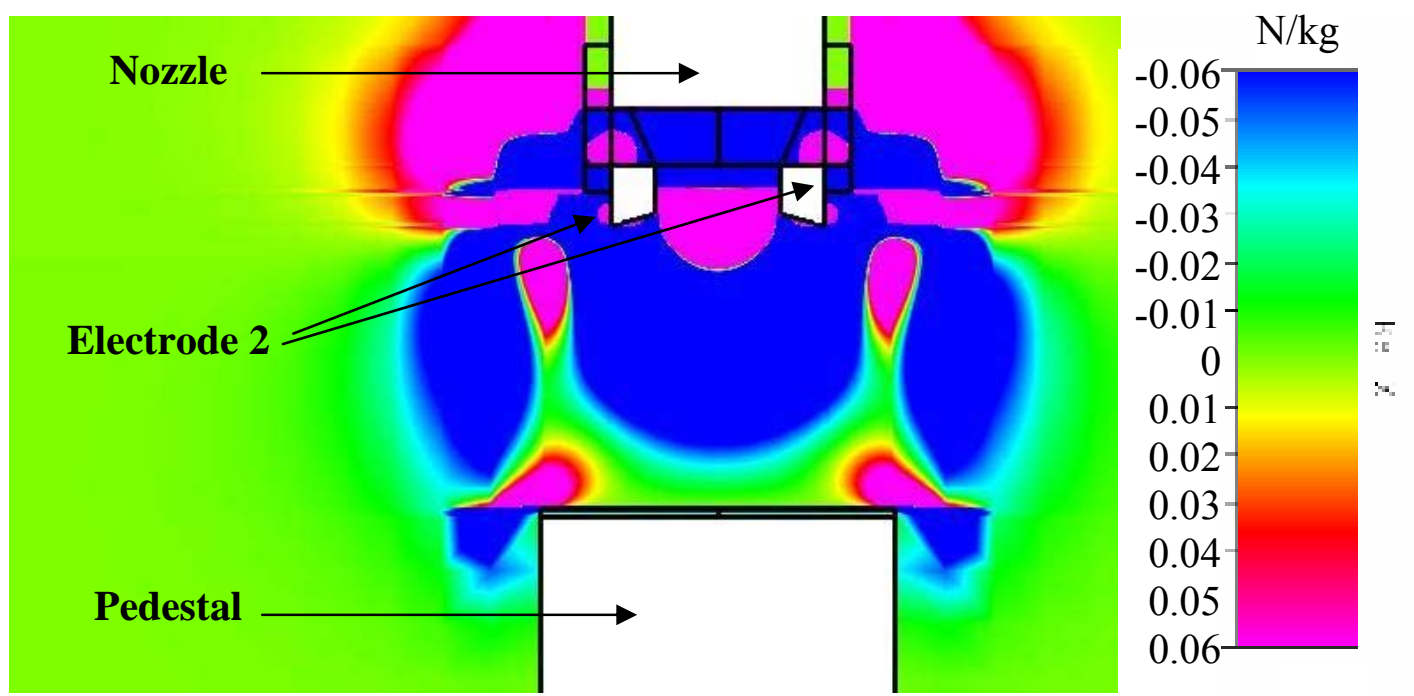

Figure 5.54: Calculated Axial Kelvin Force/Mass for Electrode 2 Presented in $\mathrm{N} / \mathrm{kg}$ (Mehra, 2006)

The Coulomb force depends on both the induced charge and the electric field strength. The large potential present directly after the spray droplets leave the nozzle is desired in order to inductively charge the spray droplets. The charged droplets are then influenced by the resulting electric field until directly before they impact the heater surface. Figure 5.55 and Figure 5.56 represent the computed magnitude of the electric field in the x-direction immediately surrounding the nozzle outlet. From the plots it can be seen that the droplets experience a negative force immediately upon exiting the nozzle, and as the droplets move past the electrode the force transitions to positive thus creating a charge on the individual droplets. The effect of the electric field on the charged droplets creates a net force that depends on the polarity of the voltage source applied to the electrode. 


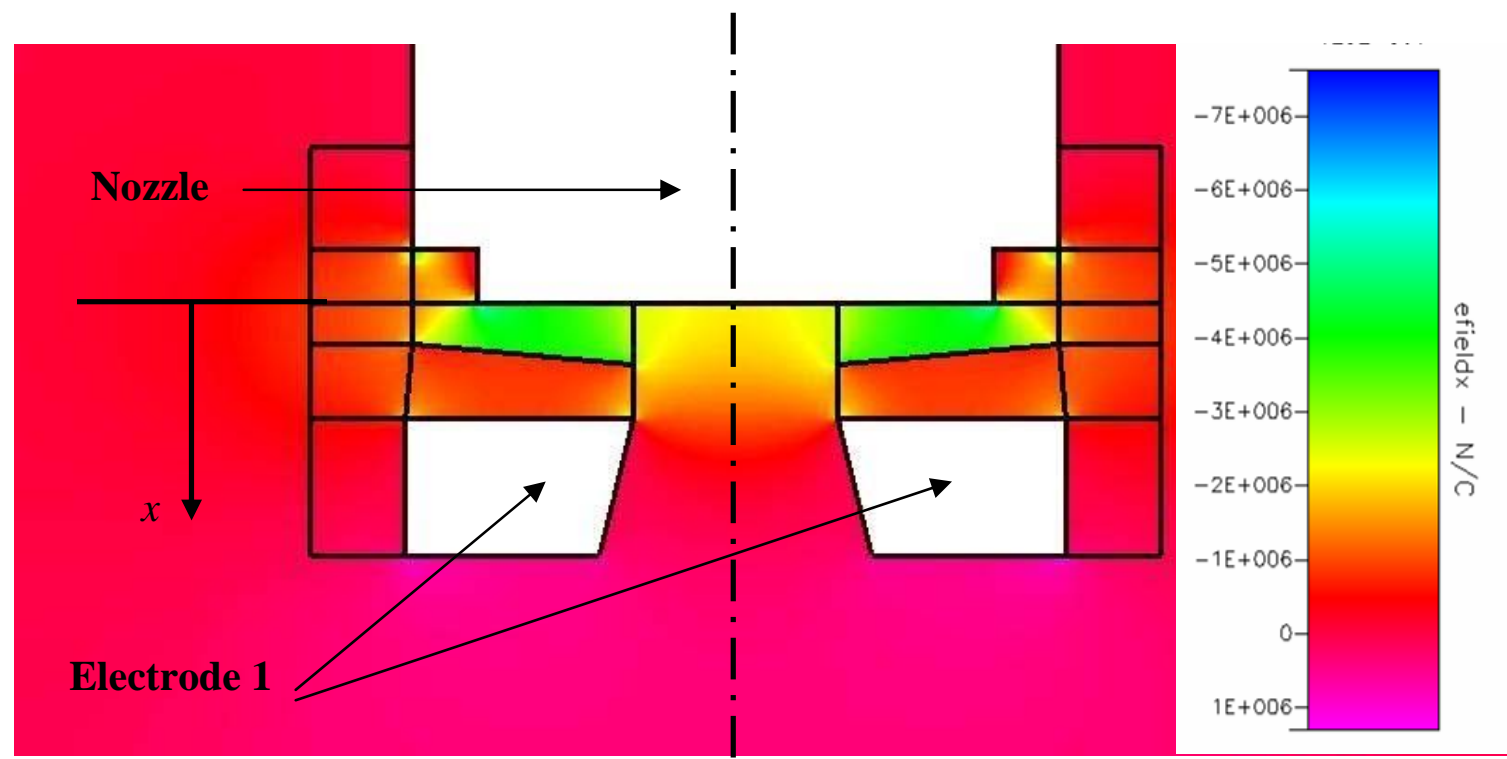

Figure 5.55: Calculated E field magnitude for Electrode 1 Presented in N/C (Mehra, 2006)
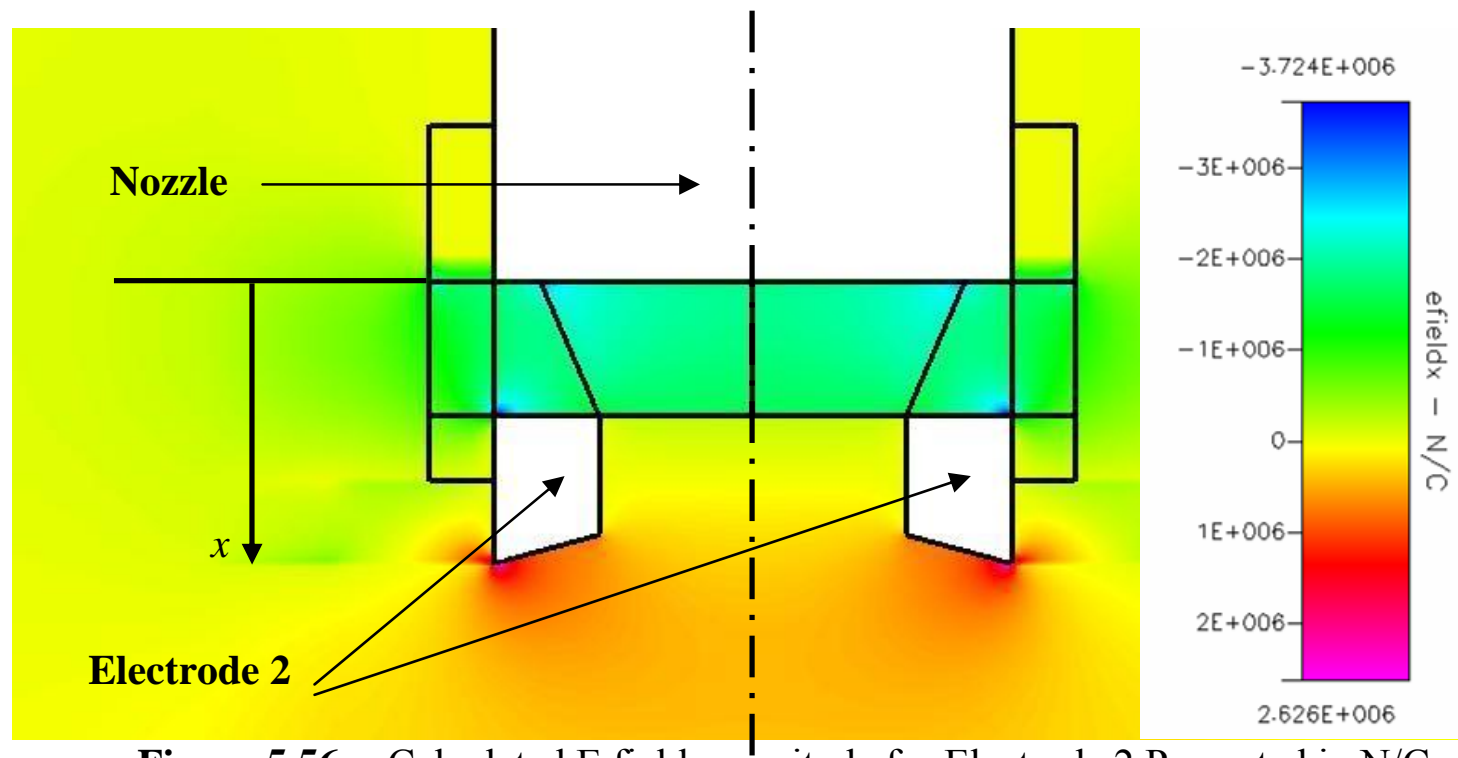

Figure 5.56: Calculated E field magnitude for Electrode 2 Presented in N/C (Mehra, 2006)

The magnitude of the resulting electric field at various axial locations can then be used to calculate the magnitude of the resulting Coulomb force experienced by the droplets. Figure 5.57 and Figure 5.58 represent the magnitude of the electric field in the $\mathrm{x}$ direction along the centerline of the previous two figures (Note: that the $\mathrm{x}$-direction is positive downwards in these figures). The magnitude of the Coulomb force is then calculated based on the charge experienced by each droplet using the geometry of the 
electrode, the size of the spray droplets, and the applied charging voltage to the electrode (Law, 1978). The calculated charge applied to each droplet is shown in Equation 5.1. This value is compared with the maximum possible charge a particle of this size can withstand based on the Rayleigh limit shown in Equation 5.2.

$$
\begin{aligned}
& q_{p}=\frac{m_{p} 2 \varepsilon_{0} V}{r_{p} r_{j}^{2} \ln \left(\frac{r_{c}}{r_{j}}\right)} \\
& q_{\max }=8 \pi \sqrt{\varepsilon_{0} \sigma} r_{p}^{\left(\frac{3}{2}\right)} \\
& F_{p}=q_{p} E
\end{aligned}
$$

Here,

$$
\begin{array}{ll}
\mathrm{q}_{\mathrm{p}} & \text { Particle charge, } \mathrm{C} \\
\varepsilon_{0} & \text { Permittivity of air }=8.85 \times 10^{-12} \mathrm{C}^{2} / \mathrm{N}-\mathrm{m}^{2} \\
\mathrm{r}_{\mathrm{p}} & \text { Radius of particle, } \mathrm{m} \\
\mathrm{r}_{\mathrm{c}} & \text { Outer radius of electrode, } \mathrm{m} \\
\mathrm{r}_{\mathrm{j}} & \text { Radius of liquid jet, } \mathrm{m} \\
\mathrm{m}_{\mathrm{p}} & \text { Particle mass, kg } \\
\mathrm{V} & \text { Applied charging voltage, } \mathrm{V} \\
\sigma & \text { Surface tension, } \mathrm{kg} / \mathrm{s}^{2} \\
\mathrm{E} & \text { Electric potential gradient, } \mathrm{N} / \mathrm{C}
\end{array}
$$

The efficiency that each droplet is being charged using inductive spray charging can be calculated by comparing the charge applied to each droplet by the two electrodes, with the maximum charge possible on a droplet $48 \mu \mathrm{m}$ in diameter as defined in Equation 5.4. A typical calculated charging efficiency of approximately $1.5 \%$ was found using both fluids and both electrodes.

$$
\eta=\frac{q_{\text {electrode }}}{q_{\max }}
$$




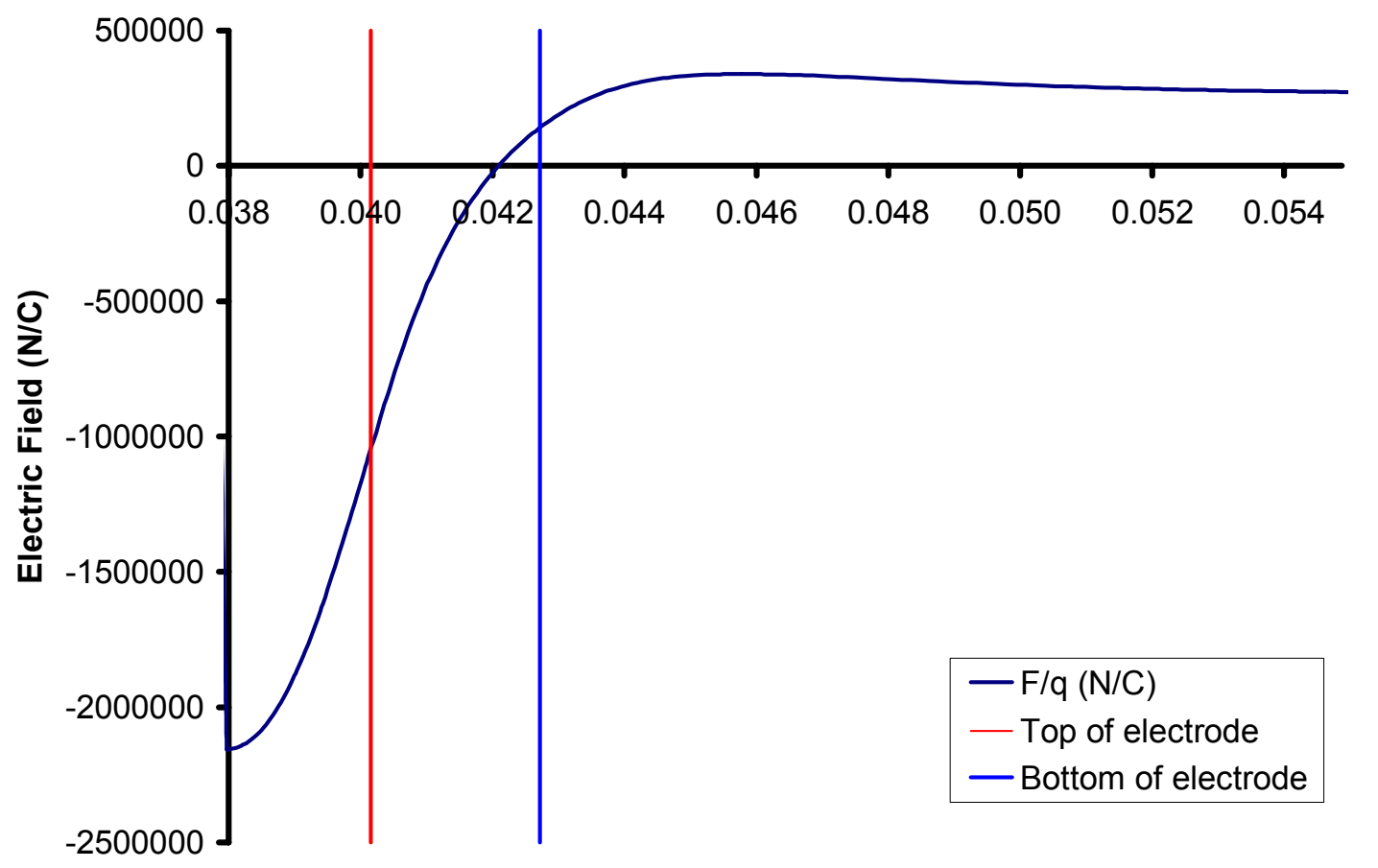

Axial Location (m)

Figure 5.57: Calculated E field magnitude along the centerline for Electrode 1 Presented in N/C (Mehra, 2006)

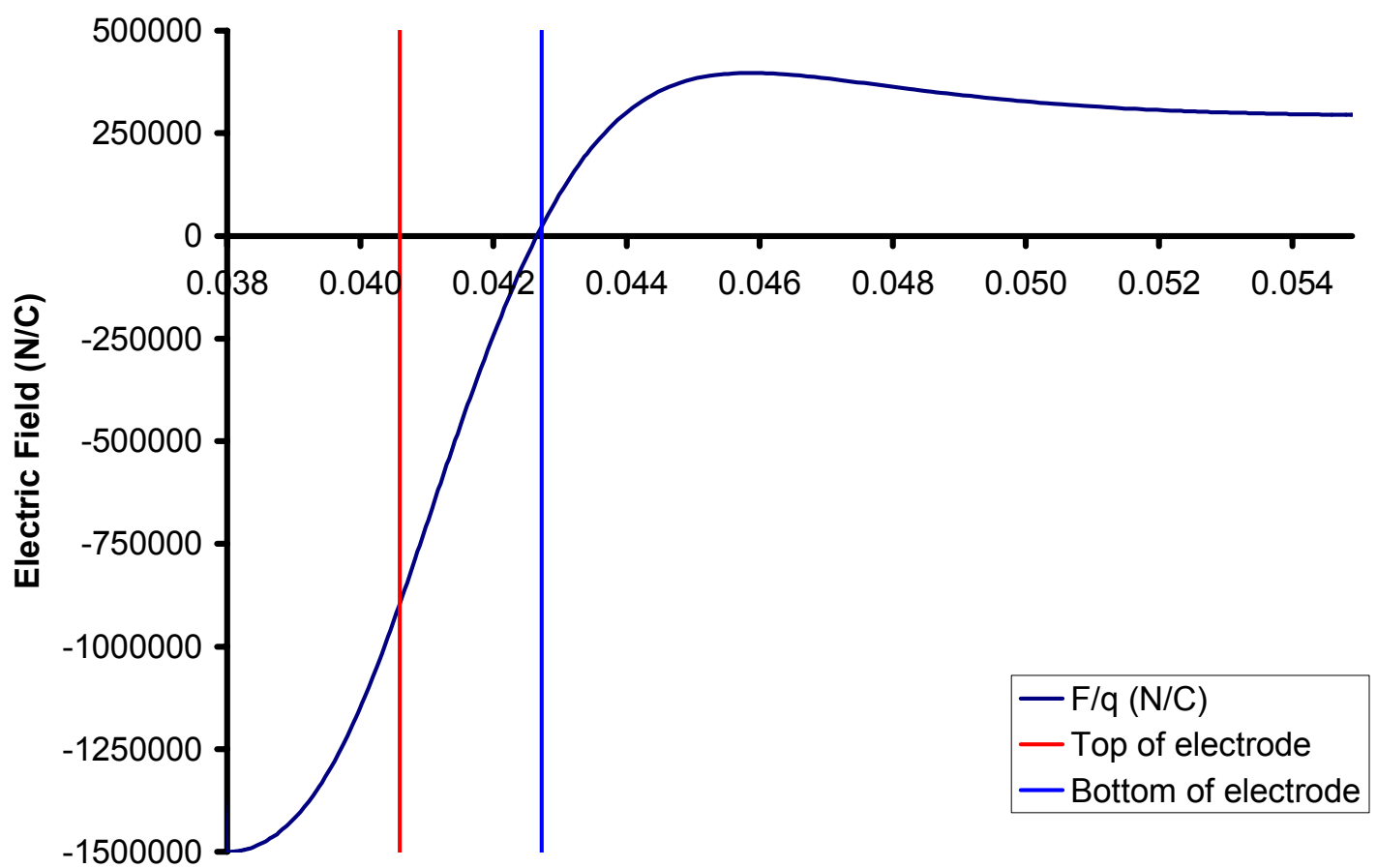

Axial Location (m)

Figure 5.58: Calculated E field magnitude along the centerline for Electrode 2 Presented in N/C (Mehra, 2006) 
Using the calculated electric field present along the centerline of the spray trajectory a force seen by the particles has been calculated based on the computed charge present. The applied voltage of the electrode in the experiments ranged from $0 \mathrm{kV}$ to 6 $\mathrm{kV}$. Table 5.2 and Table 5.3 represent the resulting Coulomb force calculated at the top and bottom of each electrode for voltages ranging from $0 \mathrm{kV}$ to $6 \mathrm{kV}$.

Table 5.2: $\quad$ Droplet Charge and Resulting Coulomb Force Exerted on the Droplet at the Top and Bottom of Electrode 1

\begin{tabular}{|c|ccc|ccc|}
\hline & \multicolumn{3}{|c|}{ Electrode 1 FC-72 } & \multicolumn{3}{c|}{ Electrode 1 HFE-7000 } \\
\hline Voltage & $\mathbf{q}_{\mathbf{p}}$ & $\mathbf{F}_{\mathbf{p} \text { top }}$ & $\mathbf{F}_{\mathbf{p} \text { bot }}$ & $\mathbf{q}_{\mathbf{p}}$ & $\mathbf{F}_{\mathbf{p} \text { top }}$ & $\mathbf{F}_{\mathbf{p} \text { bot }}$ \\
$\mathbf{V}$ & $\mathbf{C}$ & $\mathbf{N} / \mathbf{k g}$ & $\mathbf{N} / \mathbf{k g}$ & $\mathbf{C}$ & $\mathbf{N} / \mathbf{k g}$ & $\mathbf{N} / \mathbf{k g}$ \\
0 & 0 & 0.00 & 0.00 & 0 & 0.00 & 0.00 \\
-1000 & $-2.17 \mathrm{E}-15$ & 24.13 & -3.21 & $-2.2 \mathrm{E}-15$ & 28.95 & -3.86 \\
-2500 & $-5.43 \mathrm{E}-15$ & 60.32 & -8.03 & $-5.4 \mathrm{E}-15$ & 72.38 & -9.64 \\
-5000 & $-1.09 \mathrm{E}-14$ & 120.64 & -16.06 & $-1.1 \mathrm{E}-14$ & 144.76 & -19.28 \\
-6000 & $-1.30 \mathrm{E}-14$ & 144.76 & -19.28 & $-1.3 \mathrm{E}-14$ & 173.71 & -23.13 \\
\hline
\end{tabular}

Table 5.3: Droplet Charge and Resulting Coulomb Force Exerted on the Droplet at the Top and Bottom of Electrode 2

\begin{tabular}{|c|ccc|ccc|}
\hline & \multicolumn{3}{|c|}{ Electrode 2 FC-72 } & \multicolumn{3}{c|}{ Electrode 2 HFE-7000 } \\
\hline Voltage & $\mathbf{q}_{\mathbf{p}}$ & $\mathbf{F}_{\mathbf{p} \text { top }}$ & $\mathbf{F}_{\mathbf{p} \text { bot }}$ & $\mathbf{q _ { p }}$ & $\mathbf{F}_{\mathbf{p} \text { top }}$ & $\mathbf{F}_{\mathbf{p} \text { bot }}$ \\
$\mathbf{V}$ & $\mathbf{C}$ & $\mathbf{N} / \mathbf{k g}$ & $\mathbf{N} / \mathbf{k g}$ & $\mathbf{C}$ & $\mathbf{N} / \mathbf{k g}$ & $\mathbf{N} / \mathbf{k g}$ \\
0 & 0 & 0.00 & 0.00 & 0 & 0.00 & 0.00 \\
-1000 & $-2.39 \mathrm{E}-15$ & 22.34 & -0.55 & $-2.4 \mathrm{E}-15$ & 26.81 & -0.66 \\
-2500 & $-5.97 \mathrm{E}-15$ & 55.86 & -1.38 & $-6 \mathrm{E}-15$ & 67.03 & -1.65 \\
-5000 & $-1.19 \mathrm{E}-14$ & 111.72 & -2.75 & $-1.2 \mathrm{E}-14$ & 134.06 & -3.31 \\
-6000 & $-1.43 \mathrm{E}-14$ & 134.06 & -3.31 & $-1.4 \mathrm{E}-14$ & 160.87 & -3.97 \\
\hline
\end{tabular}

The results from this study of an ideally charged spray droplet indicate that the amount of force actually exerted on the droplets must have been much smaller than the maximum calculated force shown in Table 5.2 and Table 5.3. This conclusion has been reached because only a small effect of the electrode charging voltage on spray cooling performance has been seen in the present work. The calculated Coulomb force exerted on the droplets at $6 \mathrm{kV}$ varies slightly between electrode 1 and electrode 2 . Electrode 1 is slightly better at charging the droplets because of the larger outer radius of the electrode. 


\section{CHAPTER 6 : CONCLUSIONS AND RECOMMENDATIONS}

Throughout this research several different approaches were taken. This chapter will discuss the results from each of the different electrode configurations and draw conclusions based on the resulting trends that were observed. Several complications arose during the research process, and as a result several recommendations can be suggested to aid in future work.

\section{Section 6.1: Conclusions}

The main objective of this research was to determine the effectiveness of the Coulomb force for enhancing the heat transfer observed during spray cooling. However, before experimentation could begin, a series of modifications and upgrades had to be made to the apparatus used by Hunnell (2005) for preliminary data collection.

Based on the recommendations of Hunnell (2005) an Agilent data acquisition system was implemented. Controlling the amount of subcooling in the system was another concern that was addressed. However, due to complications the re-heater was not able to be used during the current data taking process. Similarly, a turbine flow meter was installed to more accurately and continuously measure the flow rate of the working fluid directly before the spray nozzle. However, manufacturing problems or damage to the bearings led to an unreliable measurement accuracy at the lower flow rates. New rotameters were installed to measure the flow rate, since the turbine flow meter could not be used during the current work. Finally, a bypass was installed to control the flow rate of the working fluid from the sump in the spray chamber. For FC-72 an air content of 22 
percent by volume was obtained for the WVU apparatus using a Mercury Aire-ometer at WPAFB.

Once the above changes were made to the experimental apparatus data taking could begin. Variations of Nusselt number at a constant $\mathrm{G} \Delta$ of as much as $7 \%$ to $14 \%$ were observed in performance between nozzles made of different materials. However, these variations were not much larger than the $5 \%$ observed variation between two identical brass nozzles. This study was not able to determine definitively if the observed differences were due to the different nozzles or the changes in alignment of the nozzle assembly, but it is believed that much of this observed variation was due to variation in the nozzle alignment.

Initial testing with the first electrode and the original TFR heater placed on a glass pedestal yielded a repeatable, negative effect on heat transfer performance. The heater surface temperature was seen to increase as much as $5{ }^{\circ} \mathrm{C}$ with application of a negative polarity voltage level of $6 \mathrm{kV}$ to the electrode. Unfortunately $\mathrm{CHF}$ events damaged the initial TFR heater during these tests to a point where it had to be replaced. Results gathered with the repaired pedestal and new TFR heater showed no effects when a voltage was applied to the electrode. A transition in working fluid was then made from FC-72 to HFE-7000 which had better electrical properties that were expected to greatly enhance the effects of the Coulomb force. The results obtained using HFE-7000 with the repaired pedestal showed a similar lack of results.

The pedestal was then changed to the PTFE pedestal. Two separate test runs were then conducted with the new experimental configuration at two different flow rates. The higher flow rate yielded an increase in heat flux of approximately $13 \%$ at a specific 
surface temperature. With a lower flow rate this increase was seen to increase to as much as $17 \%$. It is believed that the slower droplet velocity present with the lower flow rate allowed a larger charge to transfer from the electrode to the droplets as they pass through the electrode. More exhaustive testing must be performed in the future in order to determine the optimal electrode design and desired flow rate that will produce the largest enhancement in heat transfer during spray cooling.

\section{Section 6.2: $\quad$ Recommendations}

Seeing the amount of change that varying very few parameters has on the resulting heat transfer effects, more exhaustive tests should be performed that include several additional parameters. Introducing precise controllability and measurement of these parameters will help to better understand what factors enhance heat transfer in spray cooling the most.

One such parameter is the use of a re-heater to control the amount of subcooling. The ability to control the amount of subcooling present in the spray chamber will possibly initiate nucleate boiling at lower levels of heat flux. Because the present work is concerned primarily with what occurs during the two-phase heat transfer region controlling the level of subcooling may allow data acquisition for most of the singlephase region to be skipped. Installing the re-heater directly before the spray nozzle will give maximum controllability of the temperature of the impinging spray with respect to the saturation temperature inside the spray chamber. Another recommendation would be to return the turbine flow meter to proper working order. A precise measurement of the flow rate throughout the entire test matrix would allow more reliable results to be 
obtained. Another parameter that can alter heat transfer performance is the air content of the working fluid. Building an air content measurement system into the flow loop would allow for continuous measurements as opposed to the current system that requires samples to be taken and measured in a mercury Aire-ometer.

Because of the varying test conditions that were present due to the TFR heater failing and the need to replace the heater on the pedestal, a lower temperature limit setting in the cut out relay should be implemented, in an effort to avoid damaging the heaters. It is recommended by Mini Systems Inc. that the heater surface temperature should not exceed $150{ }^{\circ} \mathrm{C}$ for optimal performance. Typically CHF occurs at or below $100{ }^{\circ} \mathrm{C}$; therefore, the increased temperature only allows more data points to be taken as CHF is occurring. This is not necessarily desired, and could be a reason for the pedestal and/or heater cracking prematurely.

The test matrix should also be repeated with a new pedestal. The observable results only occurred with the original new TFR which was mounted to a glass pedestal and the newer PTFE TFR pedestal. The test matrix should also include several runs at the same flow rate to prove repeatability.

Another aspect of the experiment that should be addressed is the increased system operating pressure that was observed after switching fluids from FC-72 to HFE-7000. This could be due to several things. To correct this problem the entire working fluid flow loop should be cleaned. This would include replacing all filters, checking for pipe tape in the line from changing the fluid, and the sump should be examined to make sure that the sump drain lines have not become partially clogged. Also, because of the current design a valve should be installed between the reservoir and the nozzle pump. This would allow 
greater control in changing components after this point in the system without having any fluid losses.

Most importantly, since the original results were not able to be repeated, tests should be run varying the electrode position with respect to the spray nozzle. It is believed that small changes in how the electrode was positioned on the spray nozzle, as well as the axial spacing between the nozzle and the pedestal may have contributed to the lack of results in some of the present test runs (Law, 1978). Another item that should be tested is the spacing between the nozzle and the electrode. For inductive charging of spray droplets to take place it is desired that the electrode be positioned at the proper location with respect formation of the spray droplets (Law, 1978). It is also recommended that contact charging of the spray should be investigated, where the nozzle is charged and the electrode is grounded.

Research has shown a drastic increase in electrical forces seen by different fluids. Another suggestion would be to find a different dielectric working fluid that could be inductively charged even better, or more easily. Also, further research should be conducted to determine if the calculated heater surface temperature is accurate. Several methods could be used to perform this task, including but not limited to placing a thermocouple on the heater surface to measure the surface temperature directly. An infrared camera might also be used to visually show the different temperatures inside the spray chamber, focusing particularly on the heater surface. Other methods of flow visualization should also be used to better understand the physics that is taking place on the surface of the pedestal heater as CHF takes place. This type of analysis may also be 
able to better determine the details of the interaction of the fluid droplets with the thin layer of liquid on the heater surface. 


\section{REFERENCES}

Baysinger, K., "Experimental Testing and Numerical Modeling of Spray Cooling Under Terrestrial Gravity Conditions,” M. S. Thesis, Wright State University, Dayton, OH, 2004.

Baysinger, K. M., Yerkes, K. L., and Michalak, T. E., "Design of a Microgravity Spray Cooling Experiment," 42 ${ }^{\text {nd }}$ AIAA Aerospace Sciences Conference and Exhibit, Reno, NV, January, 2004.

Bernardin, J. D., Stebbins, C. J., and Mudawar, I., "Mapping of Impact and Heat Transfer Regimes of Water Drops Impinging on a Polished Surface," Int. J. Heat Mass Transfer, Vol. 40, pp. 247-267, 1997.

Chen, R.H., Chow, L.C., and Navedo, J.E., "Effects of Spray Characteristics on Critical Heat Flux in Subcooled Water Spray Cooling," International Journal of Heat and mass Transfer, Vol. 45, pp. 4033-4043, 2002.

Chow, L. C., Sehmbey, M. S., and Pais, M. R., "High Heat Flux Spray Cooling," Annual Review of Heat Transfer, Vol. 8, pp. 291-318, Hemisphere Pub. Corp., New York, 1997.

Cipriani, M., Di Marco, P., and Grassi, W., "Effect of an Externally Applied Electric Field on Pool Film Boiling of FC-72," Heat Transfer Engineering, Vol. 25, No. 6, pp. 3-13, January, 2004.

Di Marco, P. and Grassi, W., "Motivation and Results of a Long-Term Research on Pool Boiling Heat Transfer in Low Gravity," International Journal of Thermal Sciences, Vol. 41, pp. 567-585, 2002.

Hunnell, C. A., "Design, Construction, and Initial Testing of Experimental Test Package for Convective Spray Cooling in Terrestrial Gravity Conditions," M. S. Thesis, West Virginia University, Morgantown, WV, 2005.

Glaspell, S., Personal Communication, 2006.

Kim, J., "Spray Cooling Heat Transfer: The State of the Art," ECI International Conference on Boiling Heat Transfer, Spoleto, Italy, May, 2006.

Kuhlman, J. M., Gray, D. D., Glaspell, S. L., and Kreitzer, P. J., "Positioning of Simulated Vapor Bubbles in Microgravity by the Kelvin Force," $38^{\text {th }}$ AIAA Thermophysics Conference, Toronto, Canada, June, 2005.

Law, S., "Embedded-Electrode Electrostatic-Induction Spray-Charging Nozzle: Theoretical and Engineering Design," Transactions of the American Society of Agricultural Engineers, pp. 10961104, 1978.

Lin, L., Ponnappan, R., "Heat Transfer Characteristics of Spray Cooling in a Closed Loop," International Journal of Heat and Mass Transfer 46, pp. 3737-3746, 2003. 
Mahefkey, T., Yerkes, K., Donovan, B., and Ramalingam, M. L., "Thermal Management Challenges for Future Military Aircraft Power Systems," SAE Technical Paper 2004-01-3204, Reno, Nevada, November, 2004.

Mehra, D., Personal Communication, April, 2006.

Mudawar, I., "Assessment of High-heat Flux Thermal Management Schemes," 2000 Intersociety Conference on Thermal Phenomena, Las Vegas, Nevada, 2000.

Pautsch, A.G. and Shedd, T. A., "Spray Impingement Cooling with Single- and Multiple-Nozzle Arrays Part I: Heat Transfer Data Using FC-72," International Journal of Heat and Mass Transfer, Vol. 48, No. 15, pp. 3176-3184, July, 2005.

Rainey, K.M., You, S.M., Lee, S., "Effects of Pressure, Subcooling, and Dissolved Gas on Pool Boiling Heat Transfer From Microporous Surfaces in FC-72," Journal of Heat Transfer, Vol. 125, pp. 75-83, February, 2003.

Sehmbey, M. S., Chow, L. C., Hahn, O. J., and Pais, M. R., "Effect of Spray Characteristics on Spray Cooling with Liquid Nitrogen," Journal of Thermophysics and Heat Transfer, Vol. 9, No. 4, October-December, 1995.

Shedd, T. A. and Pautsch, A. G., "Spray Impingement Cooling with Single- and Multiple-Nozzle Arrays Part II: Visualization and Empirical Models," International Journal of Heat and Mass Transfer, Vol. 48, No. 15, pp. 3176-3184, July, 2005.

Straub, J., "Boiling heat transfer and bubble dynamics in microgravity," Advances In Heat Transfer, Vol 35, pgs 57-172, 2001.

Tilton, D. E., "Spray Cooling," Ph. D. Dissertation, University of Kentucky, Lexington, KY, 1989.

Wolf, D., Incropera, F., Viskanta, R., “Jet Impingement Boiling,” Advance In Heat Transfer, Vol. 23, pgs 1-133, 1993.

Yang, J., "Spray Cooling with an air atomizing nozzle," Ph. D. Dissertation, University of Kentucky, Lexington, KY, 1993.

Yerkes, K. L., Michalak, T., Baysinger, K., Puterbaugh, R., Thomas, S. K., and McQuillen, J., 2006, "Variable-Gravity Effects on a Single-Phase Partially-Confined Spray Cooling System," 44th AIAA Aerospace Sciences Meeting and Exhibit, AIAA-2006-0596, Reno NV, 9-12 Jan. 2006; also accepted for publication, AIAA Journal of Thermophysics and Heat Transfer.

You, S.M., Simon, T.W., Bar-Cohen, A., Hong, Y.S., "Effects of Dissolved Gas Content on Pool Boiling of a Highly Wetting Fluid," Journal of Heat Transfer, Vol. 117, pp. 687-692, August, 1995. 


\section{APPENDIX A : THERMOCOUPLE CALIBRATION}

In order to have a valid data set for each proposed data run, the slope and intercept (also known as offset and gain) for each thermocouple had to be determined. Thermocouple calibration creates a correction factor for each thermocouple. These correction factors offset the value read by the data acquisition system for each thermocouple by a set amount, insuring that the reading is correct according to industry standards.

To perform the calibration a Hart Scientific 7320 constant temperature calibration bath was used to regulate the temperature seen by each thermocouple. A previously calibrated resistance temperature detector (RTD) probe was used as a temperature standard to read the actual or correct temperature. Since the test fluid of interest is FC-72 which evaporates quickly and is expensive, an alternative fluid had to be used. Water is usually a good substitute. However, this would limit the maximum temperature, since the water would boil off during the two days of data taking. Therefore, the bath was filled with oil to give maximum thermal flexibility during the calibration, thus allowing the temperature bath to exceed 100 degrees Celsius $\left({ }^{\circ} \mathrm{C}\right)$ without the liquid boiling away.

The calibration was limited to 16 temperature channels because of a shipment error that resulted in only one of the three data acquisition cards arriving in time for the calibration. Because of this limitation the 16 most important thermocouple locations were established and those were thermocouples that were calibrated. It was decided that the thermocouples in the two Thick Film Resistor (TFR) pedestals, the nozzle inlet, and the sump up and sump down were the thermocouples that were selected. 
In order to ensure an accurate as possible calibration, the setup used had to be as close to the actual experimental setup as possible. The data acquisition system used was an Agilent 34970A data acquisition switch unit. This unit has slots for three data acquisition cards, and three Agilent 34902A 16 channel multiplexer modules were chosen. The 16 channels of the data acquisition card present during calibration were wired using Omega TT-E-30 duplex thermocouple wire, and Omega MQSS type E thermocouples and connectors.

Next, the data acquisition system and calibration bath were connected to a Dell laptop using an Agilent 82357A USB/GPIB interface connection and an RS-232 serial connection, respectively. This allowed a Visual Basic computer program developed by Mr. Richard Harris (WPAFB) to run the calibration. The program set the temperature of the calibration bath and monitored the accuracy using the previously calibrated RTD temperature probe.

The temperature of the bath was then started at $35^{\circ} \mathrm{C}$ and incremented by steps of $10{ }^{\circ} \mathrm{C}$ to an upper limit of $140{ }^{\circ} \mathrm{C}$ (therefore the final reading was taken at $135^{\circ} \mathrm{C}$ ). Each step was monitored for over two hours, reading a temperature value every 10 seconds allowing the proper slope and intercept for each thermocouple to be accurately determined. To obtain a more accurate calibration, once the bath reached the upper limit, an additional calibration was performed while the bath was cooled down in a regulated fashion and temperatures readings were taken. The entire calibration process took just over two days to complete.

The raw data from the calibration consisted of the actual temperature as read by the RTD for each step along with the readings of each thermocouple channel averaged 
over the two hour step interval. The raw calibration data can be seen in Table A.1. Table

3.1 describes the location of $\mathrm{T}_{1}-\mathrm{T}_{16}$ in the experimental apparatus. Note that channels $\mathrm{TC}$

\#1 and TC \#7 correspond to the interface thermocouples for the old and new TFR heater pedestals respectively.

Table A.1: $\quad$ Raw Calibration Data

\begin{tabular}{|r|r|r|r|r|r|r|r|r|r|}
\hline $\begin{array}{c}\text { RTD } \\
\text { Temp }\end{array}$ & TC \#1 & TC \#2 & TC \#3 & \multicolumn{1}{|c|}{ TC \#4 } & TC \#5 & TC \#6 & TC \#7 & TC \#8 & TC \#9 \\
\hline 34.779 & 35.158 & 35.166 & 35.148 & 35.073 & 35.065 & 35.060 & 34.873 & 34.871 & 34.816 \\
\hline 44.745 & 45.098 & 45.135 & 45.135 & 45.065 & 45.051 & 45.062 & 44.837 & 44.861 & 44.831 \\
\hline 54.747 & 55.106 & 55.150 & 55.153 & 55.069 & 55.048 & 55.057 & 54.806 & 54.835 & 54.805 \\
\hline 64.746 & 65.199 & 65.265 & 65.282 & 65.189 & 65.167 & 65.175 & 64.904 & 64.946 & 64.928 \\
\hline 74.729 & 75.206 & 75.302 & 75.324 & 75.216 & 75.187 & 75.185 & 74.876 & 74.922 & 74.906 \\
\hline 84.698 & 85.240 & 85.339 & 85.368 & 85.257 & 85.226 & 85.218 & 84.900 & 84.952 & 84.940 \\
\hline 94.678 & 95.186 & 95.341 & 95.379 & 95.273 & 95.252 & 95.251 & 94.919 & 94.990 & 94.997 \\
\hline 104.677 & 105.250 & 105.434 & 105.475 & 105.352 & 105.326 & 105.316 & 104.940 & 105.019 & 105.026 \\
\hline 114.697 & 115.274 & 115.511 & 115.563 & 115.428 & 115.404 & 115.392 & 114.985 & 115.078 & 115.089 \\
\hline 124.684 & 125.262 & 125.586 & 125.643 & 125.492 & 125.476 & 125.464 & 125.005 & 125.174 & 125.192 \\
\hline 134.658 & 135.188 & 135.587 & 135.633 & 135.466 & 135.467 & 135.437 & 134.954 & 135.120 & 135.140 \\
\hline 94.675 & 95.237 & 95.414 & 95.447 & 95.333 & 95.306 & 95.302 & 94.923 & 95.029 & 95.023 \\
\hline 74.725 & 75.165 & 75.298 & 75.321 & 75.233 & 75.219 & 75.225 & 74.915 & 74.990 & 74.981 \\
\hline 54.746 & 55.162 & 55.202 & 55.203 & 55.116 & 55.101 & 55.096 & 54.872 & 54.886 & 54.839 \\
\hline 39.920 & 40.379 & 40.386 & 40.362 & 40.298 & 40.298 & 40.286 & 40.107 & 40.106 & 40.035 \\
\hline
\end{tabular}

\begin{tabular}{|r|r|r|r|r|r|r|r|c|c|}
\hline $\begin{array}{c}\text { RTD } \\
\text { Temp }\end{array}$ & TC \#10 & TC \#11 & TC \#12 & TC \#13 & TC \#14 & TC \#15 & TC \#16 & $\begin{array}{c}\text { Time } \\
\text { (Days) }\end{array}$ & $\begin{array}{c}\text { dTdt } \\
\text { ( }{ }^{\circ} \text { C/hr) }\end{array}$ \\
\hline 34.779 & 34.791 & 34.619 & 34.563 & 33.673 & 34.487 & 34.132 & 33.858 & 0.1042 & -0.2911 \\
\hline 44.745 & 44.808 & 44.632 & 44.598 & 43.239 & 44.594 & 44.122 & 43.989 & 0.2044 & 0.0508 \\
\hline 54.747 & 54.779 & 54.604 & 54.592 & 52.793 & 54.635 & 54.144 & 54.050 & 0.3046 & 0.0010 \\
\hline 64.746 & 64.906 & 64.733 & 64.730 & 62.626 & 64.823 & 64.218 & 64.244 & 0.3848 & -0.0910 \\
\hline 74.729 & 74.882 & 74.721 & 74.724 & 72.512 & 74.824 & 74.264 & 74.245 & 0.4650 & -0.0072 \\
\hline 84.698 & 84.918 & 84.769 & 84.786 & 82.496 & 84.911 & 84.464 & 84.348 & 0.5452 & 0.0215 \\
\hline 94.678 & 94.989 & 94.850 & 94.887 & 92.476 & 95.057 & 94.605 & 94.483 & 0.6253 & -0.0041 \\
\hline 104.677 & 105.019 & 104.898 & 104.937 & 102.569 & 105.101 & 104.615 & 104.514 & 0.7055 & 0.0632 \\
\hline 114.697 & 115.096 & 114.992 & 115.040 & 112.786 & 115.223 & 114.814 & 114.608 & 0.7857 & -0.0008 \\
\hline 124.684 & 125.195 & 125.088 & 125.136 & 122.964 & 125.319 & 125.002 & 124.720 & 0.8659 & -0.1944 \\
\hline 134.658 & 135.147 & 135.067 & 135.124 & 133.068 & 135.321 & 134.995 & 134.696 & 0.9461 & -0.0055 \\
\hline 94.675 & 95.010 & 94.863 & 94.874 & 92.685 & 94.991 & 94.472 & 94.396 & 1.1063 & 0.0014 \\
\hline 74.725 & 74.967 & 74.810 & 74.802 & 72.918 & 74.874 & 74.332 & 74.281 & 1.2665 & -0.0004 \\
\hline 54.746 & 54.826 & 54.660 & 54.636 & 53.163 & 54.611 & 53.952 & 54.015 & 1.4667 & -0.1220 \\
\hline 39.920 & 40.023 & 39.868 & 39.816 & 38.911 & 39.692 & 39.154 & 39.065 & 1.6669 & 0.2462 \\
\hline
\end{tabular}


Using least-squares curve fitting, an intercept and slope were calculated for each thermocouple. A sample plot of the calibration data and the curve fit equation can be seen in Figure A.1. The curve fit values then were entered into the data acquisition program to correct the measured temperature data. This calibration resulted in temperature data for channels 1-16 of the data acquisition system that are referenced to the RTD standard.

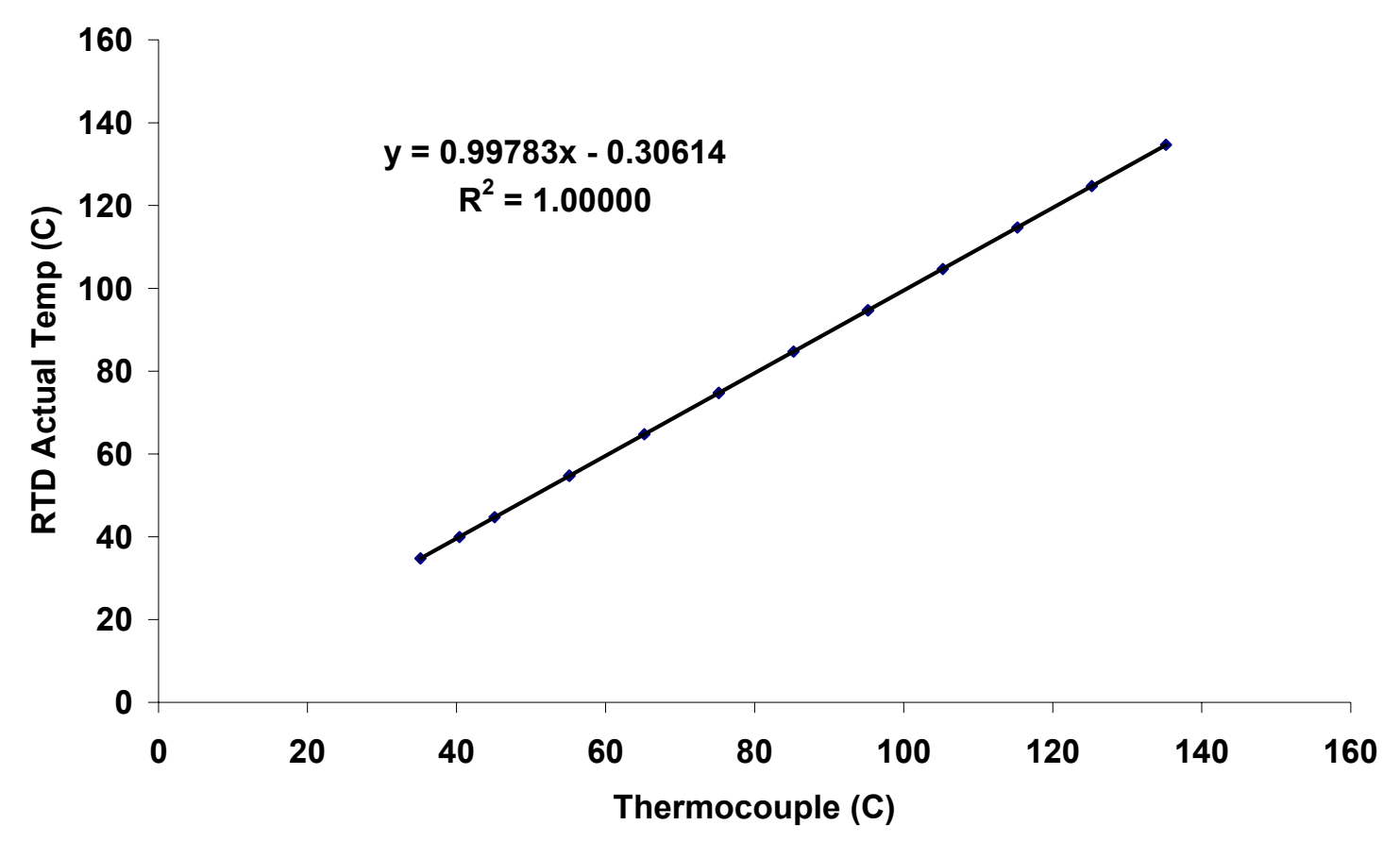

Figure A.1: Calibration Plot for Thermocouple 1 - Pedestal Interface 


\section{APPENDIX B : $\quad$ NOZZLE COMPARISON}

In order to install several electrode designs all metal components had to be moved away from the electrode configuration to prevent electric breakdown. The first step in accomplishing this is to replace the brass spray nozzle with an identical PVC 1/8-G Full Jet 1 nozzle made by Spraying Systems Incorporated. To make sure that the PVC nozzle was performing the same way as the brass nozzle, experiments were run to compare the nozzles. Three nozzles were tested, two brass and one PVC. The initial testing compared a brass nozzle to a PVC nozzle, resulting in a 14 percent variance in non-dimensional heat flux at a set temperature difference.

The spray pattern between the two nozzles looked different. The spray using the brass nozzle looked like it created a finer mist than the spray generated from the PVC nozzle. Therefore a second brass nozzle was also tested. The second brass nozzle fell directly in-between the two nozzles tested previously. The second brass nozzle varied 5 percent from the first brass nozzle and 7 percent from the PVC nozzle.

The test was conducted by increasing the heater power level from $10 \mathrm{~W}$ to $70 \mathrm{~W}$ in increments of $10 \mathrm{~W}$. All important parameters were recorded and used to calculate the heat flux, heat transfer coefficient, non-dimensional heat flux and the Nusselt number. These parameters were plotted to show the overall trend of each nozzle. It is important to note that even though nozzles may be manufactured by the same company with the same specifications, different spray patterns may result. This has been evident in the data runs comparing the brass nozzle with the PVC nozzle.

In order to completely ensure that no arcing would take place in the spray chamber, the entire nozzle assembly was replaced with a non conducting material. To 
accomplish this various fittings and pipe lengths were replaced with PTFE as shown in Figure B.1. For the nozzle testing the only variable changed was the nozzle, everything else being constant. With the new assembly there is plenty of room for different electrode configurations. Only minor changes had to be made after this test in order for the electrodes to be installed. The most important alteration was the thermocouple locations, two thermocouples had to be moved away from the nozzle, electrode assembly, to prevent arcing from taking place.

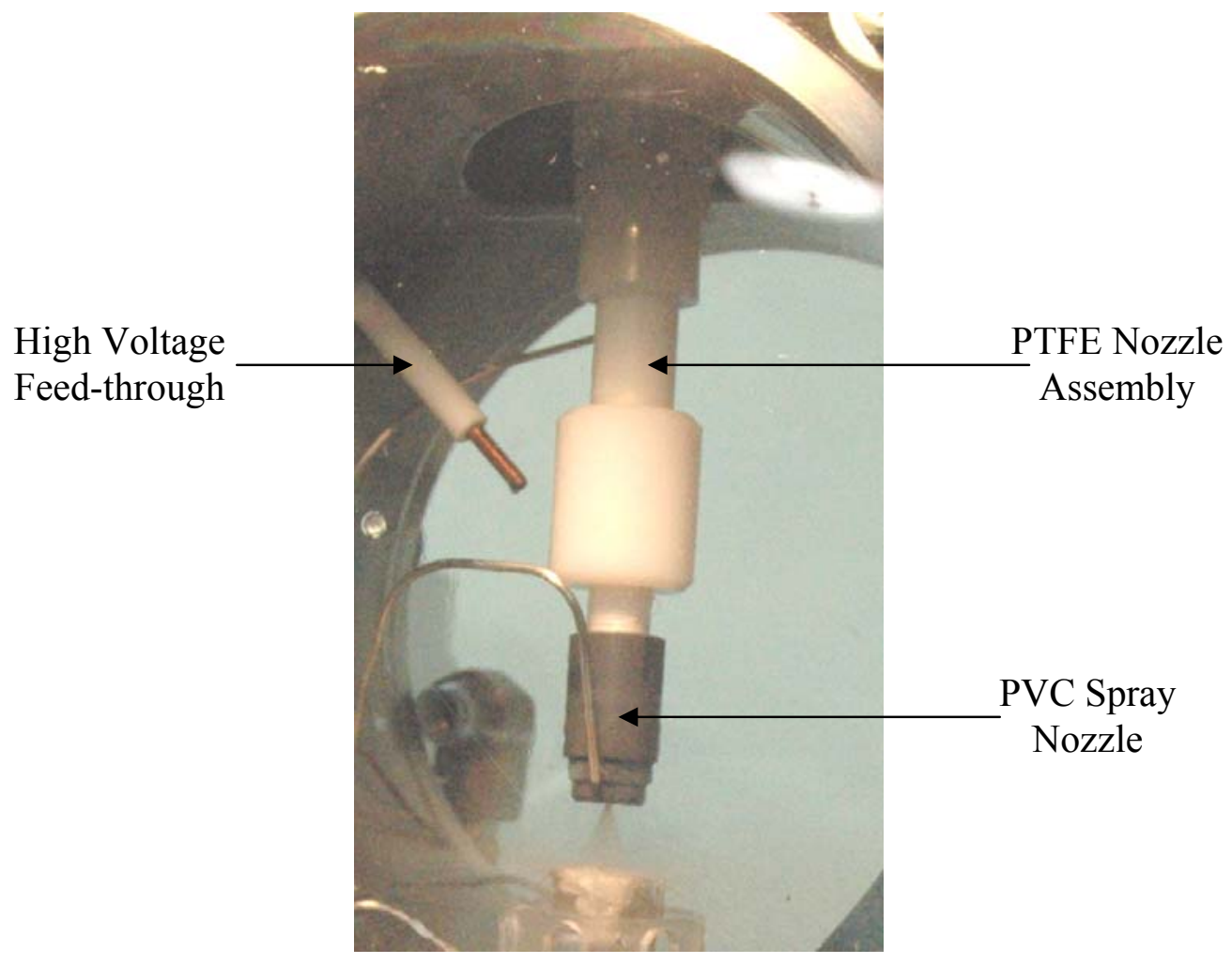

Figure B.1: Non-Conducting Nozzle and Assembly

The results of the nozzle comparison are shown in Figure B.2 - Figure B.5. Figure B.2 shows the heat flux as a function of temperature difference between the surface temperature and the spray temperature. Focusing in on the different curves, the same trend can be seen for all three nozzles at all three flow rates. However, there is a 
slight shift between different nozzles at the same flow rates. Looking closer, there is not a consistent difference between the PVC nozzle and both brass nozzles. The variation in heat flux at any fixed temperature ranges from 5 percent to 14 percent between the three nozzles. As one would expect, the curves related to the highest flow rate show the best performance. Figure B.3 shows a similar plot in the non-dimensional form with the same trends noticed.

Figure B.4 shows the heat transfer coefficient as a function of heat flux. From this plot there appears to be a steady and consistent increase of heat transfer coefficient as the heat flux increases. As to be expected, the highest flow rate shows the highest heat transfer coefficient at any given heat flux. Figure B.5 is similar to the previous figure, but shows the non-dimensional form. The same trends are noticed in performance between nozzles and flow rates.

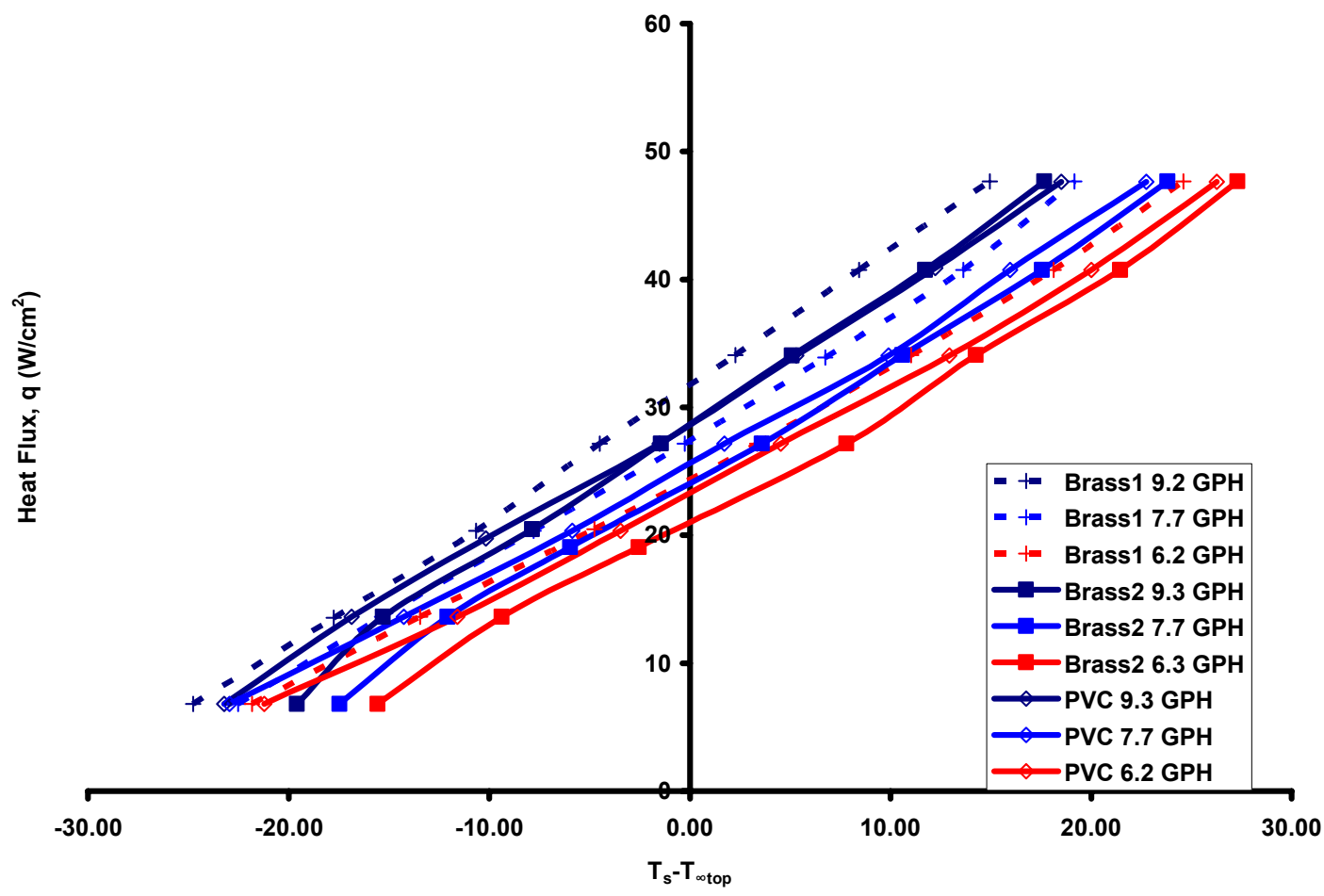

Figure B.2: Heat Flux as a Function of Temperature Difference for Nozzle Comparison at Different Flow Rates 


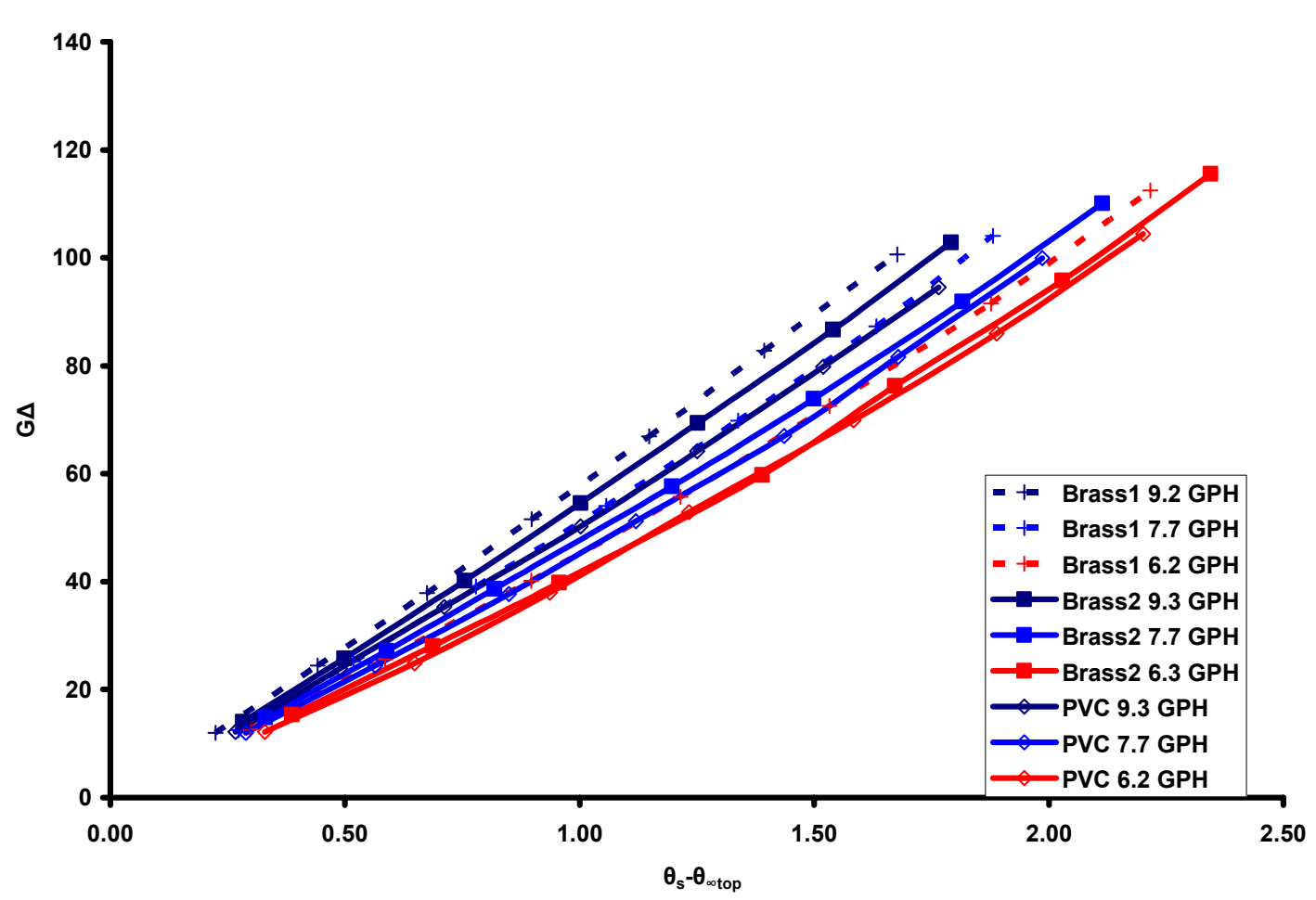

Figure B.3: Non-Dimensional Heat Flux as a Function of NonDimensional Temperature Difference for Nozzle Comparison at Different Flow Rates

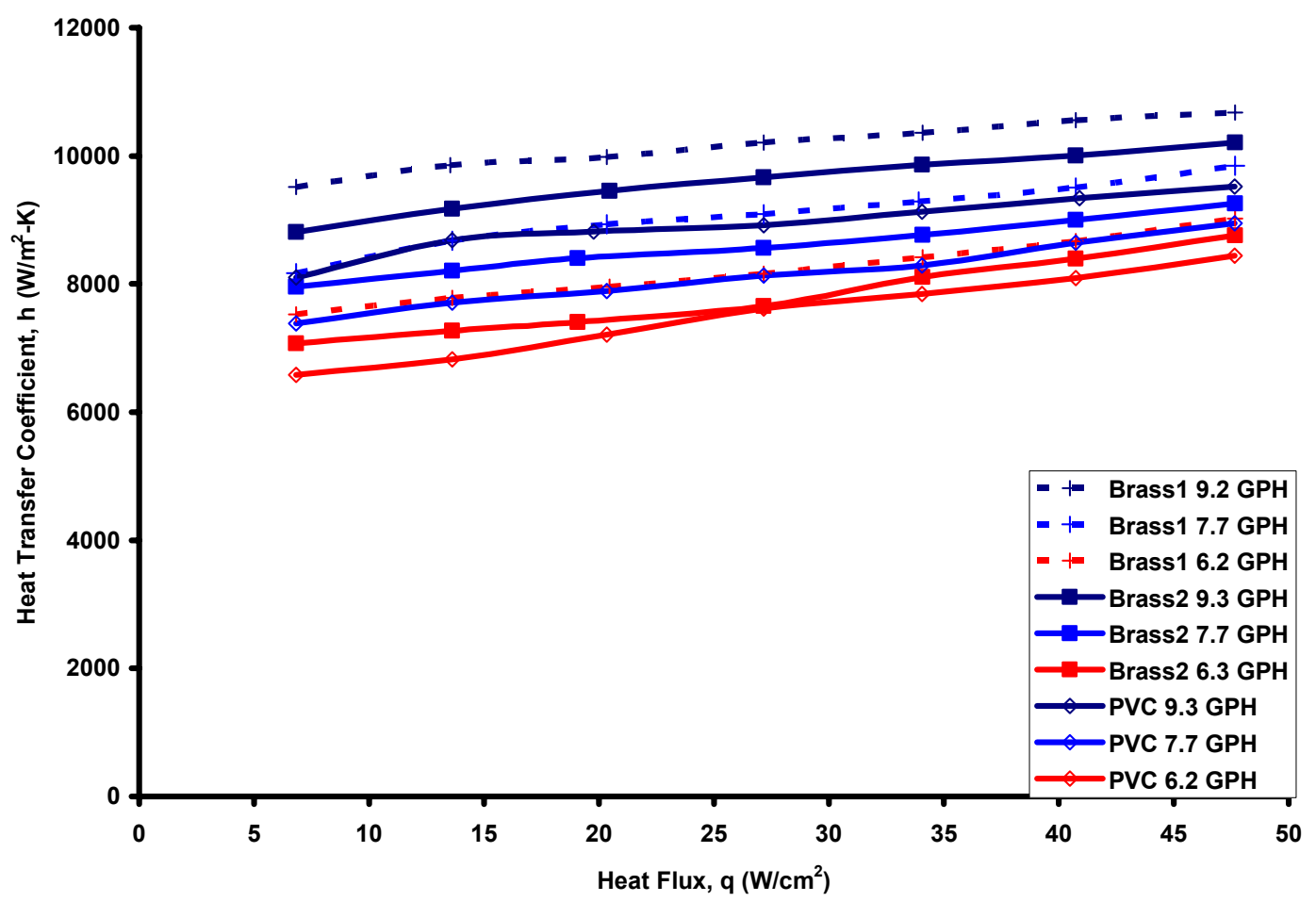

Figure B.4: Heat Transfer Coefficient as a Function of Heat Flux for Nozzle Comparison at Different Flow Rates 


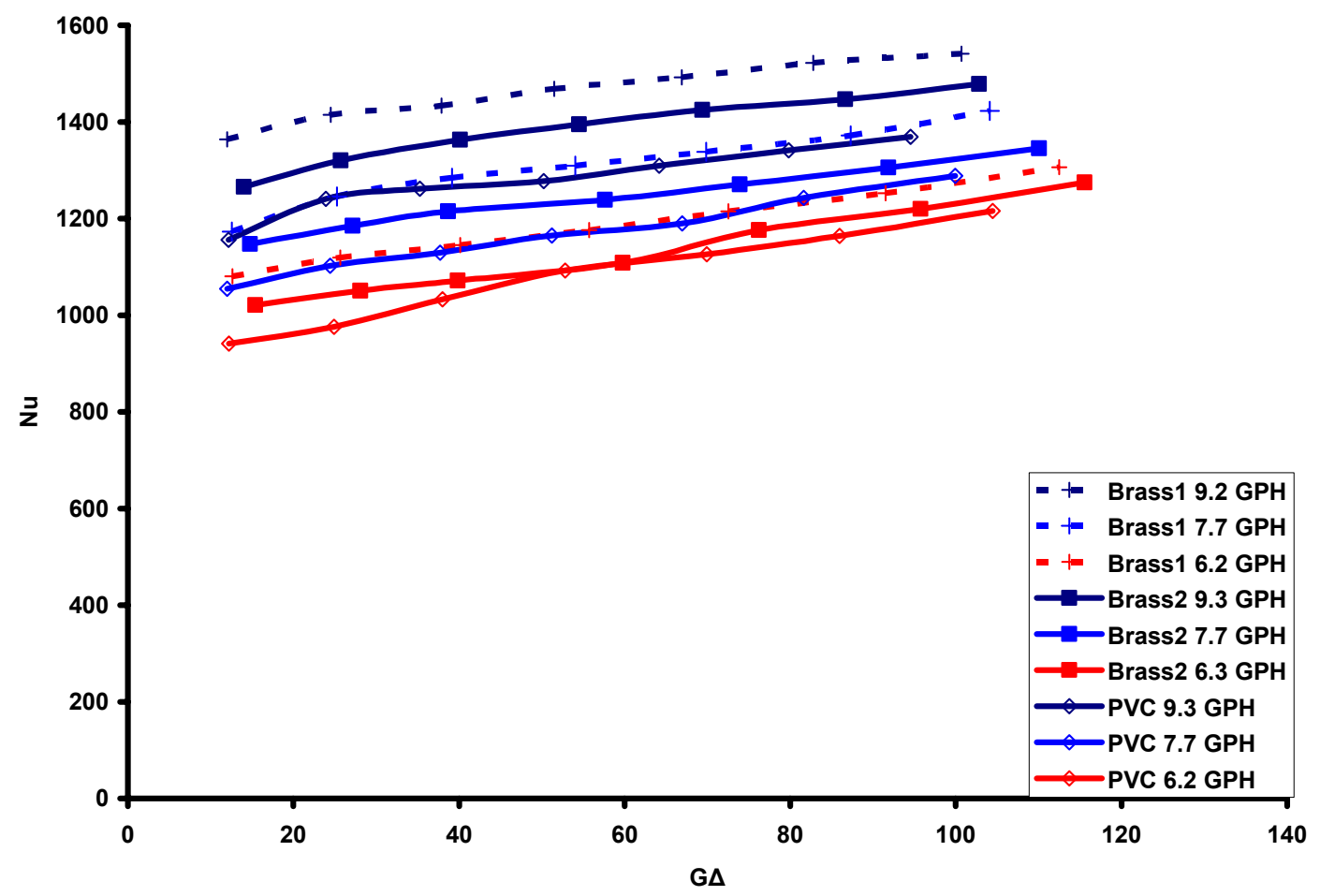

Figure B.5: Nusselt number as a Function of Non-Dimensional Heat Flux for Nozzle Comparison at Different Flow Rates 


\section{APPENDIX C : $\quad$ EXPERIMENTAL PLOTS}

Data plots showing the results for the repaired TFR pedestal with new TFR heater, electrode 1, and using a working fluid of FC-72 at 6.2, 7.7, and 9.3 GPH.

- Heat Flux vs. Temperature Difference

- Non-dimensional Heat Flux vs. Non- dimensional Temperature Difference

- Heat Transfer Coefficient vs. Heat Flux

- Non-dimensional Heat Transfer Coefficient vs. Non-dimensional Heat Flux 


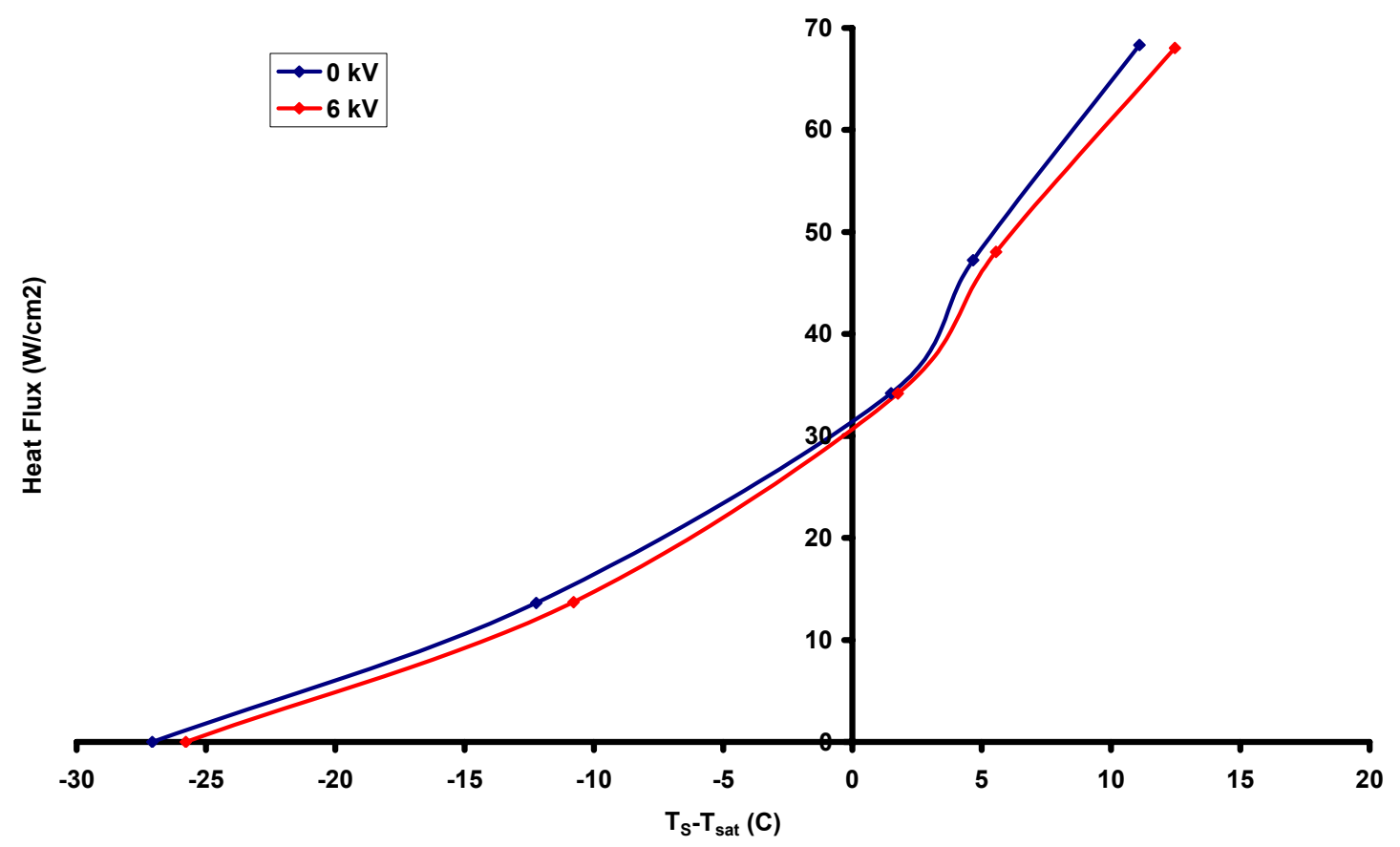

Figure C.1: Heat Flux vs. Temperature Difference for Repaired TFR Pedestal with New TFR Heater and Electrode 1 using FC-72 at 6.2 GPH

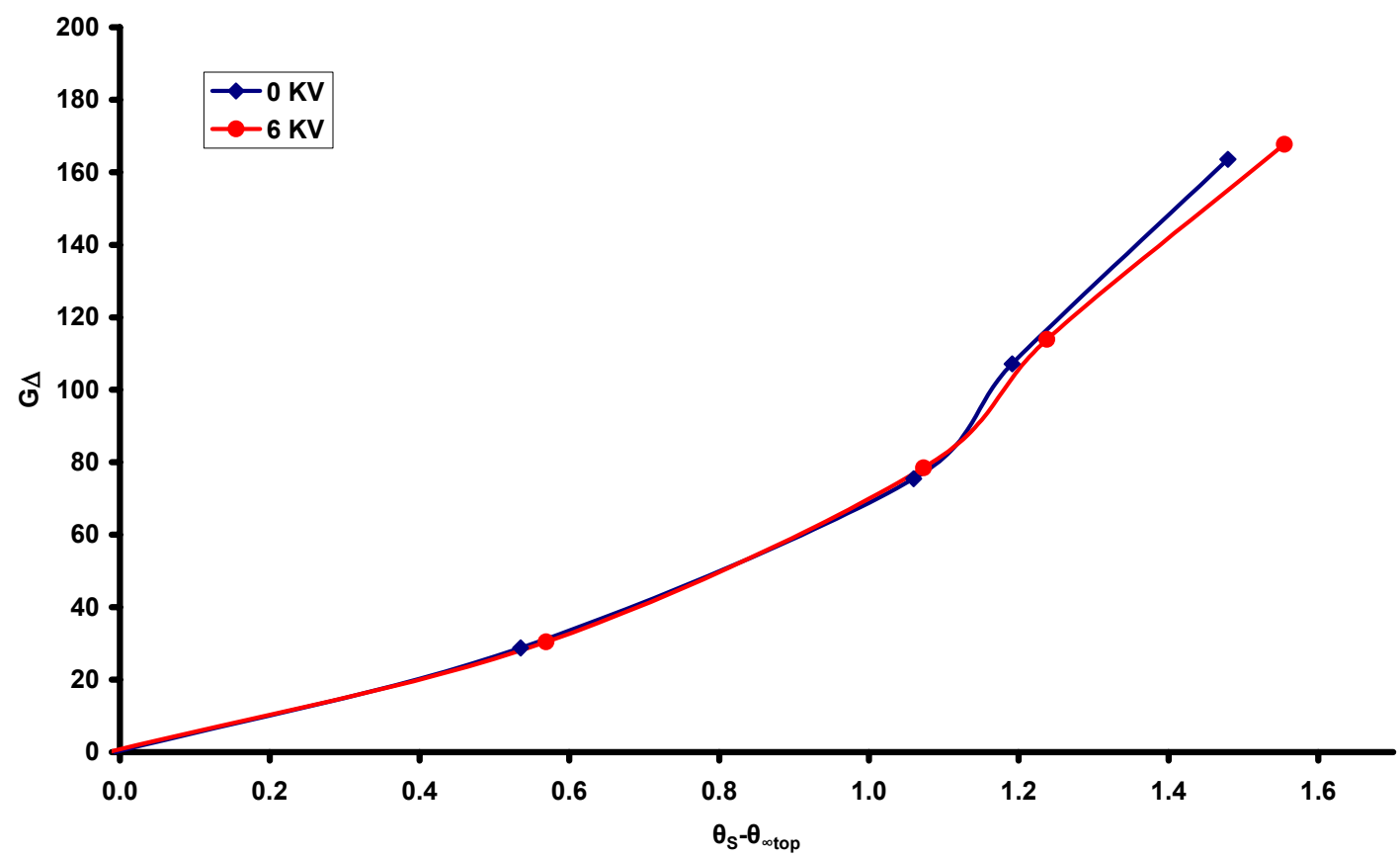

Figure C.2: Non-dimensional Heat Flux vs. Non- dimensional Temperature Difference for Repaired TFR Pedestal with New TFR Heater and Electrode 1 using FC-72 at $6.2 \mathrm{GPH}$ 


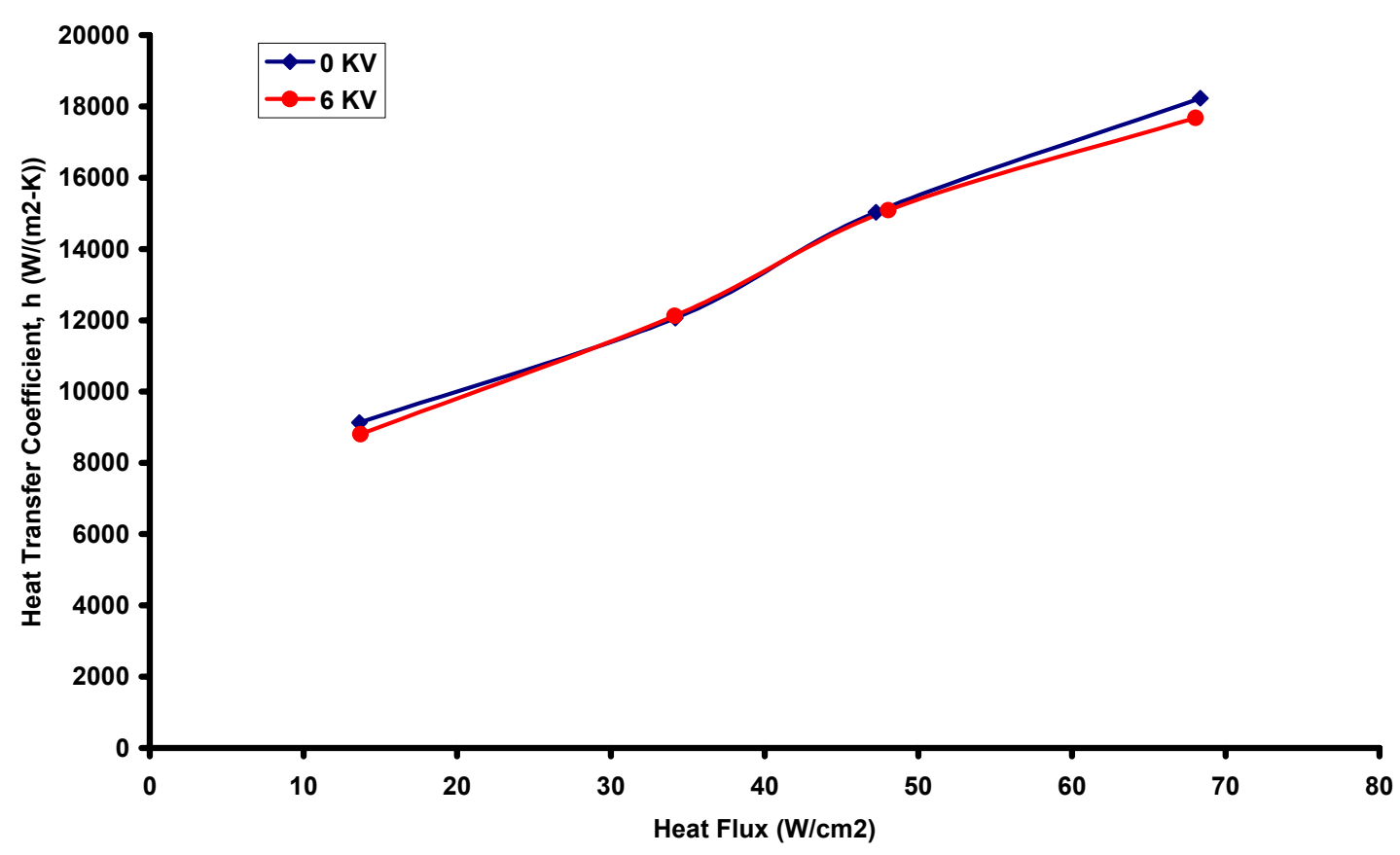

Figure C.3: Heat Transfer Coefficient vs. Heat Flux for Repaired TFR Pedestal with New TFR Heater and Electrode 1 using FC-72 at 6.2 GPH

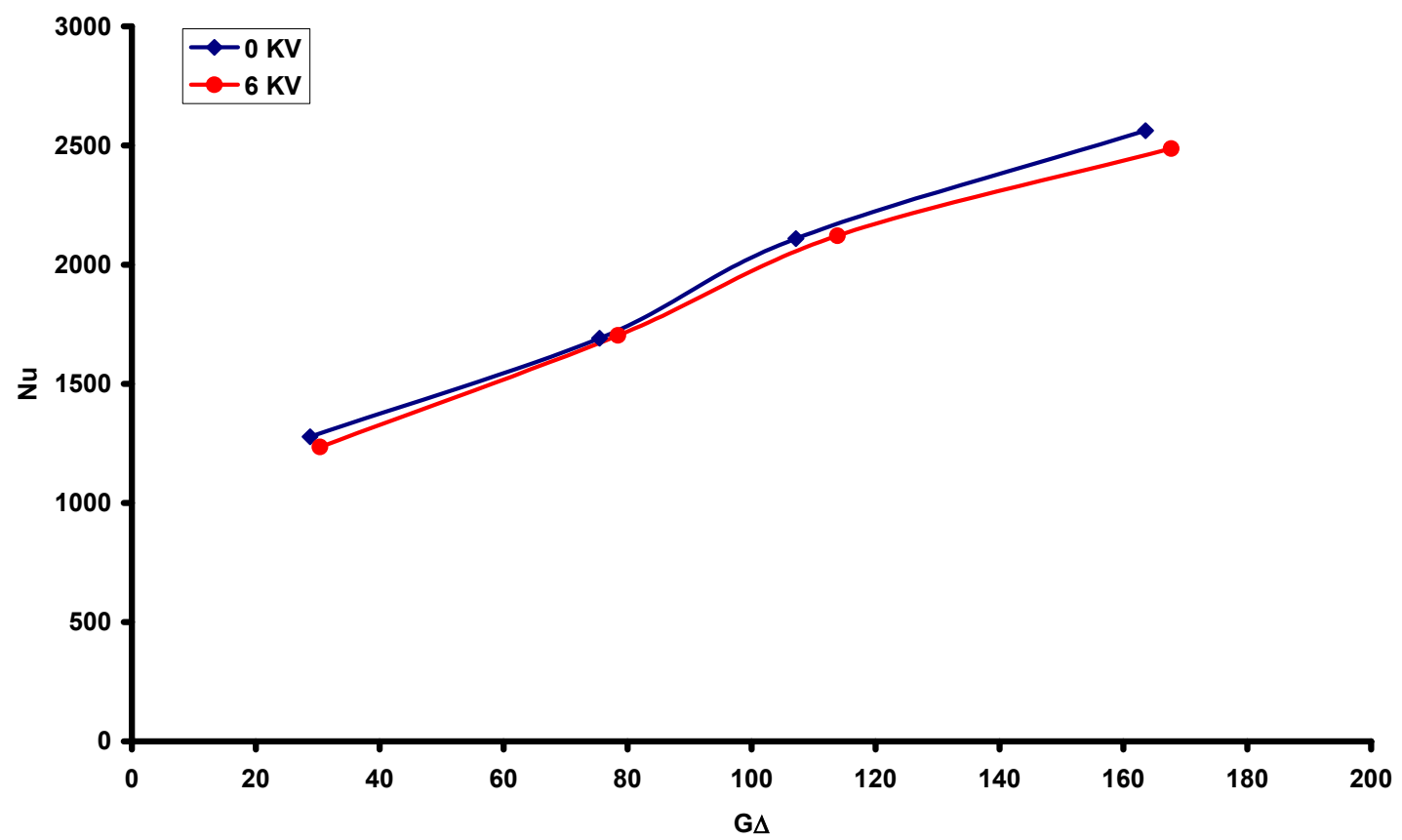

Figure C.4: Non-dimensional Heat Transfer Coefficient vs. Non-dimensional Heat Flux for Repaired TFR Pedestal with New TFR Heater and Electrode 1 using FC-72 at $6.2 \mathrm{GPH}$ 


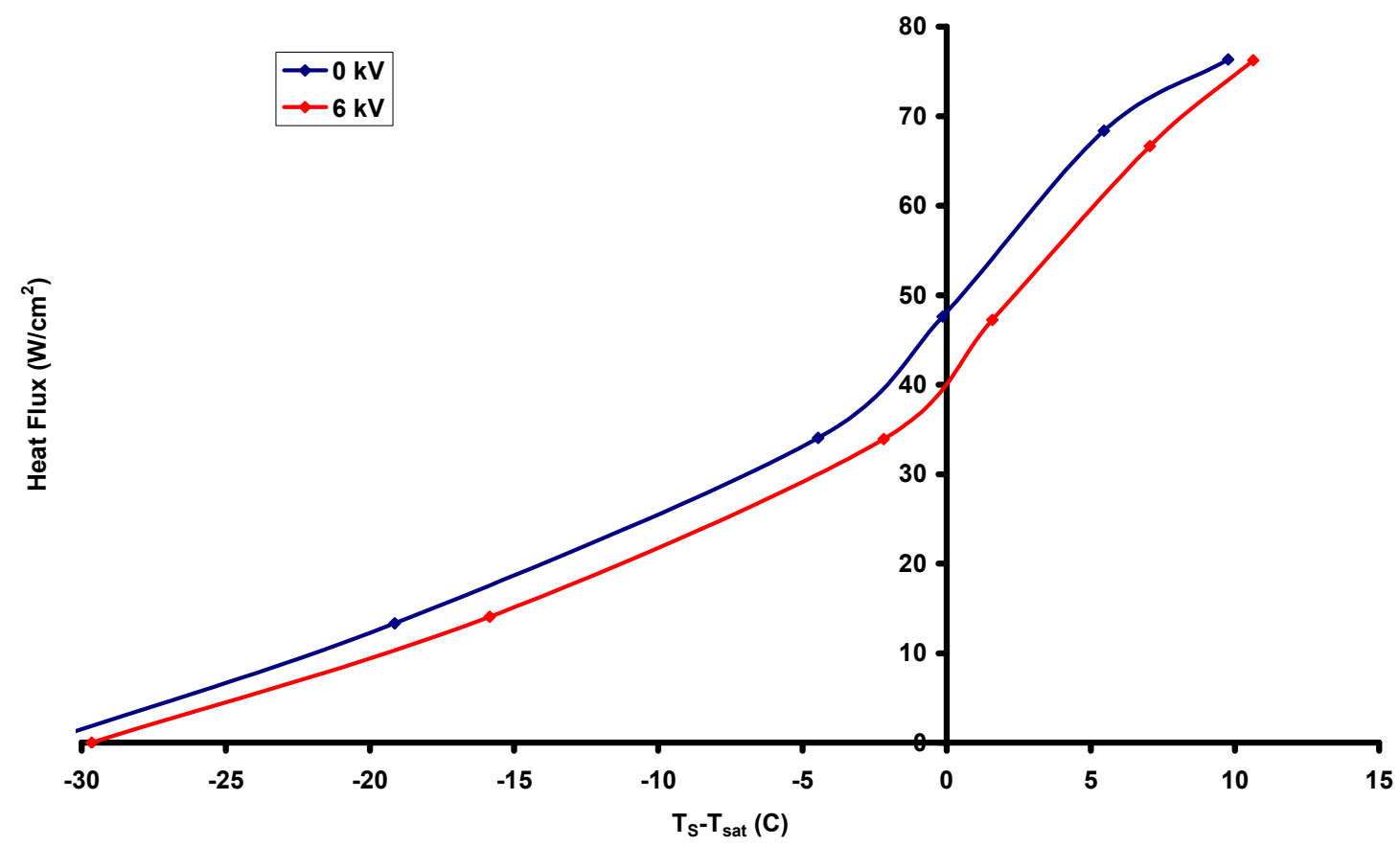

Figure C.5: Heat Flux vs. Temperature Difference for Repaired TFR Pedestal with New TFR Heater and Electrode 1 using FC-72 at 7.7 GPH

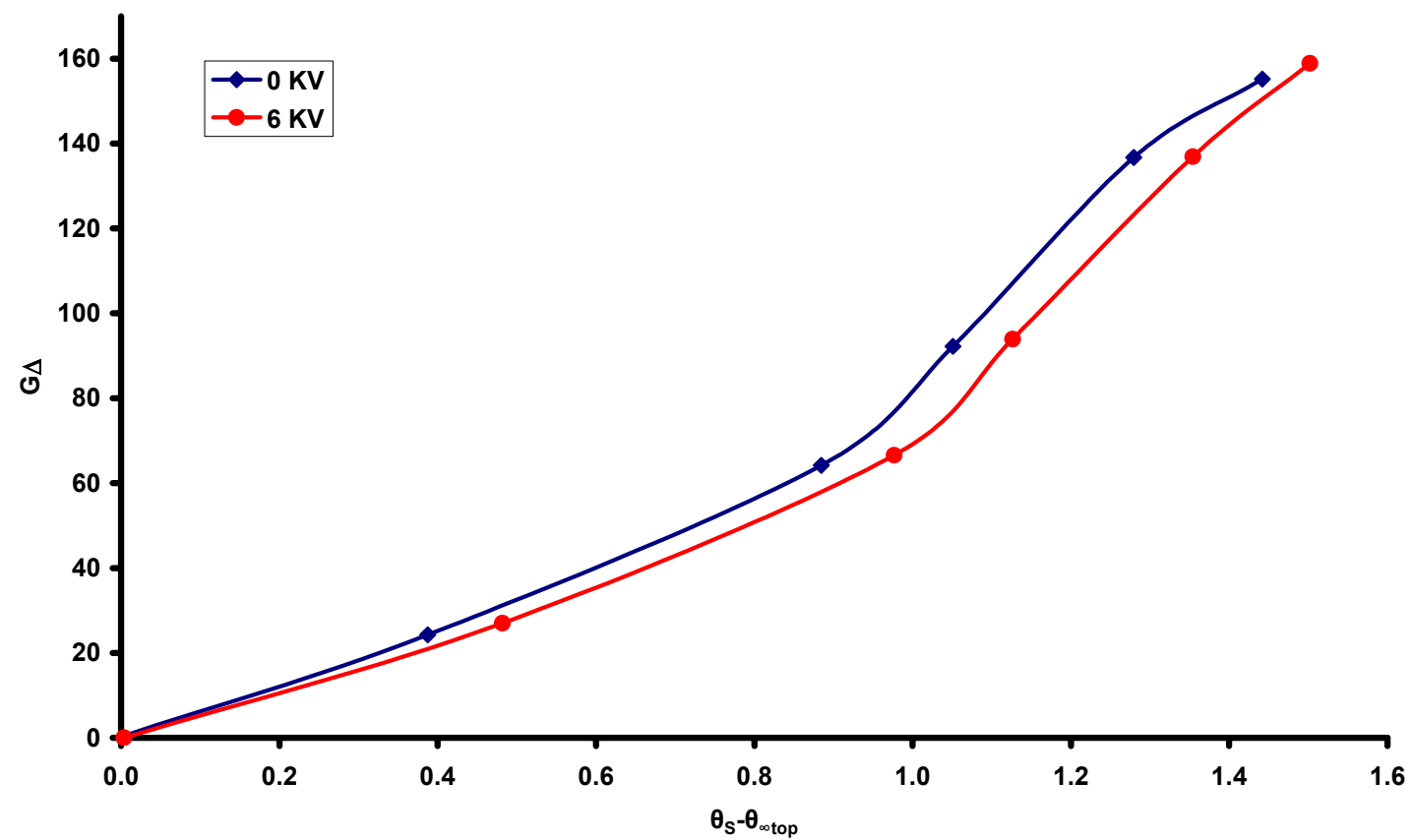

Figure C.6: Non-dimensional Heat Flux vs. Non- dimensional Temperature Difference for Repaired TFR Pedestal with New TFR Heater and Electrode 1 using FC-72 at $7.7 \mathrm{GPH}$ 


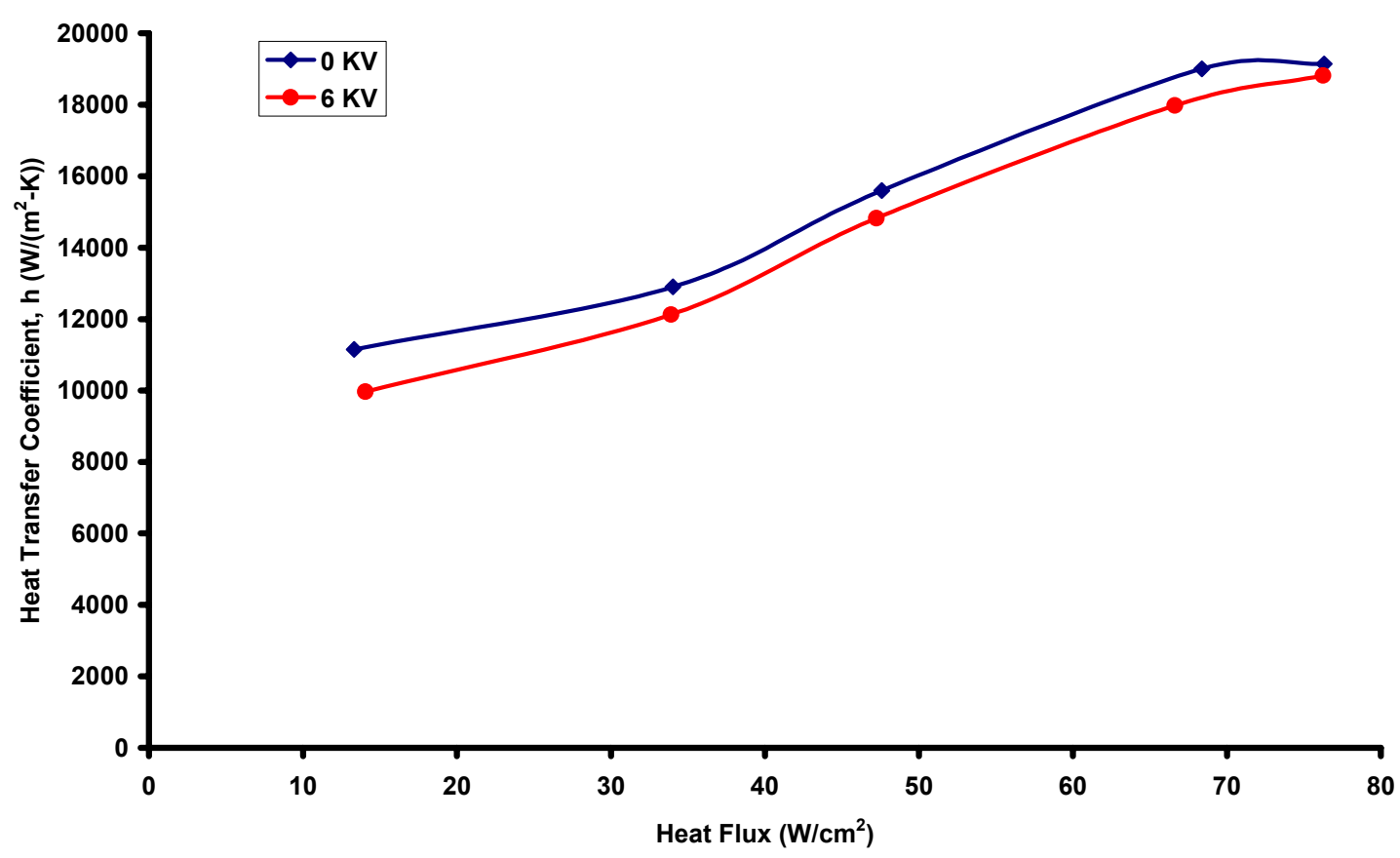

Figure C.7: Heat Transfer Coefficient vs. Heat Flux for Repaired TFR Pedestal with New TFR Heater and Electrode 1 using FC-72 at 7.7 GPH

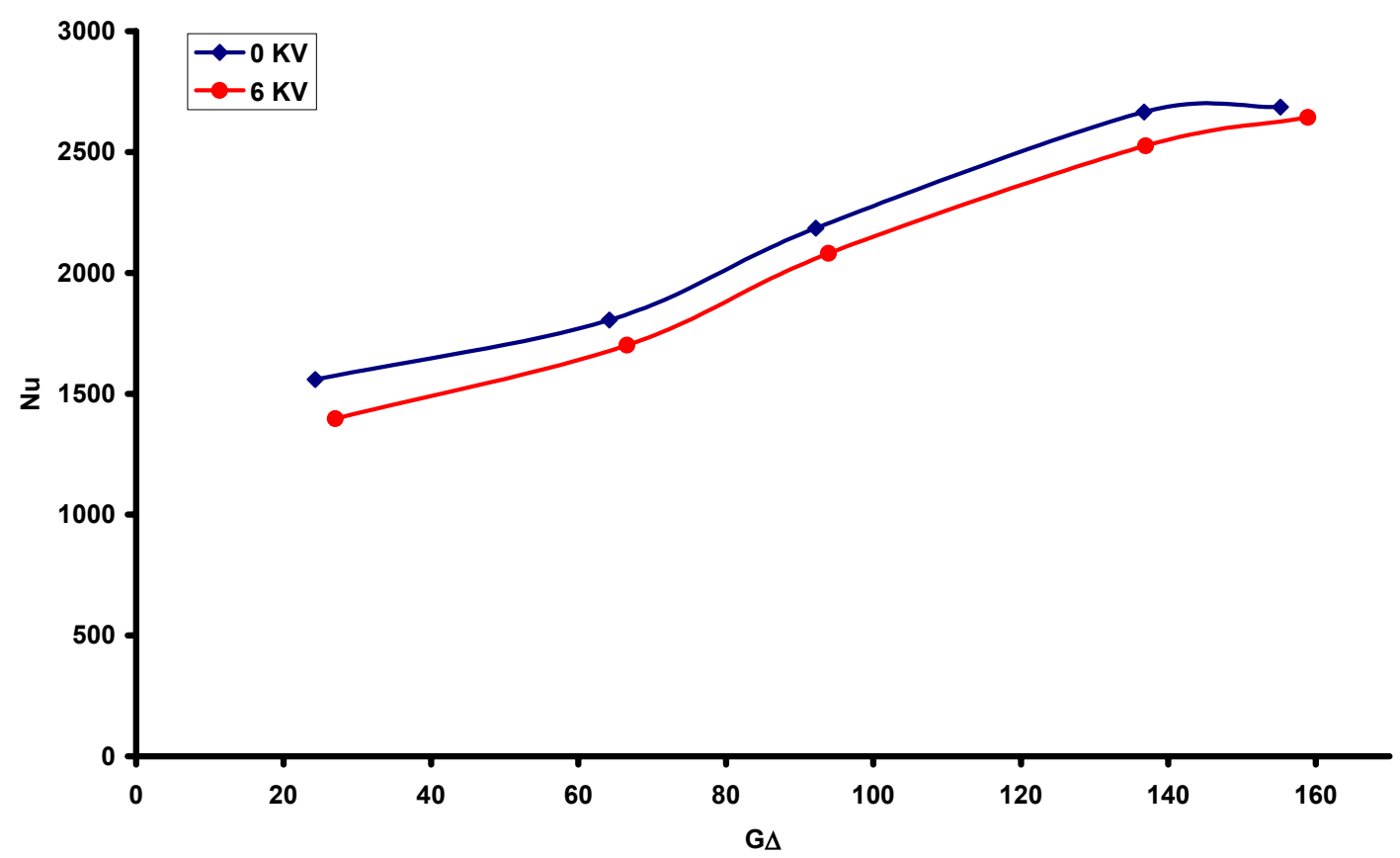

Figure C.8: Non-dimensional Heat Transfer Coefficient vs. Non-dimensional Heat Flux for Repaired TFR Pedestal with New TFR Heater and Electrode 1 using FC-72 at $7.7 \mathrm{GPH}$ 


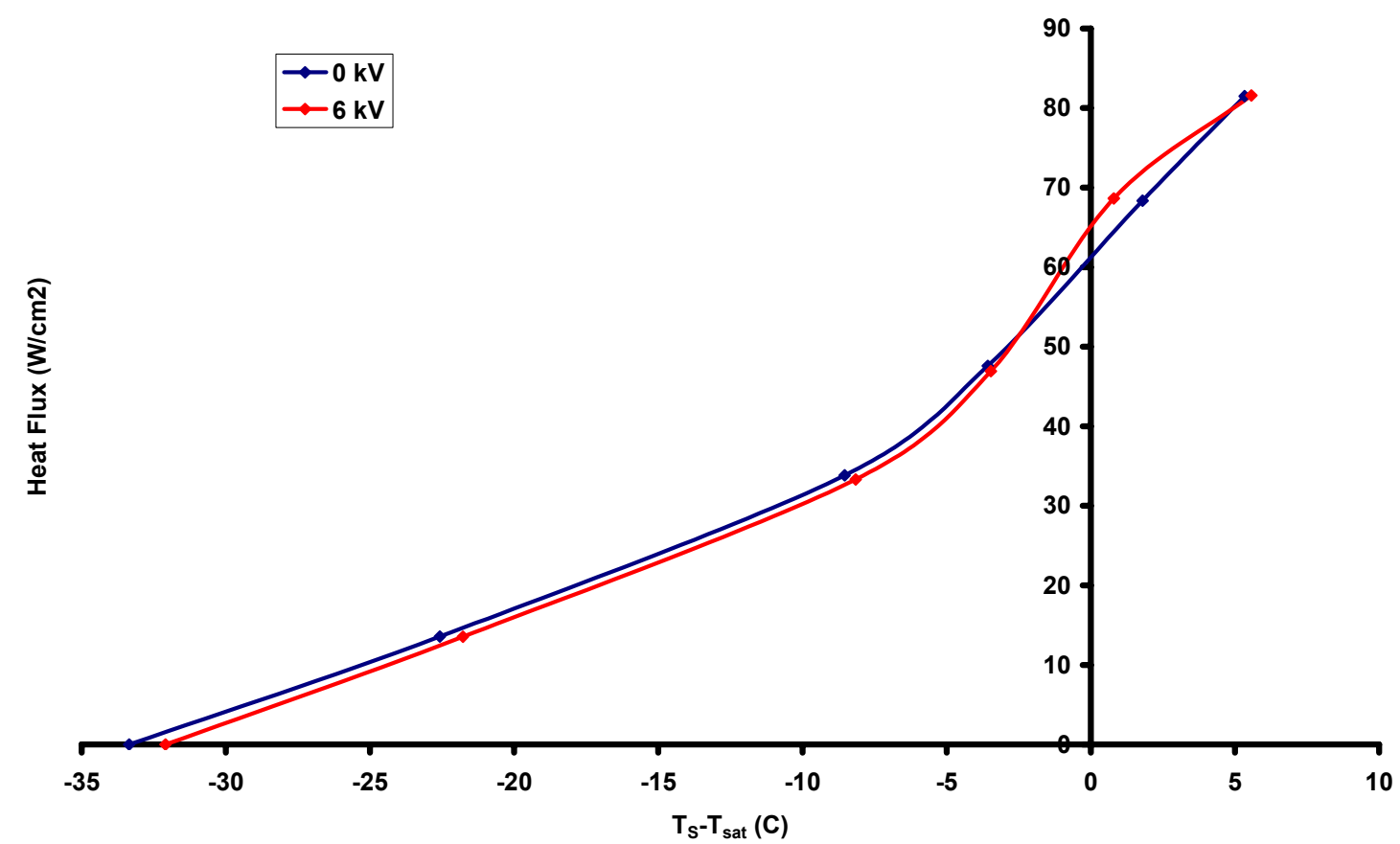

Figure C.9: Heat Flux vs. Temperature Difference for Repaired TFR Pedestal with New TFR Heater and Electrode 1 using FC-72 at 9.3 GPH

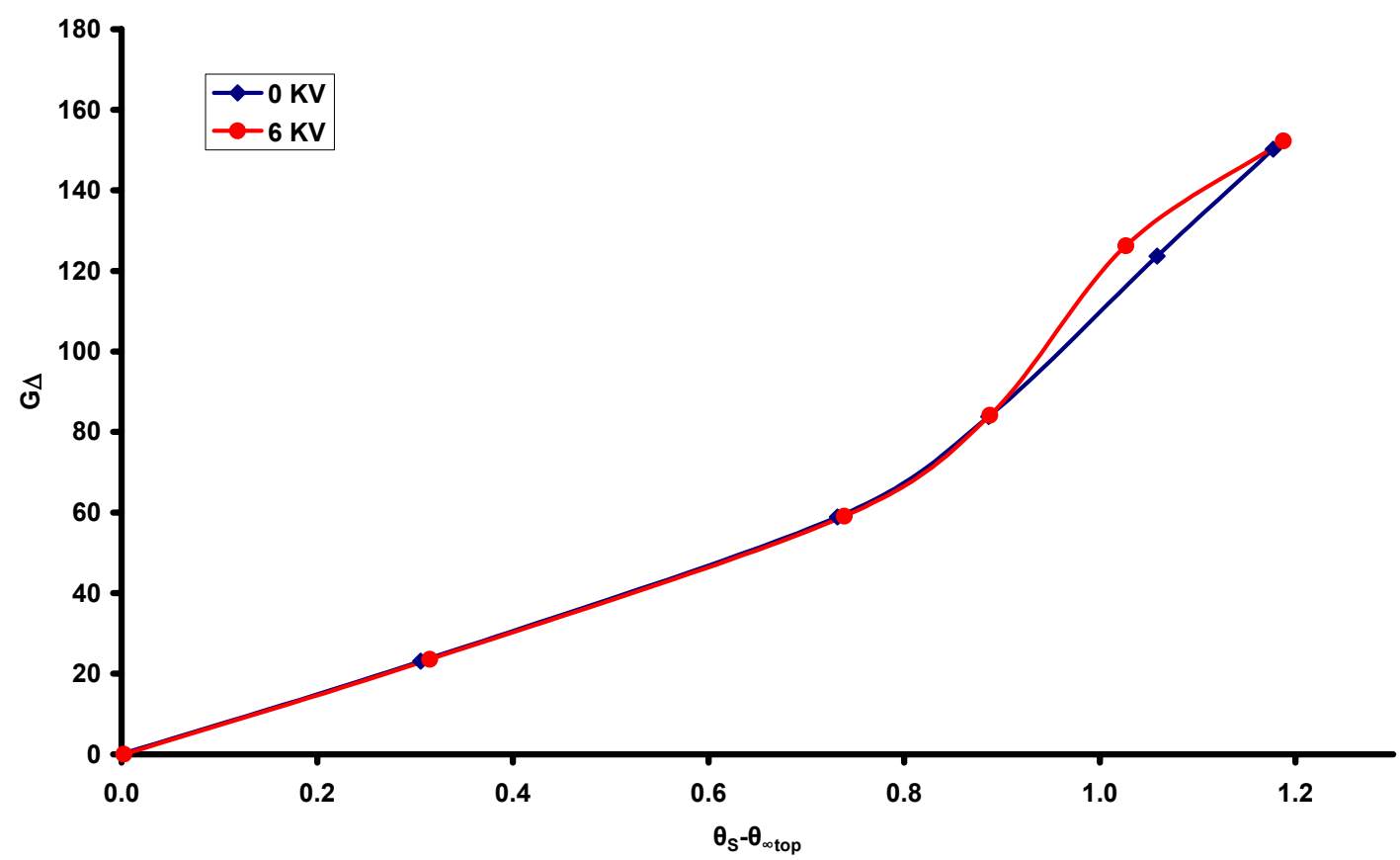

Figure C.10: Non-dimensional Heat Flux vs. Non- dimensional Temperature Difference for Repaired TFR Pedestal with New TFR Heater and Electrode 1 using FC-72 at 9.3 GPH 


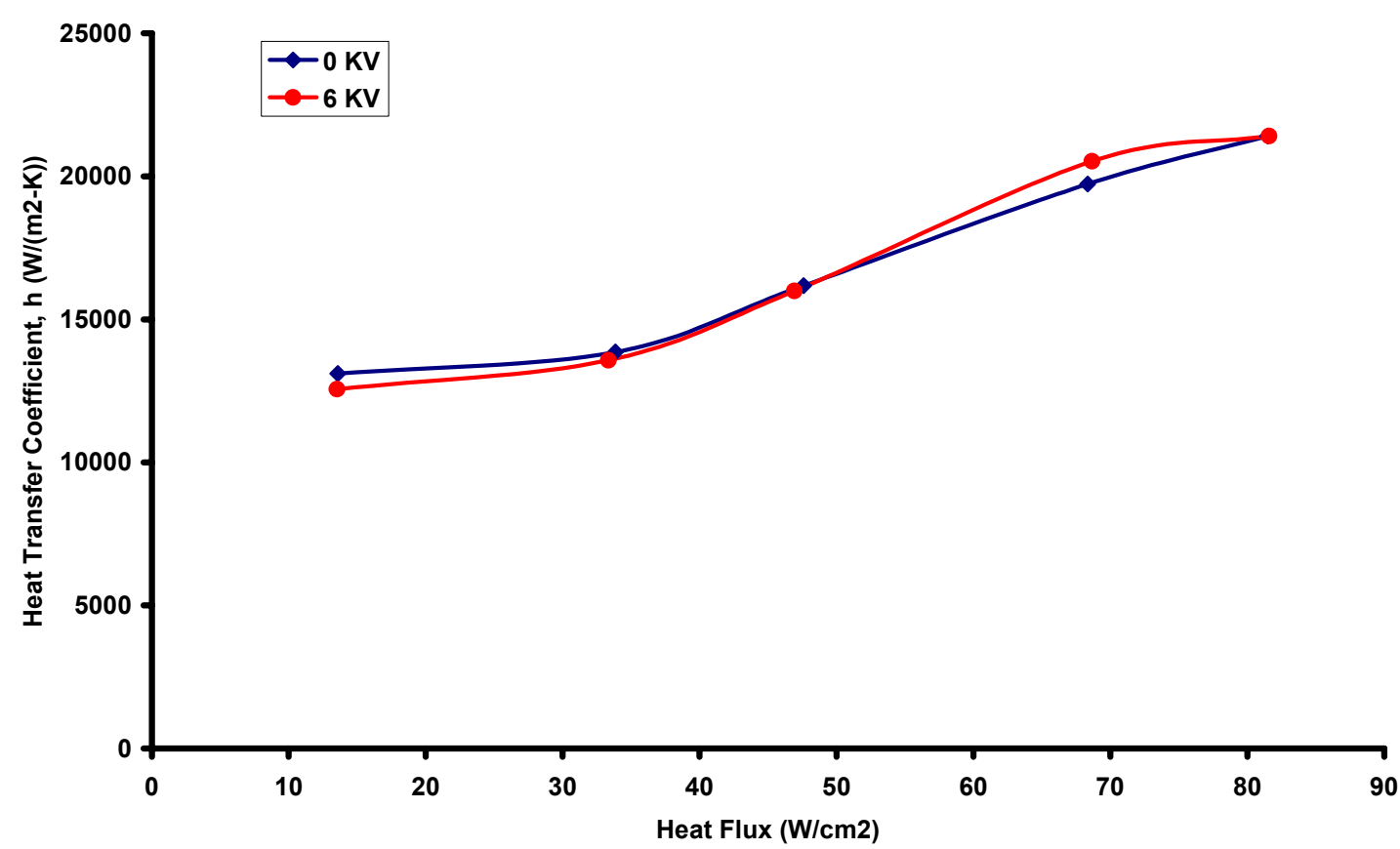

Figure C.11: Heat Transfer Coefficient vs. Heat Flux for Repaired TFR Pedestal with New TFR Heater and Electrode 1 using FC-72 at 9.3 GPH

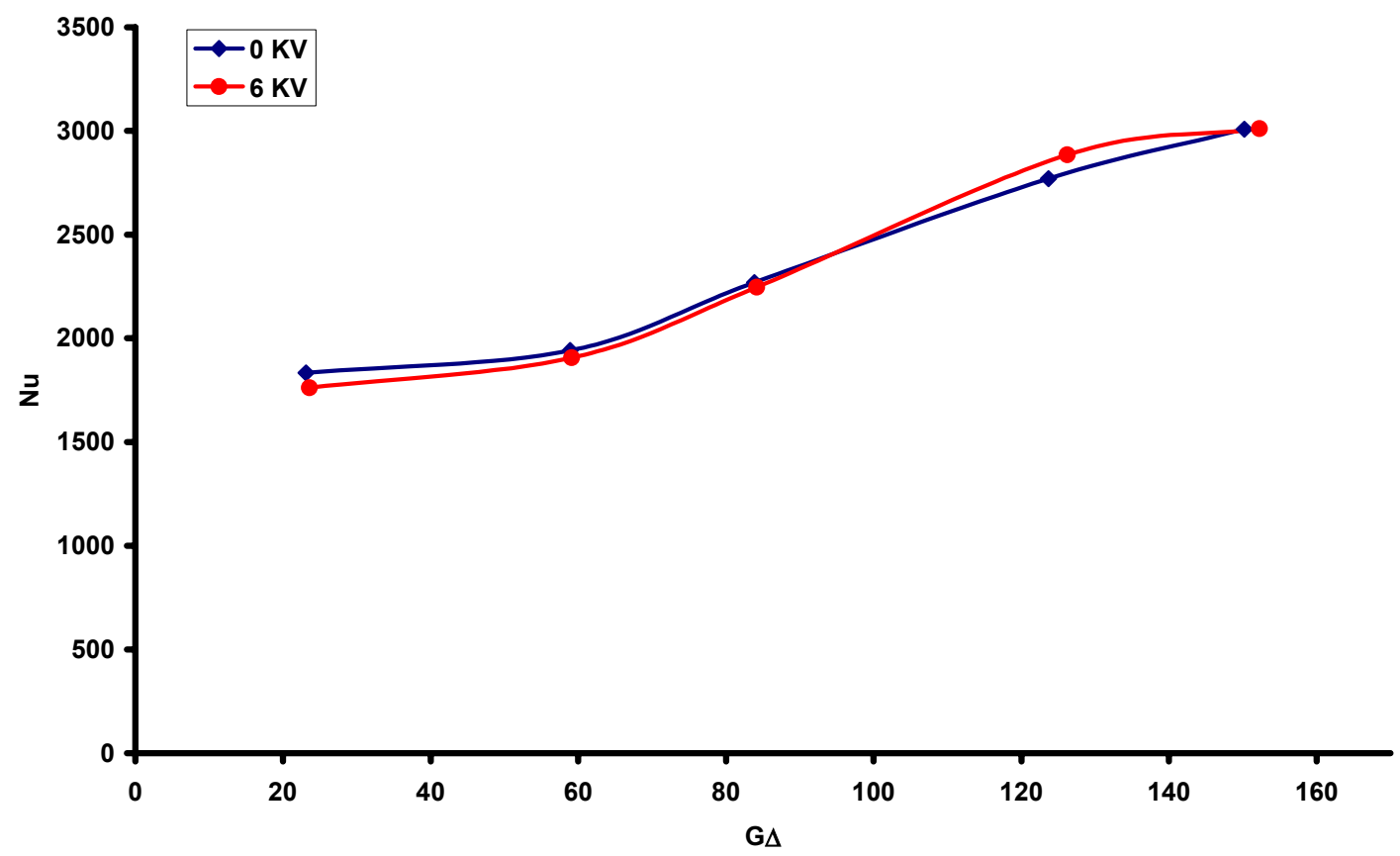

Figure C.12: Non-dimensional Heat Transfer Coefficient vs. Non-dimensional Heat Flux for Repaired TFR Pedestal with New TFR Heater and Electrode 1 using FC-72 at $9.3 \mathrm{GPH}$ 
Data plots showing the results for the repaired TFR pedestal with new TFR heater, electrode 2, and using a working fluid of FC-72 at 6.2, 7.7, and 9.3 GPH.

- Heat Flux vs. Temperature Difference

- Non-dimensional Heat Flux vs. Non- dimensional Temperature Difference

- Heat Transfer Coefficient vs. Heat Flux

- Non-dimensional Heat Transfer Coefficient vs. Non-dimensional Heat Flux 


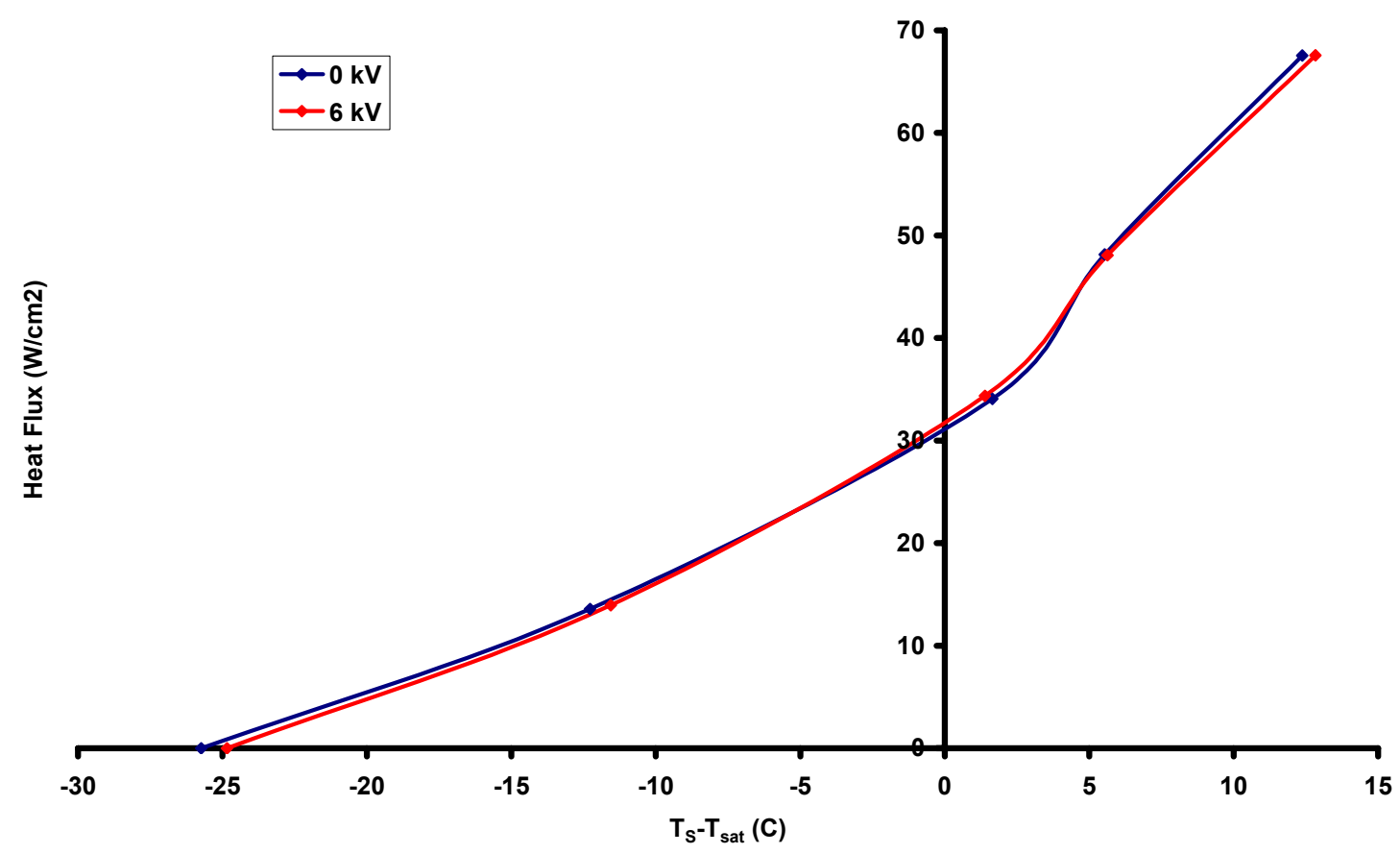

Figure C.13: Heat Flux vs. Temperature Difference for Repaired TFR Pedestal with New TFR Heater and Electrode 2 using FC-72 at 6.2 GPH

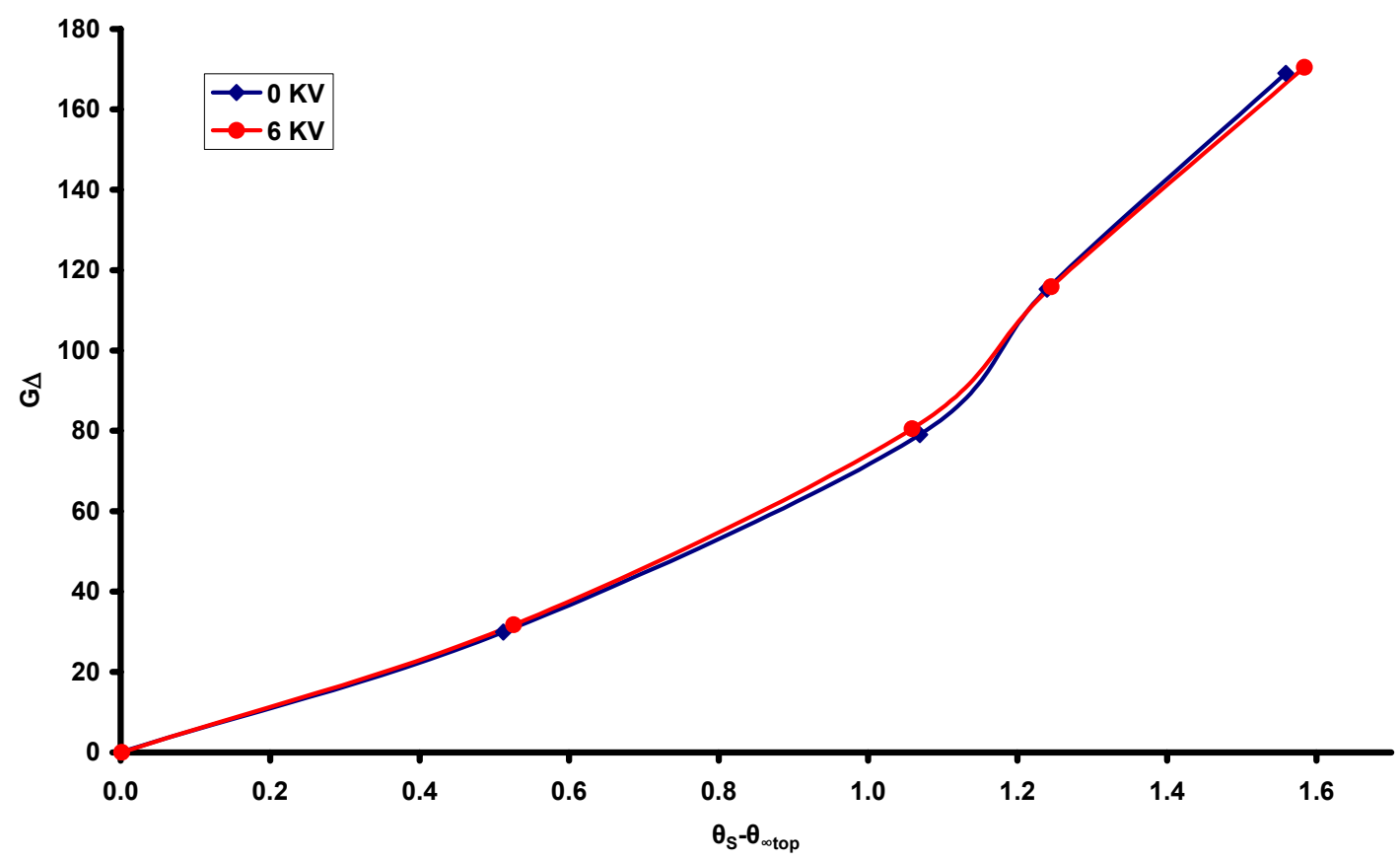

Figure C.14: Non-dimensional Heat Flux vs. Non- dimensional Temperature Difference for Repaired TFR Pedestal with New TFR Heater and Electrode 2 using FC-72 at $6.2 \mathrm{GPH}$ 


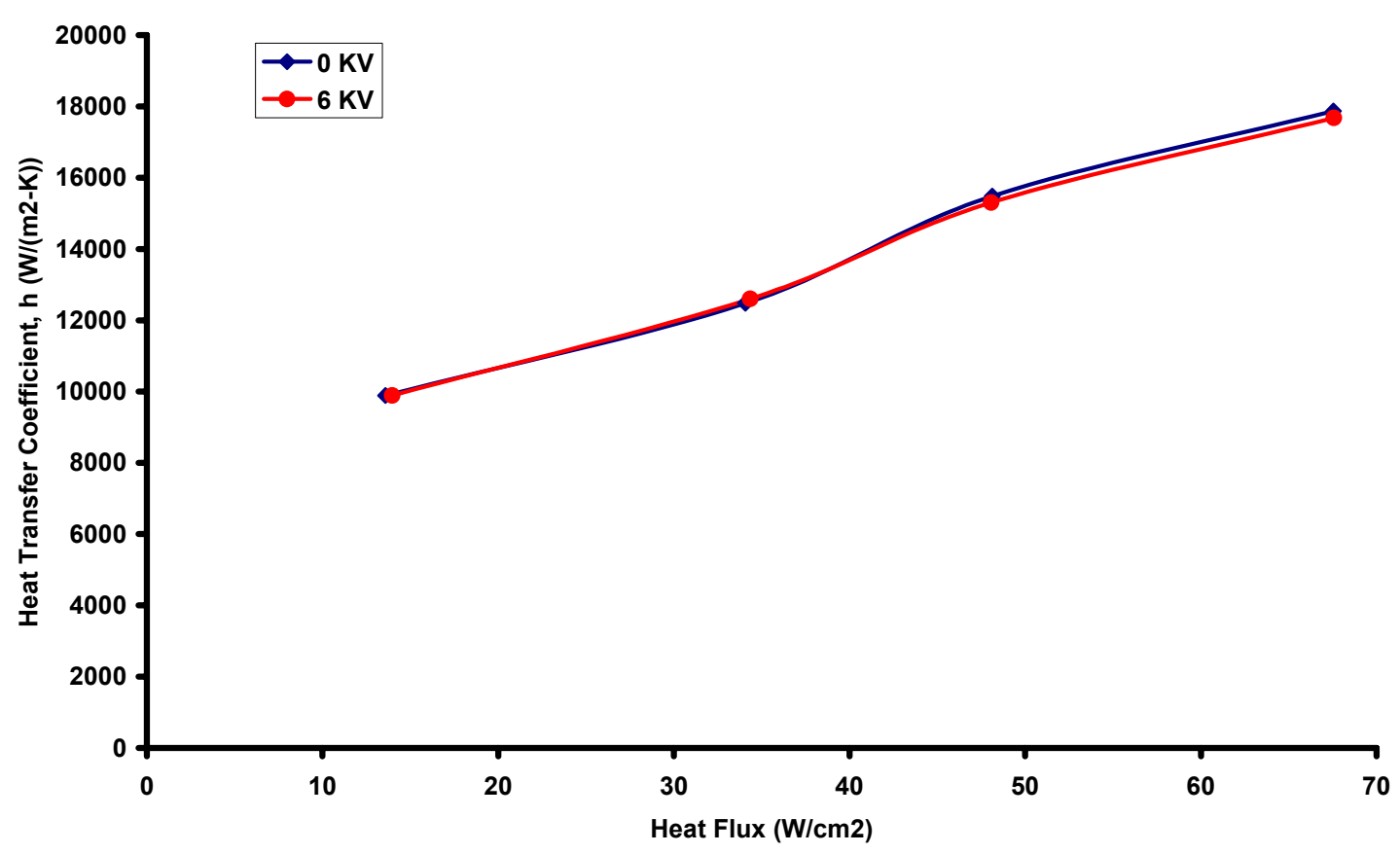

Figure C.15: Heat Transfer Coefficient vs. Heat Flux for Repaired TFR Pedestal with New TFR Heater and Electrode 2 using FC-72 at 6.2 GPH

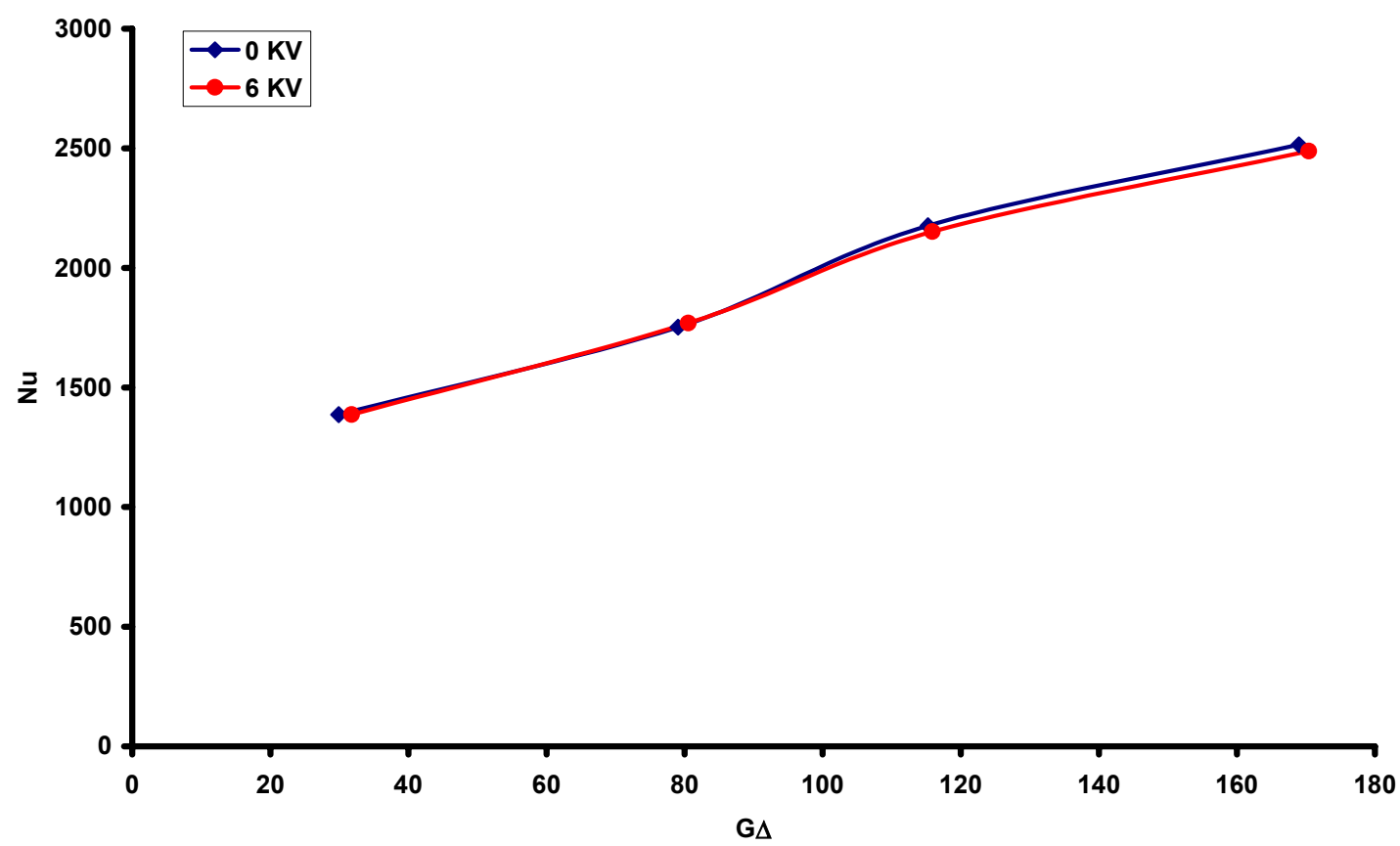

Figure C.16: Non-dimensional Heat Transfer Coefficient vs. Non-dimensional Heat Flux for Repaired TFR Pedestal with New TFR Heater and Electrode 2 using FC-72 at $6.2 \mathrm{GPH}$ 


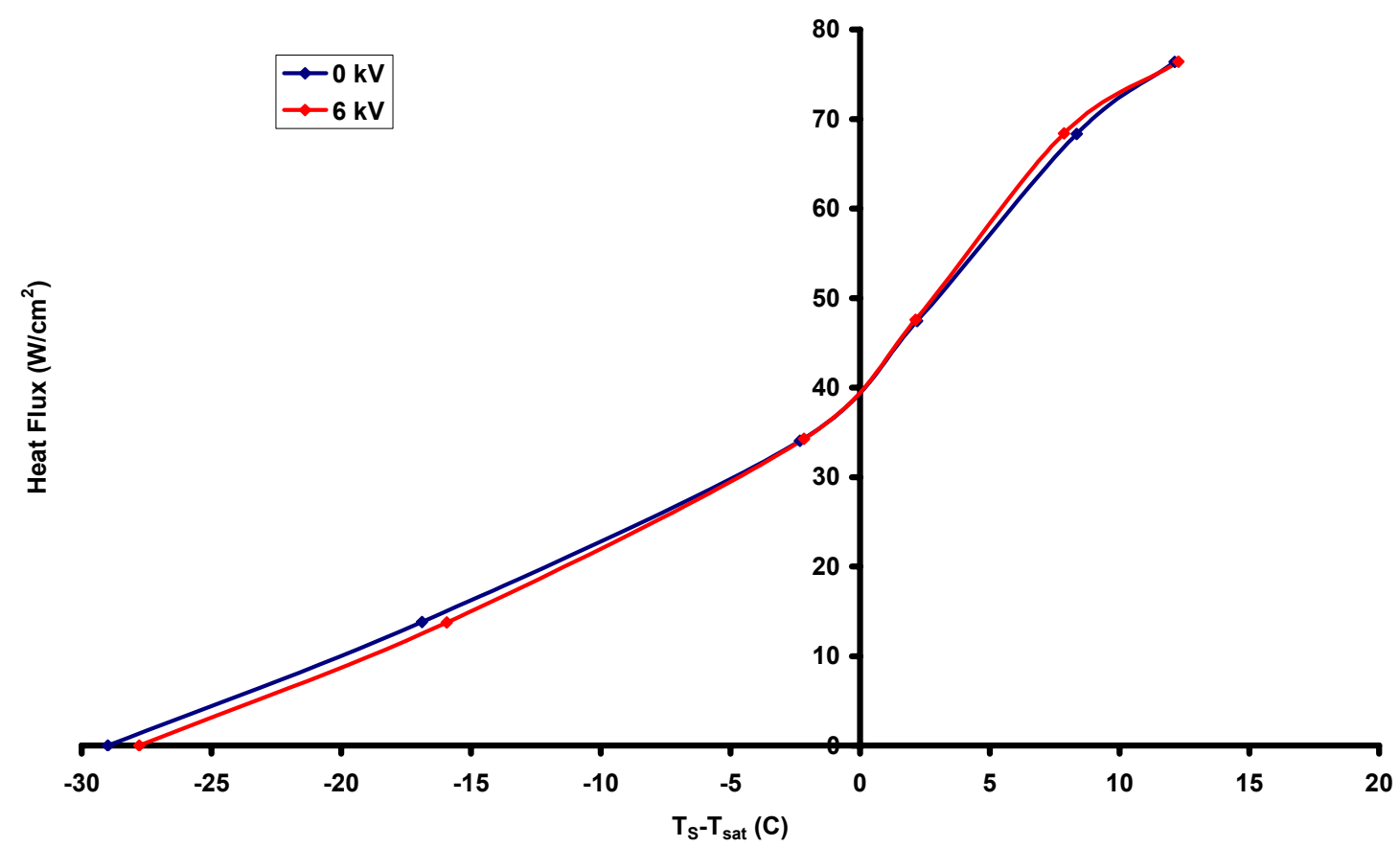

Figure C.17: Heat Flux vs. Temperature Difference for Repaired TFR Pedestal with New TFR Heater and Electrode 2 using FC-72 at 7.7 GPH

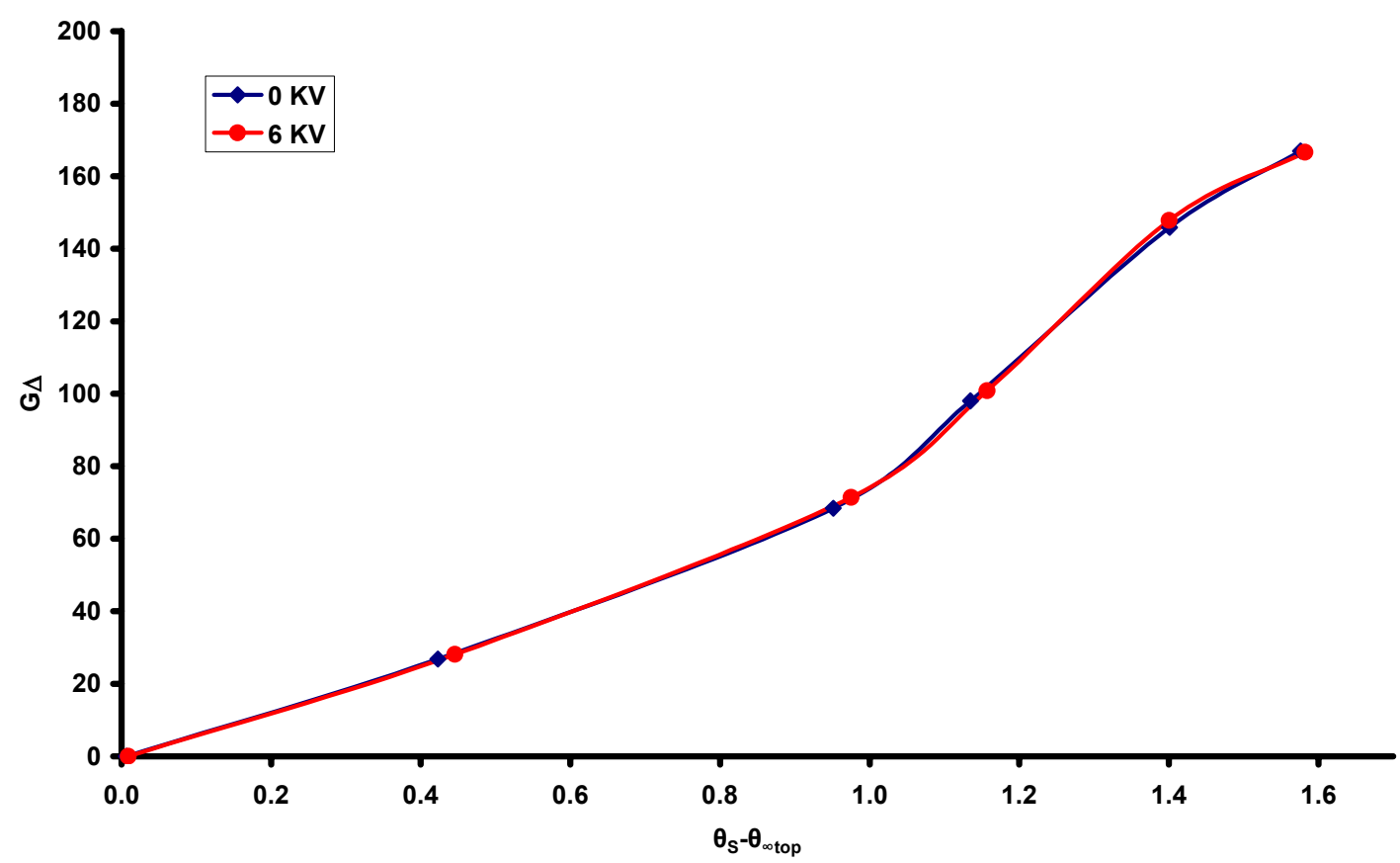

Figure C.18: Non-dimensional Heat Flux vs. Non- dimensional Temperature Difference for Repaired TFR Pedestal with New TFR Heater and Electrode 2 using FC-72 at $7.7 \mathrm{GPH}$ 


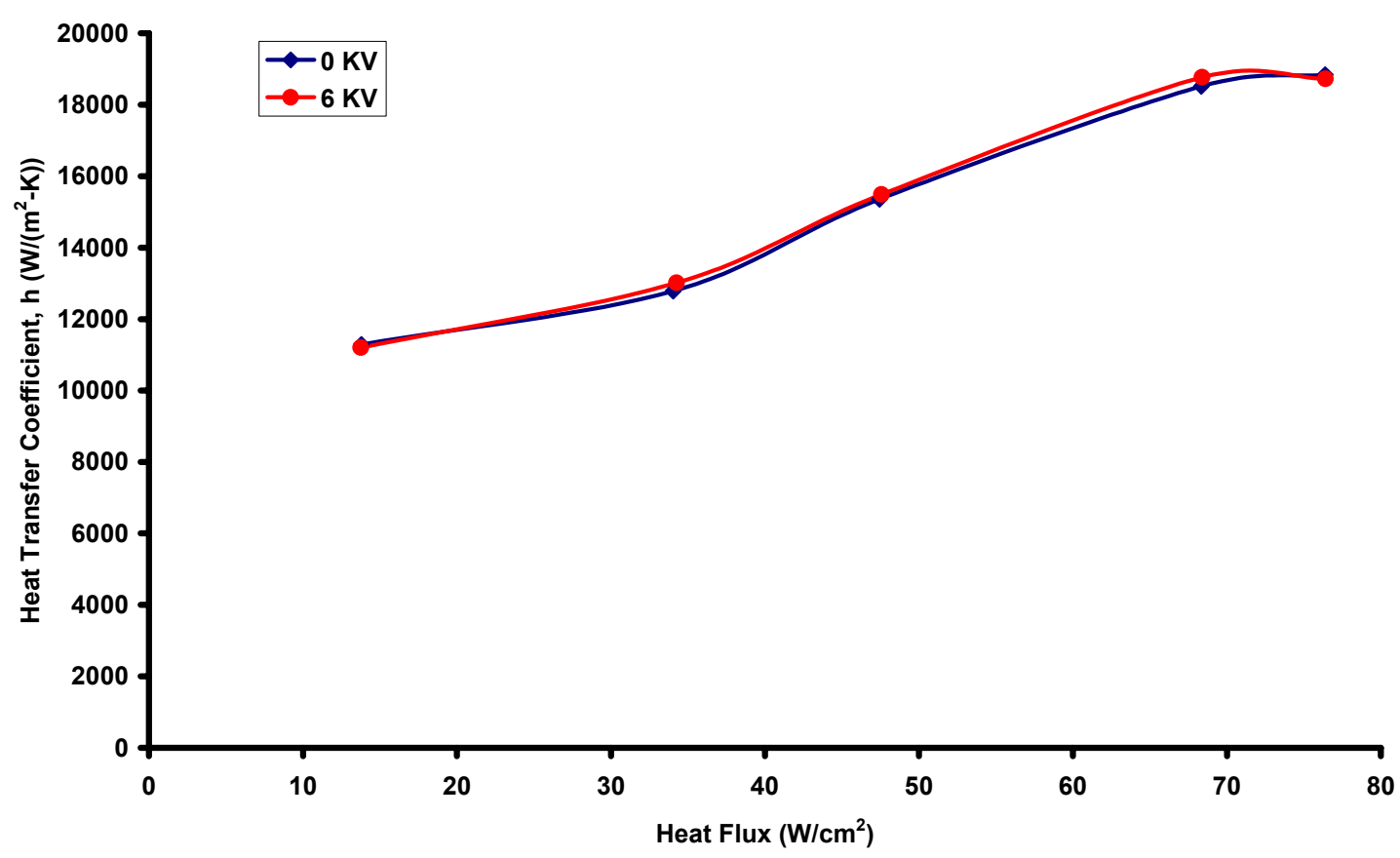

Figure C.19: Heat Transfer Coefficient vs. Heat Flux for Repaired TFR Pedestal with New TFR Heater and Electrode 2 using FC-72 at 7.7 GPH

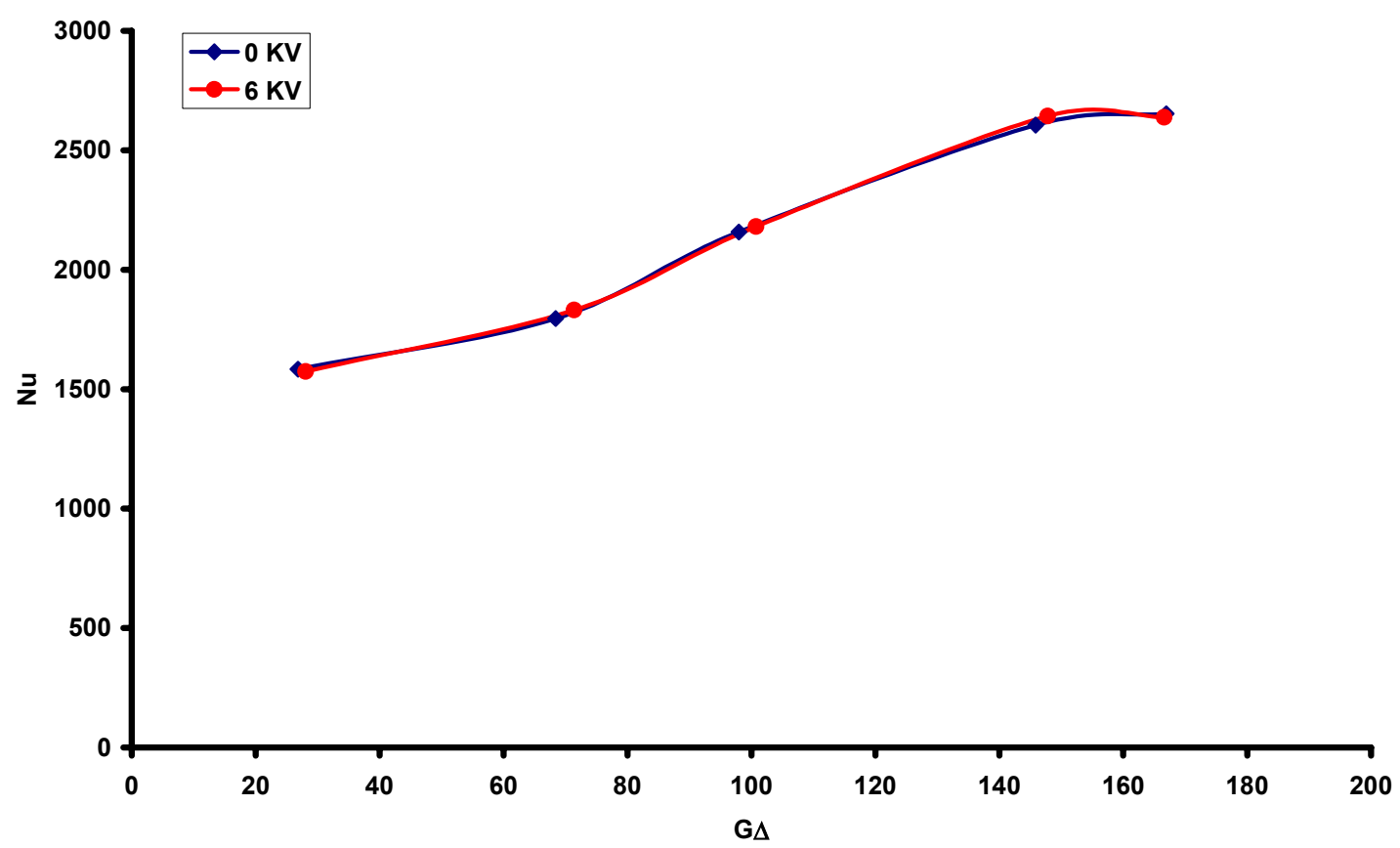

Figure C.20: Non-dimensional Heat Transfer Coefficient vs. Non-dimensional Heat Flux for Repaired TFR Pedestal with New TFR Heater and Electrode 2 using FC-72 at $7.7 \mathrm{GPH}$ 


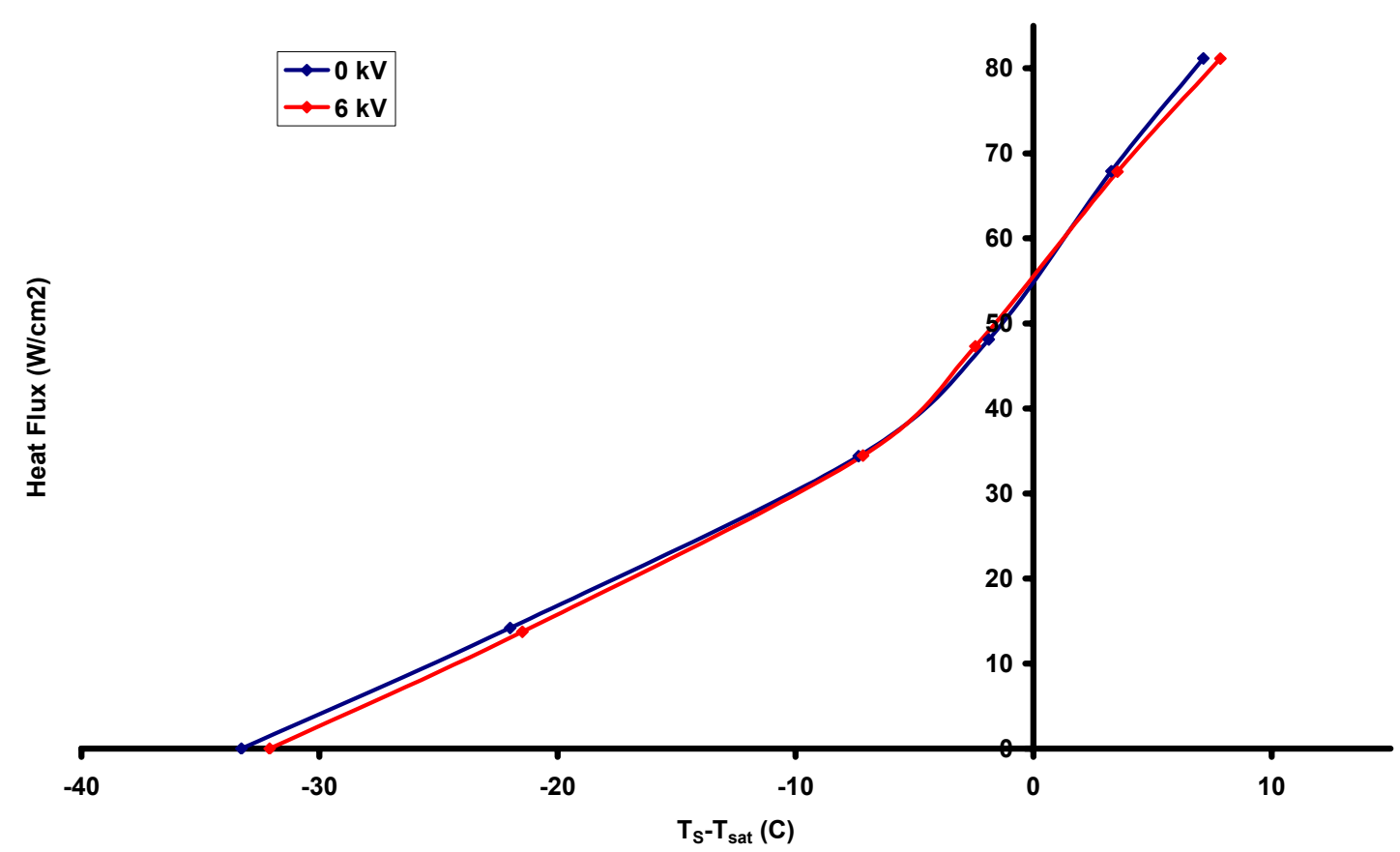

Figure C.21: Heat Flux vs. Temperature Difference for Repaired TFR Pedestal with New TFR Heater and Electrode 2 using FC-72 at 9.3 GPH

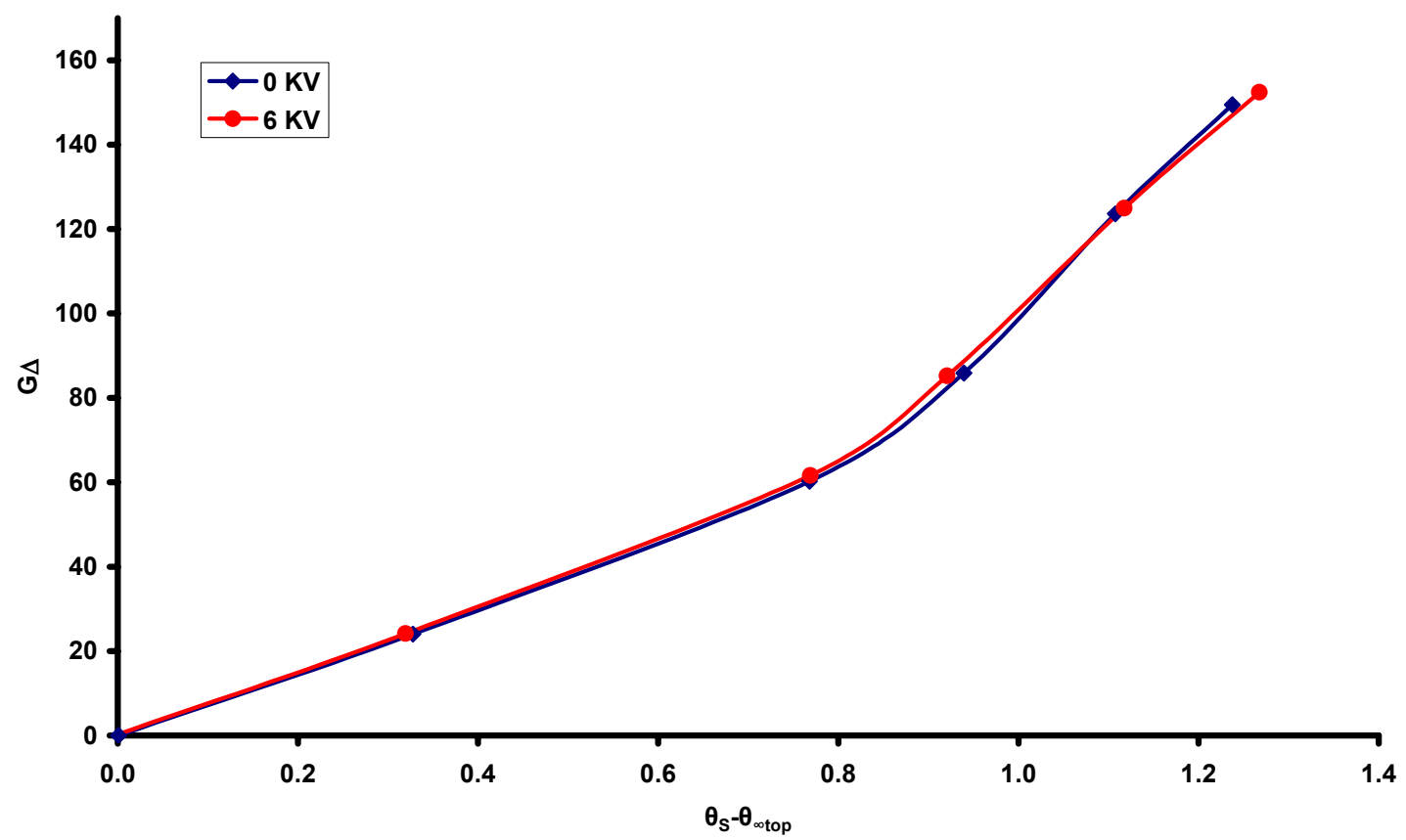

Figure C.22: Non-dimensional Heat Flux vs. Non- dimensional Temperature Difference for Repaired TFR Pedestal with New TFR Heater and Electrode 2 using FC-72 at 9.3 GPH 


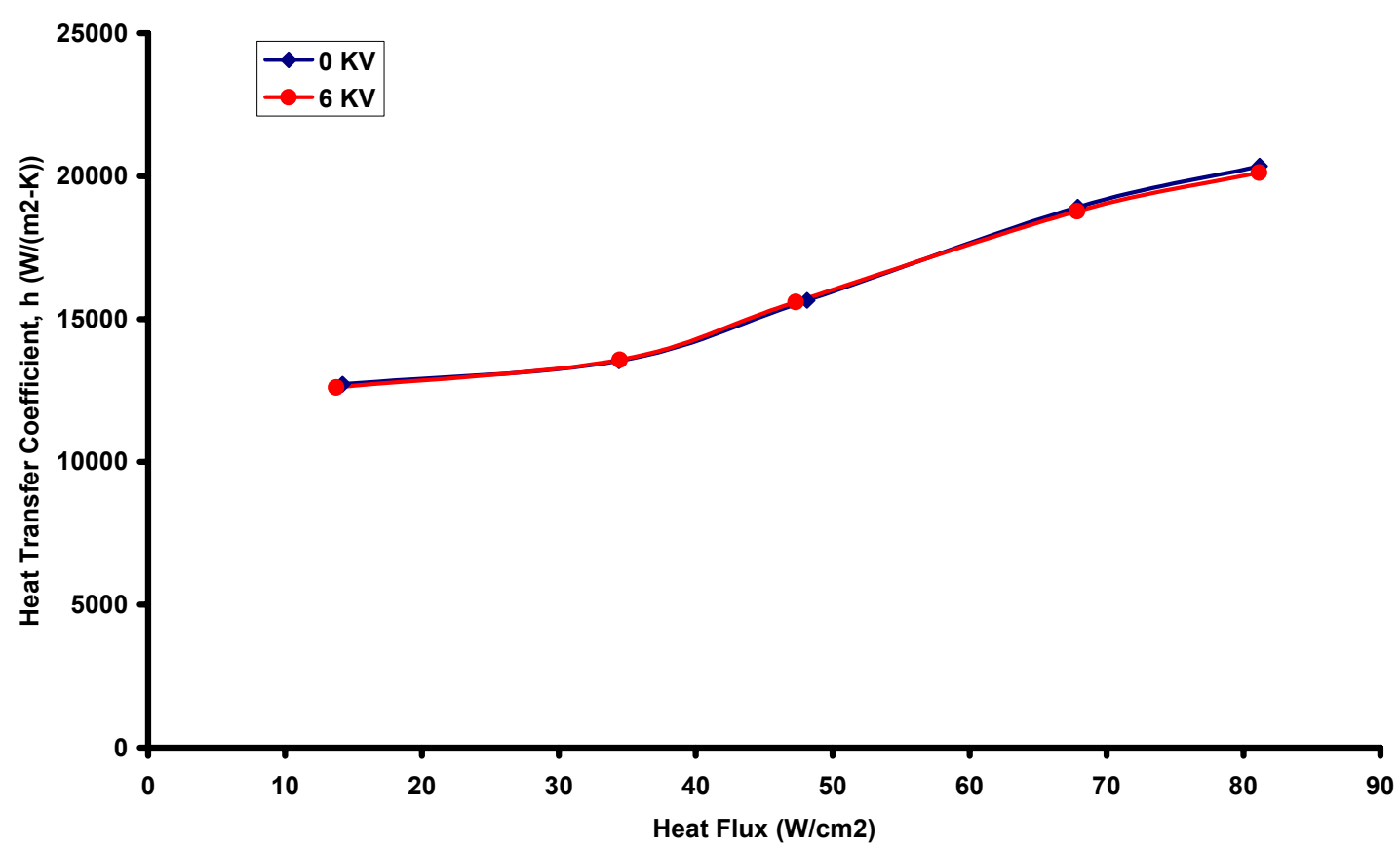

Figure C.23: Heat Transfer Coefficient vs. Heat Flux for Repaired TFR Pedestal with New TFR Heater and Electrode 2 using FC-72 at 9.3 GPH

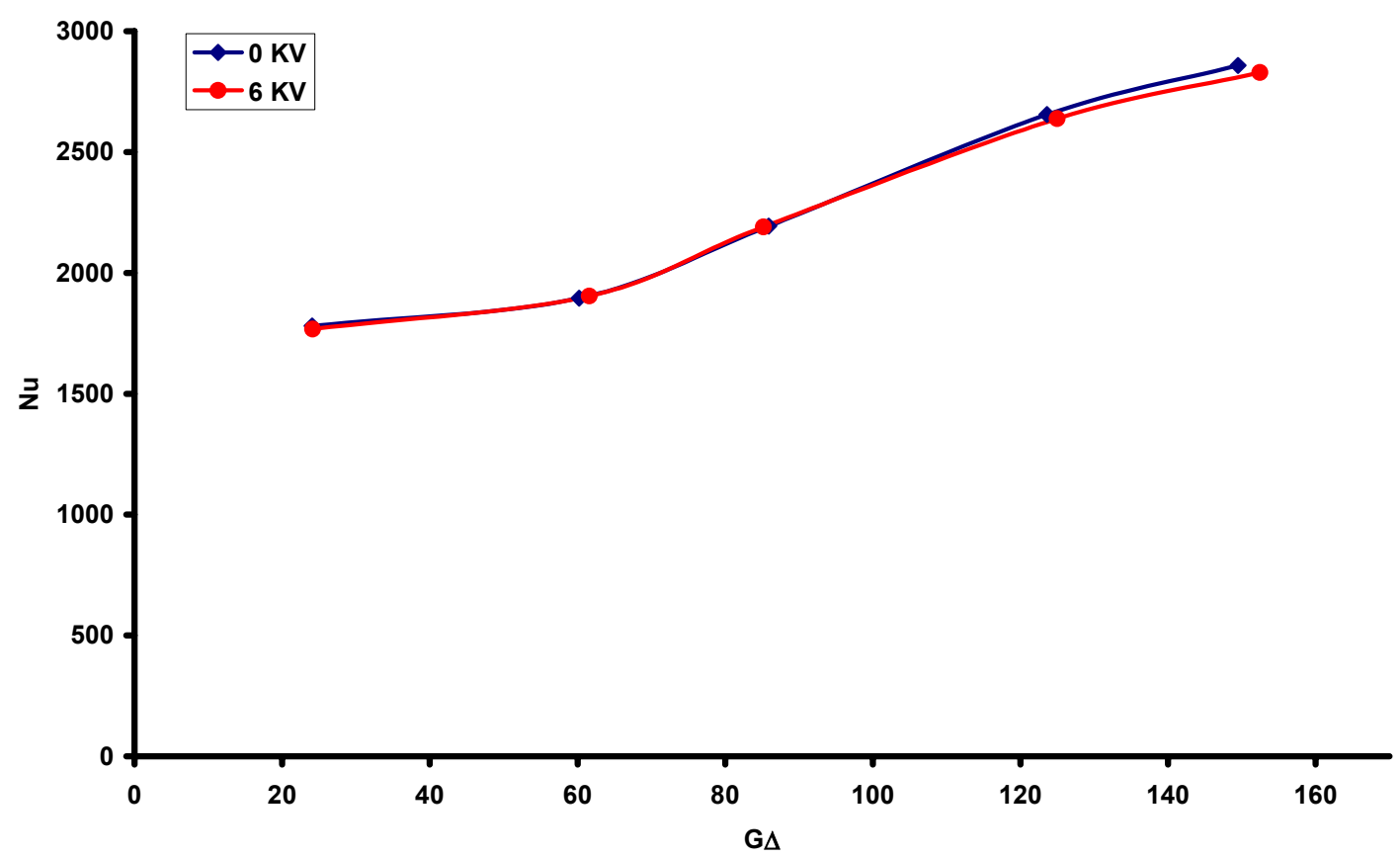

Figure C.24: Non-dimensional Heat Transfer Coefficient vs. Non-dimensional Heat Flux for Repaired TFR Pedestal with New TFR Heater and Electrode 2 using FC-72 at $9.3 \mathrm{GPH}$ 
Data plots showing the results for the repaired TFR pedestal with new TFR heater, electrode 1, and using a working fluid of HFE-7000 at 5.9, 8.0, and 8.5 GPH.

- Heat Flux vs. Temperature Difference

- Non-dimensional Heat Flux vs. Non- dimensional Temperature Difference

- Heat Transfer Coefficient vs. Heat Flux

- Non-dimensional Heat Transfer Coefficient vs. Non-dimensional Heat Flux 


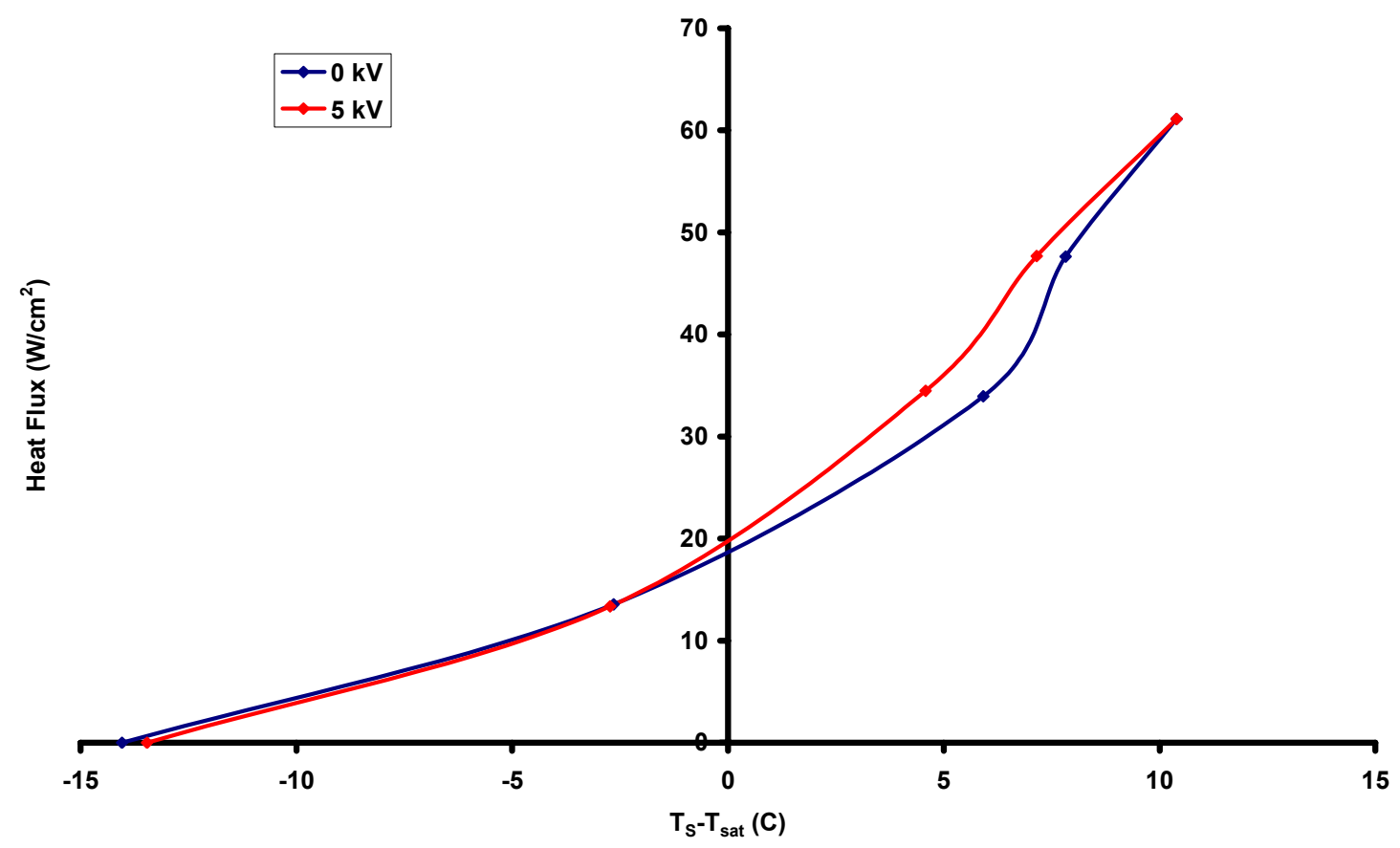

Figure C.25: Heat Flux vs. Temperature Difference for Repaired TFR Pedestal with New TFR Heater and Electrode 1 using HFE-7000 at 5.9 GPH

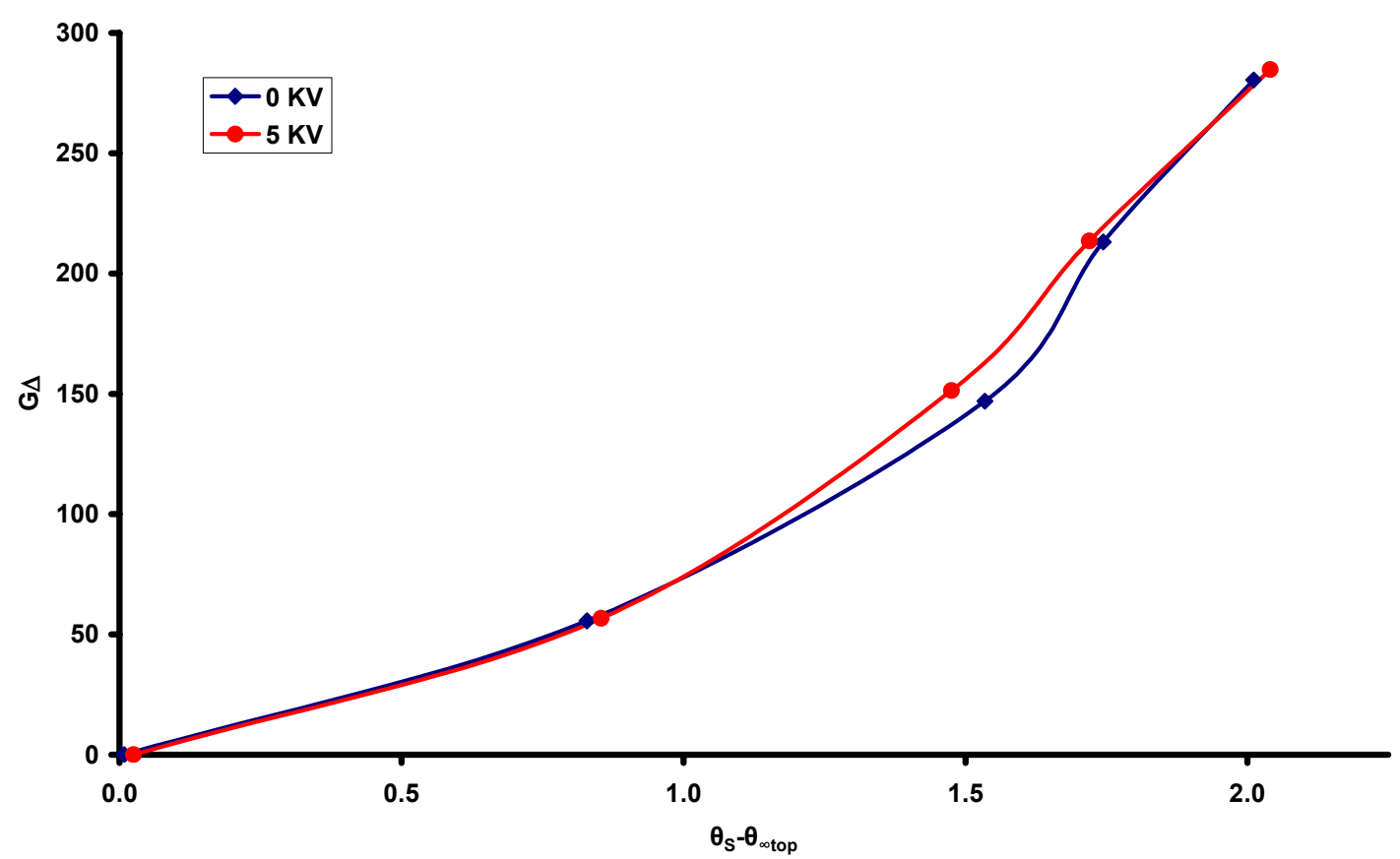

Figure C.26: Non-dimensional Heat Flux vs. Non- dimensional Temperature Difference for Repaired TFR Pedestal with New TFR Heater and Electrode 1 using HFE-7000 at $5.9 \mathrm{GPH}$ 


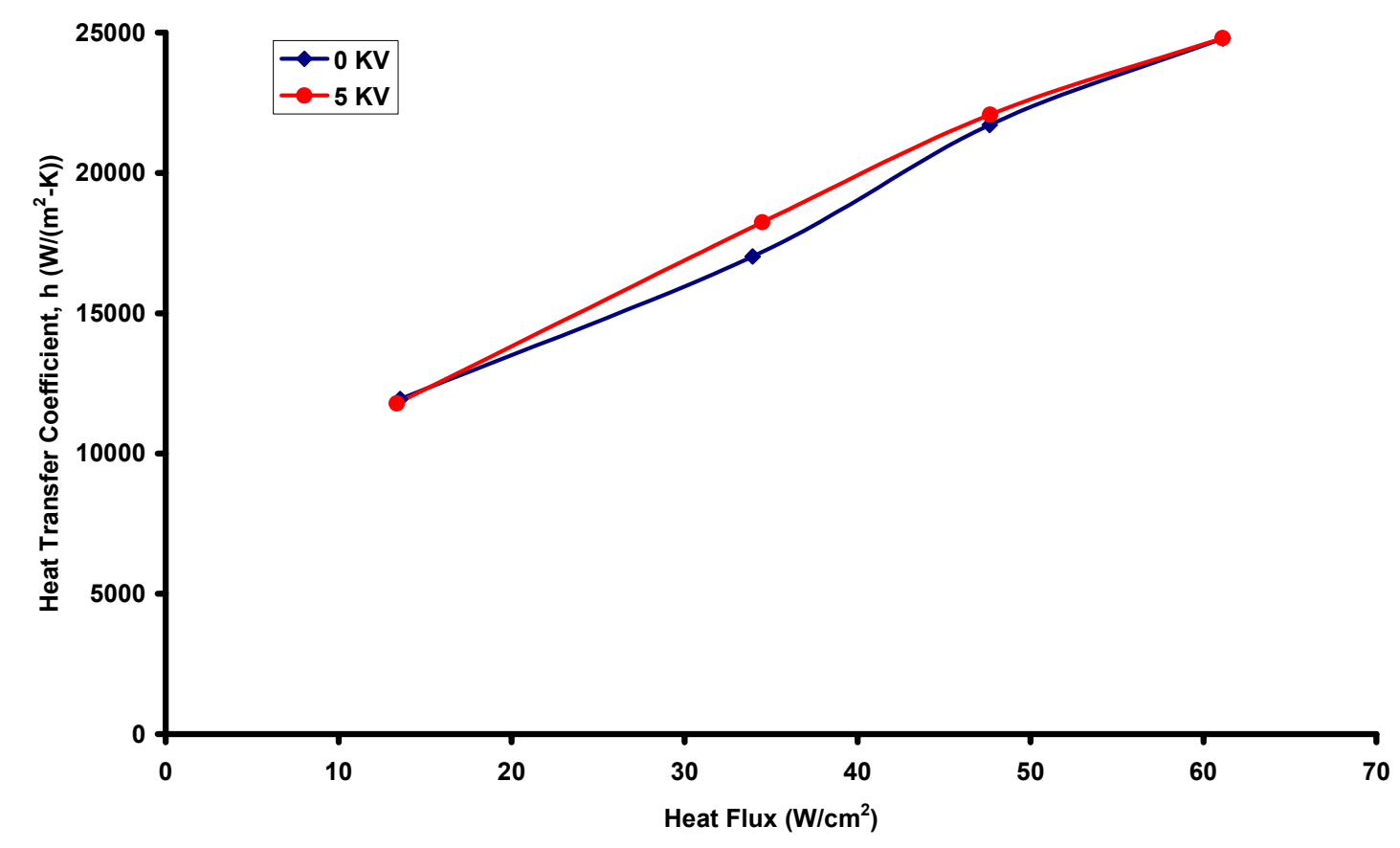

Figure C.27: Heat Transfer Coefficient vs. Heat Flux for Repaired TFR Pedestal with New TFR Heater and Electrode 1 using HFE-7000 at 5.9 GPH

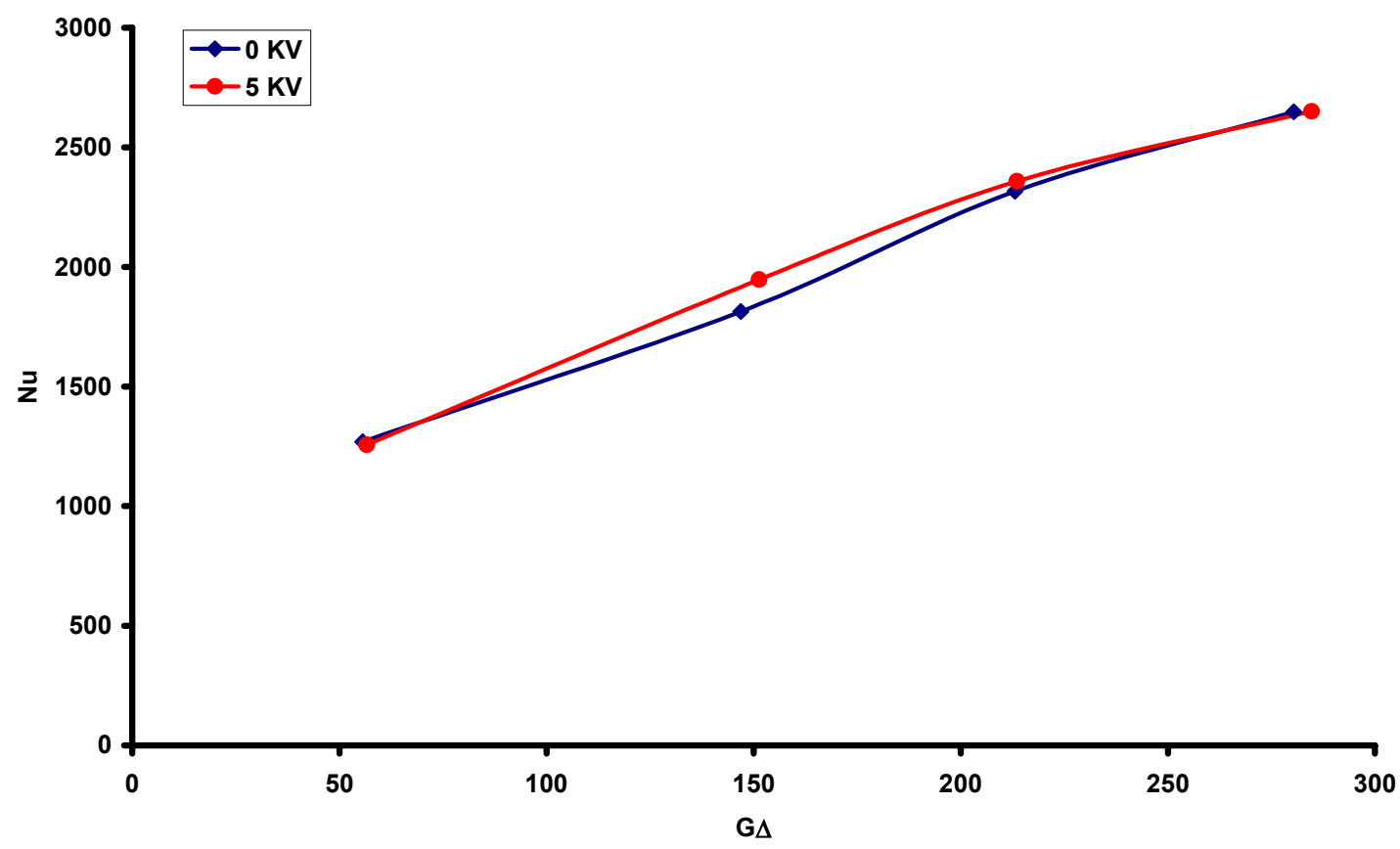

Figure C.28: Non-dimensional Heat Transfer Coefficient vs. Non-dimensional Heat Flux for Repaired TFR Pedestal with New TFR Heater and Electrode 1 using HFE-7000 at 5.9 GPH 


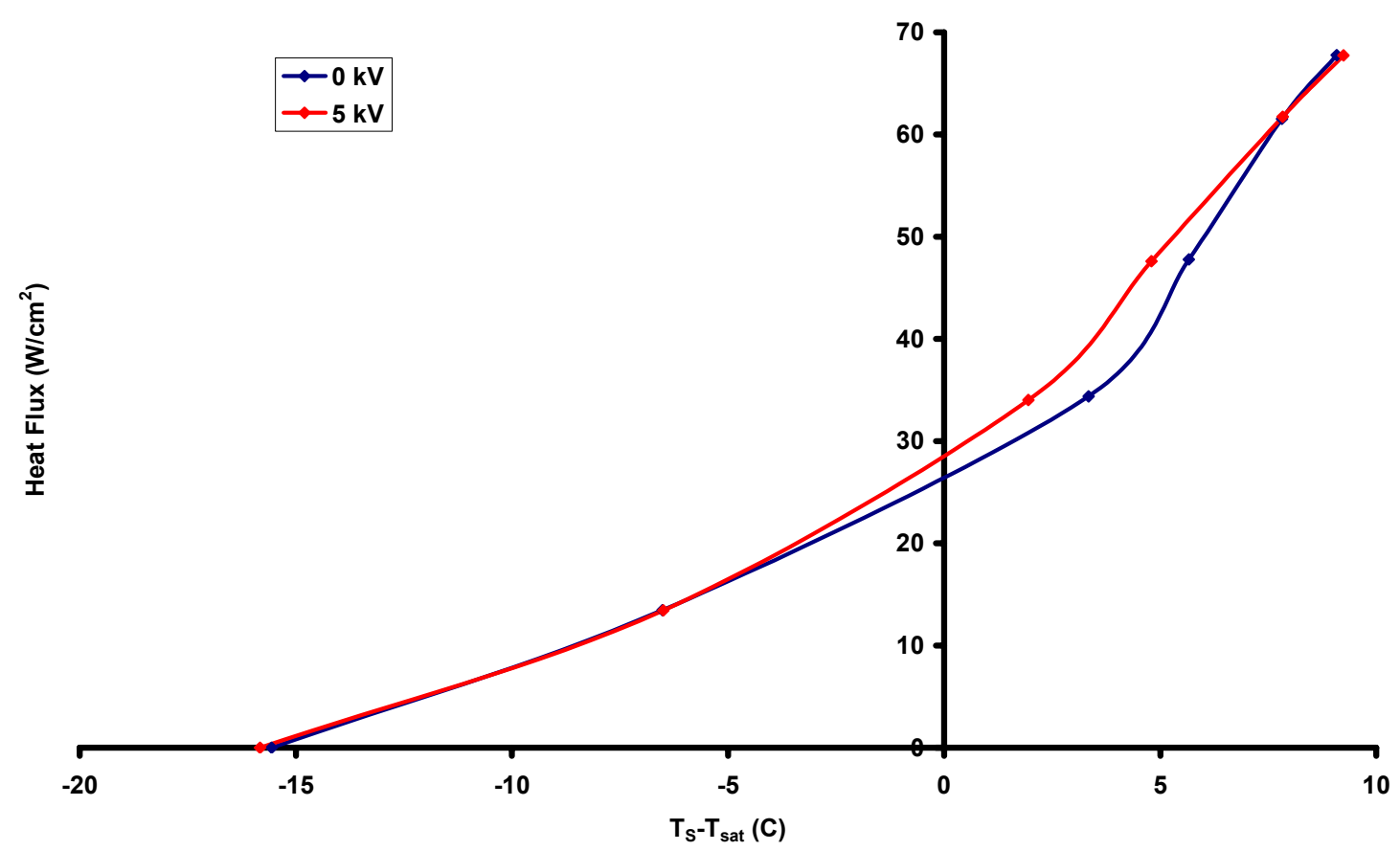

Figure C.29: Heat Flux vs. Temperature Difference for Repaired TFR Pedestal with New TFR Heater and Electrode 1 using HFE-7000 at 8.0 GPH

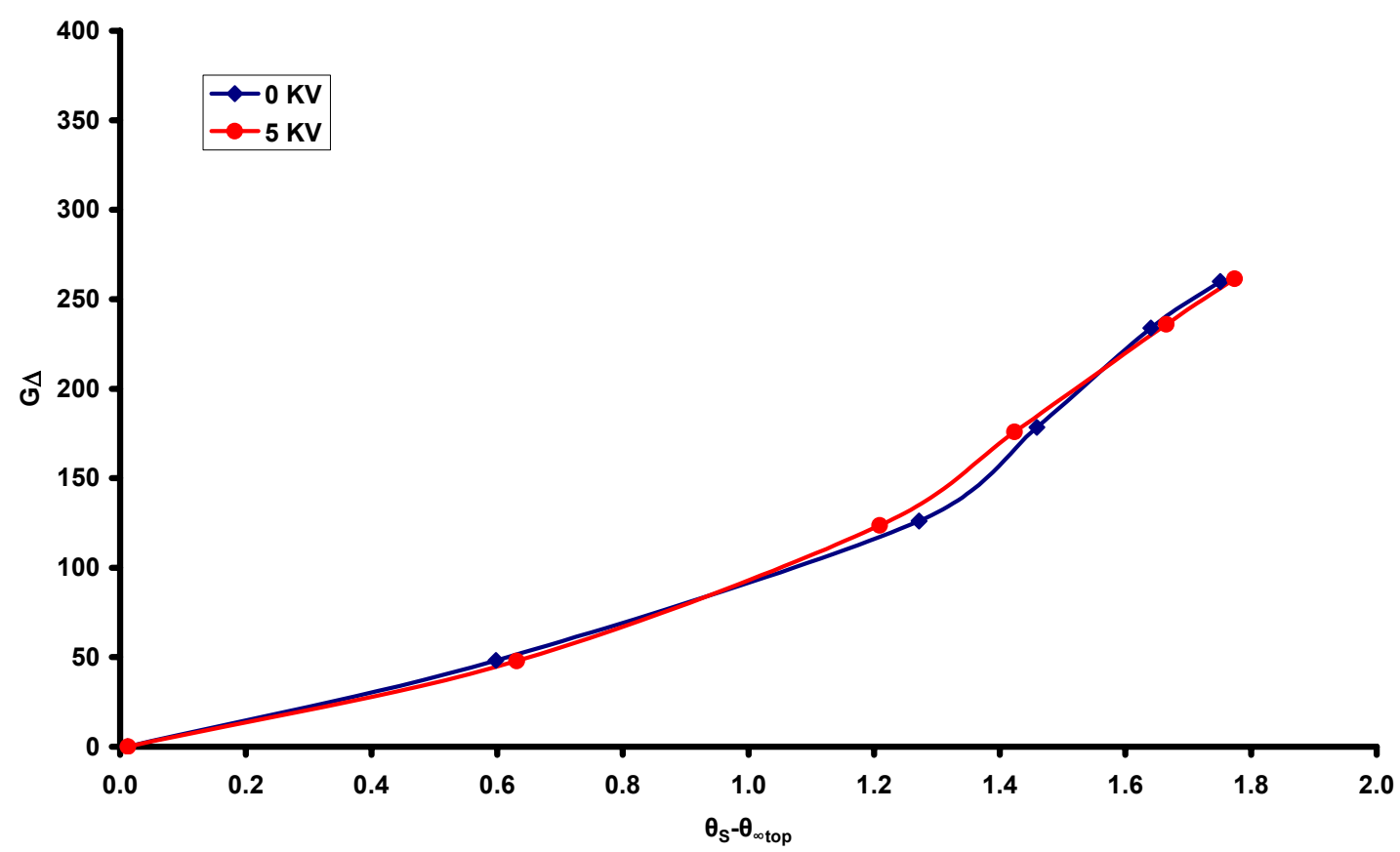

Figure C.30: Non-dimensional Heat Flux vs. Non- dimensional Temperature Difference for Repaired TFR Pedestal with New TFR Heater and Electrode 1 using HFE-7000 at $8.0 \mathrm{GPH}$ 


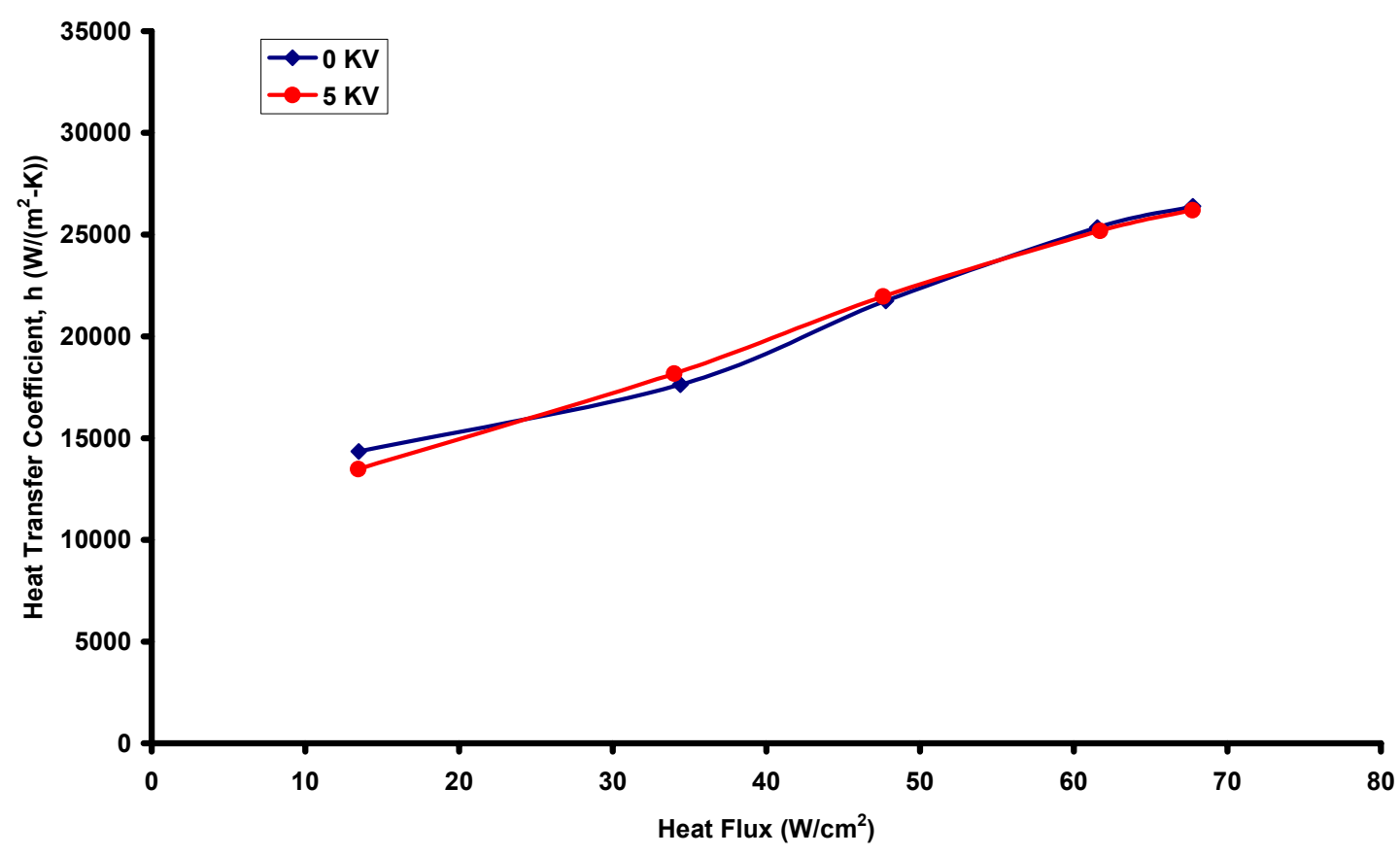

Figure C.31: Heat Transfer Coefficient vs. Heat Flux for Repaired TFR Pedestal with New TFR Heater and Electrode 1 using HFE-7000 at $8.0 \mathrm{GPH}$

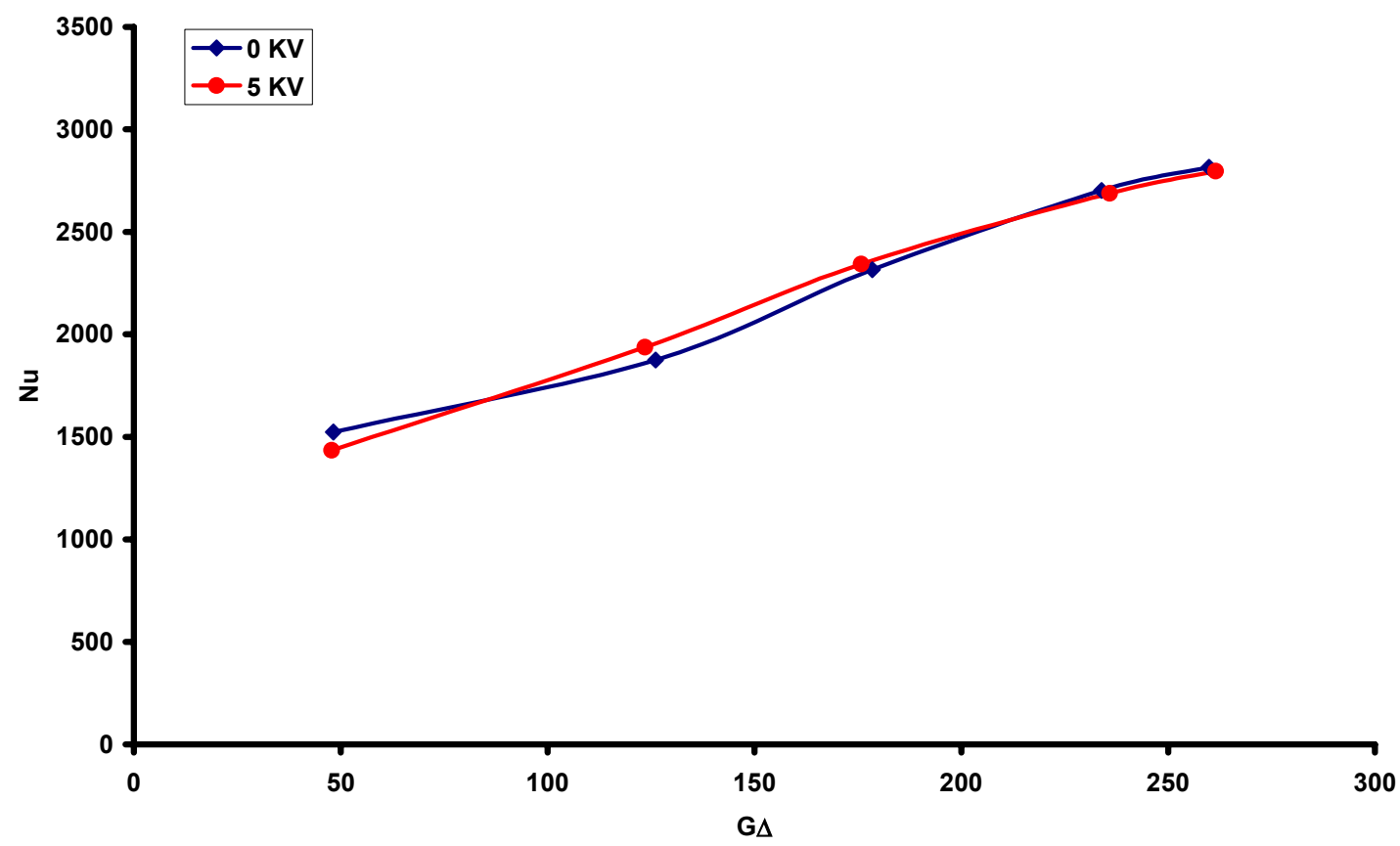

Figure C.32: Non-dimensional Heat Transfer Coefficient vs. Non-dimensional Heat Flux for Repaired TFR Pedestal with New TFR Heater and Electrode 1 using HFE-7000 at 8.0 GPH 


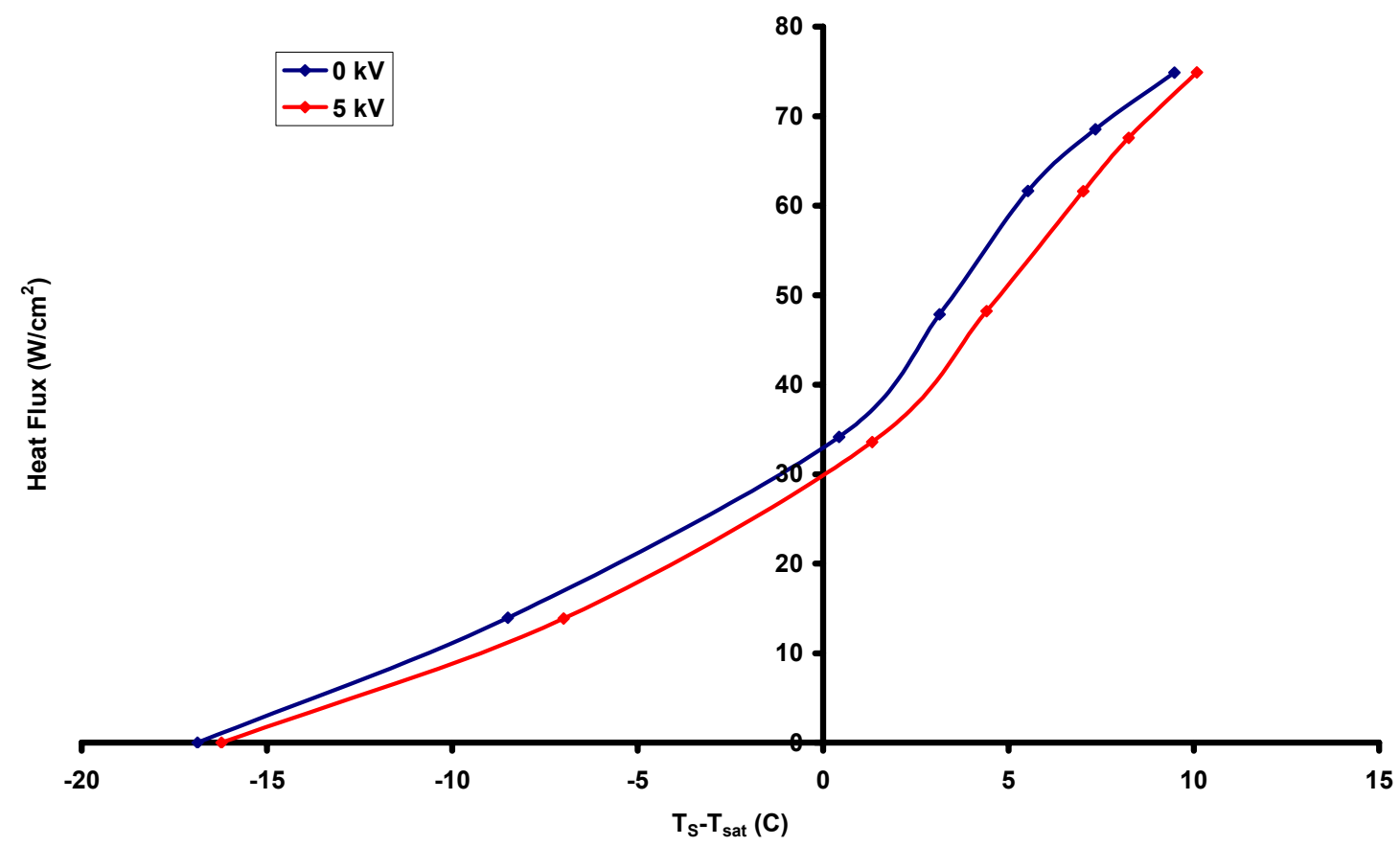

Figure C.33: Heat Flux vs. Temperature Difference for Repaired TFR Pedestal with New TFR Heater and Electrode 1 using HFE-7000 at $8.5 \mathrm{GPH}$

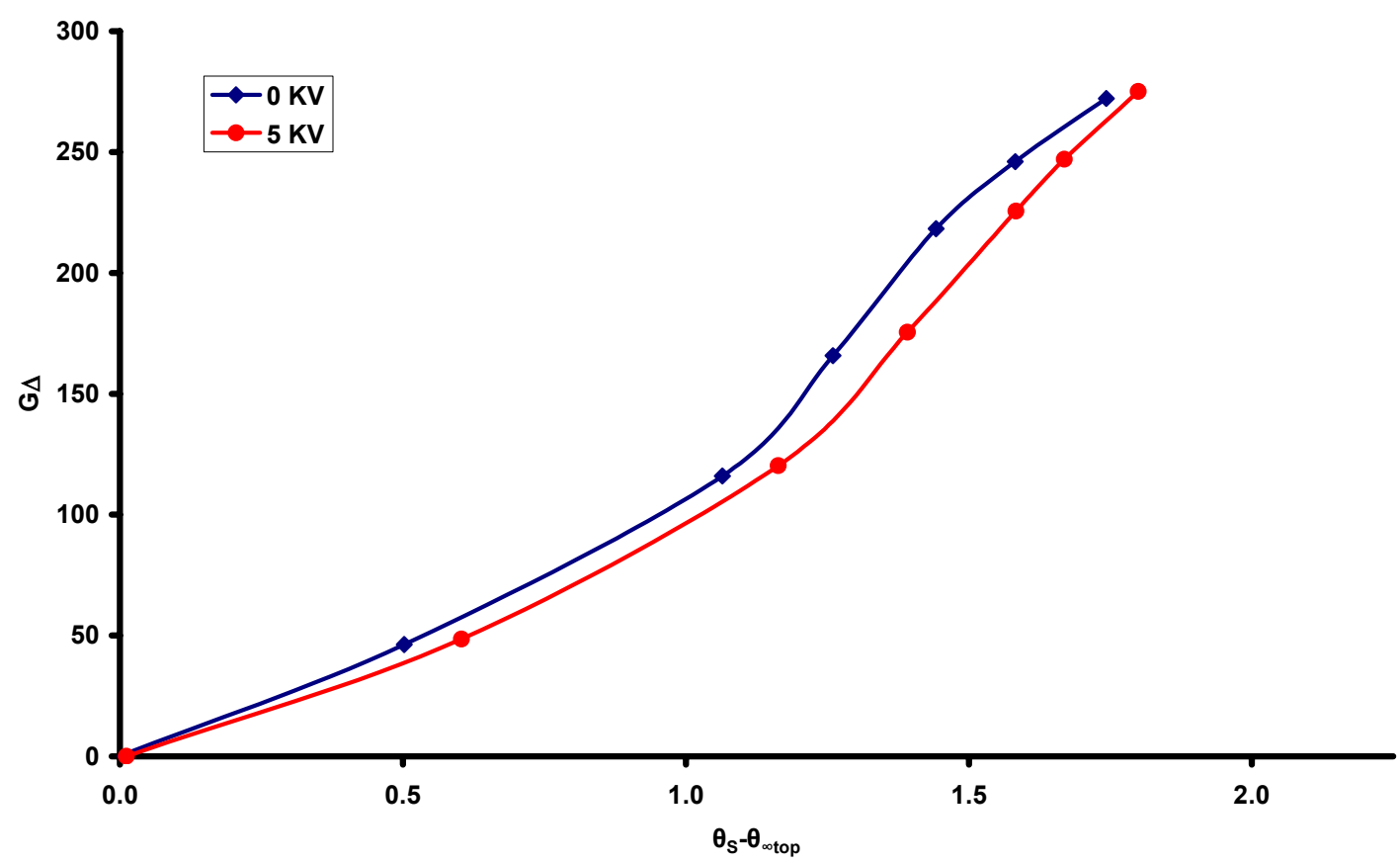

Figure C.34: Non-dimensional Heat Flux vs. Non- dimensional Temperature Difference for Repaired TFR Pedestal with New TFR Heater and Electrode 1 using HFE-7000 at 8.5 GPH 


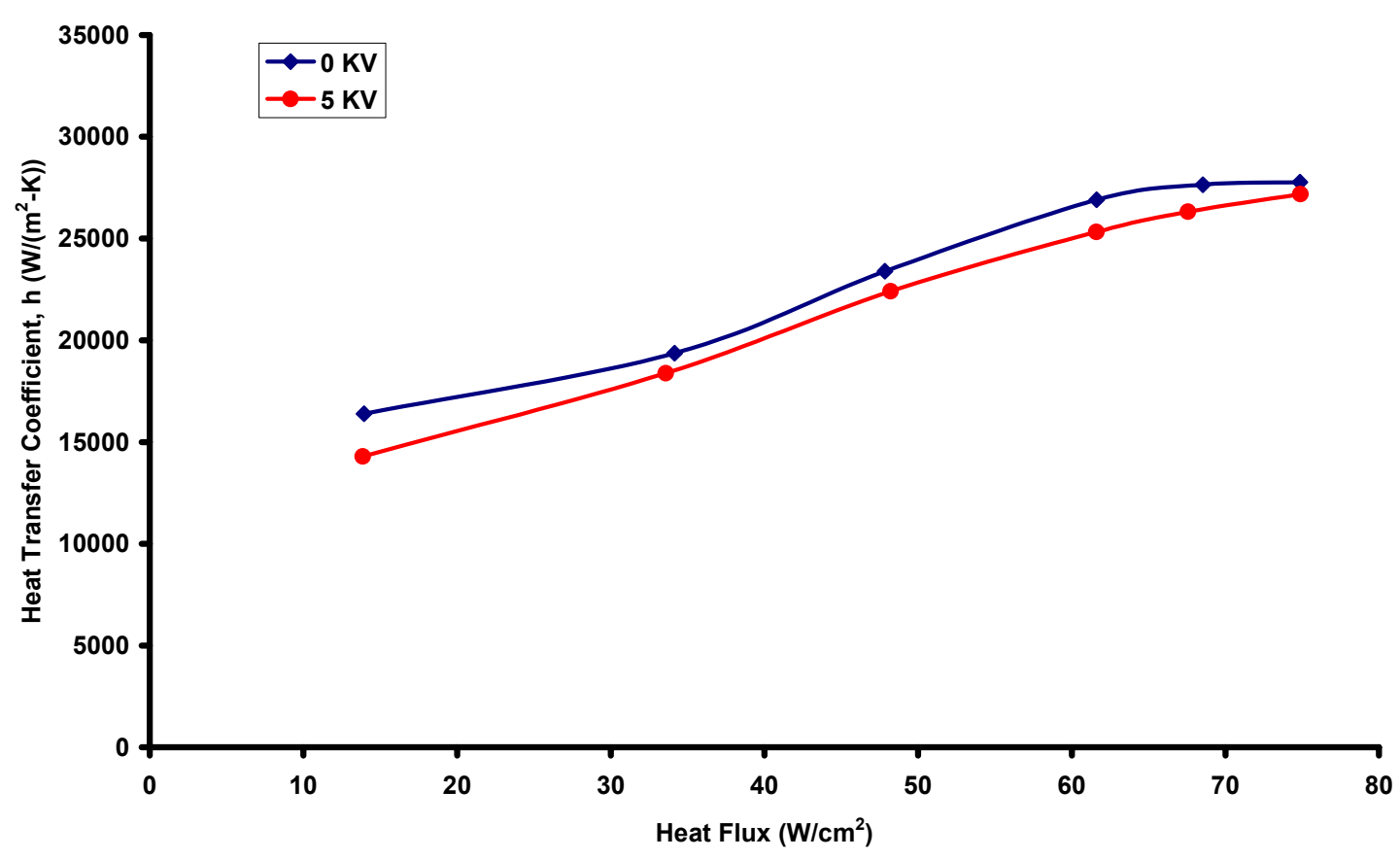

Figure C.35: Heat Transfer Coefficient vs. Heat Flux for Repaired TFR Pedestal with New TFR Heater and Electrode 1 using HFE-7000 at 8.5 GPH

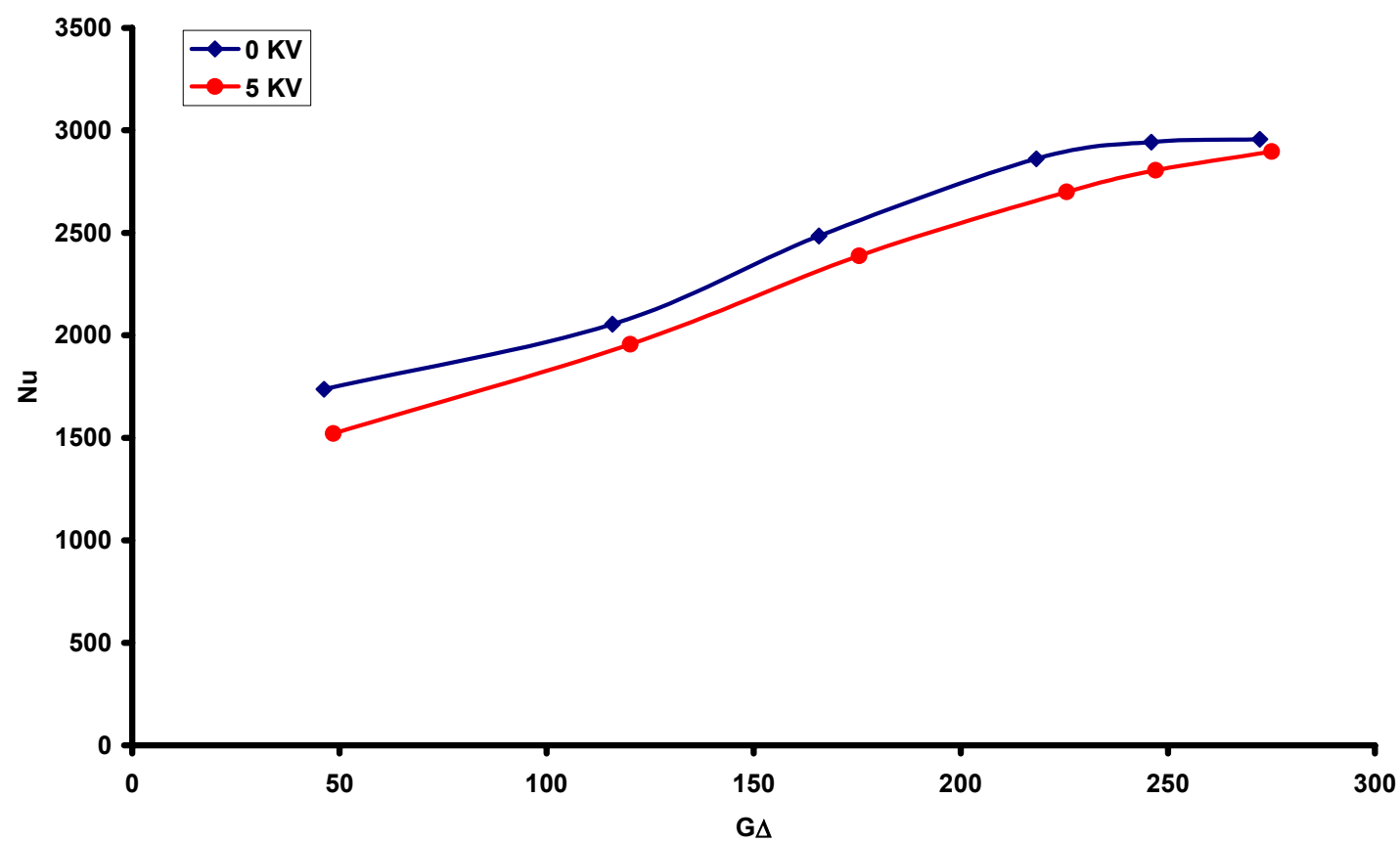

Figure C.36: Non-dimensional Heat Transfer Coefficient vs. Non-dimensional Heat Flux for Repaired TFR Pedestal with New TFR Heater and Electrode 1 using HFE-7000 at $8.5 \mathrm{GPH}$ 
Data plots showing the results for the repaired TFR pedestal with new TFR heater, electrode 2, and using a working fluid of HFE-7000 at 5.9, 8.0, and 8.5 GPH.

- Heat Flux vs. Temperature Difference

- Non-dimensional Heat Flux vs. Non- dimensional Temperature Difference

- Heat Transfer Coefficient vs. Heat Flux

- Non-dimensional Heat Transfer Coefficient vs. Non-dimensional Heat Flux 


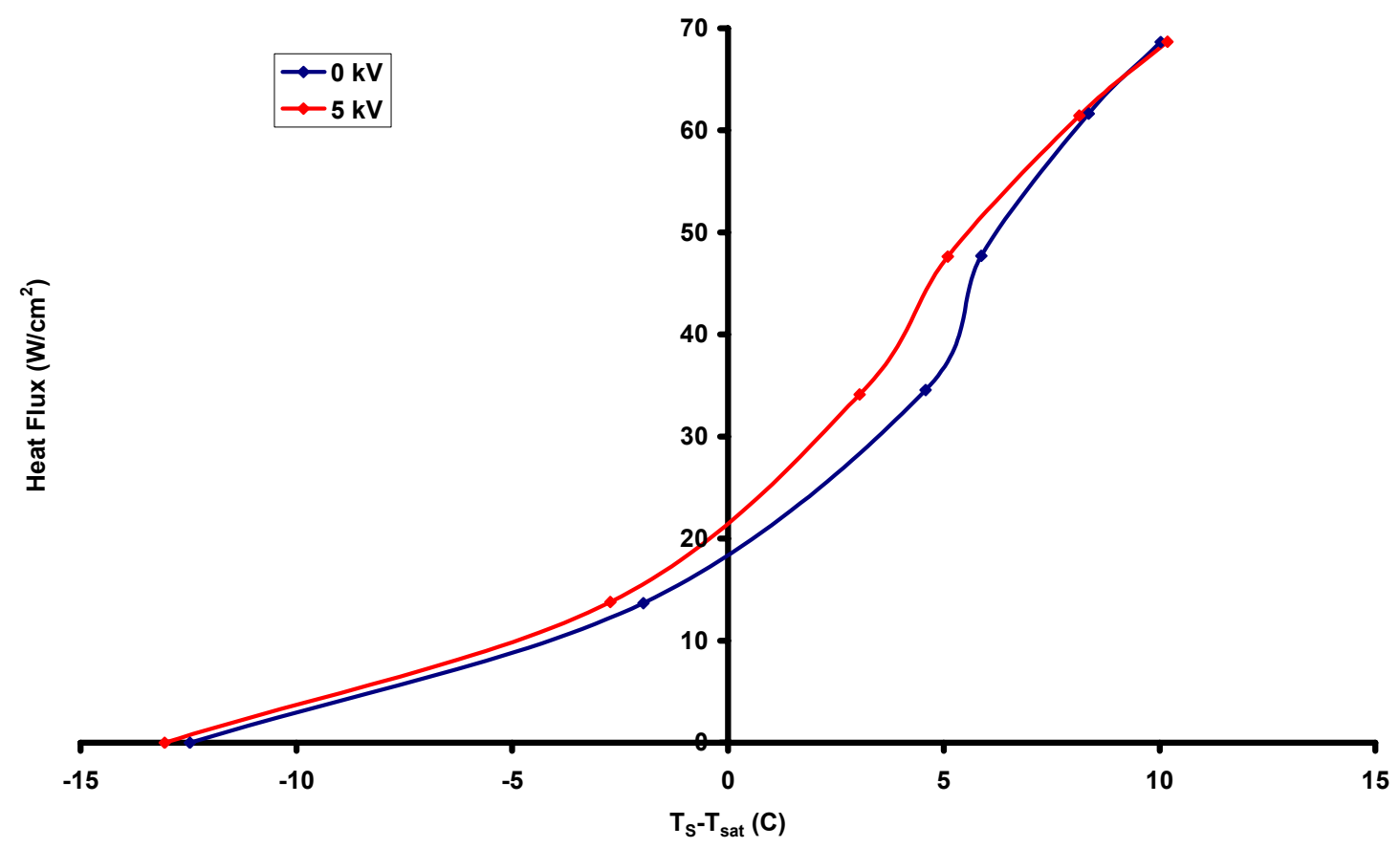

Figure C.37: Heat Flux vs. Temperature Difference for Repaired TFR Pedestal with New TFR Heater and Electrode 2 using HFE-7000 at 5.9 GPH

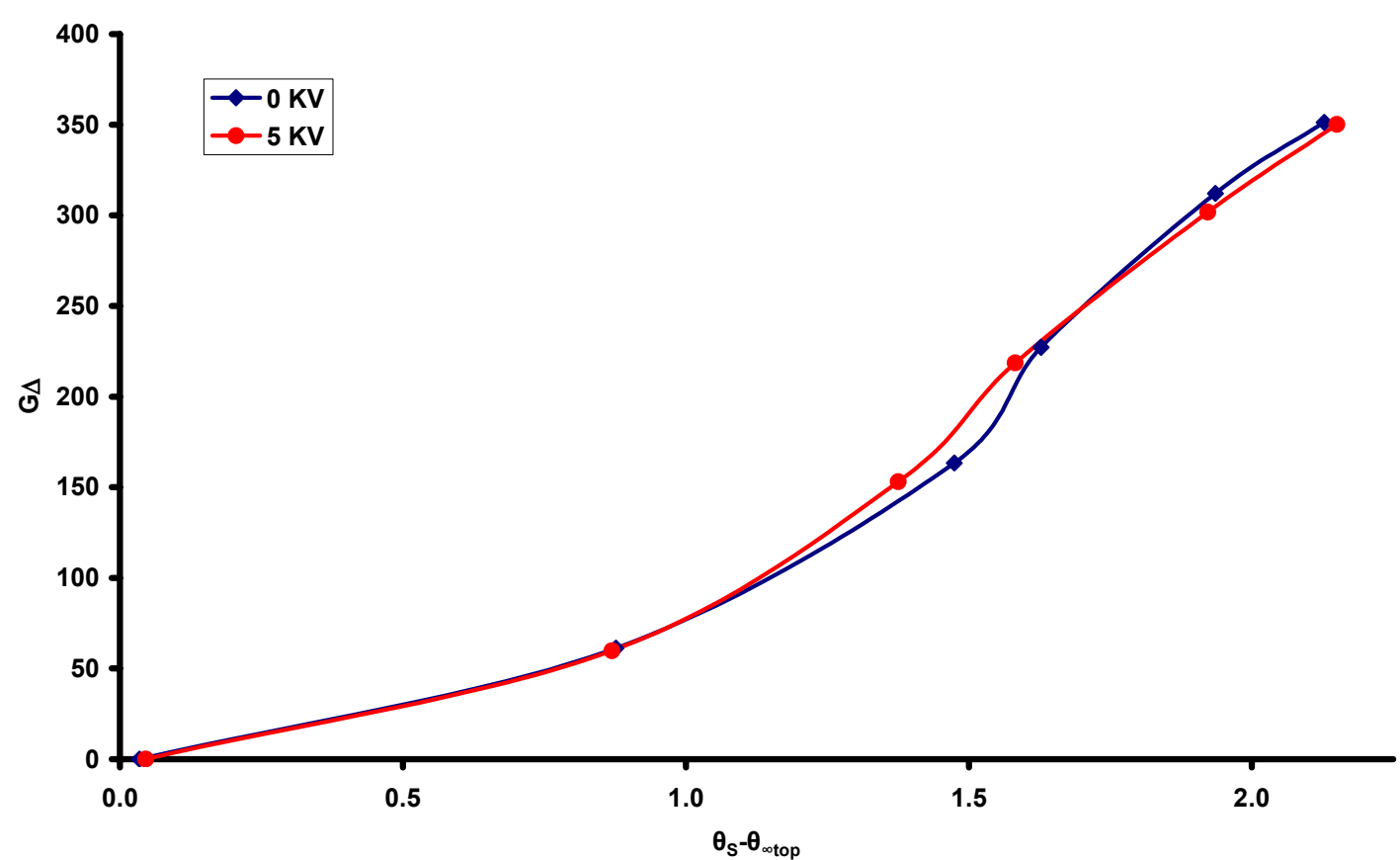

Figure C.38: Non-dimensional Heat Flux vs. Non- dimensional Temperature Difference for Repaired TFR Pedestal with New TFR Heater and Electrode 2 using HFE-7000 at $5.9 \mathrm{GPH}$ 


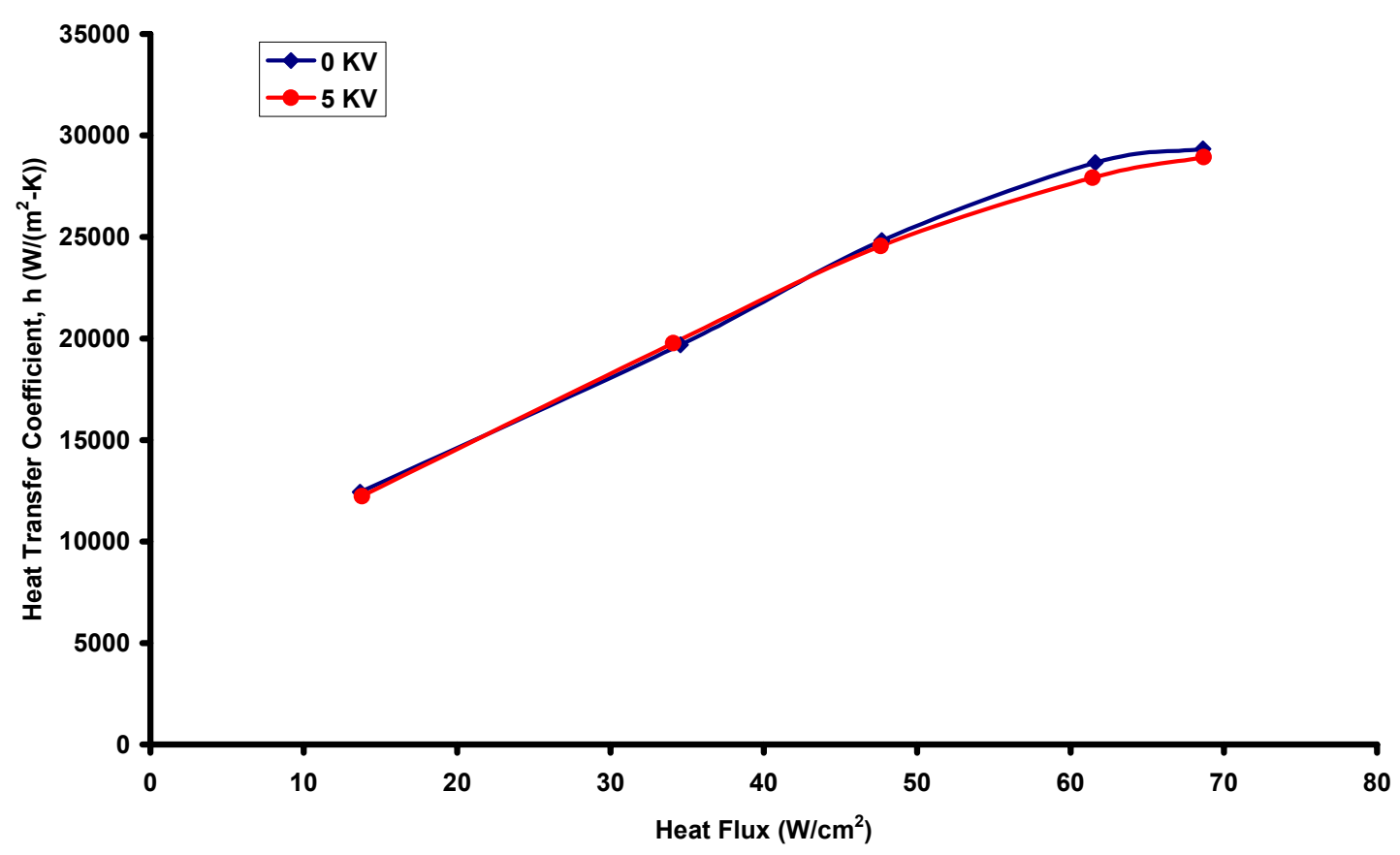

Figure C.39: Heat Transfer Coefficient vs. Heat Flux for Repaired TFR Pedestal with New TFR Heater and Electrode 2 using HFE-7000 at 5.9 GPH

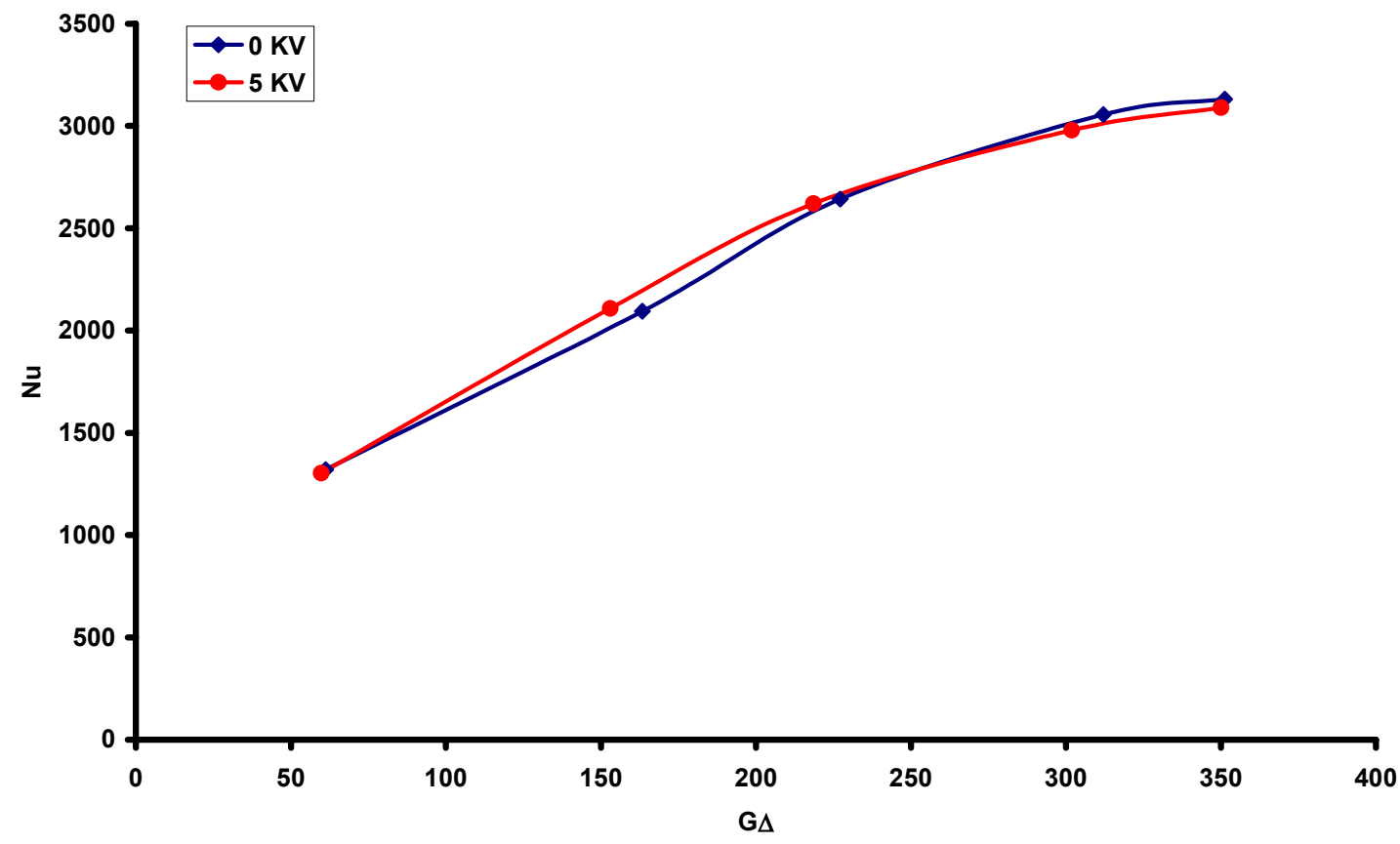

Figure C.40: Non-dimensional Heat Transfer Coefficient vs. Non-dimensional Heat Flux for Repaired TFR Pedestal with New TFR Heater and Electrode 2 using HFE-7000 at $5.9 \mathrm{GPH}$ 


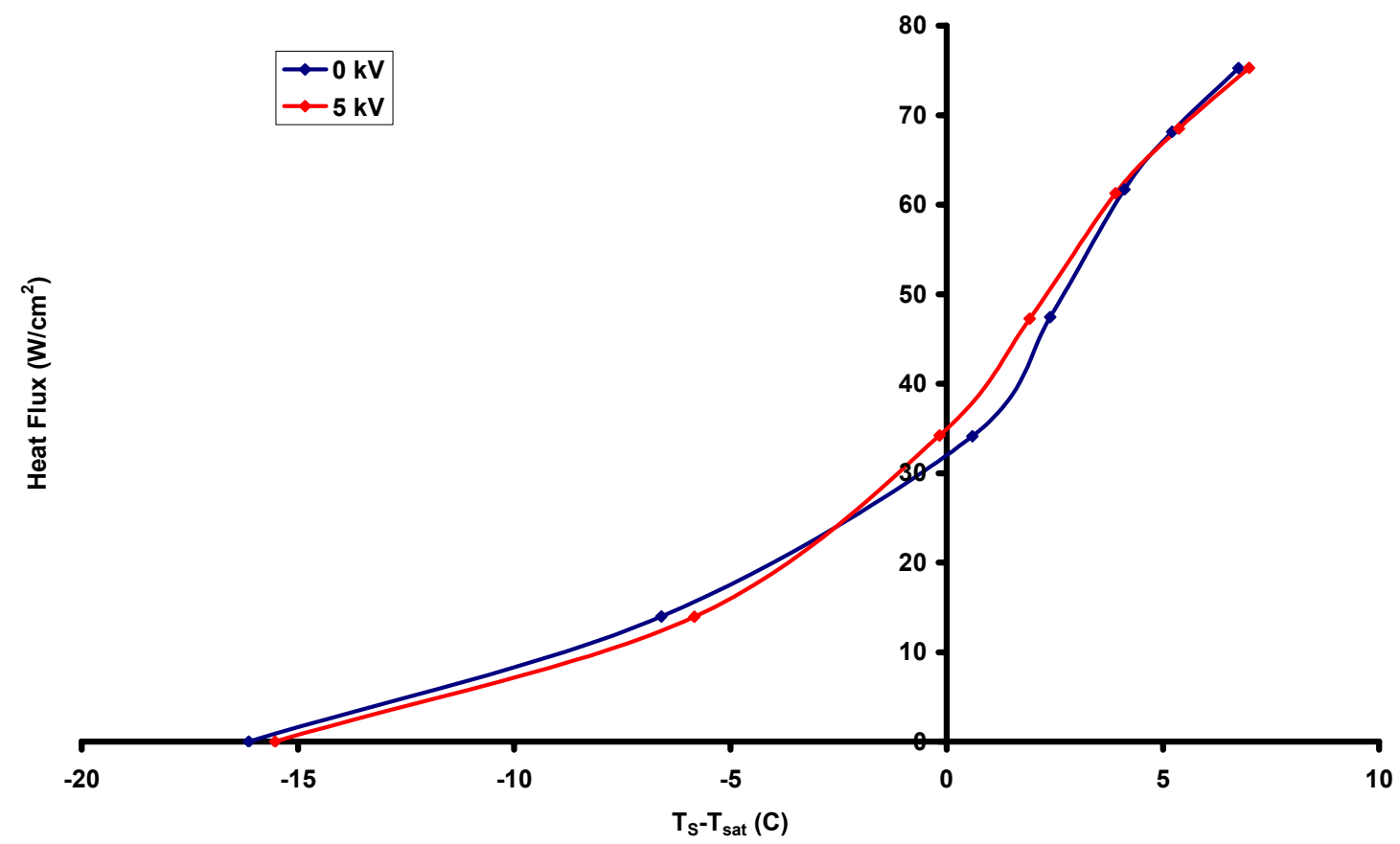

Figure C.41: Heat Flux vs. Temperature Difference for Repaired TFR Pedestal with New TFR Heater and Electrode 2 using HFE-7000 at $8.0 \mathrm{GPH}$

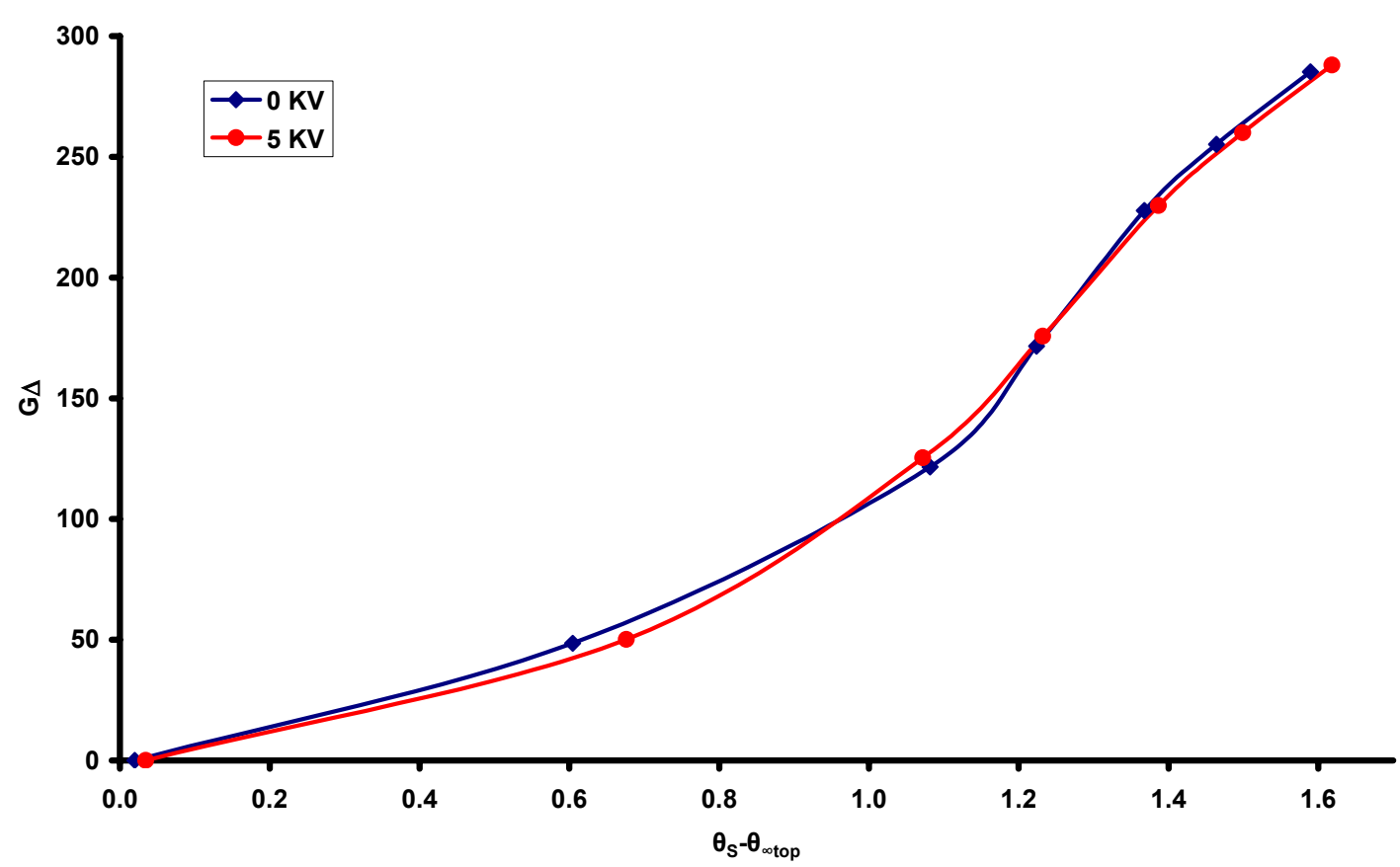

Figure C.42: Non-dimensional Heat Flux vs. Non- dimensional Temperature Difference for Repaired TFR Pedestal with New TFR Heater and Electrode 2 using HFE-7000 at 8.0 GPH 


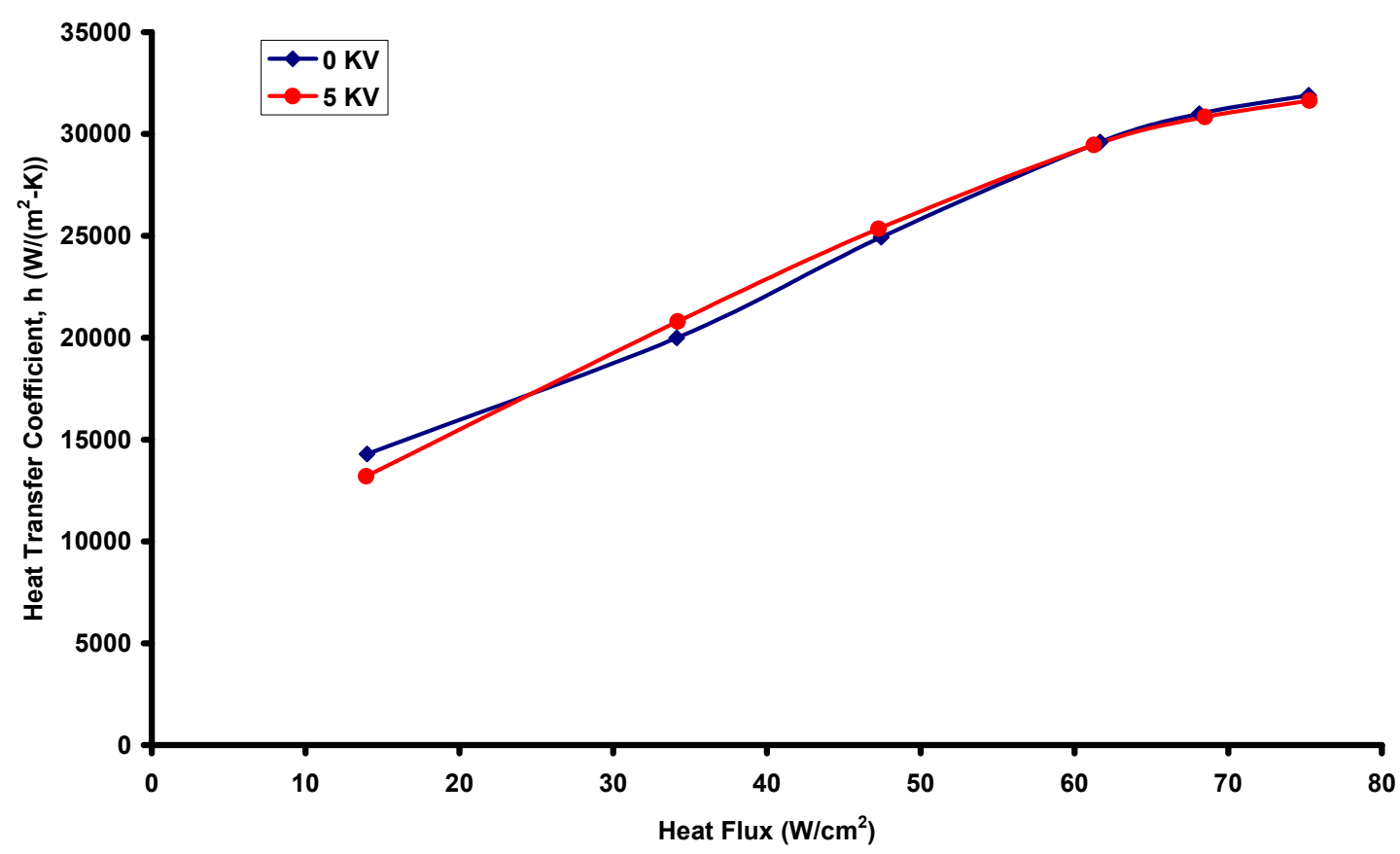

Figure C.43: Heat Transfer Coefficient vs. Heat Flux for Repaired TFR Pedestal with New TFR Heater and Electrode 2 using HFE-7000 at 8.0 GPH

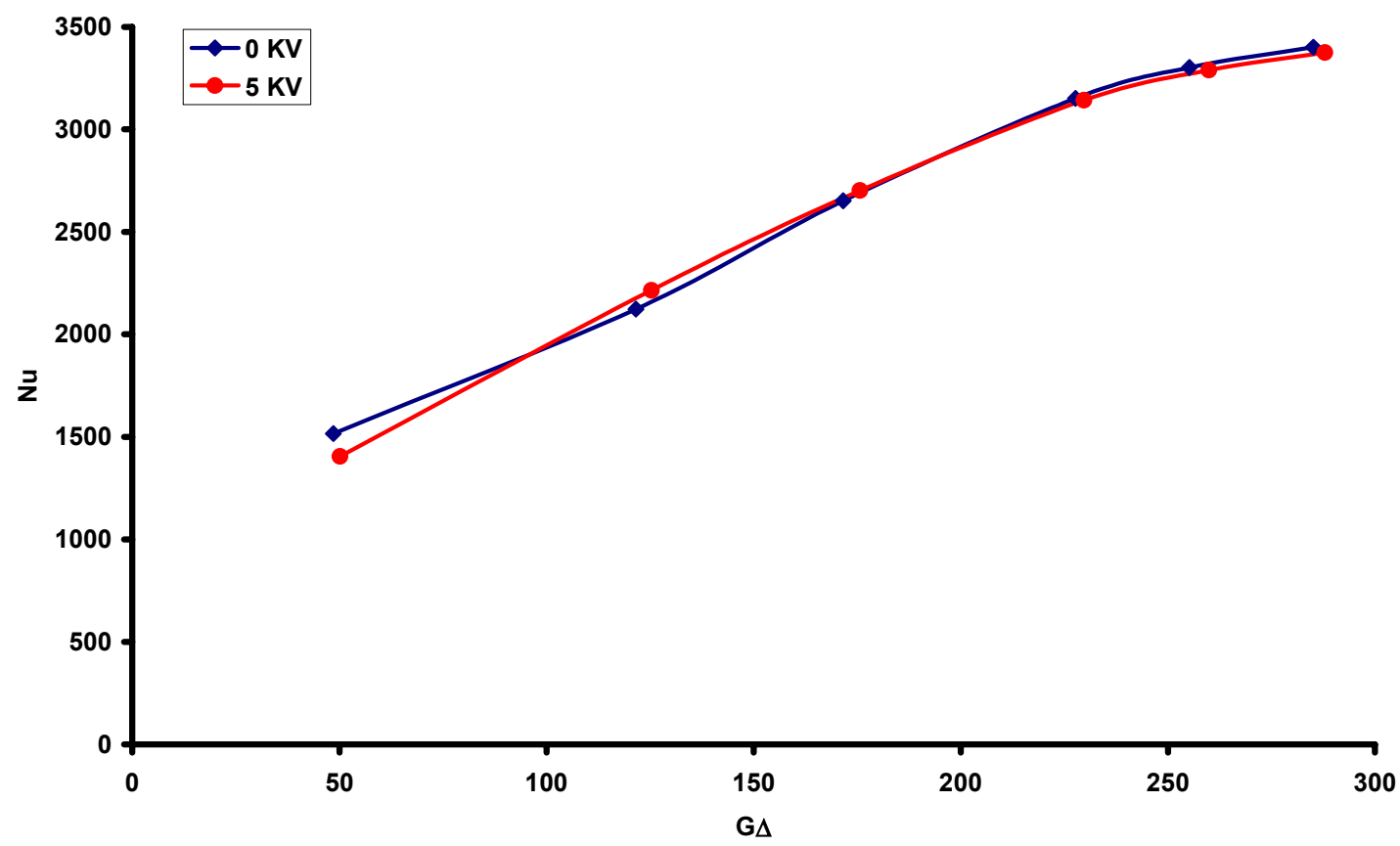

Figure C.44: Non-dimensional Heat Transfer Coefficient vs. Non-dimensional Heat Flux for Repaired TFR Pedestal with New TFR Heater and Electrode 2 using HFE-7000 at $8.0 \mathrm{GPH}$ 


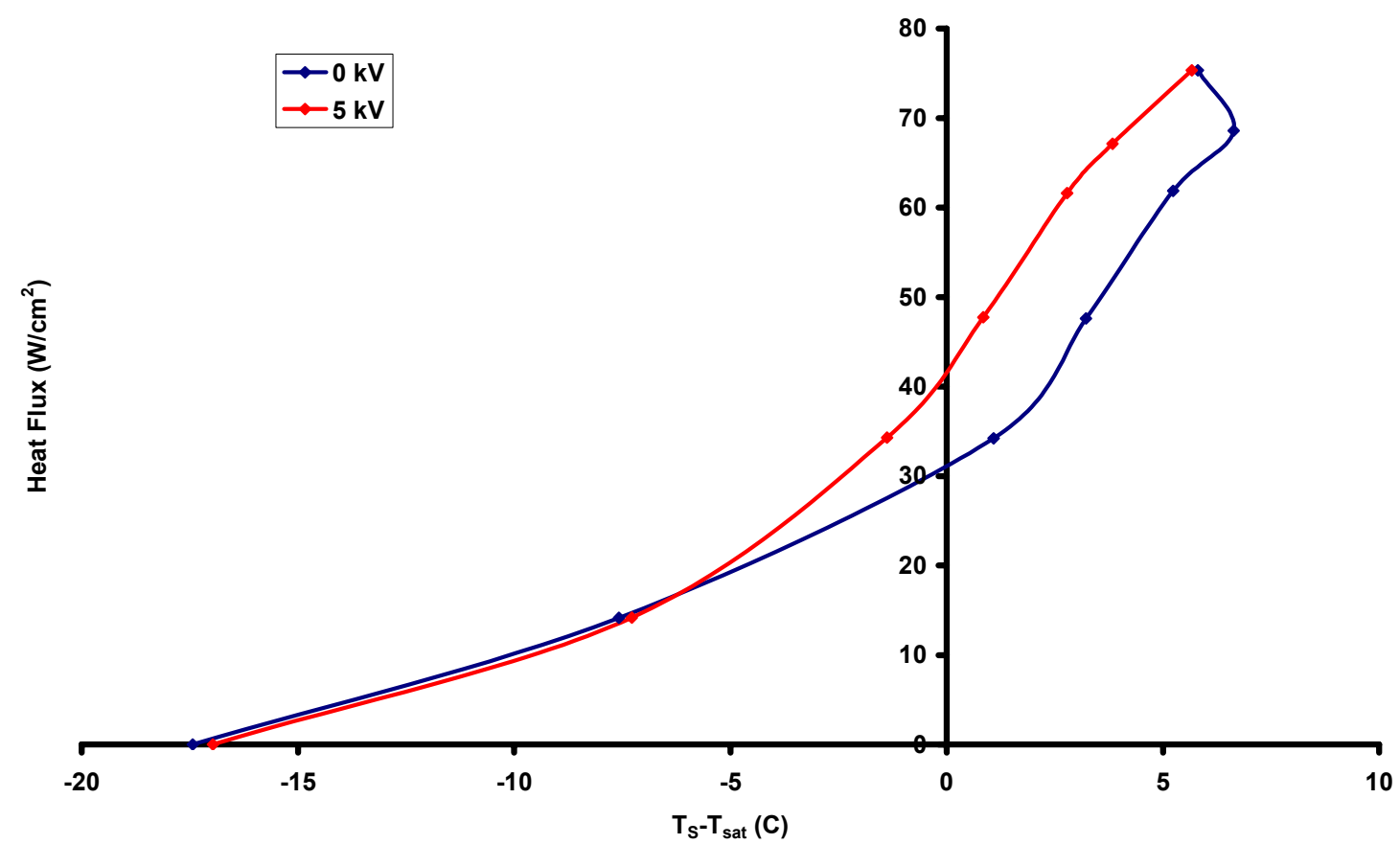

Figure C.45: Heat Flux vs. Temperature Difference for Repaired TFR Pedestal with New TFR Heater and Electrode 2 using HFE-7000 at $8.5 \mathrm{GPH}$

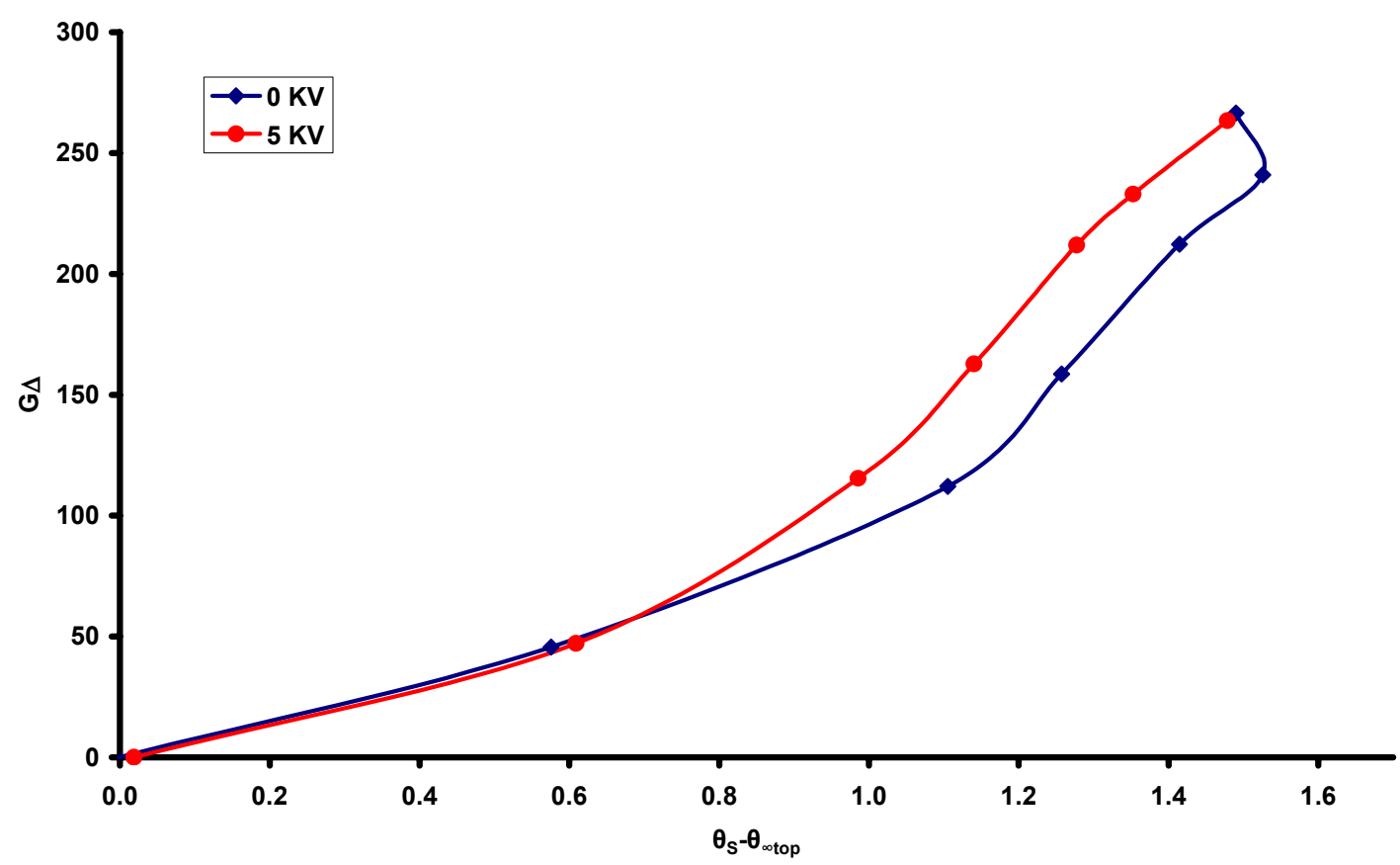

Figure C.46: Non-dimensional Heat Flux vs. Non- dimensional Temperature Difference for Repaired TFR Pedestal with New TFR Heater and Electrode 2 using HFE-7000 at 8.5 GPH 


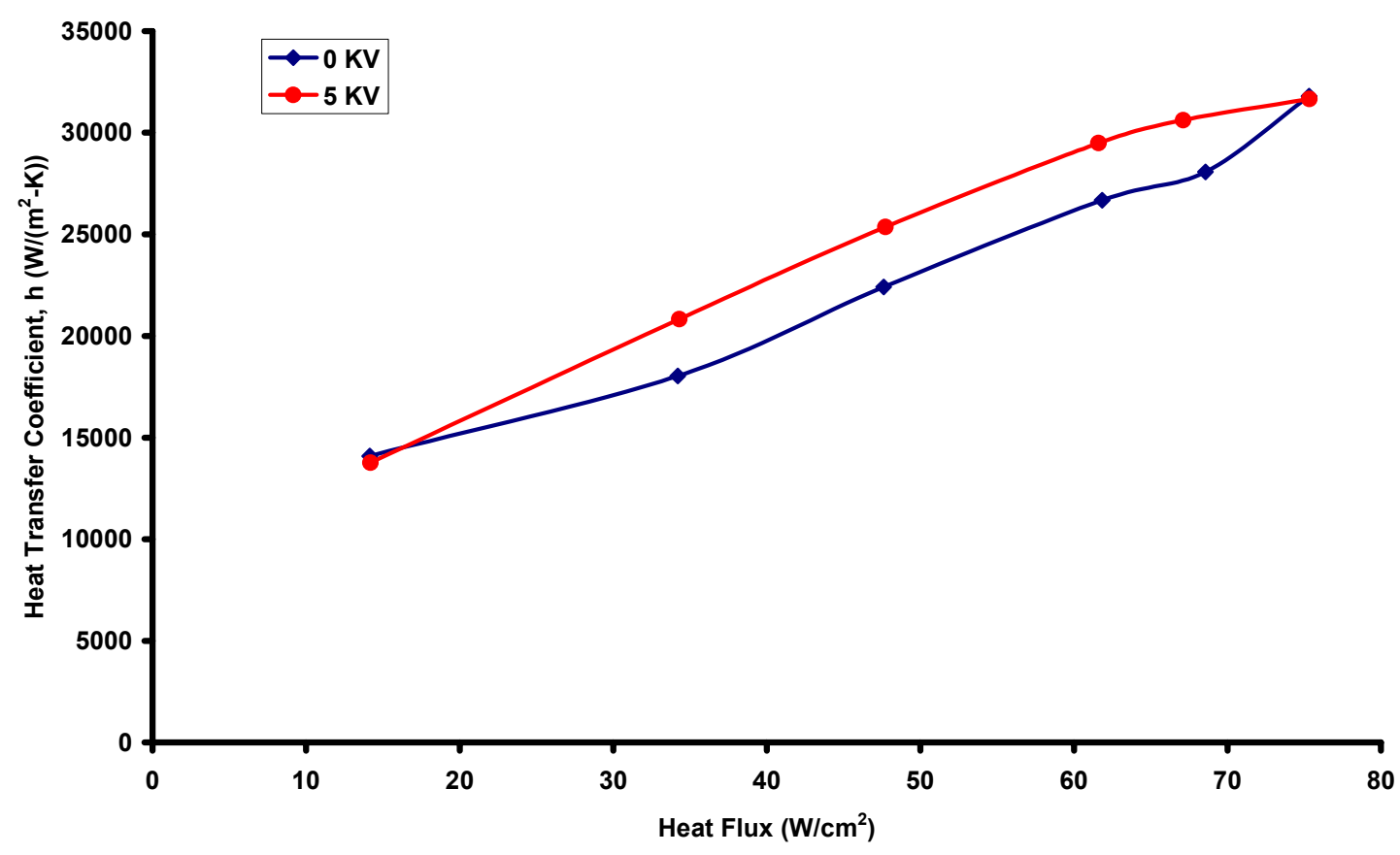

Figure C.47: Heat Transfer Coefficient vs. Heat Flux for Repaired TFR Pedestal with New TFR Heater and Electrode 2 using HFE-7000 at $8.5 \mathrm{GPH}$

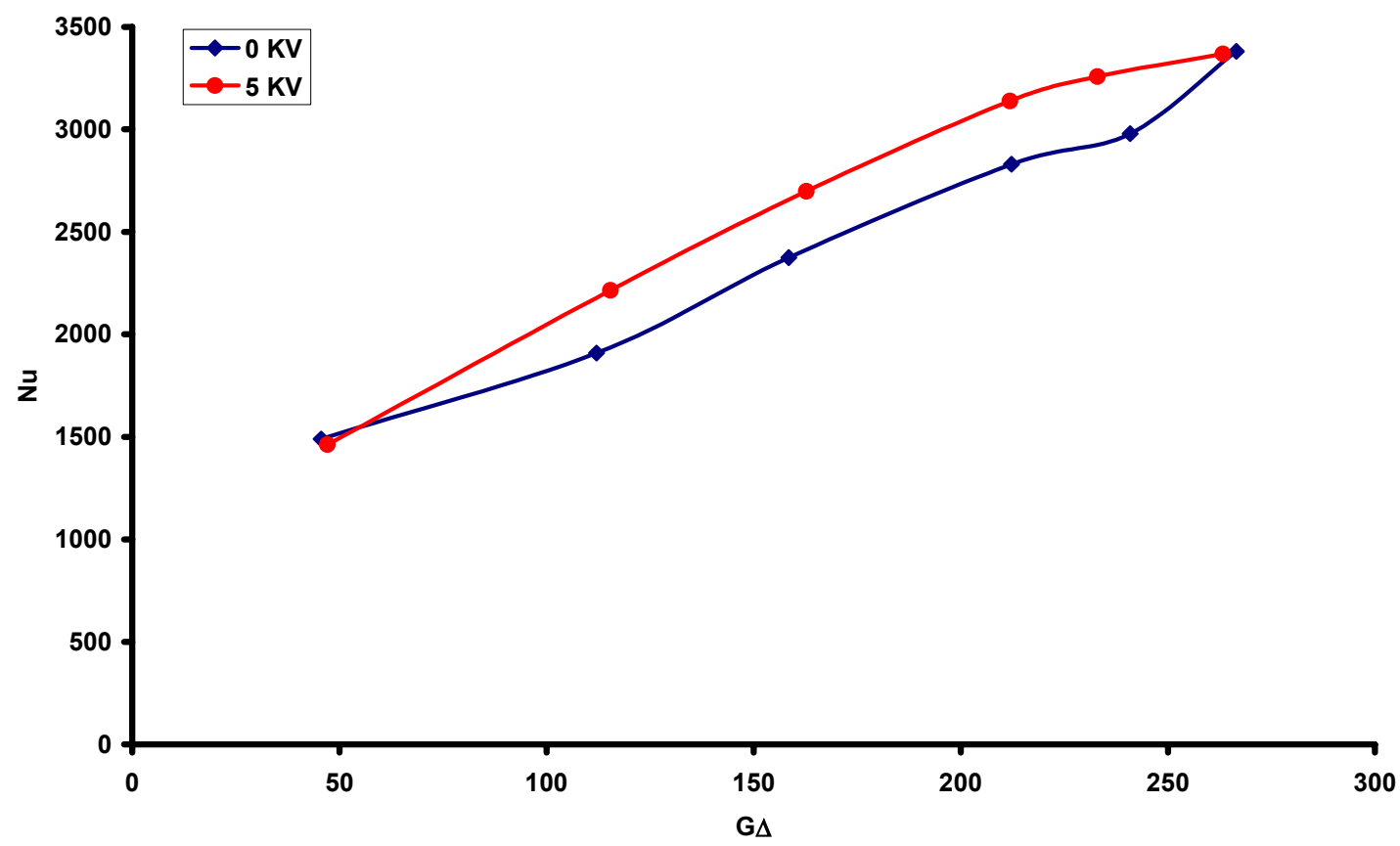

Figure C.48: Non-dimensional Heat Transfer Coefficient vs. Non-dimensional Heat Flux for Repaired TFR Pedestal with New TFR Heater and Electrode 2 using HFE-7000 at $8.5 \mathrm{GPH}$ 
Data plots showing the results for the repaired TFR pedestal with new TFR heater, electrode 2, and using a working fluid of HFE-7000 at 5.9 and 8.5 GPH.

- Heat Flux vs. Temperature Difference

- Non-dimensional Heat Flux vs. Non- dimensional Temperature Difference

- Heat Transfer Coefficient vs. Heat Flux

- Non-dimensional Heat Transfer Coefficient vs. Non-dimensional Heat Flux 


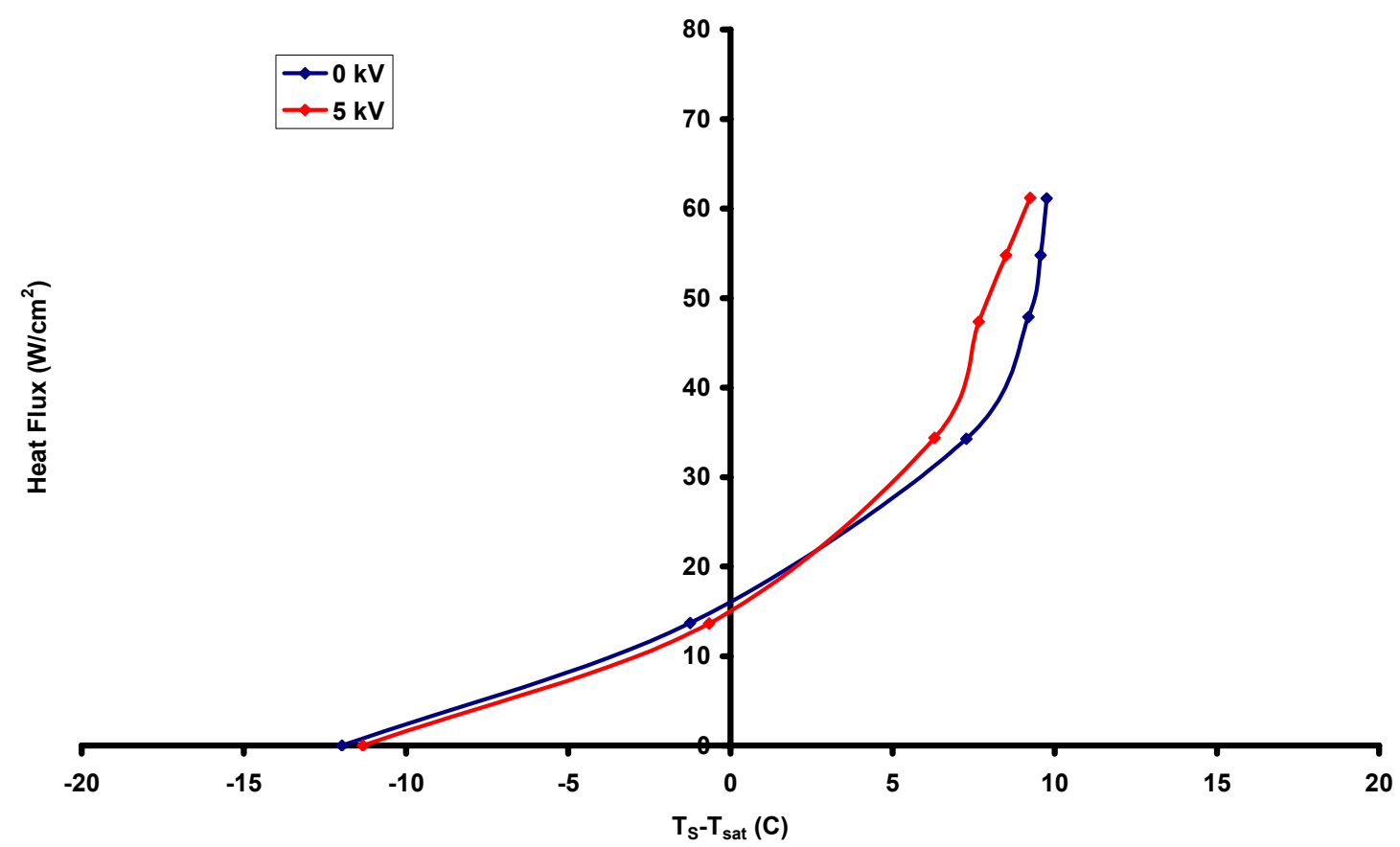

Figure C.49: Heat Flux vs. Temperature Difference for PTFE Pedestal with New TFR Heater and Electrode 1 using HFE-7000 at 5.9 GPH

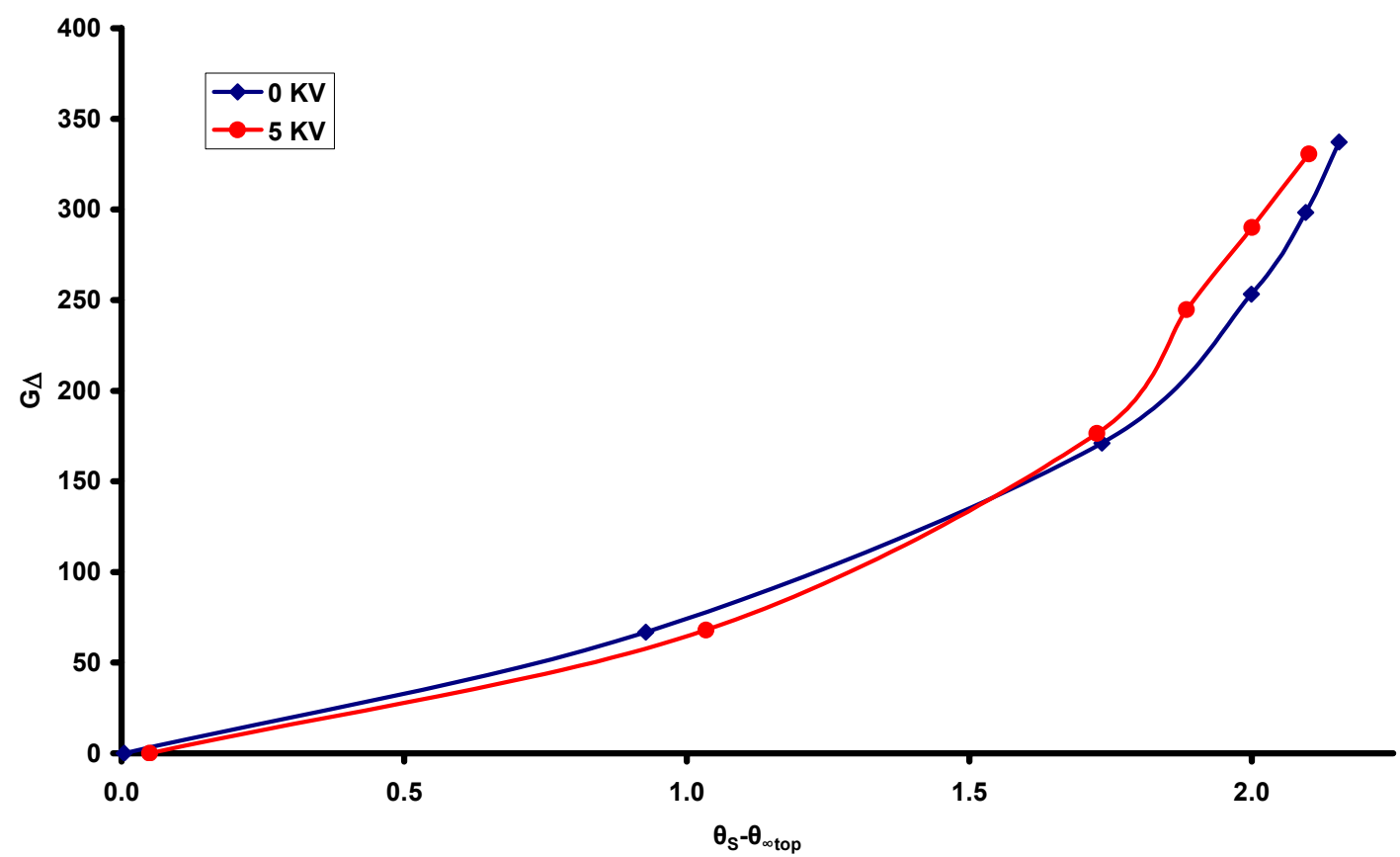

Figure C.50: Non-dimensional Heat Flux vs. Non- dimensional Temperature Difference for PTFE Pedestal with New TFR Heater and Electrode 1 using HFE-7000 at $5.9 \mathrm{GPH}$ 


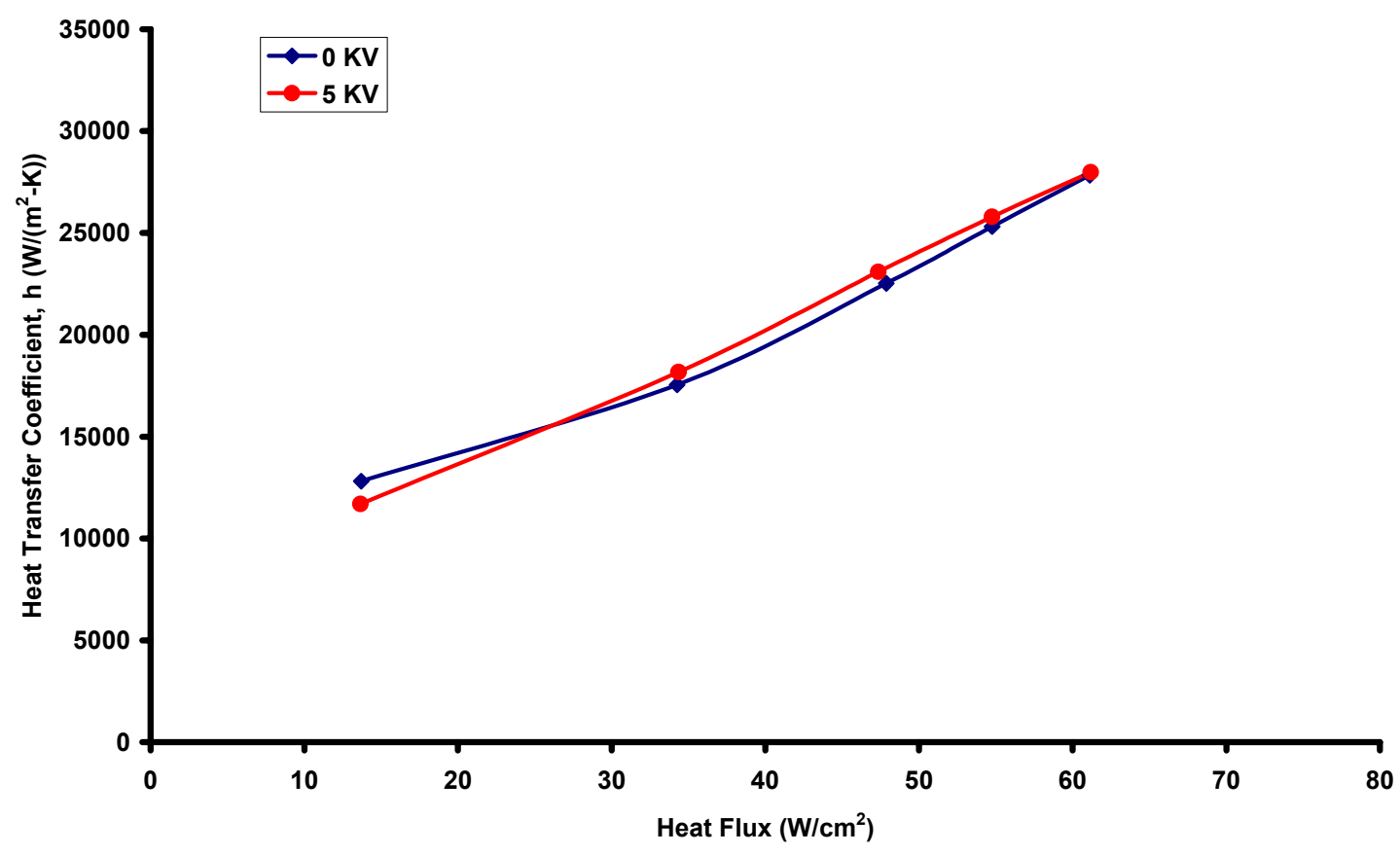

Figure C.51: Heat Transfer Coefficient vs. Heat Flux for PTFE Pedestal with New TFR Heater and Electrode 1 using HFE-7000 at 5.9 GPH

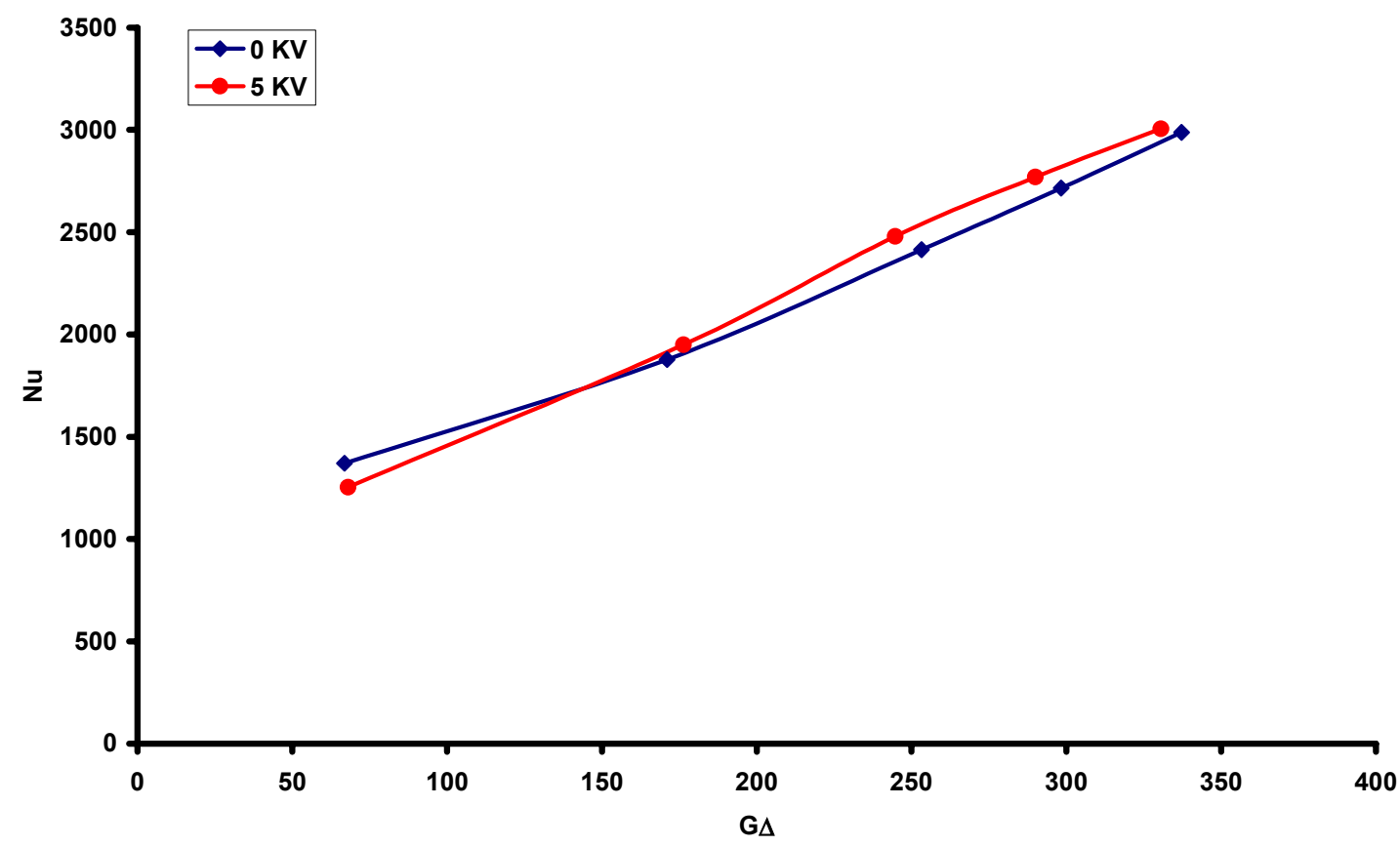

Figure C.52: Non-dimensional Heat Transfer Coefficient vs. Non-dimensional Heat Flux for PTFE Pedestal with New TFR Heater and Electrode 1 using HFE7000 at $5.9 \mathrm{GPH}$ 


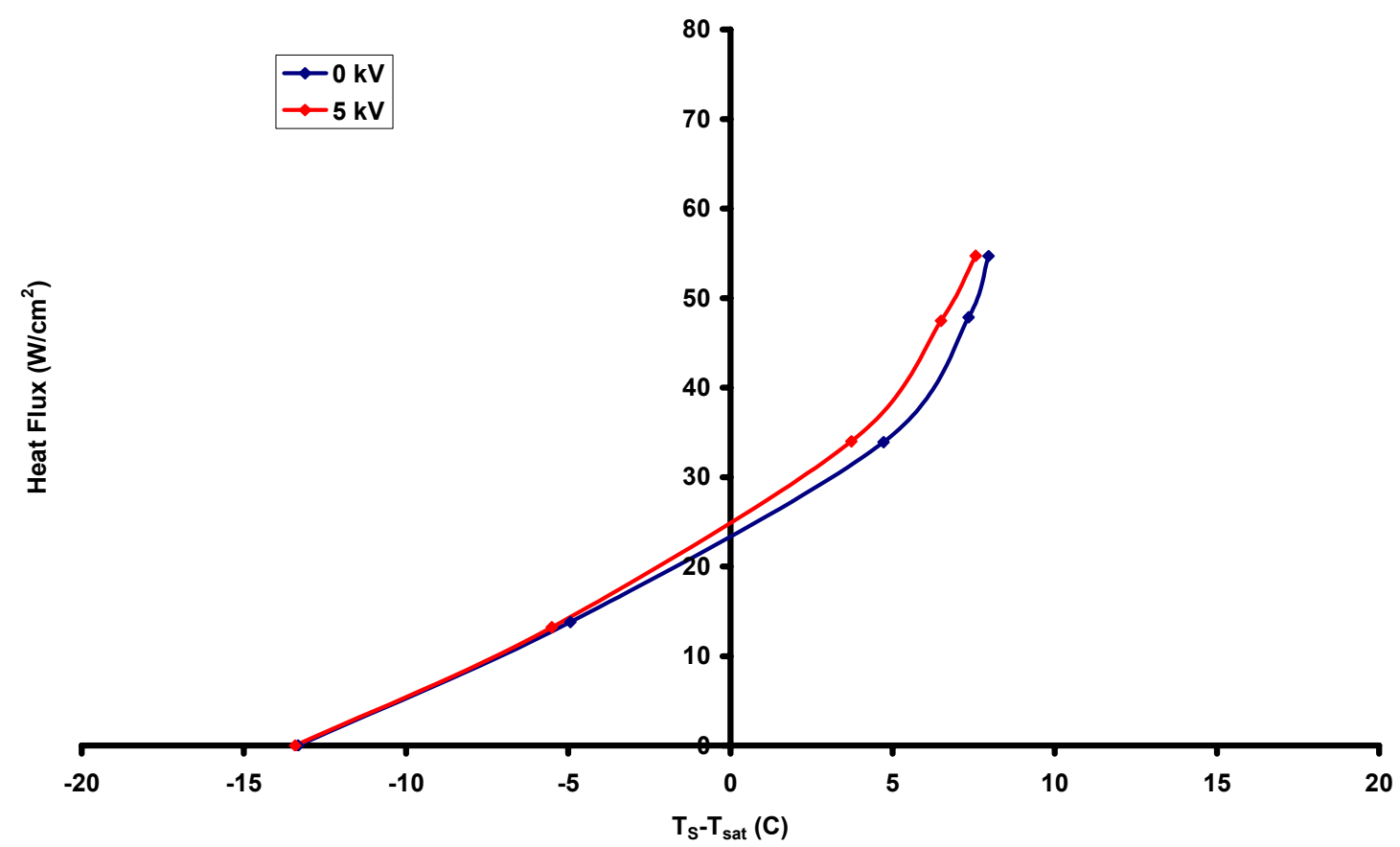

Figure C.53: Heat Flux vs. Temperature Difference for PTFE Pedestal with New TFR Heater and Electrode 1 using HFE-7000 at 8.5 GPH

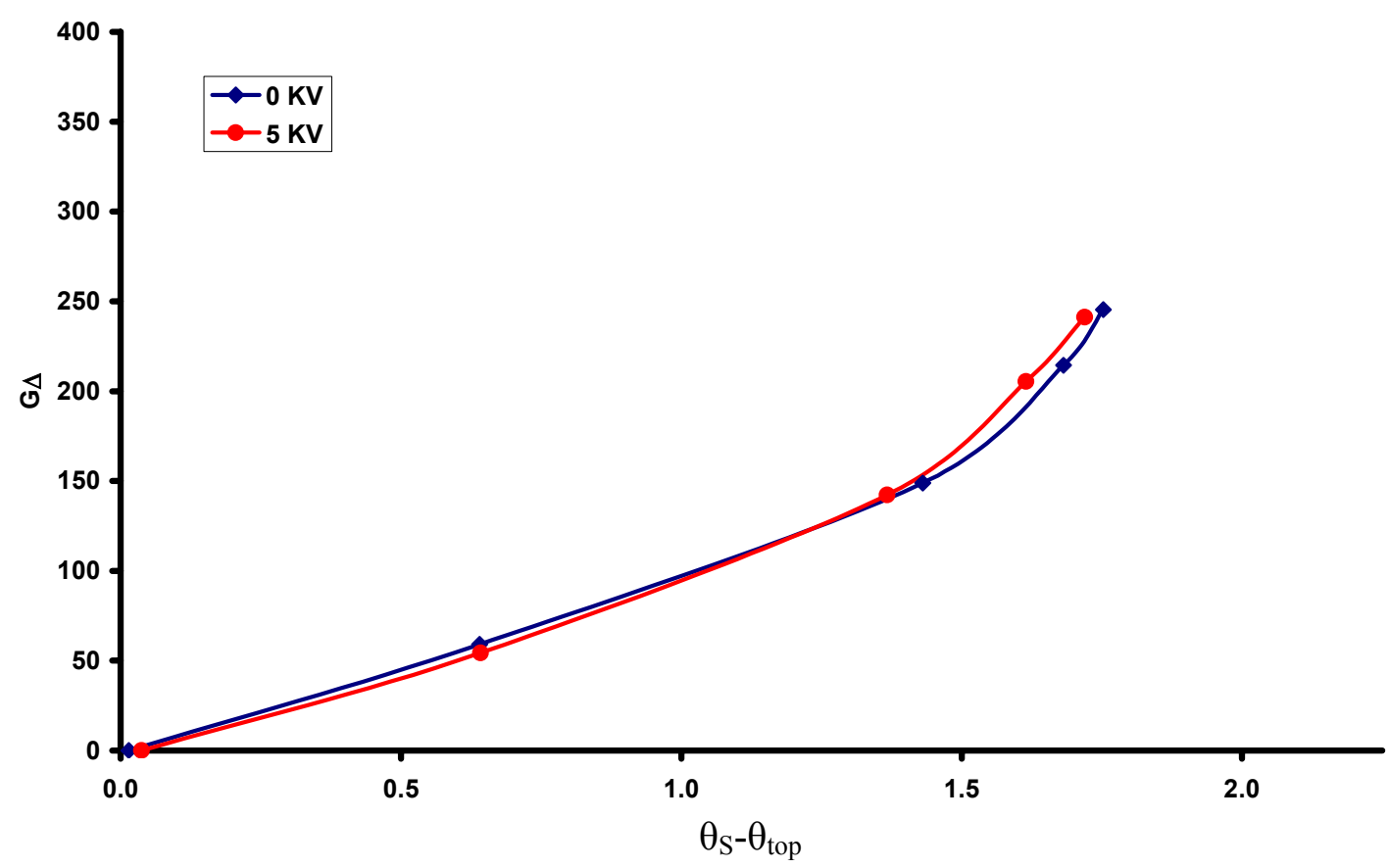

Figure C.54: Non-dimensional Heat Flux vs. Non- dimensional Temperature Difference for PTFE Pedestal with New TFR Heater and Electrode 1 using HFE-7000 at $8.5 \mathrm{GPH}$ 


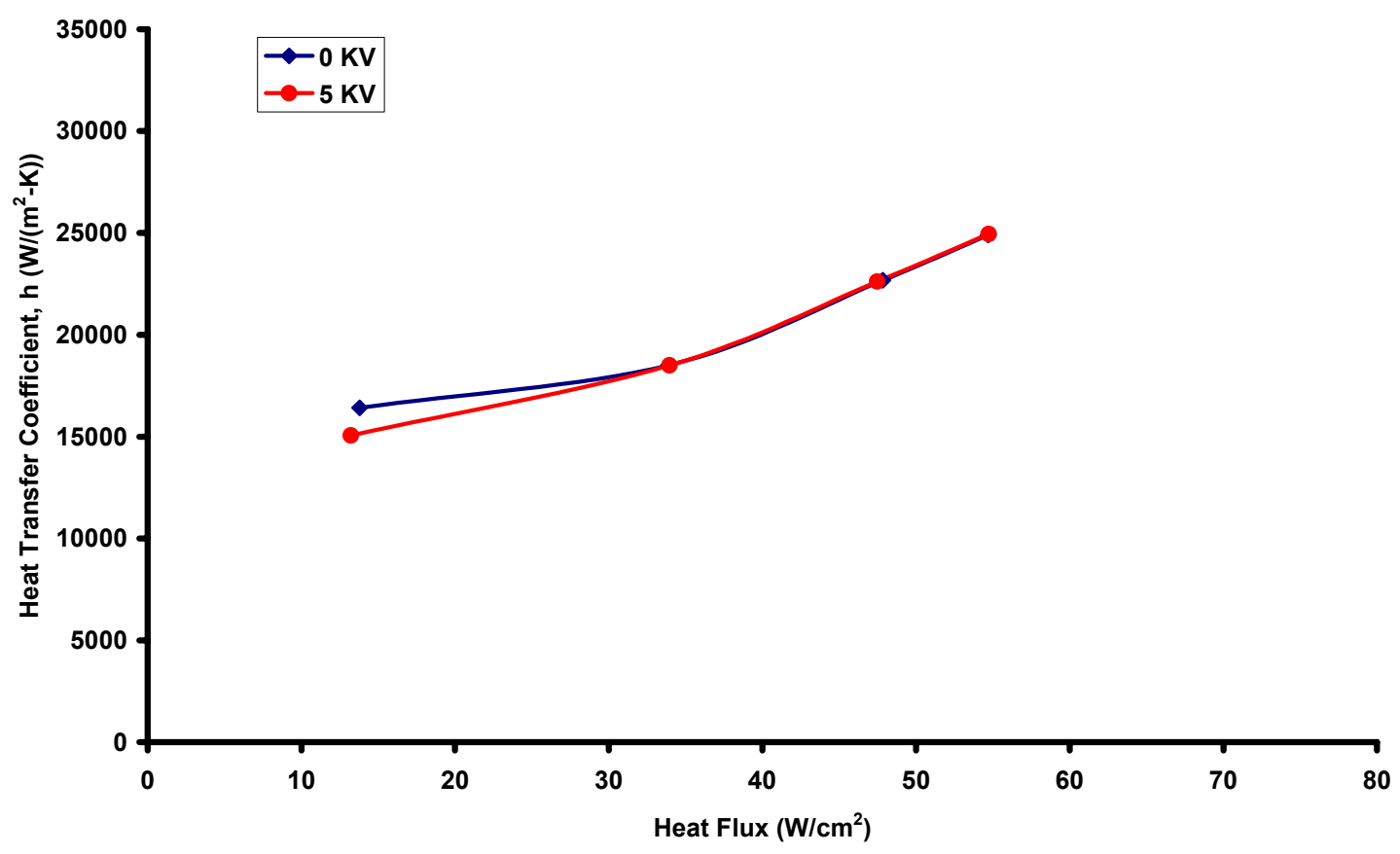

Figure C.55: Heat Transfer Coefficient vs. Heat Flux for PTFE Pedestal with New TFR Heater and Electrode 1 using HFE-7000 at $8.5 \mathrm{GPH}$

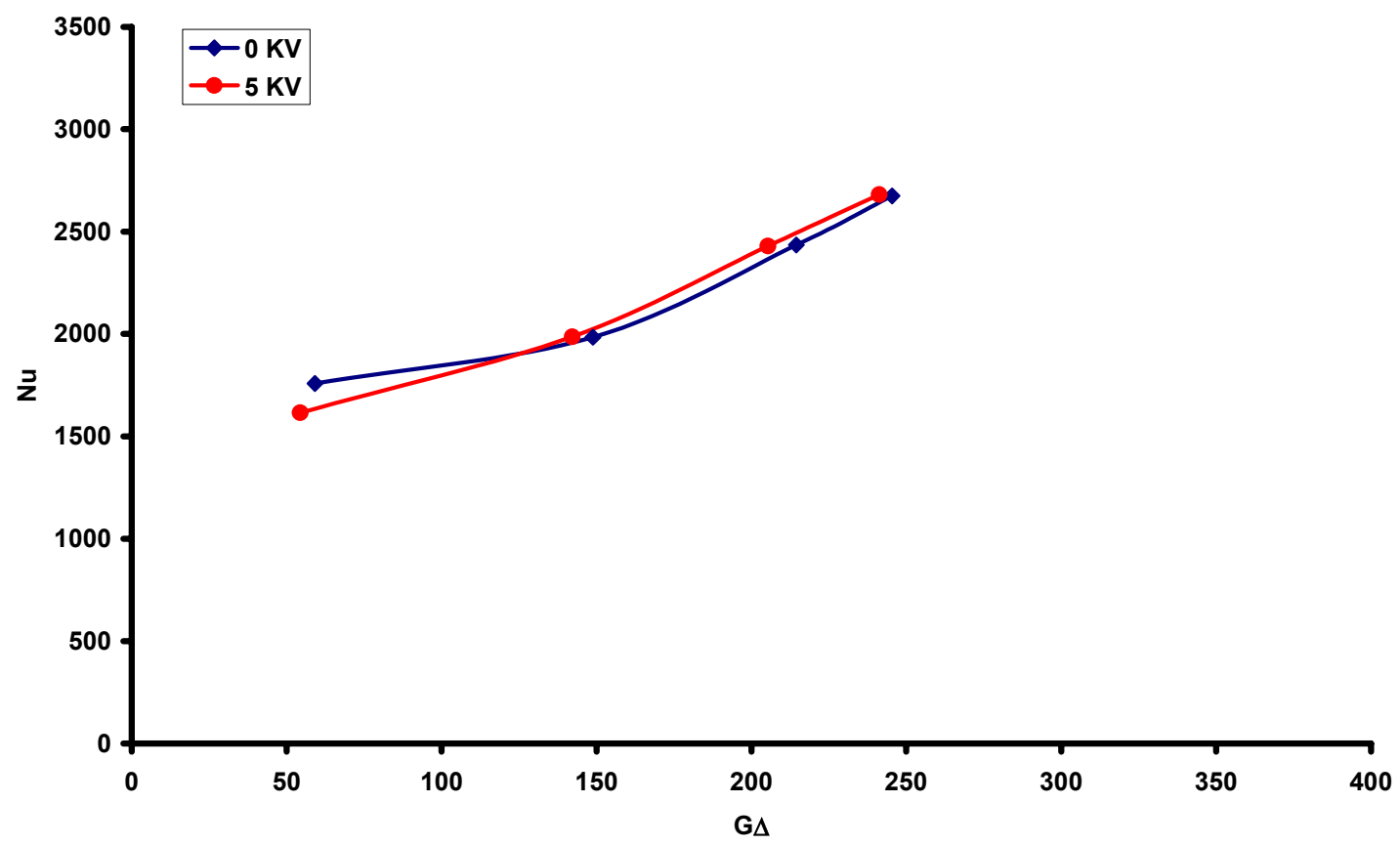

Figure C.56: Non-dimensional Heat Transfer Coefficient vs. Non-dimensional Heat Flux for PTFE Pedestal with New TFR Heater and Electrode 1 using HFE7000 at $8.5 \mathrm{GPH}$ 


\section{APPENDIX D : $\quad$ HEAT TRANSFER DERIVATIONS}

Derivations of the basic heat transfer data reduction equations used in this research to calculate surface conditions are presented in this Appendix. The temperature at the heater surface is a key calculated parameter that is necessary to quantify the heat transfer coefficient in the liquid layer on the surface; this is discussed in Section D.1. The heat transfer coefficient calculation is discussed in Section D.2. Nondimensionalization of the results is another important aspect in the present work, and is presented in Section D.3.

\section{Section D.1: $\quad$ Derivation of Surface Temperature}

With the experimental setup used in this work it is important to understand how to calculate the surface temperature based on the measured interface temperature located beneath the TFR heater, TC \#1. The TFR heater is broken down into three main segments: the substrate onto which a resistive layer is deposited, the resistor itself, and finally a thin glass layer. The heat loss from the heater occurs in both convection as well as conduction. However, due to the large difference in surface area between the top and bottom of each layer compared to the surface area of the outside wall, convection out the wall can be neglected, leading to a 1-D model of conduction in each layer. Figure D.1 shows a schematic of the pedestal and TFR heater with the upper glass layer present. The corresponding dimensions of each layer are listed in Table D.1. The TFR heater makes up the upper most three layers of this figure. Several assumptions can me made with regards to this analysis: 
1. Steady state

2. One-dimensional

3. Axi-symmetric

4. Infinite contact interfaces (interface temperatures and heat fluxes are continuous)

5. Heat transfer out the side walls is neglected, $\mathrm{h}_{\text {wall }}=0$

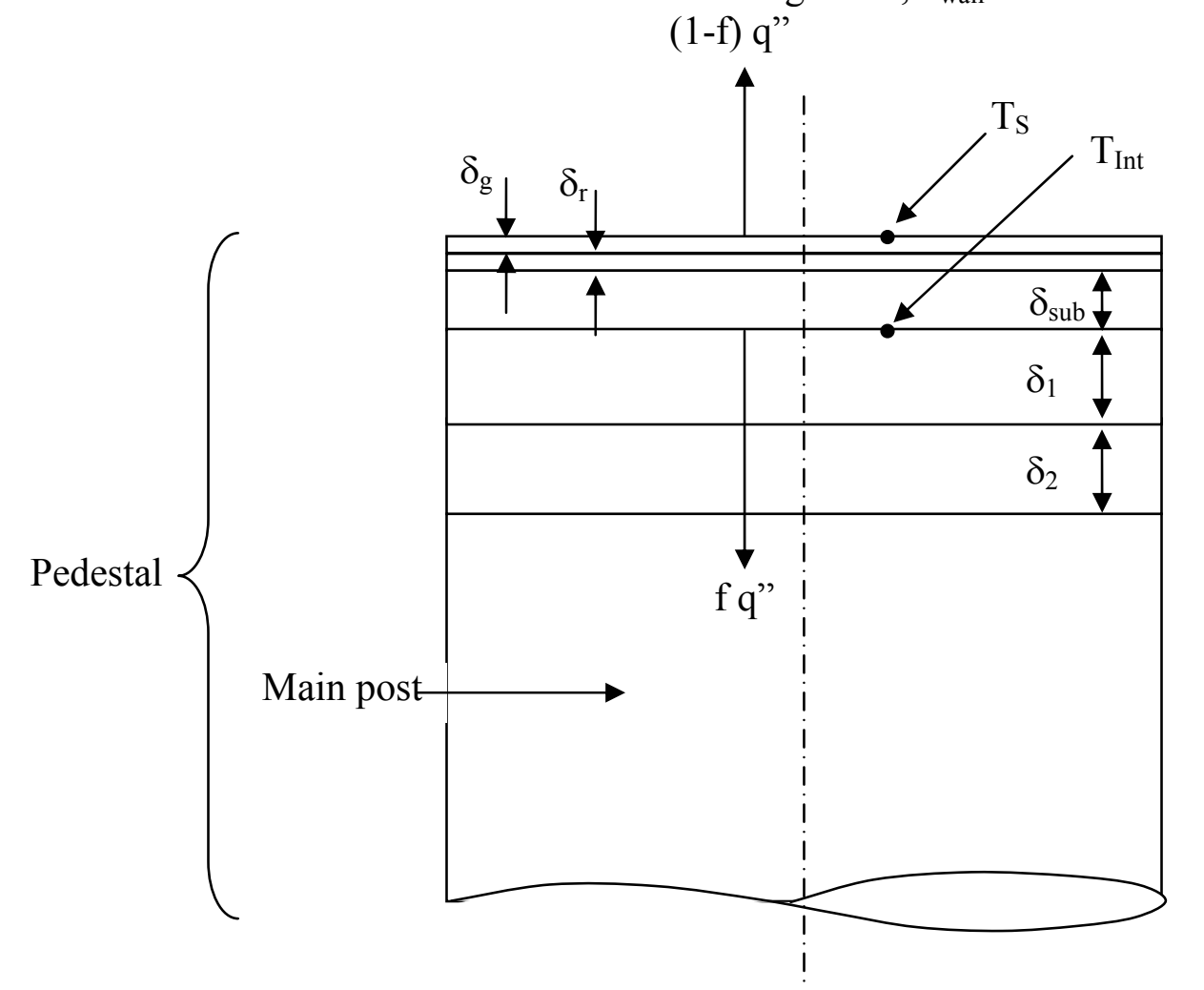

Figure D.1: Schematic of Pedestal and TFR Heater with Glass Layer

Table D.1: Thickness of TFR Layers (Glaspell, 2006)

\begin{tabular}{|c|c|c|}
\hline Layer & $\begin{array}{c}\text { TFR with Glass } \\
\text { Layer, } \boldsymbol{\delta}(\boldsymbol{\mu m})\end{array}$ & $\begin{array}{c}\text { TFR without Glass } \\
\text { Layer, } \boldsymbol{\delta}(\boldsymbol{\mu m})\end{array}$ \\
\hline Glass & $40 \pm 5$ & --- \\
\hline Resistor & $8 \pm 2$ & $20 \pm 5$ \\
\hline Substrate & $634 \pm 10$ & $634 \pm 10$ \\
\hline
\end{tabular}

The problem can be broken down into three separate problems that can be solved separately and combined together to yield a final solution. Since the thermal conductivity of the glass post located below the TFR heater is so much smaller than that of the substrate the amount of conduction into the glass post can be assumed to be minimal. 
Analytical analysis by Baysinger (2004) provided an estimated loss down the pedestal of approximately $1.5 \%$. This value will be used throughout this solution, and will be labeled, $f .1 .5 \%$ of the heat generated in the resistive layer is then conducted down the pedestal, while the remaining $98.5 \%$ is conducted through the upper glass layer and removed via convection as shown in Figure D.2.

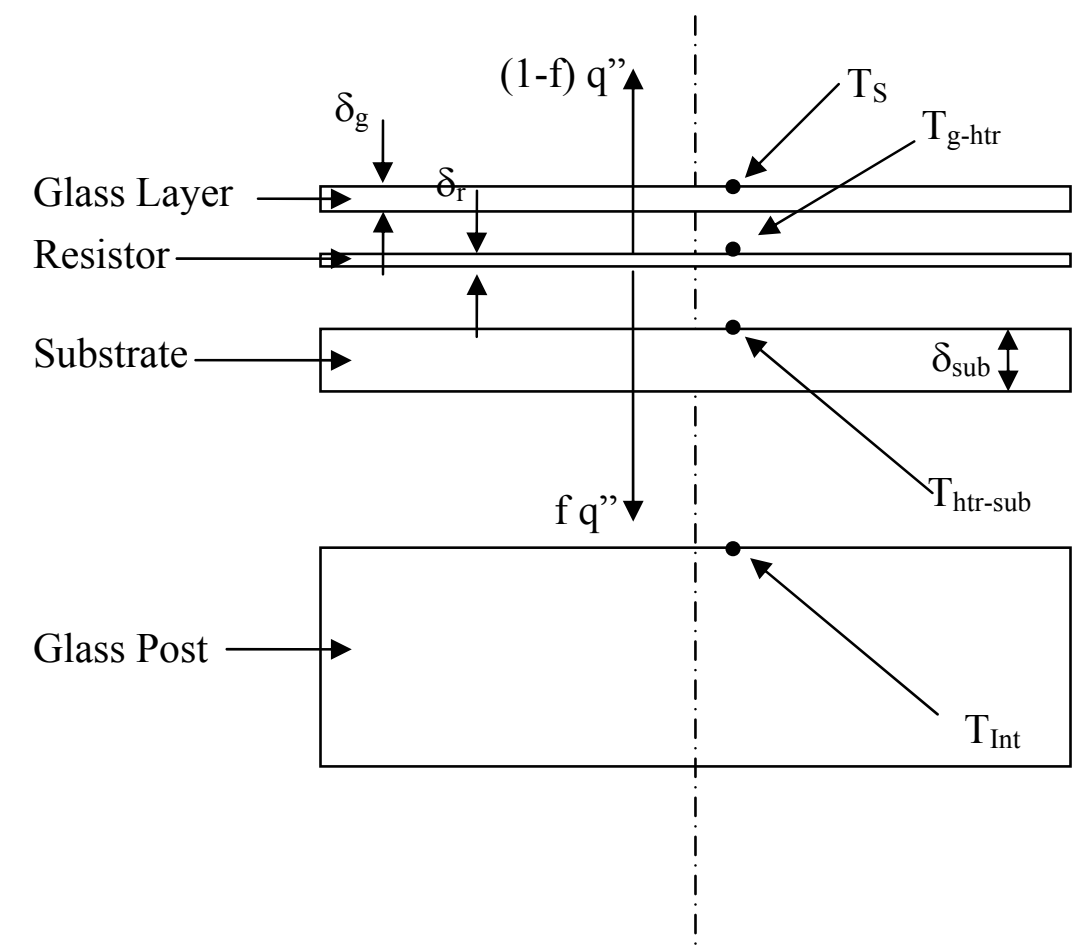

Figure D.2: Schematic of TFR Heater Showing Heat Losses

Conservation of energy must be satisfied by each layer and therefore the general equation must hold true and assuming steady state can be written as:

$$
\frac{\partial^{2} T}{\partial z^{2}}+\frac{g}{k}=0
$$

From this general equation the boundary conditions can be established for each layer and solved for the temperature difference across each layer. 


\section{Glass Layer}

Taking the general equation, neglecting the heat generation $(\mathrm{g}=0)$, and solving at the top and bottom of the glass layer yielded the following boundary conditions:

$$
\begin{aligned}
& \frac{d T_{g}}{d z_{g}}+\frac{h}{k_{g}} T_{s}=\frac{h}{k_{g}} T_{\infty} \quad \text { at } \quad \mathrm{z}=\delta_{\mathrm{g}} \\
& \frac{d T_{g}}{d z_{g}}=\frac{-f q^{\prime \prime}}{k_{g}} \quad \text { at } \quad \mathrm{z}=0
\end{aligned}
$$

the solution then becomes:

$$
T_{S}=\frac{-f q^{\prime \prime} \delta_{g}}{k_{g}}+T_{g-h t r}
$$

\section{Resistor Layer}

The general solution to the general equation with heat generation is a quadratic in z, which can be solved using the following top and bottom boundary conditions:

$$
\begin{array}{lll}
\frac{d T_{h t r}}{d z_{h t r}}=\frac{-(1-f) q^{\prime \prime}}{k_{h t r}} & \text { at } & \mathrm{z}=\delta_{\mathrm{htr}} \\
\frac{d T_{h t r}}{d z_{h t r}}=\frac{-f q^{\prime \prime}}{k_{h t r}} & \text { at } & \mathrm{z}=0,
\end{array}
$$

the solution then becomes:

$$
T_{g-h t r}=\frac{-g \delta_{h t r}^{2}}{2 k_{h t r}}+\frac{f q^{\prime \prime} \delta_{h t r}}{k_{h t r}}+T_{h t r-s u b}
$$

\section{Substrate Layer}

Taking the general equation, neglecting the heat generation term and solving at the top and bottom of the substrate layer using the following boundary conditions:

$$
\frac{d T_{\text {sub }}}{d z_{\text {sub }}}=\frac{-f q^{\prime \prime}}{k_{\text {sub }}} \quad \text { at } \quad \mathrm{z}=\delta_{\text {sub }}
$$




$$
\frac{d T_{\text {sub }}}{d z_{\text {sub }}}=\frac{-f q "}{k_{\text {sub }}} \quad \text { at } \quad \mathrm{z}=0,
$$

the solution then becomes:

$$
T_{\text {htr-sub }}=\frac{-f q " \delta_{\text {sub }}}{k_{\text {sub }}}+T_{\text {int }}
$$

Finally, combining the solution at each level with that of the previous level, the overall solution can be written in terms of only $\mathrm{T}_{\text {int }}$ and $\mathrm{T}_{\mathrm{S}}$ and the material properties or each layer.

$$
T_{s}=\frac{-(1-f)) q^{\prime \prime} \delta_{g}}{k_{g}}+\frac{-g \delta_{r}^{2}}{2 k_{r}}+\frac{f q^{\prime \prime} \delta_{r}}{k_{r}}+\frac{f q^{\prime \prime} \delta_{\text {sub }}}{k_{\text {sub }}}+T_{\text {int }}
$$

A similar derivation can be performed for the TFR heater without the upper glass layer. The resulting solution is shown in Equation D.12:

$$
T_{s}=\frac{-g \delta_{r}}{2 k_{r}}+\frac{f q^{\prime \prime} \delta_{r}^{2}}{k_{r}}+\frac{f q^{\prime \prime} \delta_{\text {sub }}}{k_{\text {sub }}}+T_{\text {int }}
$$

\section{Section D.2: $\quad$ Explanation of Heat Transfer Coefficient Used}

The traditional methods for calculating the heat transfer coefficient could not be used in the present work, because the heat lost down the pedestal had to be considered. Therefore the expression used to calculate $\mathrm{h}$ was derived from the basic definition of heat flux, q".

$$
q^{\prime \prime}=h \Delta T
$$

This could then be rewritten in terms of heater power and surface area as follows: 


$$
h=\frac{Q}{A_{s} \Delta T}
$$

However, a fraction of the heater power is lost due to conduction down the pedestal. So

finally, accounting for the losses down the pedestal the heat transfer coefficient across the surface of the TFR can be written:

$$
h=\frac{(1-f) Q}{A_{s}\left(T_{S}-T_{\infty \text { top }}\right)}
$$

\section{Section D.3: $\quad$ Explanation of Heat Transfer Coefficient Non- dimensionalization}

In order to present the results in non-dimensional forms each term had to be non-

dimensionalized. The heat transfer coefficient can be non-dimensionalized by combining the terms $\mathrm{G}$ and $\Delta$ according to Yerkes et al. (2006).

$$
G \Delta=\left(\frac{g b^{2}}{T_{\infty_{\text {wall }}} k_{h t r}}\right)\left(\frac{\delta}{b}\right)
$$

Where, $g$ is the volumetric heat generation.

$$
g=\frac{Q}{\pi b^{2} \delta}
$$

Finally, we can simplify and account for the heat losses down the pedestal.

$$
G \Delta=\left(\frac{Q}{\pi \delta T_{\infty_{\text {wal }}} k_{h t r}}\right)\left(\frac{\delta}{b}\right)=\frac{Q}{\pi b T_{\infty_{\text {wall }}} k_{h t r}}=\frac{(1-f) Q}{\pi b T_{\infty_{\text {wall }}} k_{h t r}}
$$

The other non-dimensional terms use standard definitions.

$$
\theta_{S}=\frac{T_{s}-T_{\infty_{\text {wall }}}}{T_{\text {Sat }}-T_{\infty_{\text {Wall }}}}
$$




$$
\begin{aligned}
& \theta_{\infty_{\text {Top }}}=\frac{T_{\infty_{\text {top }}}-T_{\infty_{\text {wall }}}}{T_{\text {Sat }}-T_{\infty_{\text {Wall }}}} \\
& N u=\frac{h_{f} b}{k_{f}}
\end{aligned}
$$

Page 183 